\title{
Sustainability of banana-based
}

agroecosystems affected by

Xanthomonas wilt disease of banana 
Sustainability of banana-based

agroecosystems affected by Xanthomonas wilt disease of banana

Walter Ocimati 


\section{Thesis committee}

\section{Thesis promoter}

Prof. Dr P. Tittonell

Professor of Farming Systems Ecology Group

Wageningen University \& Research

\section{Thesis co-promoters}

Dr J.C.J Groot

Associate Professor at Farming Systems Ecology Group

Wageningen University

\section{Other members}

Prof. Dr L.G. Hein, Wageningen University \& Research

Dr H. Meijer, Wageningen University \& Research

Dr P. Reidsma, Wageningen University \& Research

Dr L. Cournac, Institut de Recherche pour le Développement, Montpellier, France

This research was conducted under the auspices of the C.T. de Wit Graduate School of Production Ecology and Resource Conservation (PE\&RC). 


\title{
Sustainability of banana-based agroecosystems affected by Xanthomonas wilt disease of banana
}

\author{
Walter Ocimati
}

Thesis

submitted in fulfilment of the requirements for the degree of doctor

at Wageningen University

by the authority of the Rector Magnificus

$$
\begin{aligned}
& \text { Prof. Dr A.P.J. Mol, } \\
& \text { in presence of the }
\end{aligned}
$$

Thesis Committee appointed by the Academic Board to be defended in public

on Wednesday 11 December 2019

at 1.30 p.m. in the Aula 
Ocimati, W.

Sustainability of banana-based agroecosystems affected by Xanthomonas wilt disease of banana, 240 pages

Thesis Wageningen University, Wageningen, The Netherlands (2019)

With references, with summaries in English

ISBN: 978-94-6395-202-6

DOI: https://doi.org/10.18174/505782 


\section{Dedication}

To my spouse Hellen Candiru, daughter Faith E. Awadifo, parents Edinance K. Buga and Richard Buga (RIP), siblings, friends and smallholder banana farmers from whom I drew courage, strength and inspiration for this study. 


\section{Table of contents}

Chapter 1: General introduction 1

Chapter 2: Xanthomonas wilt of banana drives changes in land-use and ecosystem services across infected landscapes

Chapter 3: Effects of Xanthomonas wilt disease of banana on ecosystem services in banana-based agroecosystems

Chapter 4: Banana Xanthomonas wilt disease hotspots, fronts and vulnerable landscapes

Chapter 5: Field level risk of Xanthomonas wilt - an assessment of the potential role of alternative host plants

Chapter 6: Banana-legume intensification: pruning banana canopy to intercrop legumes in the East African highlands

Chapter 7: Trade-offs and synergies due to banana leaf pruning to intercrop legumes in eastern DR Congo

Chapter 8: Agroecological integration strategies for optimal exploitation of available land spaces under banana

Chapter 9: General discussion

Summary

About the author

Training and education

Acknowledgements

Funding 


\section{Chapter 1}

General introduction

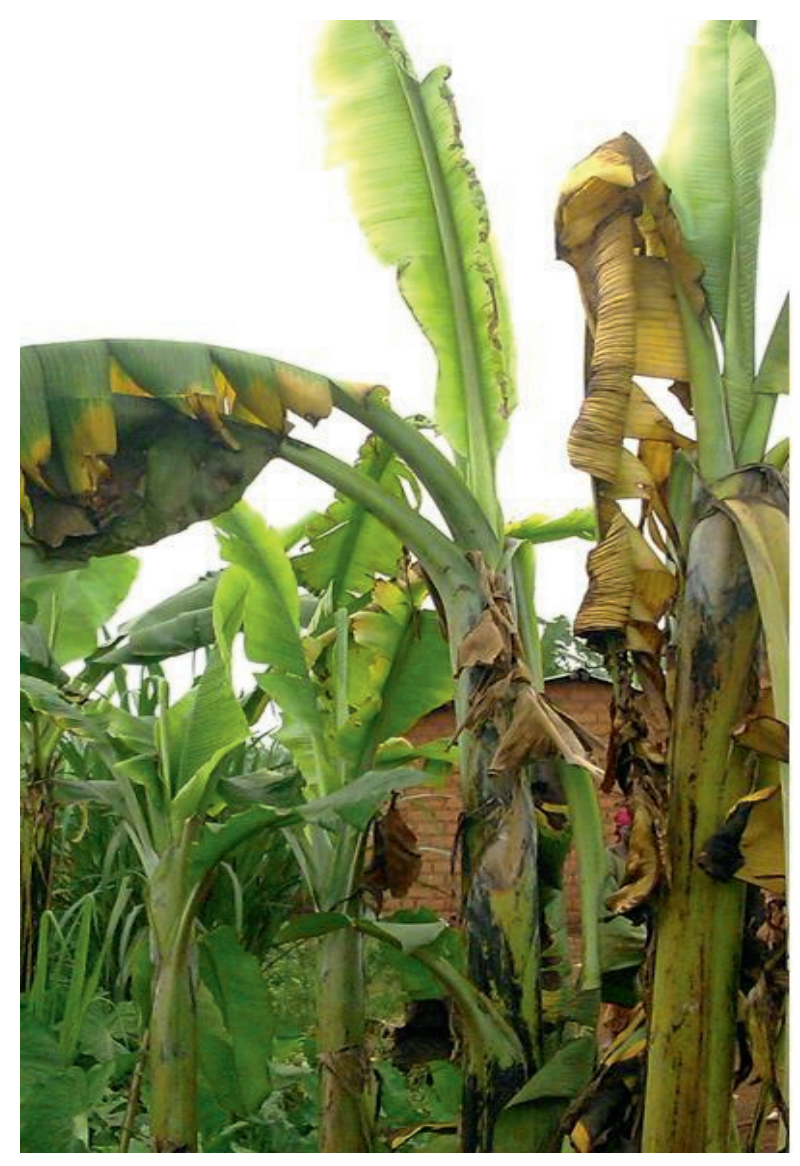




\subsection{Importance of banana in the African Great Lakes region}

Musa spp. (grouped into banana and plantain), hereafter called banana is an important crop worldwide. With a harvested area of 9.9 million hectares and annual production of 151.2 million $\mathrm{Mg}$ in 2016, it ranks the World's $7^{\text {th }}$ most important source of carbohydrates (FAO, 2019). Only $14.5 \%$ of the annual world banana production, predominantly the dessert types, is traded, indicating that the crop is important for household food security (FAO, 2019). In the same period, Africa produced 44.1 million $\mathrm{Mg}$ of banana, accounting for about 29.2\% of the world production. Only $1.9 \%$ of the African production was traded (FAO, 2019). Banana in Africa is produced on an area of about 5.95 million hectares, which is equivalent to $55 \%$ of the total land area under banana globally (FAO, 2019). This translates to an average yield of $16.6 \mathrm{Mg} \mathrm{ha}^{-1}$ for Africa and $28 \mathrm{Mg} \mathrm{ha}^{-1}$ for the World, suggesting a low productivity of the crop in Africa.

The African Great Lakes region (AGLR) which traverses Burundi, Democratic Republic of Congo (DR Congo), Kenya, Rwanda, Tanzania, and Uganda, is a secondary centre of diversity of East African highland bananas and plantains (Simmonds and Shepherd, 1955; Simmonds, 1966). The crop is cultivated over a wide range of agroecologies and cropping systems in the region (Eledu et al., 2004; AATF, 2009; Ocimati et al., 2013a). About $42 \%$ of Africa's banana production ( $12 \%$ of world production) in 2016 came from the AGLR (FAO, 2019). In the AGLR, it provides 30$60 \%$ of food energy needs for over 70 million people (Abele et al., 2007; Karamura et al., 2008), with the leading per capita consumption rates in the world of up to 243 kg per annum reported in Uganda, Burundi and Rwanda (Sharrock and Frison, 2000). Bananas unlike cereals or other annual crops that are seasonal provide an all yearround bunch/ food supply and thus important for stability in food supply to the households. In this region, the crop also contributes to incomes along the value chain of the crop (Okech et al., 2004; Edmeades et al., 2007) and other provisional services such as animal feed, herbal medicine, crafts and ornaments, construction materials and bedding for poultry and livestock (Kamira et al., 2015; Frison and Sharrock, 1998).

Across banana growing landscapes in the AGLR, banana plantations are multifunctional agroecosystems, which in addition to the wide range of provisioning services above also deliver a range of supporting, regulatory and cultural ecosystem services. For example, the crop contributes to soil erosion control (Lufafa et al., 2003) and supports nutrient recycling and carbon sequestration (Kamusingize et al., 2017). Culturally, the crop is used for ritual practices (Frison and Sharrock, 1998). Given the multiple functions played by the crop, any disturbance that affects the resilience of 
the banana systems could thus profoundly impact on households, communities and landscapes. Thus, strategies for sustainably managing the banana production systems are crucial.

\subsection{Banana production constraints in the African Great Lakes region}

FAO data (FAO, 2017) shows a downward trend in banana production in the AGLR. In Uganda, for example, FAO (2017) data respectively, shows a 39 and 50\% drop in area under banana production and total production (Fig. 1.1) in 2014, compared to 2002. The decline in production in the AGLR region can be attributed to a wide range of abiotic and biotic factors that include sub-optimal management of the crop; land tenure and fragmentation; declining soil fertility; reliance on rain for production, with high risk of drought; and pests and diseases (van Asten et al., 2004, 2011; Gold et al., 1999; Kalyebara et al., 2007; Tinzaara et al., 2019). Although the ranking of importance of constraints in the region is a point of contest, declining soil fertility and drought stress stand out as the key abiotic stresses, while Xanthomonas wilt of banana (XW), banana bunchy top disease (BBTD) and fusarium wilt are most important among the biotic stresses. Other biotic constraints of importance in the region include the banana weevil and nematodes, and the fungal leaf spots.

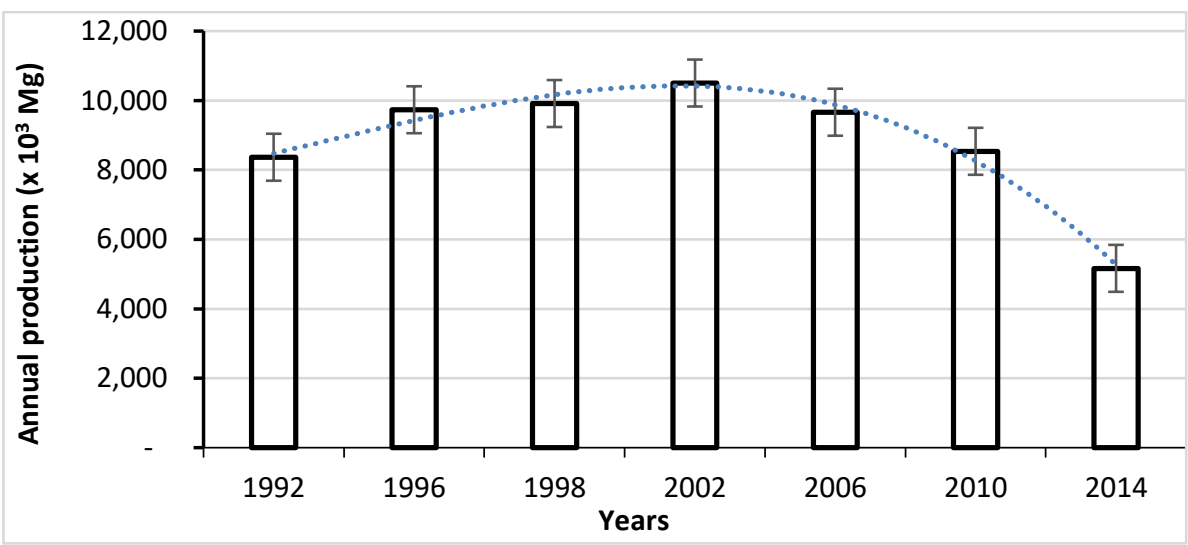

Figure 1.1. Banana production trends between 1992 and 2014 in Uganda (Source: FAO, 2017).

The past two decades have especially seen an increase in disease and pest pressure on the banana production landscapes in the AGLR (Blomme et al., 2013). Damage caused by the diseases vary from very minor effects to extremely serious effects, depending on the virulence of the pathogen, host resistance or susceptibility, agroecology, climate, farmers awareness and adoption of control practices and 
presence and activity of vectors. For example, black leaf streak (caused by Pseudocercospora fijiensis) does not lead to complete death of plants though can result in small to moderate yield losses, thus often accommodated by farmers. In contrast, fusarium wilt, BBTD and XW diseases lead to complete death of plants and/or mats and plantations and thus causing major yield losses. XW, a bacterial disease is the most recent of all the constraints and has severely distressed banana producing households and landscapes in the region. Outbreaks of XW have been associated with extensive land degradation due to exposure of soil through massive uprooting of plants as a recommendation for its management, total arrest of agricultural activity and associated food insecurity and financial crisis (Ocimati et al., 2014). More recent studies still show that that the disease is a major problem (e.g. Blomme et al., 2017a, b; Bioversity International, 2017) and strategies are thus still needed for sustainably managing it.

\subsection{Xanthomonas wilt of banana, impact and management}

The outbreak of the Xanthomonas wilt disease of banana (XW) caused by the Gramnegative bacteria Xanthomonas campestris pv. musacearum $(\mathrm{Xcm})$ has drawn the greatest attention due to its severe impact on production systems and its fast rate and diverse modes of spread. The disease causes rapid wilting after tool-mediated infections and premature ripening and rotting of fruits in florally infected plants, leading to a complete loss of the infected plants (Tushemereirwe et al., 2006; Tripathi et al., 2009; Ocimati et al., 2013a). Delayed intervention can result in up to $100 \%$ yield loss. In the Kagera region of Tanzania, Muchuruza and Melchoir (2013) reported yield and income losses of $84 \%$ and $64 \%$ per annum, respectively due to the disease. In Tanzania and Rwanda, a 35\% drop in sales and doubling of bunch prices were reported (Nkuba et al., 2015) whereas a potential loss of US\$ 200 of food and income per year and household was estimated if disease control measures were not implemented in Uganda (Kalyebara et al., 2006). The disease thus severely compromises the food and income security of the affected households in the AGLR.

In addition to direct losses due to $\mathrm{XW}$, some of the management practices involve uprooting entire mats/ fields and cutting down of sick plants (Jogo et al., 2013; Ocimati et al., 2014). Cutting or uprooting of plantations out of frustration is also common (Blomme et al., 2014; 2017) and could partly explain the observed decline in both production and area under production e.g. in Uganda (Fig. 1.1).

Land uses and covers are closely related to the integrity of ecosystems and the associated ES (Sohel et al., 2015). Widespread decline in ES has been reported due to anthropogenic activities across the world (MEA, 2005; Sohel et al., 2014). The 
land-uses and land-use trajectories driven by XW raise concerns over sustainability in the supply of some key ecosystem services, e.g. regulatory and supporting ecosystem services that are crucial for the resilience of the agroecosystem; an aspect not assessed to-date. Past studies have mainly focused on disease impact on production and incomes, which is an understatement of the total impact of the disease. In this thesis, I seek to understand the ongoing changes in land-use and landuse trajectories due to XW in the banana-based agroecosystems/landscapes and the potential effects of XW and the changes in land-use/ land-use trajectories on the supply of ecosystem services as a basis for mitigating any potentially negative effects and bolstering the resilience of the banana producing landscapes.

Xanthomonas wilt disease of banana, first observed in central Uganda in 2001 (Tushemereirwe et al., 2004), has over a period of a decade spread to the whole AGLR (Fig. 1.2, Ndungo et al., 2006; Reeder et al., 2007; Tripathi et al., 2009; Carter et al., 2010; Blomme et al., 2013). This rate of spread also puts other yet unaffected banana growing areas within or neighbouring this region at risk. $\mathrm{XW}$ control efforts over the past 15 years have been reactive or focused on mitigation and the drivers of XW spread at various spatial scales are yet to be unravelled. Existing mapping efforts (Tushemereirwe et al., 2006; Bouwmeester et al., 2016; Shimwela et al., 2017) focused specifically on individual countries or regions within countries and often only highlighted disease presence or absence in a zone. Knowledge and spatial mapping of the relationship between these covariates and XW disease severity and/or incidence can help to pin-point disease hot spots, fronts and vulnerable landscapes. The increasing availability of maps of environmental variables (c.f. Hijmans et al., 2005; Jarvis et al., 2008), specialized GIS and analysis software and methods (c.f. Goovaerts, 1997; Hosmer and Lemeshow, 2000; Webster and Oliver, 2007; R Core Team, 2017; Hijmans, 2017; Bouwmeester et al., 2016) and other supportive technologies make mapping of diseases feasible. Knowledge of XW hotspots, fronts and vulnerable landscapes will be important for pro-actively and comprehensively guiding the design of $\mathrm{XW}$ control and mitigation measures on vulnerable landscapes within the AGLR and across Africa. Proactive measures could include surveillance and early warning systems; risk assessment; priority setting and resource allocation; and timely information dissemination and disease management. 


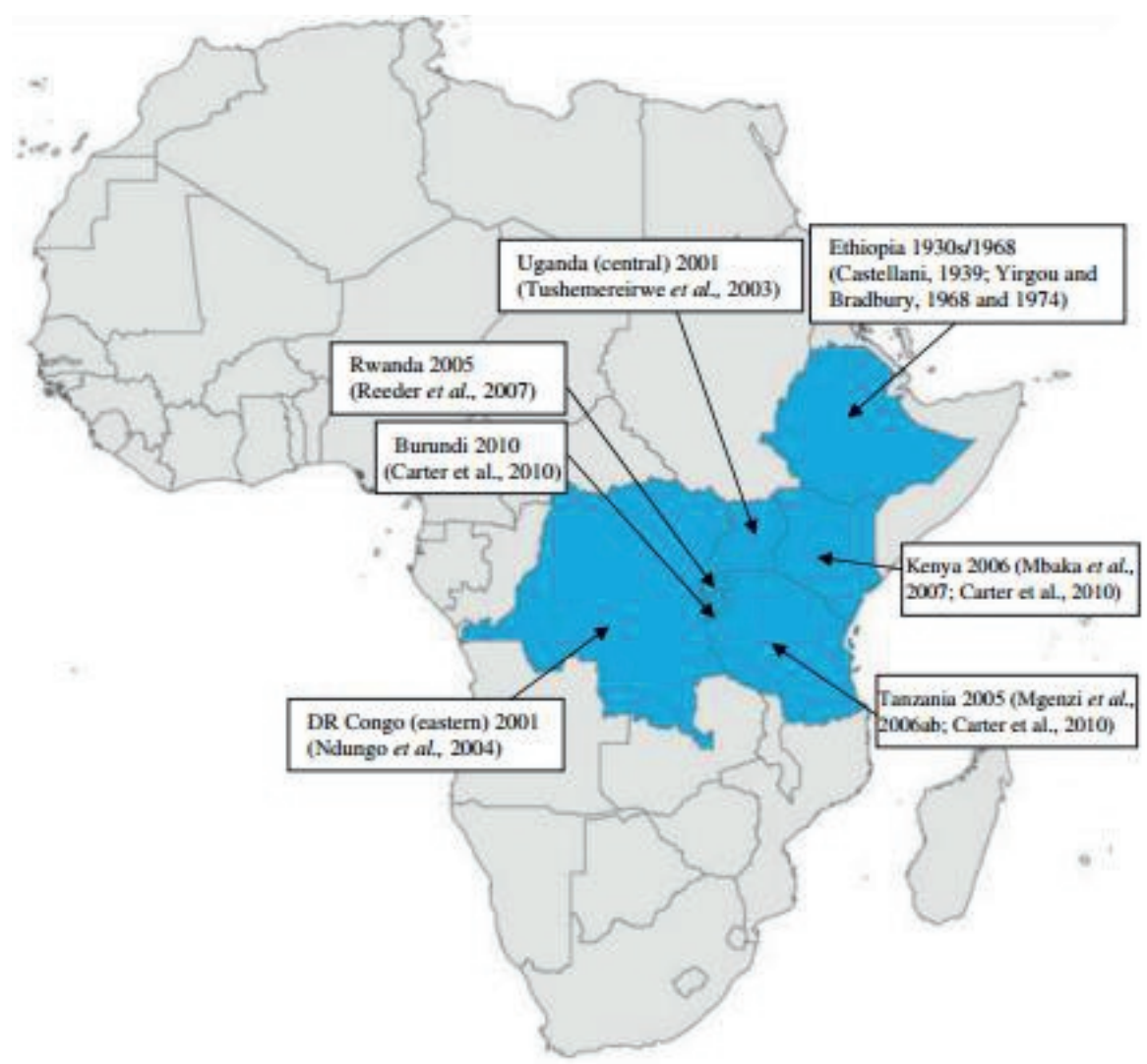

Figure 1.2. Map shows first reports of Xanthomonas wilt in different African countries (Source: Blomme et al., 2013).

The management of $\mathrm{XW}$ in the $\mathrm{AGLR}$ is further influenced by the high population density and small (<2 ha) fragmented farm sizes (van Asten et al., 2004, Wairegi et al., 2010) that drive cultural practices at field or farm level. Bananas are predominantly intercropped (AATF, 2009) while cultural practices such as crop rotation, agroforestry and fallowing of importance in managing soil fertility and pests and diseases are not always feasible. Banana intercropping with other crops is common to optimally use the available land space and spread production risks. The common intercrops include beans, coffee, taro, leafy vegetables, agroforestry trees, cassava, yams and sweet potato (Sebasigari, 1985; Ocimati et al., 2013c; Mpiira et al., 2013; Ssebulime et al., 2017). High diversity and functional biodiversity within agroecosystems have been associated higher opportunities for beneficial interactions between species and to enhance agroecosystem sustainability (Vandermeer, 1995; Altieri, 1995; Poeydebat et al., 2017). However, other plants 
species could exacerbate and perpetuate diseases and pests in an agroecosystem. Understanding the nature of interactions of plants in the survival and perpetuation of pests and pathogens in a system and key risk factor at field/ and farm level is important. With respect to XW disease, $\mathrm{Xcm}$, the causal organism has been shown to cause disease in a common weed Canna lily (Canna indica) in controlled experiments (Ssekiwoko et al., 2006). Xcm has also been recovered from some crop species (e.g. maize, sugarcane) grown in association with, or in close proximity to bananas following artificial inoculations (Karamura, 2012; Rutikanga et al., 2016), but it is not clear if $\mathrm{Xcm}$ interaction with these plants can perpetuate XW on farm. This thesis thus sought to determine if $\mathrm{Xcm}$ survives within and/or affects other crops spp. and weeds, and if this association poses any risk to the banana and these crops. The study also sought to determine the key factors influencing XW risk at farm level. Understanding the key factors responsible for $\mathrm{XW}$ perpetuation on farm is crucial for informing the control strategies.

At field level, banana leaf pruning to reduce shading of the short understory intercrops is common so as to boast their performance. This practice together with damaging of the banana corms and roots during tillage in preparation or at intercropping spread XW and thus could undermine benefits associated with banana intercropping. However, some of these practices, especially banana leaf pruning to integrate legumes has persisted in some of the production zones (Blomme et al., 2014; 2017b). Dissuading farmers from these practices and developing strategies to harness agroecological benefits from the agroecosystem will thus require an indepth understanding of the merits and demerits of farmers' current intensification practices. This will form a good basis for either dissuading farmers from their current practices or identifying alternative banana intercrop management options that will sustainably improve productivity given the current constraints without compromising the resilience of the banana agroecosystem. This is often complex given the large number of interrelated farm components determine overall farm performance (Groot and Rossing, 2011; Groot et al., 2012) whereas farmers own trial and error experiments can be costly, time consuming and risky (Le Gal et al., 2011; Baudron et al., 2012). This will require an understanding of the potential trade-offs in the allocation of resources and between the different production objectives (Tittonell et al., 2007; Groot et al., 2012). Optimisation models can overcome these challenges and help explore alternative land-use options (Mayer et al., 1998; Groot et al., 2007; 2012; Groot and Rossing, 2011). In this thesis, an empirical field experiment is combined with a multi-objective optimization model that allows analysing trade-offs and synergies among various productive, environmental and socio-economic indicators, and thereby helps to identify options for integration of 
banana legume intercropping. The thesis also explores through review of relevant literature best-fit agroecological intensification alternatives for improving the performance of the banana-based agroecosystem.

\subsection{Thesis goal, objectives and guiding hypotheses}

The overall goal of the study was to explore strategies for preventing and minimising shocks caused by XW disease outbreaks and improving the adaptability of banana agroecosystems under XW stress. This study addressed the following specific objectives.

i. To retrospectively characterize the XW driven land-use changes and trajectories and potential changes in the supply of key ecosystem services within XW affected landscapes. This objective was guided by the following hypothesis: a). $\mathrm{XW}$ is driving changes in land-use within farms and landscapes within affected banana-based agroecosystems.

b). XW driven changes in land-use are independent of the time of exposure to XW shocks and negatively impact on the supply of supporting and regulatory ecosystem services within the landscape.

ii. To evaluate the risk of $X W$ transmission in space as a function of environmental variables at landscape level. This objective is supported by the hypothesis that the spatial risk of $\mathrm{XW}$ is influenced by its characteristic biotic and abiotic covariates such as vegetation, banana cultivar composition, rainfall, temperature, crop and disease management practices.

iii. To determine the field level risk factors including the role of intercrops and weeds as alternative hosts to Xanthomonas campestris pv. musacearum, the XW causing pathogen in banana. I hypothesise that though Xcm can affect or survive on other crops and weeds in the banana-based agroecosystems, its association with these potential alternative hosts poses no risk to banana or these other crops.

iv. To explore trade-offs and synergies between different productive objectives in the current banana-legume intercrop management practices in the eastern DR Congo as basis for discouraging the practice or improving the performance of the system. I hypothesize that in addition to spreading XW disease, the current practice of banana leaf pruning to intercrop legumes results in a sub-optimal performance for a broad range of production objectives and this could form a good basis for discouraging the practice.

v. To explore the best-fit agroecological intensification alternatives for optimizing banana-based smallholder farms affected by XW. I hypothesize that best-fit 
agroecological intensification strategies are needed to mitigate $\mathrm{XW}$ effects on the supply of key ecosystem services within fields, farms and landscapes.

\subsection{Thesis outline and methods}

Figure 1.3 shows the outline of this thesis, with each objective being addressed by 1 to 3 thesis chapters. Objective 1 is addressed through Chapters 2 and 3. Chapter 2 uses both a qualitative and quantitative approach for data collection. Qualitatively focus group discussions (FGDs) and the Four-cell chart analysis are used to explore the ongoing XW-driven changes in land-use and land-use trajectories within banana-based landscapes, while quantitatively field measurements across fields with varying land-uses are used as proxies for selected ecosystem services potentially affected by land-use changes/ trajectories. Chapter 3 supplemented Chapter 2 by reviewing available literature on the potential effects of $\mathrm{XW}$ on ecosystem services other than the provisional services that to-date have received little or no attention.

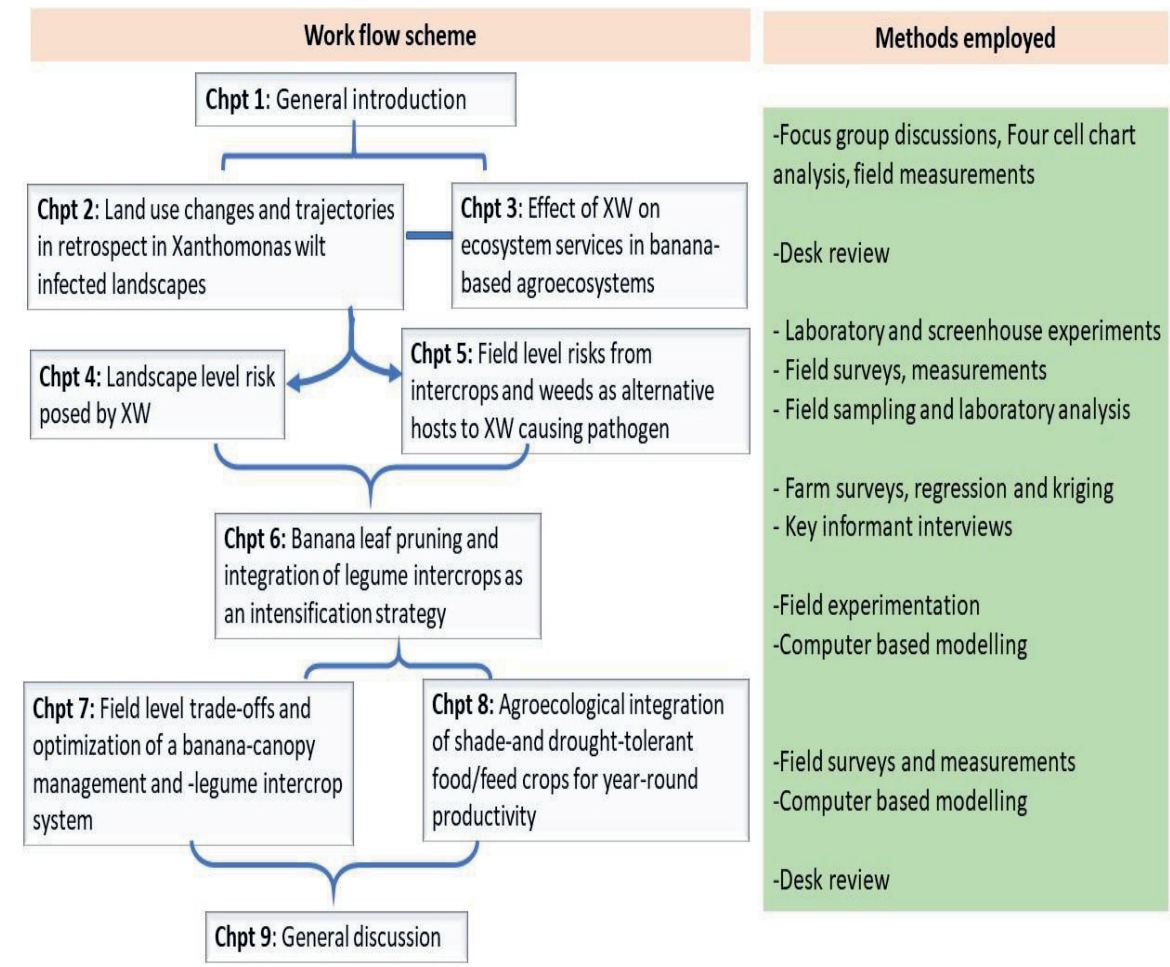

Figure 1.3. Schematic outline of the thesis. 
Objective 2 of this thesis is addressed through Chapter 4. In this chapter, field survey data collected/collated on XW disease incidence, is regressed against environmental and expert developed covariates and interpolated using the indicator regression kriging to develop the map of the AGLR showing the XW hotspots, fronts and vulnerable landscapes. In addition, expert generated covariates and relevant environmental covariates are used for mapping the possible risk due to $\mathrm{XW}$ across banana producing zones across Africa.

Objective 3 of the study is addressed by Chapter 5 . In this chapter, the ability of $\mathrm{Xcm}$, the XW causal agent to cause disease symptoms on selected weed and intercrop species is determined through screenhouse and laboratory studies. At field and farm level a survey followed by a multivariate analysis is used to determine the main factors (including the presence of plants that succumbed to $\mathrm{XW}$ in the screenhouse studies) explaining the variance of XW incidence and prevalence.

Objective 4 of this thesis is addressed by Chapters 6 and 7. Chapter 6 uses an empirical field experiment to determine the effects of farmer's banana leaf-pruning (a practice that spreads XW disease) to integrate legumes on the agronomic and economic performance of the system. Chapter 7 employs data from the field experiment in Chapter 6, a market study and literature to explore ex-ante with the multi-objective Pareto-based optimization FarmDESIGN model the trade-offs and synergies among economic, nutritional and environmental production objectives of the banana-bush bean intercropping system. This chapter also explores alternative scenarios and identifies superior banana-bush bean management options for improving the banana-bush bean system.

Objective 5 is attained through Chapters 3, 7 and 8. Chapter 3, through a review of literature suggests agroecological intensification options that bridge the gaps in ecosystem services lost due to XW disease outbreaks. Chapter 7 uses the FarmDESIGN model to explore alternative scenarios for improving the bananabush bean intensification system for multiple objectives while Chapter 8 explores from literature alternative agroecological intensification options, especially through use of shade and drought tolerant species for improving biomass production in banana-based agroecosystems affected by XW. 


\section{References}

AATF [African Agricultural Technology Foundation] (2009). Feasibility Study on Technologies for Improving Banana for Resistance Against Bacterial Wilt in Sub-Saharan Africa. Nairobi, Kenya. http://aatf-africa.org/userfiles/Banana_Bacterial_Wilt_Feasibility_Study.pdf (Accessed: August 2013).

Abele, S., Twine, E., and Legg, C. (2007). Food security in Eastern Africa and the Great Lakes. Crop Crisis Control Project Final Report to USAID. Pp. 110. http://c3project.iita.org/Doc/ Final\%20report\%20C3P\%20small.pdf (Accessed: March 2016).

Baudron, F., Tittonell, P., Corbeels, M., Letourmy, P., and Giller, K.E. (2012). Comparative performance of conservation agriculture, and current smallholder farming practices in semi-arid Zimbabwe. Field Crops Res. 132, 117-128.

Blomme, G., Dita, M., Jacobsen, K.S., Pérez Vicente, L., Molina, A., Ocimati, W., ... and Prior, P. (2017). Bacterial diseases of bananas and enset: Current state of knowledge and integrated approaches toward sustainable management. Front Plant Sci. 8, 1290.

Blomme, G., Jacobsen, K., Ocimati, W., Beed, F., Ntamwira, J., Sivirihauma, C., ... and Karamura, E. (2014). Fine-tuning banana Xanthomonas wilt control options over the past decade in East and Central Africa. Eur. J. Plant Pathol. 139, 265-281.

Blomme, G., Ploetz, R., Jones, D., De Langhe, E., Price, N., Gold, C., ... and Buddenhagen, I. (2013). A historical overview of the appearance and spread of Musa pests and pathogens on the African continent: highlighting the importance of clean Musa planting materials and quarantine measures. Ann. Appl. Biol. 162, 4-26.

Carter, B.A., Reeder, R., Mgenzi, S.R., Kinyua, Z.M., Mbaka, J.N., Doyle, K., ... and Smith, J.J. (2010). Identification of Xanthomonas vasicola (formerly X. campestris pv. musacearum), causative organism of banana Xanthomonas wilt, in Tanzania, Kenya and Burundi. Plant Pathol. 59(2), 403-403.

Edmeades, S., Smale, M., Kikulwe, E.M., Nkuba, J., Byabachwezi, M.S.R. (2007). Characteristics of banana-growing households and banana cultivars in Uganda and Tanzania. Pages 4974 in: An Economic Assessment of Banana Genetic Improvement and Innovation in the Lake Victoria Region of Uganda and Tanzania. M. Smale and W.K. Tushemereirwe, eds. IFPRI Research Report 155. IFPRI, Washington, DC.

Eledu, C.A., Karamura, E.B., and Tushemereirwe, W.K. (2004). Agroecological distribution of banana systems in the Great Lakes region. Afr. Crop Sci. J. 12 (1), 33-42

FAO (2017). FAOSTAT Data: Crops. http://www.fao.org/faostat/en/\#data/QC (Accessed: Nov. 2017).

Frison, E., and Sharrock, S. (1998). The economic, social and nutritional importance of banana in the world. In: Bananas and food security. Proceedings of an International Symposium held in Douala, Cameroon (Vol. 1014, p. 2135).

Gold C.S., Karamura, E.B., Kiggundu, A., Bagamba, F., and Abera, A.M.K. (1999). Monograph on geographic shifts in highland cooking banana (Musa, group AAA-EA) production in Uganda. Afr. Crop Sci. J. 7(3).

Groot, J.C., and Rossing, W.A. (2011). Model-aided learning for adaptive management of natural resources: an evolutionary design perspective. Methods Ecol. Evol. 2(6), 643-650.

Groot, J.C.J., Oomen, G.J.M., and Rossing, W.A.H. (2012). Multi-objective optimization and design of farming systems. Agr. Sys. 110, 63-77.

Groot, J.C.J., Rossing, W.A.H., Jellema, A., Stobbelaar, D.J., Renting, H., and Van Ittersum, M.K. (2007). Exploring multi-scale trade-offs between nature conservation, agricultural profits 
and landscape quality -a methodology to support discussions on land-use perspectives. Agr. Ecosyst. Environ. 120: 58-69.

Jogo, W., Karamura, E., Tinzaara, W., Kubiriba, J., and Rietveld, A. (2013). Determinants of farm-level adoption of cultural practices for banana Xanthomonas wilt control in Uganda. J. Agr. Sci. 5, 70-82.

Kalyebara, M.R, Ragama, P.E., Kagezi, G., Kubiriba, J., Bagamba, F., Nakinga, K.C., and Tushemereirwe, W. (2006). Economic importance of the banana bacterial wilt in Uganda. Afr. Crop Sci. J. 14, 93-103.

Kalyebara, R., Wood, S., and Abodi, P.M. (2007). Assessing the potential impact of selected technologies on the banana industry in Uganda. In: M. Smale, \& W.K. Tushemereirwe (Eds.), An Economic Assessment of Banana Genetic Improvement and Innovation in the Lake Victoria Region of Uganda and Tanzania. IFPRI Research Report 155. IFPRI, Washington, DC, pp. 141-156.

Kamira, M., Sivirihauma, C., Ntamwira, J., Ocimati, W., Katungu, M.G., Bigabwa, J.B., ... and Blomme, G. (2015). Household uses of the banana plant in eastern Democratic Republic of Congo. J. Appl. Biosci. 94, 8915-8929. http://dx.doi.org/10.4314/jab.v95i1.1

Kamusingize, D., Majaliwa, J.M., Komutunga, E., Tumwebaze, S., Nowakunda, K., Namanya, P., and Kubiriba, J. (2017). Carbon sequestration potential of East African Highland Banana cultivars (Musa spp. AAA-EAHB) cv. Kibuzi, Nakitembe, Enyeru and Nakinyika in Uganda. J. Soil Sci. Environ. Manag. 8 (3), 44-51. https://doi.org/10.5897/JSSEM2016.0608.

Karamura, E.B., Turyagyenda, F.L., Tinzaara, W., Blomme, G., Molina, A., and Markham, R. (2008). Xanthomonas Wilt (Xanthomonas campestris pv. musacearum) of Bananas in East and Central Africa. Diagnostic and Management Guide. Fountain Publishers, Kampala, Uganda.

Karamura, G. (2012). Development of field diagnostic tools for and characterisation of Xanthomonas campestris pv. musacearum, causal agent of banana Xanthomonas wilt. Master degree thesis. Exeter, Uk, University of Exeter.

Lufafa, A., Tenywa, M.M., Isabirye, M., Majaliwa, M.J.G., and Woomer, P.L. (2003). Prediction of soil erosion in a Lake Victoria basin catchment using a GIS-based Universal Soil Loss Model. Agr. Syst. 76, 883-894.

Mayer, D.G., Belward, J.A., and Burkage, K. (1998). Optimising simulation models of Agricultural systems. Ann. Oper. Res. 82, 291-232.

MEA (Millennium Ecosystem Assessment) (2005). Ecosystems and Human Well-being: Synthesis. Island Press, Washington, DC.

Muchuruza, Y.P., and Melchior, H.R. (2013). The effects of Banana Xanthomonas Wilt (BXW) on food security and the people's livelihood: the case of Nshamba and Rubale divisions in

https://agriprofocus.com/upload/post/BXW Research Findings1449153812.pdf

(Accessed: June 2019).

Ndungo, V., Eden-Green, S., Blomme, G., Crozier, J., and Smith, J.J. (2006). Presence of banana Xanthomonas wilt (Xanthomonas campestris pv. musacearum) in the Democratic Republic of Congo (DRC). Plant Pathol. 55(2), 294-294.

Nkuba, J., Tinzaara, W., Night, G., Niko, N., Jogo, W., Ndyetabula, I., and Karamura, E. (2015). Adverse impact of Banana Xanthomonas wilt on farmers livelihoods in Eastern and Central Africa. Afr. J. Plant Sci. 9(7), 279-286.

Ocimati, W., Karamura, D., Rutikanga, A., Sivirihauma, C., Ndungo, V., Adheka, J., ... and Blomme, G. (2013). Musa germplasm diversity status across a wide range of agroecological zones in Rwanda, Burundi and eastern Democratic Republic of Congo. In: 
Blomme, G. et al. (eds). Banana systems in the humid highlands of Sub-Saharan Africa: enhancing resilience and productivity. Wallingford, UK: CAB International, 8-21 ISBN:9781780642314.

Ocimati, W., Nakato, G.V., Fiaboe, K.M., Beed, F., and Blomme, G. (2014). Incomplete systemic movement of Xanthomonas campestris pv. musacearum and the occurrence of latent infections in Xanthomonas wilt-infected banana mats. Plant Pathol. 64, 81-90.

Okech, H.O., Gold, C.S., Abele, S., Nankinga, C.M., Wetala, P.M., van Asten, P., ... and Ragama, P. (2004). Agronomic, pests and economic factors influencing sustainability of bananacoffee systems of Western Uganda and potentials for improvement. Uganda J. Agr. Sci. 9, 432-444.

Reeder, R.H., Muhinyuza, J.B., Opolot, O., Aritua, V., Crozier, J., and Smith, J. (2007). Presence of banana bacterial wilt (Xanthomonas campestris pv. musacearum) in Rwanda. Plant Pathol. 56(6), 1038-1038.

Rutikanga, A., Sivirihauma, C., Ocimati, W., Night, G., Murekezi, C., Ndungo, V., ... and Blomme, G. (2016). Breaking the Cycle of Xanthomonas campestris pv. musacearum in Infected Fields through the Cultivation of Annual Crops and Disease Control in Adjacent Fields. J. Phytopathol. 164(9), 659-670.

Simmonds, N.W. (1966). Bananas. $2^{\text {nd }}$ edition. Longmans, London. UK.

Simmonds, N.W., and Shepherd, K. (1955). The taxonomy and origins of the cultivated bananas. Bot. J. Linn. Soc. 55, 302-312.

Sohel, M.S.I., Mukul, S.A., and Burkhard, B. (2015). Landscape's capacities to supply ecosystem services in Bangladesh: A mapping assessment for Lawachara National Park. Ecosyst. Serv. 12, 128-135.

Sohel, M.S.I., Mukul, S.A., and Chicaro, L. (2014). A new ecohydrological approach for ecosystem service provision and sustainable management of aquatic ecosystems in Bangladesh. Ecohydrol. http://dx.doi.org/10.1016/j.ecohyd.2014.10.001

Ssekiwoko, F., Taligoola, H.K., and Tushemereirwe, W.K. (2006). Xanthomonas campestris pv. musacearum host range in Uganda. Afr. Crop Sci. J. 14(2), 111-120.

Tinzaara, W., Stoian, D., Ocimati, W., Kikulwe, E., Otieno, G., and Blomme, G. (2018). Challenges and opportunities for smallholders in banana value chains. In Achieving sustainable cultivation of bananas (pp. 85-110). Burleigh Dodds Science Publishing.

Tittonnel, P., van Wijk, M.T., Rufino, M.C., Vrugt, J.A., and Giller, K.E. (2007). Analysing tradeoffs in resource and labour allocation by smallholder farmers using inverse modelling techniques: A case-study from Kakamega district, western Kenya. Agr. Syst. 95, 76-95.

Tripathi, L., Mwangi, M., Abele, S., Aritua, V., Tushemereirwe, W.K., and Bandyopadhyay, R. (2009). Xanthomonas wilt: a threat to banana production in East and Central Africa. Plant Dis. 93(5), 440-451.

Tushemereirwe, W., Kangire, A., Ssekiwoko, F., Offord, L.C., Crozier, J., Boa, E., ... and Simth, J.J. (2004). First report of Xanthomonas campestris pv. musacearum on banana in Uganda. Plant Pathol. 53(6), 802-802.

Tushemereirwe, W.K., Okaasai, O.O., Kubiriba, J., Nankinga, C., Muhangi, J., Odoi, N. ... and Opio, F. (2006). Status of banana bacterial wilt in Uganda. Afr. Crop Sci. J. 14(2), 73-82.

van Asten, P.J.A., Fermont, A.M., and Taulya, G. (2011). Drought is a major yield loss factor for rainfed East African highland banana. Agr. Water Manage. 98, 541-52.

van Asten, P.J.A., Gold, C.S., Okech, S.H.O., Gaidashova, S.V., Tushemereirwe, W., and De Waele, D. (2004). Soil quality problems in East African banana systems and their relation with other yield loss factors. InfoMusa 13, 20-25. 
Vandermeer, J. (1995). The ecological basis of alternative agriculture. Annu. Rev. Ecol. Syst. 26, 201-224.

Wairegi, L.W.I., van Asten, P.J.A., Tenywa, M.M., and Bekunda, M.A. (2010). Abiotic constraints override biotic constraints in East African highland banana systems. Field Crop Res. 117: 146-153. 


\section{Chapter 2}

\section{Xanthomonas wilt of banana drives changes in land-use and ecosystem services across infected landscapes}

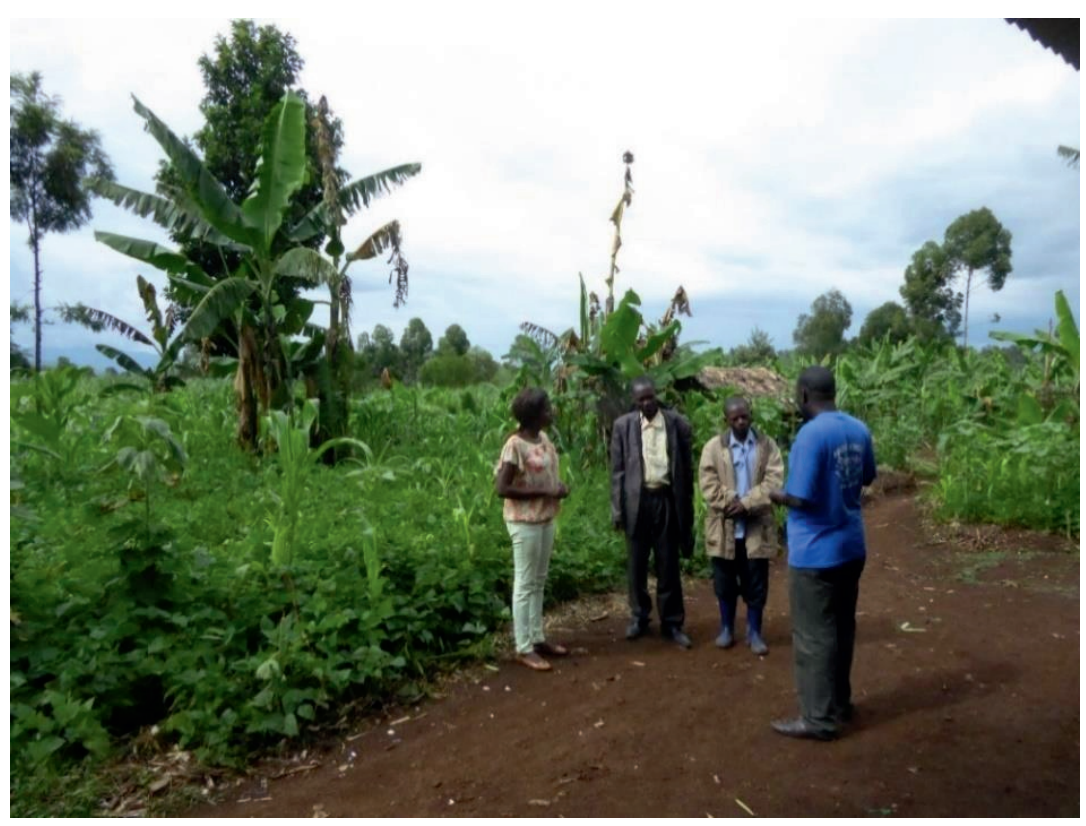

To be published as:

Ocimati, W., Groot, J.C.J., Tittonell, P., Taulya, G., Ntamwira, J., Amato, S., and G. Blomme, G. Xanthomonas wilt of banana drives changes in land-use and ecosystem services across infected landscapes of the African Great Lakes region 


\section{Abstract}

Changes in land-use/cropping patterns have been observed in banana-based systems in the African Great Lakes region affected by Xanthomonas bacterial wilt (XW) disease. Through participatory focus group discussions (FGDs) and the 4-cell method, changes in land-use were retrospectively assessed in $13 \mathrm{XW}$-affected villages at least $20 \mathrm{~km}$ apart along a $230 \mathrm{~km}$ transect from Masisi (XW arrived in 2001) to Bukavu (XW arrived around 2014) in eastern Democratic Republic of Congo during 2015. The four-cell chart ranked land-use by mapping the area under production and the number of households involved in production. Farmers' perceptions on the sustainability of new land-uses were also documented. Soil nutrient content and erosion levels were measured for five major land-use options/ trajectories on 147 fields across 55 farms and three landscapes along the transect. Before XW outbreak, banana was ranked the most important crop in $92 \%$ of the villages and produced on large areas of land and by many households across these villages. However, current ranking has it first only in one village along the transect. Farmers reportedly uprooted entire banana mats or fields, expanding land under other crops or introducing new crops. In $36 \%$ of the villages, banana is currently produced by many households but on smaller areas of land, while in $64 \%$ of cases it is produced by few households on smaller areas of land. The area shares of other fourteen crop species, mainly beans, taro, sweet potato, cassava, maize, coffee and eucalyptus increased over the same period. Species richness did not change at landscape level, though 21 crop species were introduced at farm level across the villages. Communities, however, still perceived land-use for banana to be more sustainable due to its multifunctional roles: year-round and regular supply of food, beer, fodder, building material; ability to reduce soil erosion; use as quick collateral for credits, school fees, emergencies and other social obligations; low production cost and high market value. Soils under banana plots were found in general to be better in their chemical attributes. High erosion levels ( $\mathrm{Mg} \mathrm{ha}^{-1}$ year $^{-1}$ ) were observed under cassava (1.7148.9) compared with banana (0.3-10.7) and trees (0.3-5.9). The current study offers a good basis and entry point for interventions to sustainably improve production systems, incomes and food security in XW-affected landscapes.

Key words: communities, disease, multi-functional, perceptions, soil erosion, uprooting 


\subsection{Introduction}

Musa spp. (banana and plantain, hereafter banana) is an important food and income fruit crop the world over (Robinson and Galán Saúco, 2010). The crop ranks sixth in production, with an annual world production of about 144.6 million Mg (FAO, 2017). The East and Central African Great Lakes region contributes one third of the world production, with production estimates of 5.2, 1.8, 1.4 and 1.4 million $\mathrm{Mg} \mathrm{ha}^{-1}$ year $^{-1}$ reported for Uganda, Rwanda, Burundi and the Democratic Republic of Congo, respectively (FAO, 2017). In this region, banana provides 30 - $60 \%$ of food energy needs of over 70 million people (Abele et al., 2007; Karamura et al., 2008) and is also important for income generation through market sales (Okech et al., 2004; Edmeades et al., 2007). The region is a secondary centre of diversity for the East African Highland bananas ( $A A A$ genome) and plantains ( $A A B$ genome) (Simmonds and Shepherd, 1955; Simmonds, 1966). Banana in the region, is mainly grown as a perennial crop/permanent vegetation and plantations that are 30 to 50 years old are very common (Bekunda, 1999; Gold et al., 1999).

The crop is grown across a wide range of agroecological zones either as sole crop or in association with various annual or perennial crops, offering a broad range of ecosystem services in addition to food, feed and fibre (Ocimati et al., 2018). The thick year-round canopy offered by its broad leaves, the mulch cover provided by dead leaves, leaf sheaths and harvested plant parts and an extended superficial root system help reduce soil erosion (Baragengana, 1985; Rishirumuhirwa and Roose, 1998; Lufafa et al., 2003), hence contributing to the resilience of the agroecosystems. The banana crop could thus be considered as a foundation species in this part of the word. A foundation species is a common/ abundant species whose attributes (structural or functional) define an ecological community or ecosystem (Dayton, 1972). Tampering with a foundation species can potentially affect the socio-cultural, economic and ecological resilience of a landscape. Modest to dramatic decline has been observed over the past two decades in the lifespan and productivity of banana plantations, and food and income security of banana dependent households has been severely affected by pests (weevils and nematodes) and diseases (mainly Xanthomonas wilt, banana bunchy top disease and Fusarium wilt).

The banana Xanthomonas wilt disease (XW), the most recent constraint, has been particularly devastating to banana production in this period in the region. First observed in Ethiopia in 1939 (Castellani, 1939), XW was reported in Uganda and eastern DR Congo in 2001 (Tushemereirwe et al., 2004; Ndungo et al., 2004) and has since spread to the entire East and Central Africa region, compromising plantations, and food and income security at local, national and regional levels (FAO, 2012). The disease causes death of affected plants and makes infected bunches inedible. As a control measure, or out of frustration, there has been widespread cutting and uprooting of diseased mats or fields. In response to the 
disease, farmers have also been reported to have diversified into other crop species and off-farm activities (Desire et al., 2016). Thus, in addition to XW effects on food and income security, the disease has been postulated to be accompanied by changes in land-use and species composition at farm and landscape level, with potential positive or negative effects on the food systems and other ecosystem services. These changes have not been systematically documented as a basis for evaluating the repercussions to livelihood outcomes and ecosystem services in the affected landscapes.

This study retrospectively analysed the i) trajectories of change in land-use patterns in response to $\mathrm{XW}$ in the $\mathrm{XW}$-affected landscapes, ii) changes in production, consumption and marketing of banana and other key crop species in the landscape, iii) soil nutrient content and amount of soil erosion for major land use types and iv) farmers' perceptions on the sustainability of the new land-uses. Objectives (i) and (ii) were achieved through recall studies in landscapes exposed to XW disease for time periods varying between 1 to 14 years. Objectives (iii) and (iv) were attained through field measurements and interviews across farms.

\subsection{Materials and methods}

\subsubsection{Study area}

This study was conducted in the eastern part of the Democratic Republic of Congo (DR Congo) that comprises two provinces, North Kivu and South Kivu. The province of North Kivu covers an area of $59,631 \mathrm{~km}^{2}$ and has 4.9 million inhabitants. It is located between $0^{\circ}$ $58^{\prime}$ latitude North to $02^{\circ} 03^{\prime}$ latitude South and $27^{\circ} 14^{\prime}-29^{\circ} 58^{\prime}$ longitude East (UNDP, 2009), mean annual rainfall ranges between $1268 \mathrm{~mm}$ and $1556 \mathrm{~mm}$ and an altitude range of 909 - 1803 meters above sea level $(\mathrm{m})$ (Farrow et al., 2006). South Kivu is located between $1^{\circ}$ $36^{\prime}-5^{\circ}$ latitude South and $26^{\circ} 47^{\prime}-29^{\circ} 20^{\prime}$ longitude East and has an area of 69,130 km², a population of 3.9 million people (UNDP, 2009). Annual rainfall in South Kivu varies between $1,437 \mathrm{~mm}$ and 1,661 $\mathrm{mm}$ and an altitude range varying between 950 to $2019 \mathrm{~m}$ (Farrow et al., 2006). In this predominantly highland region, agriculture is the main basis of livelihoods of the rural and peri-urban population, with most of them farming at a subsistence level. Banana and plantain are important staple and cash crops contributing to the food and income security of over five million people (CIALCA, 2009). For example, banana/plantain and their products (e.g. beer) were reported to provide about 80 percent of incomes in South Kivu (Food for the Hungry, 2013).

\subsubsection{Land-use trajectories and food systems}

The study was conducted along a $230 \mathrm{~km}$-long axis from Masisi in North Kivu province to Bukavu in South Kivu province (Figure 1) in 2015. This transect was selected as a case study 
because it starts at a disease front and comprises sites with various timespans of high disease presence/pressure.

The data for this study was collected using a total of 13 village-level focus group discussions (FGDs). Eleven of the 13 FGDs were conducted at approximately $20 \mathrm{~km}$ interval along the 230-km axis starting from Kahanga-Kabingu village in Masisi territory to Kashusha village in Bukavu, while the other two FGDs were conducted on Idjwi Island (i.e., Idjwi North and Idjwi South) located in Lake Kivu, South-Kivu province (Fig. 1, Table 1). XW was first reported at Masisi in the year 2001 while it arrived at Bukavu, the last FGD location, in 2014 (Fig. 1, Table 1).

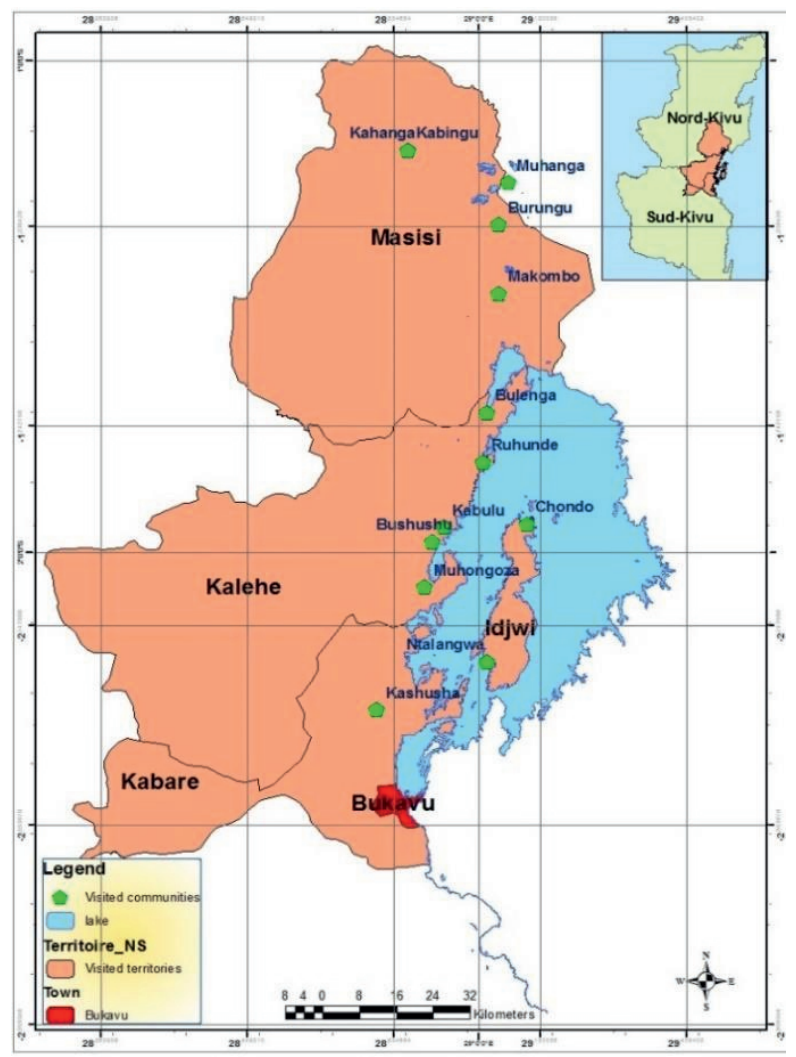

Figure 1. Map showing the locations of the communities/landscapes that participated in the Focus Group Discussions conducted in North and South Kivu provinces in eastern DR Congo.

The snowball sampling technique was used for the identification of parishes affected by XW along the study transect. With the snowball sampling technique (Cohen and Crabtree, 2006), the existing study objects inform the recruitment of the subsequent subjects based on their acquaintance. Within the parishes, villages affected by XW were purposively 
sampled for the FGDs through interaction with community leaders, key informants and extension agents in the study area (Table 1 ).

A total of 10 farmers in a sex ratio 1:1, each at least 30 years of age participated in FGDs. Precaution was taken to select only farmers that had been fully active in the study sites for a period of over 10 years. It was postulated that this category of farmers had a better understanding/experience with the impact of the biotic stresses, especially XW, and understanding of the changes and trajectories in the crop diversification and food systems at these sites. The distribution of the FGDs in the study area is detailed in the Table 1 below.

Table 1. The positioning of the sampled villages and focus group discussions along the $230 \mathrm{~km}$ study axis.

\begin{tabular}{|c|c|c|c|c|c|c|c|}
\hline Province & Territory & Village & $\begin{array}{c}\text { Year of } \\
\text { XW } \\
\text { outbreak }\end{array}$ & Longitude & Latitude & Altitude & $\begin{array}{c}\text { Distance } \\
\text { from } \\
\text { Masisi }\end{array}$ \\
\hline \multirow{4}{*}{$\begin{array}{l}\text { North- } \\
\text { Kivu }\end{array}$} & \multirow{4}{*}{ Masisi } & Kahanga- Kabingu & 2004 & - & - & - & 0 \\
\hline & & Muhanga & 2001 & S01.24778 & E029.05931 & 1701 & 20 \\
\hline & & Burungu & 2004 & - & - & - & 40 \\
\hline & & Makombo & 2008 & S01.47358 & E029.04045 & 2010 & 60 \\
\hline \multirow{9}{*}{$\begin{array}{r}\text { South- } \\
\text { Kivu }\end{array}$} & \multirow{5}{*}{ Kalehe } & Bulenga & 2005 & S01.71581 & E29.01702 & 1525 & 80 \\
\hline & & Ruhunde & 2005 & S01.81677 & E029.00951 & 1520 & 100 \\
\hline & & Kabulu & 2005 & S01.94952 & E028.93301 & 1757 & 120 \\
\hline & & Bushushu & 2009 & S01.97875 & E28.90992 & 1486 & 140 \\
\hline & & Muhongoza & 2004 & S02.07115 & E28.89534 & 1585 & 160 \\
\hline & \multirow[t]{2}{*}{ Kabare } & Kahanga & 2009 & S01.18282 & E028.8617 & 1488 & 180 \\
\hline & & Kashusha & 2012 & S02.32044 & E28.80240 & 1713 & 210 \\
\hline & \multirow[t]{2}{*}{ Idjwi } & Chondo & 2002 & S01.94219 & E029.09471 & 1550 & - \\
\hline & & Ntalangwa & 2008 & S02.22220 & E029.01602 & 1492 & - \\
\hline
\end{tabular}

The FGDs were guided using a structured questionnaire. The facilitator used a checklist to elicit information from the participants and probed for triangulation of the responses whenever necessary. Care was also taken to ensure full participation of all the FGD participants. A four-cell chart (Bellon and Raneri, 2014; Raneri et al., 2016) was used to retrospectively rank the trajectories and changes in crop species and cultivar diversification and importance in landscapes affected by XW. The four-cell is a participatory rapid rural appraisal technique created to assess agrobiodiversity and local food system flows (Sthapit et al., 2006; Raneri et al., 2016). It allows for a quick identification and assessment of changes in food security and diet diversity (Raneri et al., 2016). The four-cell chart ranks species abundance and distribution by looking at area under production and the number of households involved in production. This results into four cells or groupings i.e. a species 
being grown on: i) a large acreage and being produced by many households; ii) large acreage but by few households; iii) small acreage but by many households and iv) small acreage and few households (Fig. 2)

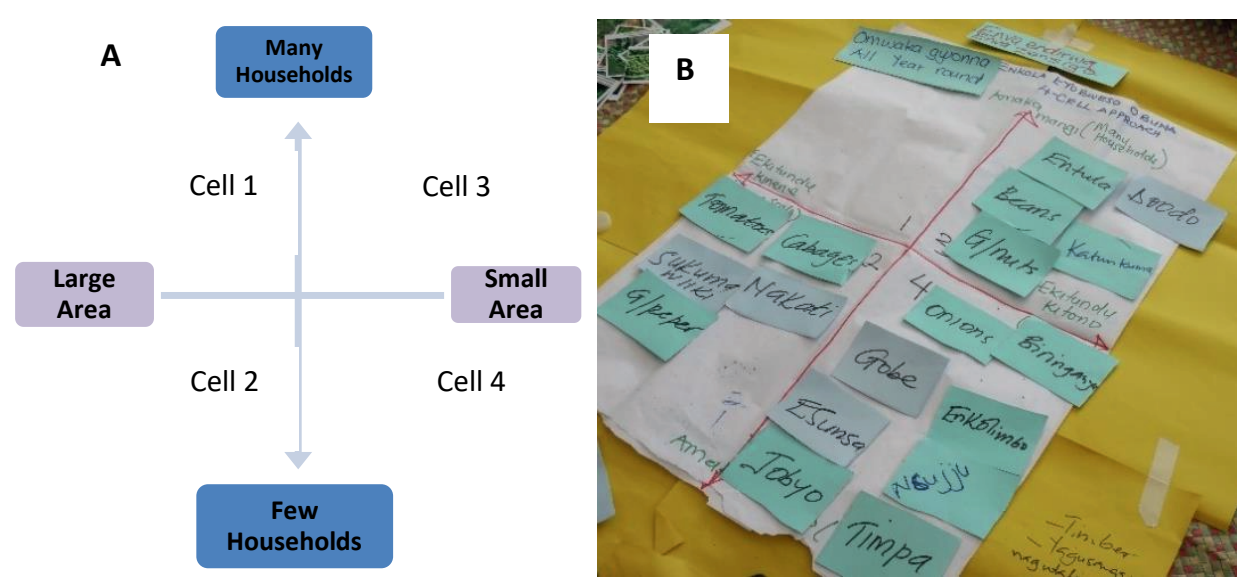

Figure 2. A four-cell chart (A) and an example of farmers posting of different crop species on a fourcell chart within a landscape and a point in time (B). The four-cell analysis were conducted across 13 landscapes in South/North Kivu provinces, eastern DR Congo.

Data were coded and analysed using both quantitative and qualitative methods. Descriptive statistics were carried out using STATA and GenStat v. 12 software (VSN International Ltd, 2009). MS Excel was used for developing figures. The qualitative information was either used to explain and interpret the quantitative information provided by the respondents during the group discussions or compiled and sorted through a coding process to generate descriptive tables and figures.

\subsubsection{Effect of XW driven land use trajectories of change on selected supporting and regulatory ecosystem services}

To determine the potential effect of land use changes and trajectories on selected supporting and regulatory services (objective iv), 147 fields spread across 55 farms on three sites along the transect, namely Idjwi North (Northern part), Katana (midway) and Mushinga (southern part) were examined. All the three sites are in South Kivu province. Soil related agroecosystem services such as pest and disease regulation, nutrient flows, soil formation and structure are provided by several interrelated processes that govern decomposition, soil formation, soil structure, erosion control, soil moisture and aeration, and cycling of mineral nutrients and carbon (Bommarco et al., 2013). These soil variables are thus a good measure of the effect of farm management on soil health and a good proxy for soil ecosystem services (Wood et al., 2001; Bommarco et al., 2013; Gliessman, 2015). To 
infer the potential effect of the land-use trajectories of change due to XW on ecosystem services, soil chemical properties and soil erosion rates were determined. Soil chemical properties served as a proxy for nutrient recycling, an import supporting ecosystem function, while soil erosion rates served as proxy for erosion control, an important regulatory service in the landscape.

\subsubsection{Soil carbon and nutrients}

The content of soil organic matter (SOM), total nitrogen $(N)$, available phosphorus and exchangeable bases ( $\mathrm{K}$ and $\mathrm{Ca}$ ) were measured as indicators for soil quality and were used to compare different land-use options and to infer the potential impact of the land-use trajectories. Composite samples of five soil cores $(2 \mathrm{~cm}$ in diameter and $15 \mathrm{~cm}$ deep; using a soil auger) were collected diagonally in fields under different land uses (crops or plant species) in the middle of the main growing season (i.e. October 2016). Each sample was air dried, sieved to pass through a 2-mm mesh and analysed for soil $\mathrm{pH}$ and nutrient composition at the National Agricultural Research Laboratories, Kawanda, in central Uganda. The exchangeable cations and available phosphorus were extracted using Mehlich 3 extraction method at a $\mathrm{pH}$ of 2.5 (Mehlich, 1984) then determined using an atomic absorption spectrophotometer. Soil organic carbon content was determined colorimetrically at $600 \mathrm{~nm}$ after digestion with potassium dichromate and sulphuric acid (Walkley-Black). Nitrogen was extracted using sulphuric/selenium digestion mixture, at $330^{\circ} \mathrm{C}$ and later quantified colorimetrically using salicylate method. $\mathrm{pH}$ was read from a 1:2.5 soil:water extract. Soil texture was determined using the Bouyoucos hydrometer method (Bouyoucos, 1962).

Mean levels of SOM, N, available phosphorus and exchangeable bases across the different land use options were analysed through Analysis of Variance, with means separation using LSD at 5\%. The GenStat statistical package v.12 (VSN International Ltd, 2009) was used for the analysis.

\subsubsection{Soil erosion losses}

Erosion rates for different land uses were determined using the revised universal soil loss equation (RUSLE) (Renard et al., 1997; Wall et al., 2002; Stone and Hilborn, 2015). RUSLE estimates the annual erosion rate on a field based on field slope, rainfall intensity, soil type, crop characteristics and management practices. It is expressed as (Renard et al., 1997):

$$
A=R^{*} K^{*} L S^{*} C^{*} P
$$

Where: $\boldsymbol{A}$ = estimated average soil loss $\left(\mathrm{Mg} \mathrm{ha}^{-1}\right.$ year $\left.^{-1}\right) ; \boldsymbol{R}=$ rainfall-runoff erosivity factor $\left(\mathrm{MJ} \mathrm{mm} \mathrm{ha}{ }^{-1} \mathrm{~h}^{-1}\right.$ year $\left.{ }^{-1}\right) ; \boldsymbol{K}=$ soil erodibility factor $\left(\mathrm{Mg} \mathrm{h} \mathrm{MJ}^{-1} \mathrm{~mm}^{-1}\right) ; \boldsymbol{L}=$ slope length 
factor; $\boldsymbol{S}=$ slope steepness factor $\boldsymbol{C}=$ cover-management factor; and $\boldsymbol{P}=$ support practice factor.

Rainfall-runoff erosivity $(R)$ is a measure of erosion potential of a rainfall event and is influenced by duration and intensity of the event; and $R$ for the study site were in the order of 3,750 MJ mm ha-1 $\mathrm{h}^{-1}$ year ${ }^{-1}$, as calculated by Vrieling et al. (2010). Soil erodibility factor $K$ is a measure of susceptibility of soil particles to detachment and transport by rainfall and water runoff. $K$ was determined using the method developed by Kassam et al. (1992) for Kenyan soils. Using this approach, soil texture results for each land-use unit/ field (see Section 2.3.1) and soil units for the study areas were used as input for determining the $\mathrm{K}$ classes and the associated $\mathrm{K}$ values. The soil units for Mushinga, Katana and Idjwi were respectively, haplic Acrisols, humic Cambisols and haplic Ferralsols (Beernaert, 1999, Van Engelen et al., 2006). On farm data for input in the RUSLE included the slope length ( $L$ ) and steepness $(S)$ of fields, main crop species grown on fields, tillage practices and supportive field management practices. The lengths for each field or segment, was measured using a $100 \mathrm{~m}$ length tape measure whereas the \% slope was computed using the equation:

$$
S=\text { Rise of slope/ Run of slope } * 100 \%
$$

The rise $(\mathrm{m})$ was obtained from the difference between the elevations of the upper and lower parts of the field along the length of the slope measured using global positioning unit (GPS, Garmin - GPSMAP 64s; www.garmin.com) whereas run of slope was obtained using the Pythagoras theorem (i.e. Run of slope ${ }^{2}=L^{2}-$ Rise of slope ${ }^{2}$ ).

LS, which is the proportion of soil loss under a given condition compared to that of a site with a standard slope steepness of $9 \%$ and length $22.13 \mathrm{~m}$ was determined as described by Stone and Hilborn (2015) using:

$$
L S=\left[0.065+0.0456(S)+0.006541(S)^{2}\right](L \div \text { constant })^{N}
$$

Where: $S=$ slope steepness in \%; $L=$ length of slope $(\mathrm{m})$; constant $=22.13 \mathrm{~m}$; and $\mathrm{N}=\mathrm{N}$ values of $0.2,0.3,0.4$ and 0.5 , respectively, correspond to $S$ values of $<1,1 \leq$ slope $<3,3 \leq$ slope $<5$, and $\geq 5$.

The crop management and tillage factor $(C)$ determines the relative effectiveness of crop and soil management in prevention of soil erosion and was computed as the product of the crop type factor (score of 0 to 1 ) and the tillage method (score of 0 to 1 ) (Stone and Hilborn, 2015). The plant/crop canopy cover factor (ranging between 0 and 1) was estimated using Equation (4) (Wischmeier and Smith, 1978; Renard et al, 1998): 


$$
\text { Crop type factor }=1-F c * \exp (-0.1 * H)
$$

Where $F c$ is the proportion of the ground covered by the canopy, $H(\mathrm{ft})$ is the distance the raindrops fall after hitting the canopy. $F c$ and $H$ were captured through visual assessments and estimations on farm. For the assessment of canopy height $(H)$ in intercropped fields, one species was considered if dominant, otherwise an average was considered where two or more species had a more or less equal share of the land cover. Thus, the crop type factor was influenced by the level of species diversity and the attributes of the species complex. The tillage method factor was scored between ' 0 ' and ' 1 ' (' 0 ' denoting good practice while ' 1 ' a bad practice) as described by Stone and Hilborn (2015). The supportive practice factor $P$ is the ratio of soil loss through a supportive practice to that through farming up and down the slope and varies between a scale of ' 0 ' (good practice) to ' 1 ' (bad practice) (Wischmeier and Smith, 1978; Stone and Hilborn, 2015).

The tillage method factors, crop type/cover factor, the support practices and the soil erosion rates were compared across the dominant land-use options using Analysis of Variance (ANOVA) and the means separated as described in the Section 2.3.1 above. Due to an unequal distribution of land use options across the sites and the lack of interaction between the sites and land use options, ANOVA was only computed for the land use options.

\subsubsection{Farmers' perceptions on the future role of banana crop and the sustainability of} the key land-use trajectories in XW affected landscapes

Farmers perceptions on future role of banana and the ability of the major land use trajectories to fill the gap left by the banana crop obtained through structured interviews in the FGDs in 2.2 above and on farms.

\subsection{Results and discussion}

\subsubsection{On-farm coping strategies against Xanthomonas wilt disease}

Communities affected by XW disease reported several coping strategies (Fig. 3). The most prevalent practices across communities/ landscapes included uprooting of diseased mats, cutting of sick plants and removal of male floral buds to prevent insect-mediated infections (Fig. 3). These practices form the basic cultural control practices being promoted for managing XW disease (Blomme et al. 2014). Other practices being promoted such as farm tool sterilization and formation of community task forces to enforce disease control occurred in only $45 \%$ and $27 \%$ of the landscapes, respectively. Ochola et al. (2013) reported some of these practices as the prevalent agroecological practices on farms affected by XW 
disease. Uprooting of entire banana fields was also prevalent across $73 \%$ of the communities. In $55 \%$ and $91 \%$ of the cases, landscapes reported the complete abandoning of the banana crop and expansion of the area under other crops, respectively (Fig. 3). This was mainly due to frustration due to severe yield losses and persistence of infections on farms. The consumption of banana also declined across $82 \%$ of the landscapes in eastern DR Congo while in $90 \%$ of the cases, households had diversified to other crops for beer making. Nkuba et al. (2015) reported changes in diets, with an increased consumption of maize and root and tuber crops (36\% of households) and a reduction in number and size of meals (52\%) as coping strategies within households affected by XW in Rwanda and Tanzania.

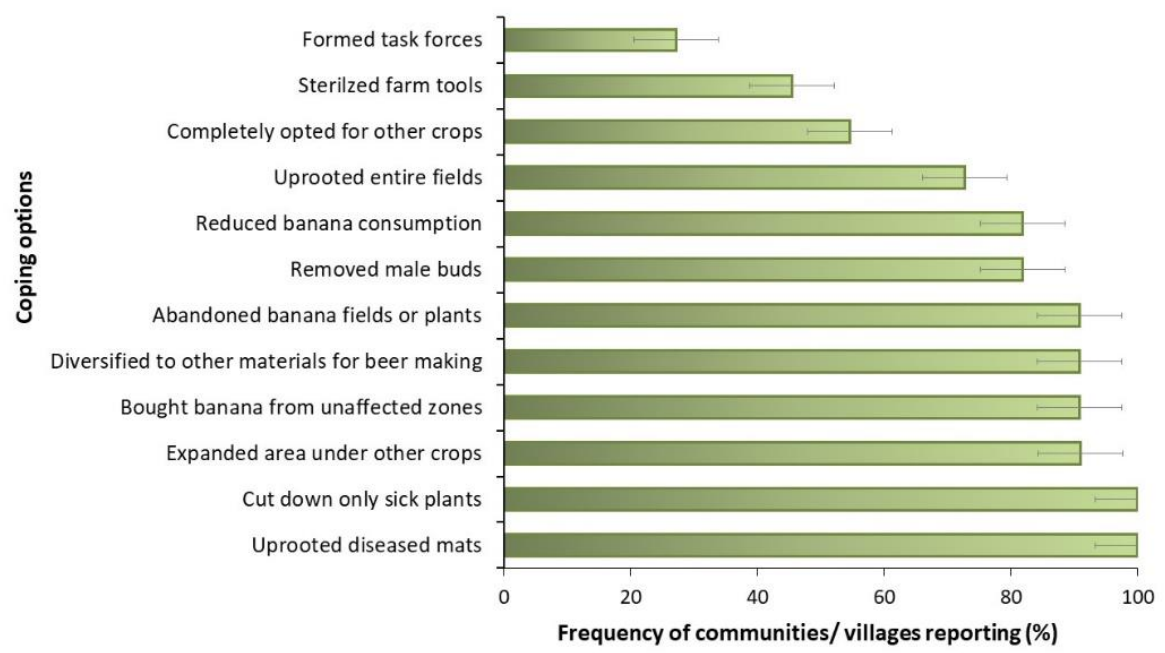

Figure 3. Responses and/ or coping strategies in reaction to Xanthomonas wilt across different banana growing communities/ landscapes in eastern DR Congo. Error bars represent standard errors.

\subsubsection{Crop diversification trajectories due to Xanthomonas wilt disease}

Prior to the outbreak of XW, farmers ranked banana as the most important crop on farms across the studied landscapes, followed by beans and cassava. However, following XW outbreak, crop rankings changed, with banana dropping to the fourth in importance, relative to the other crops, across the study landscapes (Fig. 4A). Food crops, mainly cassava, maize, sweet potato and soybean gained in importance (Fig. 4A). Cassava currently ranks as the most important crop across the XW affected landscapes in eastern DR Congo. A big shift in ranking also occurred for soybean $\left(13^{\text {th }}\right.$ to the $\left.8^{\text {th }}\right)$. The ranking of beans in the food system remained unchanged while coffee and taro dropped in importance. 
A shift was observed towards increasing the area under a large number of crop species by many households (i.e. to cell 1 ), mainly from being grown on small areas by many households (i.e. cell 3) (Fig. 4B).
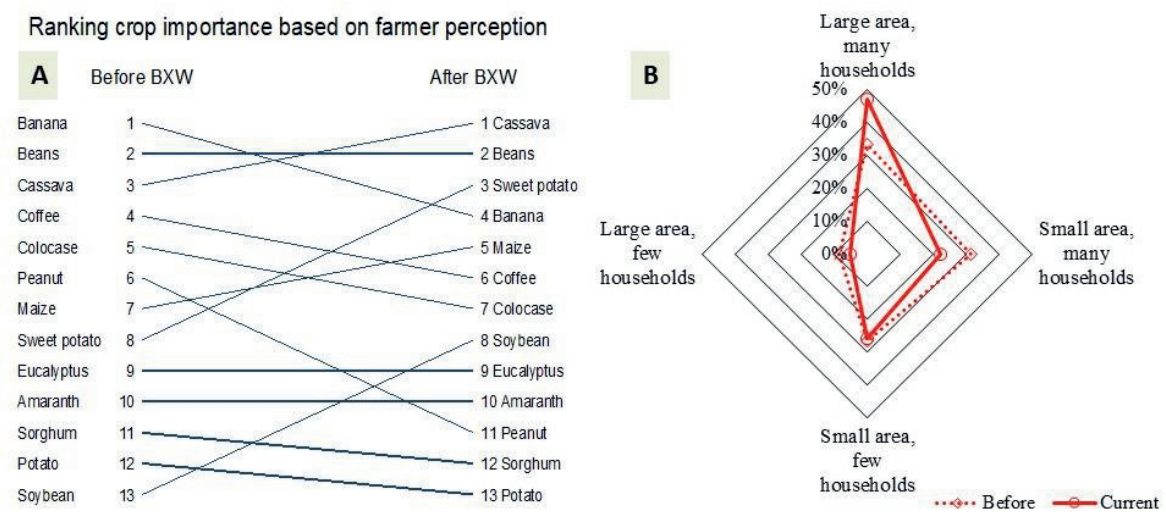

Figure 4. Farmers' perceptions on the rankings in importance of different crop species $(\mathbf{A})$ and trends in crop species richness (\%) on along the quadrants of a 4-cell chart (B) following the outbreak of XW in 13 landscapes in eastern Democratic Republic of Congo. Cells 1, 2, 3 and 4, respectively stand for a species being grown on i) a large acreage and by many households; ii) large acreage but by few households; iii) small acreage but by many households and iv) small acreage and by few households. Data was captured in the period 2015/16.

The four-cell chart predominantly grouped the banana crop into cell 1 before the outbreak of XW disease across the 13 XW-affected landscapes (Fig. 5). Banana was ranked first in $92 \%$ of the villages, produced on large land areas and by many households across the villages. Cassava (85\%) and beans (46\%) were also more likely to be grouped in cell 1 across the surveyed landscapes before the outbreak of the disease (Fig. 5; $\mathrm{Chi}^{2}=92.1, \mathrm{P}$ $<0.0001$ ). At the time of this study (after or at the peak of XW epidemics), only a single village ranked banana first among the crop species. Farmers reported uprooting entire banana mats and/or fields while expanding land under other crop species and/ or introducing new crop varieties (Figures 3,5). Banana no longer fell into cell 1 of the fourcell chart. In $36 \%$ of the villages, banana was produced by many households but on small areas (cell 3), while in $64 \%$ of cases it was produced by few households on small areas (cell 4) (Fig. 5; Chi2 = 61.1, P <0.0001). Species richness did not change at landscape level, though 21 crop species were introduced at farm level across the villages. Pronounced changes in importance were mainly observed for 14 food crops and tree species, mainly beans, taro, sweet potato, cassava, maize, coffee, eucalyptus and soybeans in terms of area under production and the number of households producing them (Figures 5 and 6). 

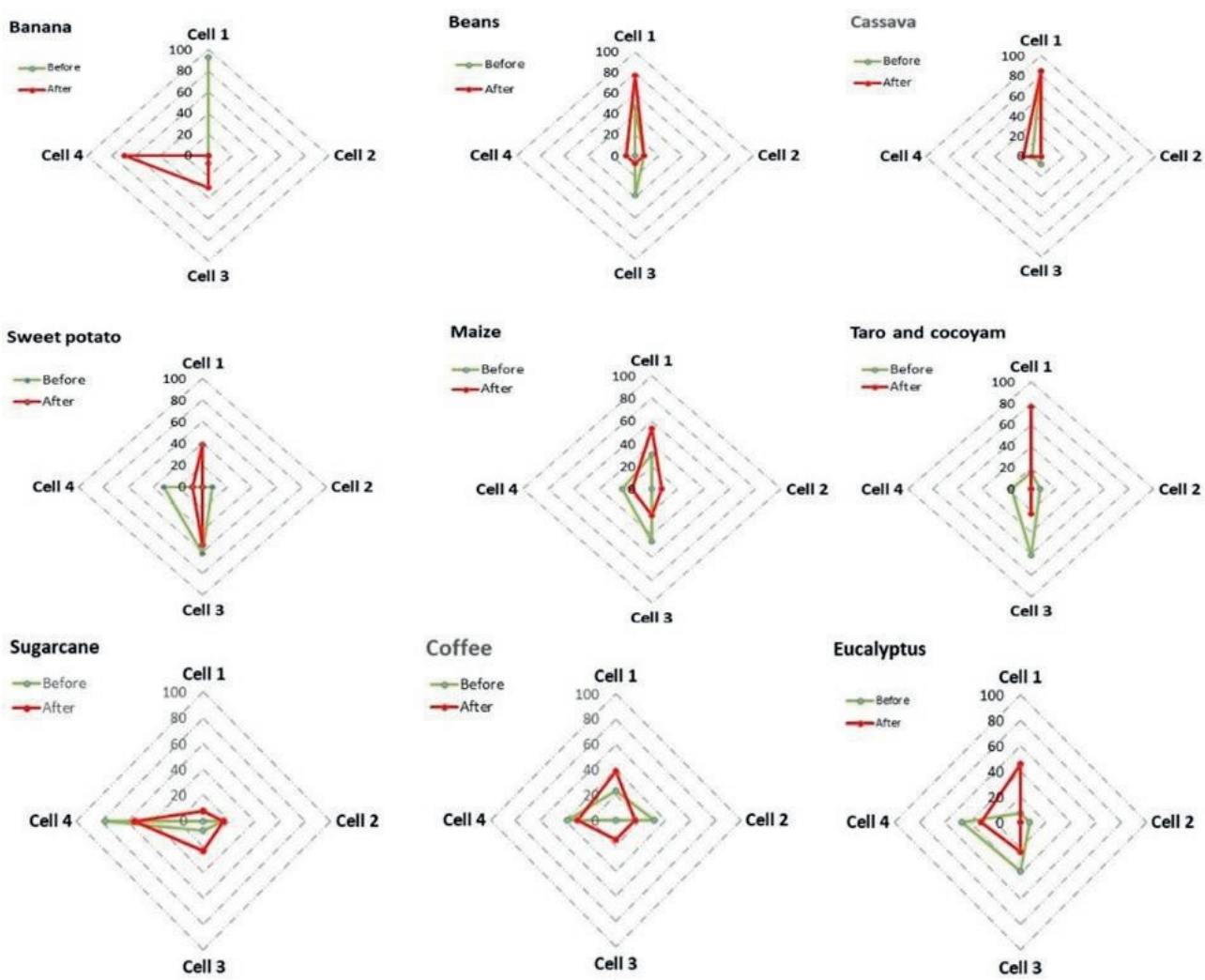

Eucalyptus

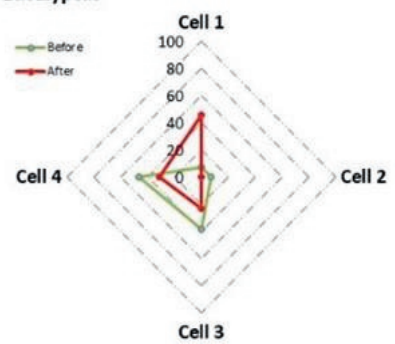

Figure 5. Spider plots showing the shifts in diversity (abundance) of selected key crop species before and after the outbreak of Xanthomonas wilt disease of banana across 13 landscapes in eastern Democratic Republic of Congo. Cells 1, 2, 3 and 4, respectively stand for a species being grown on i) a large acreage and by many households; ii) large acreage but by few households; iii) small acreage but by many households and iv) small acreage and by few households.

Increase in the importance and production of the 14 crops was reported to target the filling of the food security and income gap that arose from the loss of the banana crop to XW disease. Nkuba et al. (2015) similarly reported increases in the area under maize, root and tuber crops on XW affected farms in Tanzania and Rwanda. Replacement of banana with sweet potatoes and cassava after devastation by XW has also been reported in Uganda (Kalyebara et al., 2006). The high ranking of cassava can be attributed to its complementary role to banana as a food and income crop in these XW affected landscapes. The increments in the area and the number of households growing coffee and taro (Figures 5 and 6) is not in tandem with the drop in the rankings of these crops (Fig. 4). The slight drop in the rankings for coffee and taro (cf. Fig. 4) could be attributed to the urgent need to bridge the food and income gap, with quick maturing annual crops taking the priority. This is supported by the fact that the number of households and area under coffee, taro and cocoyam relative 
to the period before XW outbreak had increased (Fig. 5). The leap in the rank of soybean was attributed to ongoing promotion of soybean as a biological nitrogen fixation agent and source of income by international projects in the region.

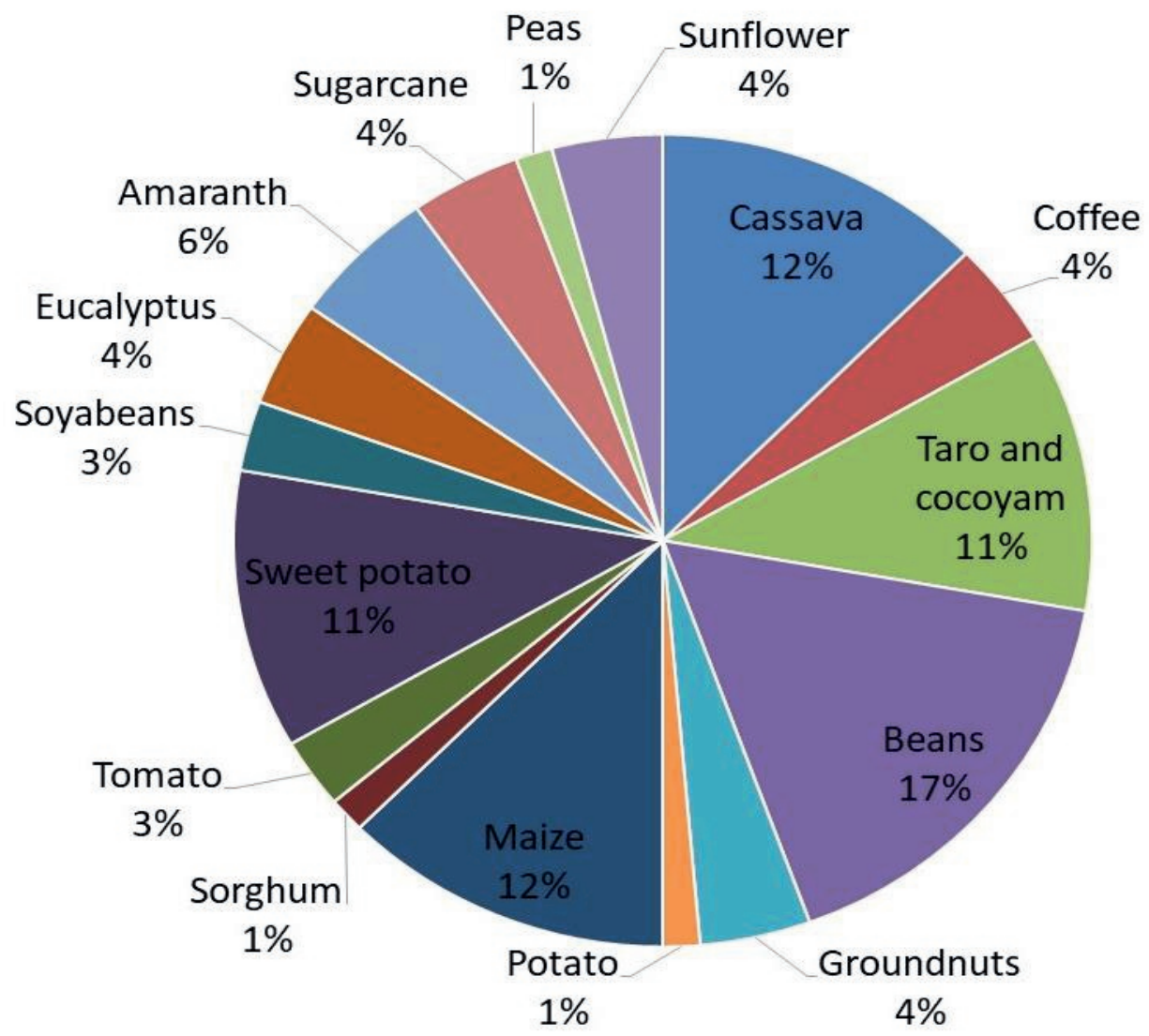

Figure 6. The crop species used to replace uprooted banana fields in landscapes affected by Xanthomonas wilt disease of banana in the eastern DR Congo.

Farmers' choices of replacement crops for banana in XW affected landscapes mainly comprised of the urgent need to bridge the income gap i.e. market value and improve food and nutrition security. The potential environmental benefits or effects on e.g. soil erosion, nutrient recycling received the least attention from farmers when considering crops to replace banana. This could be due to farmers' limited knowledge on or perceived less importance of such services, in addition to these services often being intangible (Ocimati et al., 2018). 


\subsubsection{Perceived changes in the food systems due to $X W$ stress}

$\mathrm{XW}$ disease induced changes in the value chains of major staple crops from production to consumption within the affected areas. Declines in the production and consumption of banana occurred across all (100\%) XW-affected landscapes, while the sale and purchase by households from other markets of banana only increased in $23 \%$ and $38 \%$ of the affected landscapes, respectively, relative to the time before the outbreak of XW (Fig. 7). The decline in banana production and consumption within households was predominantly attributed to XW disease. Delayed management of XW disease is reported to result in up to $100 \%$ yield losses. Increases in household sales of banana in some of the landscapes despite the decline in production and consumption can be attributed to the attractive higher market prices resulting from a low supply of bunches in the market. Nkuba et al. (2015) also reported a 35\% decline in banana sales by farmers and a doubling of banana bunch prices in Tanzania and Rwanda due to XW disease. The slight increment in household expenditure on banana bunches, is because some households were able to buy bunches from the local or urban markets to meet the household demand for banana-based food and banana beer beverage that also had an attractive price in the market. Increases in production was observed for all the major food and tree crops in most of the XW-affected landscapes (Fig. 7). These increases were due to increased land allocation (cf. Fig. 5) to meet the food and income needs of the households. For example, increases in consumption were reported for sweet potato, beans, taro, maize and cassava while relative sales of beans, coffee, cassava and eucalyptus increased. The increased production of beans was also attributed to an increased productivity of the crop in abandoned or destroyed banana fields that had a higher soil fertility. An increase in coffee purchase was also reported, possibly due to farmers and middlemen buying locally, and bulking for future sales or for transportation to outside markets (e.g. in neighbouring Rwanda) with higher prices. Pronounced increases in production and trade sugarcane were also observed (Fig. 7). 


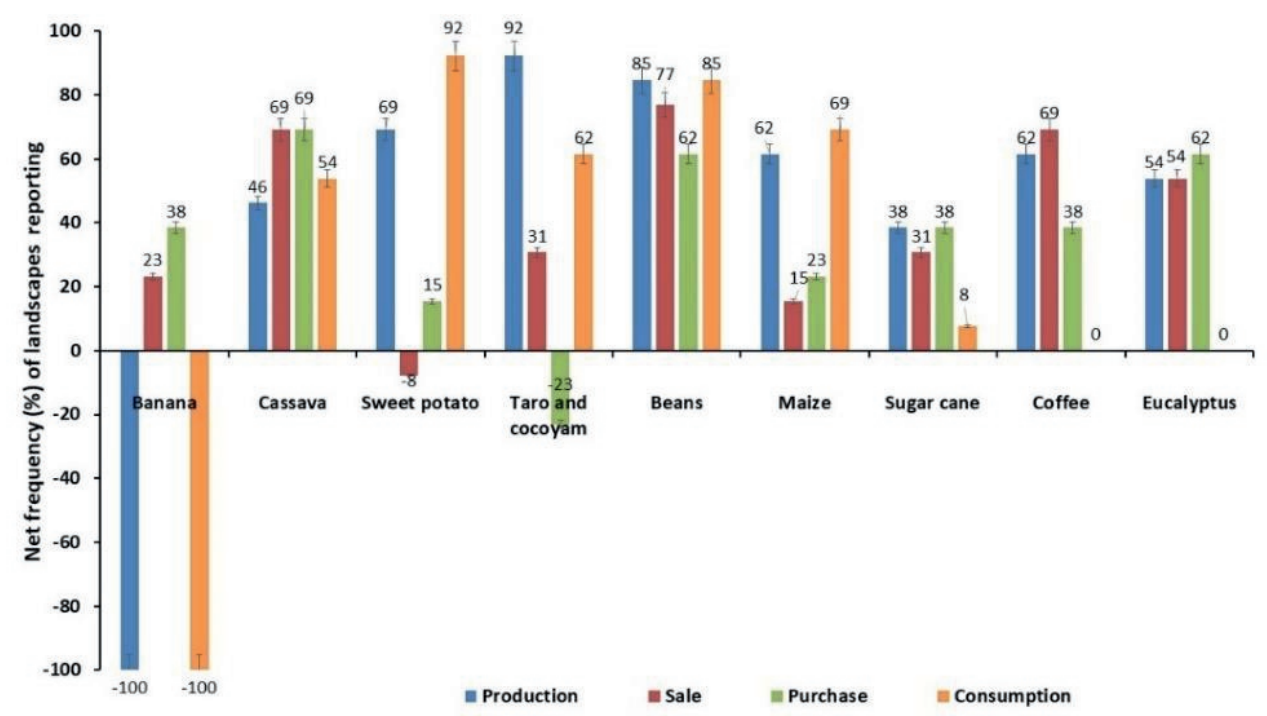

Figure 7. Net frequency (\%) of landscapes reporting changes production, sale, purchase and consumption of key food and tree crops across 13 landscapes affected by Xanthomonas wilt disease of banana in eastern Democratic Republic of Congo.

\subsubsection{Farmers' perceptions on the future role of banana and the sustainability of the} key land-use trajectories in $\mathrm{XW}$ affected landscapes

Despite banana being severely affected by $\mathrm{XW}$, it still occupies a unique position in the farming system, due to its multifunctional benefits and roles in the production system. The most important benefits reported by farmers included, its regular and all year-round production (100\% of landscapes), household preference to consume banana fruits (100\%), its high profitability $(92.3 \%)$ and its ranking as the major contributor to household income (92.3\%) (Fig. 8). Farmers described the crop to be their "local bank", stemming from the ease of its conversion into cash. This is in line with the findings of Vandamme (2008) who reported the banana crop to play an important economic role as a farmers' 'bank account' for unexpected or major expenses and thus its importance in the agriculture sector in eastern DR Congo. Banana was also important for beer making, a use that was reported to enhance social cohesion (70\%). Study groups reported the loss of banana to have exposed youth to more potent alcoholic beverages, increasing health and social problems within their landscapes, thus the need to restore banana production and the banana local beer industry. The crop is also an important source for livestock feed, materials for construction of temporary shelters. Farmers were therefore still eager to manage the disease or reintroduce the crop on their farms. Approximately half (54\%) of the landscapes visited in the study area were either still producing or had resumed banana cultivation despite the presence of the XW, while the other percentage had not. No association $\left(R^{2}=0.01\right)$ was 
observed between the time of exposure to the disease, and the continuation and resumption of a landscape to produce banana. The continuation or resumption of a landscape to produce banana was also influenced by farmers' access to clean planting materials, the differential importance of banana for food and income, and the variability in incidence and severity of the infection XW across the landscape. For example, clean planting materials were not accessible in the study region while in one out of the 13 sites, banana was not highly ranked and grown on large scale, as such XW disease was not a major concern. The key replacement crops were also reported to have failed to bridge the food security and income gap left by the banana crop. Due to the perennial nature of the banana crop, farmers reported a lower cost of production e.g. in labour and inputs whereas the other crops demanded major cultivation annually and investments in inputs annually.

Not surprisingly, only farmers in about $10 \%$ of the landscapes recognized the role of banana in reducing soil erosion in the landscape. This was because it is less tangible and lacked immediately visible benefits to most farmers.

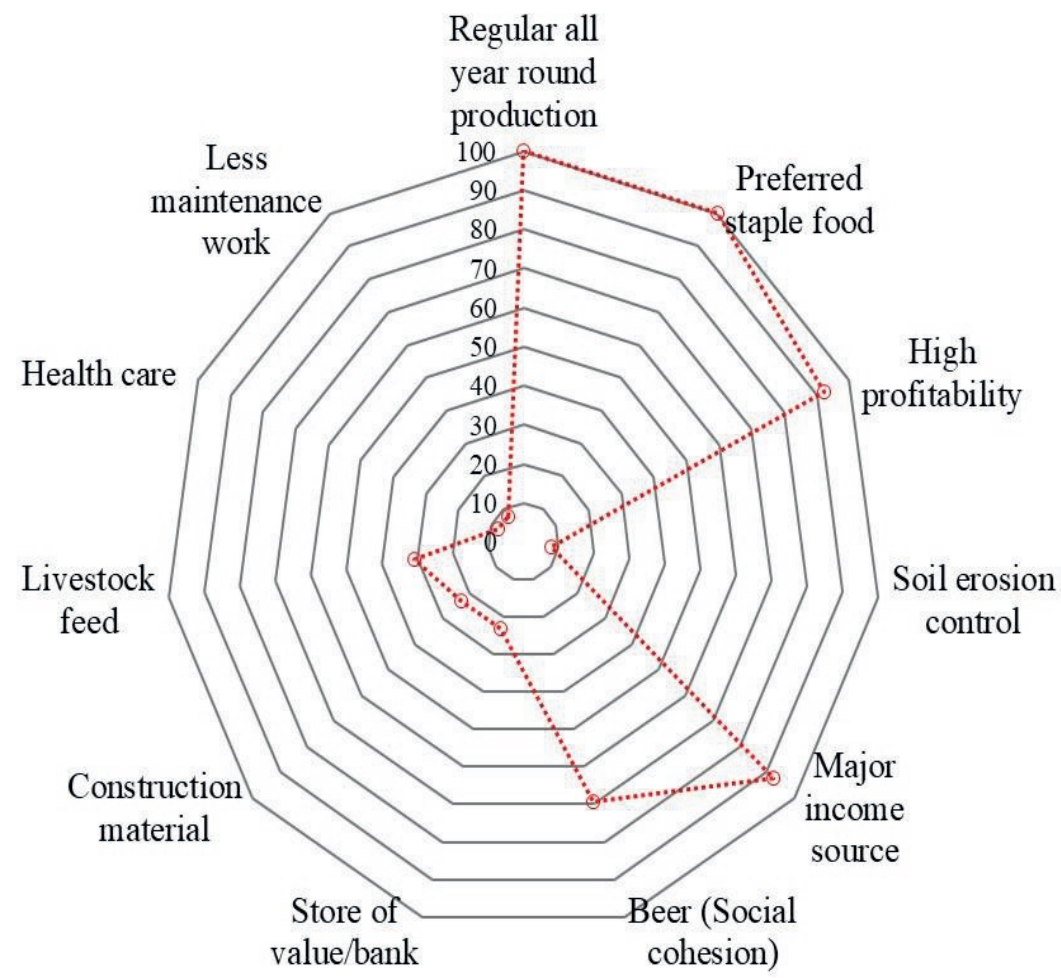

Figure 8. Farmers perceived comparative benefits offered by the banana crop across 13 landscapes in eastern Democratic Republic of Congo. Numbers denote percentage of villages reporting. 


\subsubsection{Soil quality}

The soil chemical properties significantly differed $(P<0.05)$ between the land-use options and sites, whereas no significant interactions ( $P>0.05)$ were observed between the land-use options and sites (Table 2). No use of chemical fertilizers was reported by farmers across the study sites for the analysed land-use options. Soil organic matter (SOM) and nitrogen $(\mathrm{N})$, potassium $(\mathrm{K})$ and phosphorus $(\mathrm{P})$ were consistently higher in fields planted with trees and banana (Table 2). The banana crop also scored high for exchangeable bases calcium (Ca) and magnesium (Mg). Banana extracts large amounts of soil N and P (Nyombi et al., 2010) and as such, a higher depletion of these nutrients in soils with banana would have been expected. The observed higher availability of these and other nutrients in banana fields could be linked to the location of most banana plots close to homesteads, which allows for easy application of household wastes. The banana crop, due to its large size and wide spacing, and in contrast to other crops, is more compatible with the deposition of most household wastes in between plants. It was also common to see banana plots with some mulch and/ or heavy crop litter. The permanent nature of banana fields, high recycling of banana wastes, the application of external mulch and kitchen wastes under banana fields have been reported to improve nutrient availability and recycling in banana fields (Ocimati et al., 2018). Bekunda and Woomer (1996) also reported farmers to preferentially apply available organic resources on plots close to the homestead. Mulch and crop residues also intercept, slow and reduce runoff through retaining a fraction of rainfall/runoff, increasing hydraulic roughness, ponding and infiltration, obstructing and diverting runoff (Mohamoud and Ewing, 1990), potentially reducing nutrient loss through erosion. In contrast, fields under cassava and other annual crops generally received no external inputs. Stems of cassava and some annual crops e.g. maize and sorghum were often exported out of fields and used as fuel wood while some annual crop residues were burnt on farm, practices that lead to nutrient depletion.

Fields under grass where generally low in soil $\mathrm{P}, \mathrm{K}$ and $\mathrm{Ca}$ content, possibly due to constant extraction of nutrients through livestock grazing (Table 2). Such fields also predominantly consisted of fields previously found to be less productive for food crops. 


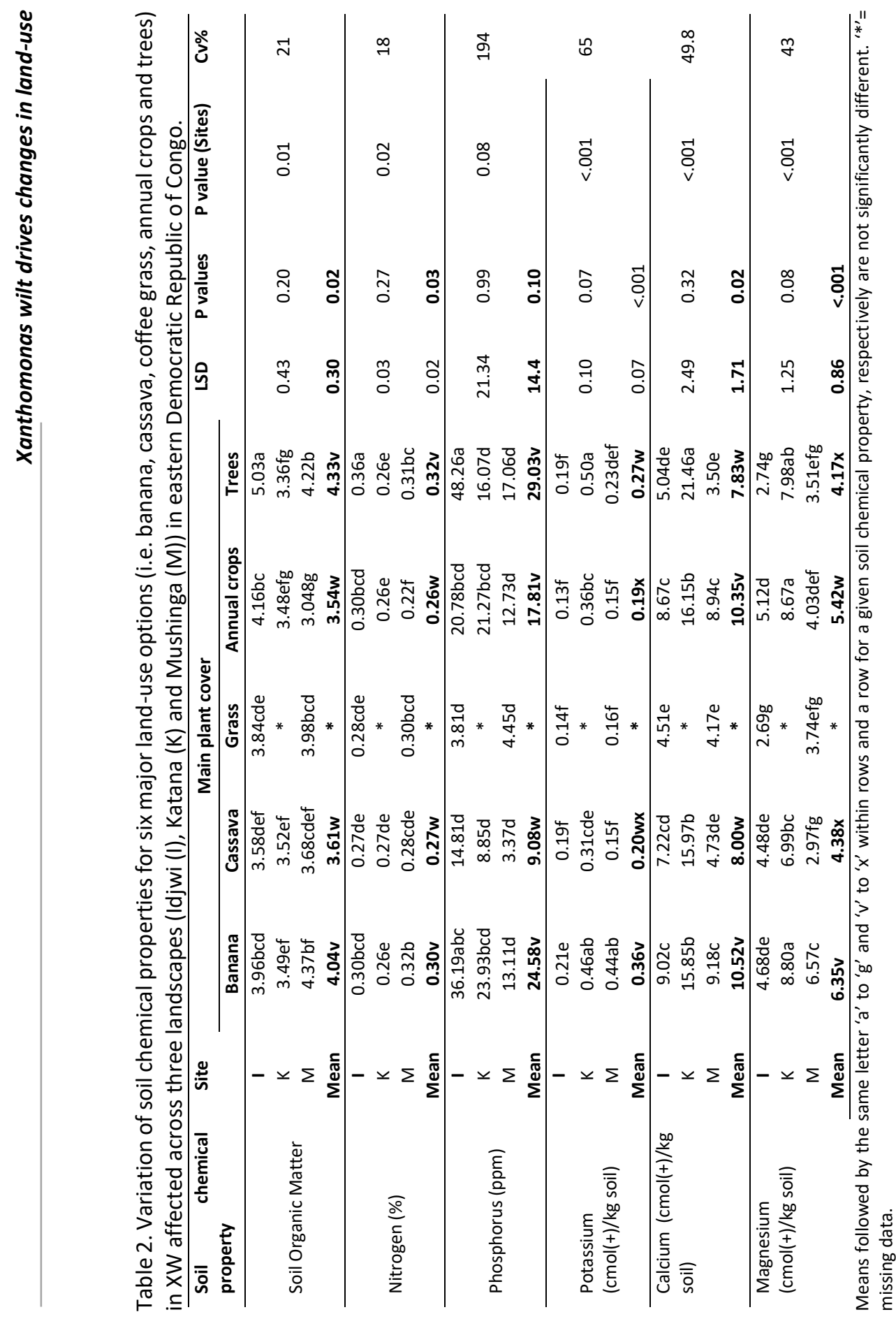




\subsubsection{Soil erosion control}

The mean values of the variables for estimating soil erosion levels or its variables with exception of slope length were significantly different across the land use options $(P<0.001)$ and the three study sites $(P<0.05)$ (Tables 3$)$. Significant interactions between land cover options and sites occurred for soil erodibility (K), the crop management factor $(C)$, and the support practice $(P)$.

The crop cover factors that influences the crop management factor $C$ were highest for land cropped with cassava (0.41-0.47) and annual crops (0.47-0.54) while least for fields covered by grass (0.01-0.02) (Table 3). Of the food crops, the banana crop (0.09-0.12) had the least crop cover factor. The cover factors in this study (Table 3) for the various crop/plant categories are comparable to those reported in literature (e.g. Howeler et al., 2001; Wall et al., 2002; Angima et al., 2003; Borrelli et al., 2017; Panagos et al., 2015; Stone and Hilborn, 2015). The tillage factor values for fields under grass and trees were low due to no tillage. Tillage practice values under coffee and banana (often minimum or zero tillage) were lower and more supportive in controlling soil erosion than those under cassava and annual crops (Table 3). Fields planted with annual crops and cassava were subjected to routine cultivation, exposing the soil to run-offs. In line with the low crop cover type factors and tillage method factors, fields under grass, trees and banana had lower $C$ values (0.002-0.06) compared with $0.21-0.33$ for cassava and $0.27-0.43$ for the annual crop fields across the sites (Table 3).

In general, most farmers did not adhere to support practices $(P)$ that minimise soil erosion. For example, most farmers cultivate up the slope (instead of along contour bands), a practice that encourages soil erosion. Cassava and annual crops ranked worst with regards to these practices while coffee and banana fields were moderate due to minimum/zero tillage practiced on some farms (Table 3).

The mean slope factor (LS) was mainly influenced by the slope gradient. LS and slope respectively, varied from 0.45-16.3 and 4-39\% and were in general highest for fields planted with trees and least for fields planted with the annual crops. The ground surface of fields planted with trees were often covered by grass and/or thick layers of leaf litter. Growing trees with deep root systems on steep slopes and annual crops on relatively flatter areas could be farmer's strategy to minimise soil loss and/or put such lands to fruitful use. Banana crops (slope $=4-16 \%$ ) relative to cassava $(4-20 \%)$ were cultivated on relatively flat areas (Table 3 ), probably due to most banana farms being located close to homesteads which were more often on flatter portions of the land. The farms at Katana were on more gentle slopes $(4-5 \%)$ compared to Idjwi (10-28\%) and Mushinga (6-39\%). 
Soil erodibility factor, $\mathrm{K}$ varied between 0.0053 and $0.0268 \mathrm{Mg} \mathrm{h} \mathrm{MJ}^{-1} \mathrm{~mm}^{-1}$ and was lower at Katana compared with Idjwi and Mushinga. These $\mathrm{K}$ values are comparable to $0.009-0.021 \mathrm{Mg} \mathrm{h} \mathrm{MJ}^{-1} \mathrm{~mm}^{-1}$ reported for the Tangata catchment in Rwanda (De Taeye, 2016), $0.016 \mathrm{Mg} \mathrm{h} \mathrm{MJ}^{-1} \mathrm{~mm}^{-1}$ for the Kainjuki highlands in Kenya and 0-0.24 Mg h MJ-1 $\mathrm{mm}^{-1}$ for the whole of Rwanda (Karamage et al., 2016).

The mean soil erosion levels (A) computed using the RUSLE equation were in general lower for the fields under grass ( $0.4 \mathrm{Mg} \mathrm{ha}^{-1}$ year ${ }^{-1}$ of soil loss per annum), trees (0.5-5.9) and banana (0.3-10.7) compared with $29.5 \% \mathrm{Mg} \mathrm{ha}^{-1} \mathrm{year}^{-1}$ for coffee, 1.4-28.3 for the annual crops and 1.7-148.9 $\mathrm{Mg} \mathrm{ha}^{-1}$ year $^{-1}$ for cassava fields (Table 3). The high erosion levels for cassava fields can be attributed to allocation of cassava to the less fertile steep slopes and the less protective tillage and support practices under cassava (Table 3). The soil erosion levels were generally lower at Katana (0.31.7 $\mathrm{Mg} \mathrm{ha}{ }^{-1}$ year $^{-1}$ ) that had less soil erodibility and more gentle slopes compared with 0.4-98.8 $\mathrm{Mg} \mathrm{ha}^{-1}$ year $^{-1}$ at Mushinga and 0.4-148.9 $\mathrm{Mg} \mathrm{ha}^{-1}$ year $^{-1}$ at Idjwi. Several farms at the Mushinga and Idjwi site were on steep slopes, coupled to their higher soil erodibility rates (Table 3 ). The trend in erosion levels for landscapes under banana, coffee and annual crops as reported by Lufafa et al. (2003) for the Lake Victoria basin catchment are similar though higher compared with those of the land uses in this study. Lufafa et al. (2003) reported soil loss levels of 32-47 Mg ha-1 year ${ }^{1}$ for banana and coffee systems and $93 \mathrm{Mg} \mathrm{ha}^{-1}$ year $^{-1}$ for the annual crops. In the Kianjuki catchment area in central Kenya, Angima et al. (2003) reported higher soil losses between 30-666 Mg ha-1 year $^{-1}$ for annual rotations, banana and coffee-based systems. However, despite a comparable LS factor (1-29), the Kianjuki site had twice higher rainfall erosivity of $8,527 \mathrm{MJ} \mathrm{mm} \mathrm{ha}^{-1} \mathrm{~h}^{-1}$ year $^{-1}$ compared with $3750 \mathrm{MJ} \mathrm{mm}$ $\mathrm{ha}^{-1} \mathrm{~h}^{-1}$ year $^{-1}$ in the current study sites. Apart from land use under grasses, trees and banana, and the Katana site, erosion levels for cassava, coffee and annual crops were above the tolerable soil loss rates of 2.2-10 $\mathrm{Mg} \mathrm{ha}^{-1}$ year $^{-1}$ reported for the Kainjuki catchment in Kenya (Angima et al., 2013) and $15 \mathrm{Mg} \mathrm{ha}^{-1}$ year $^{-1}$ used for the Tangata catchment in Rwanda (De Taeye, 2016).

Given the current trajectory of farmers in these XW affected landscapes to shift to cassava, beans and other annual crops, the unsuitable location of several farms on steep slopes (6-28\%) coupled with the poor tillage and support practices under the alternative land uses, erosion levels are likely to rise on XW affected farms and landscapes. Strategies for supporting farmers alternative land uses to mimic banana production system and land uses such as land under trees and grasses needs to be explored and promoted. Potential practices could include the integration of contour hedges, grass bands, mulching and the use of cover crops to reduce runoff in erosion prone land use options. 


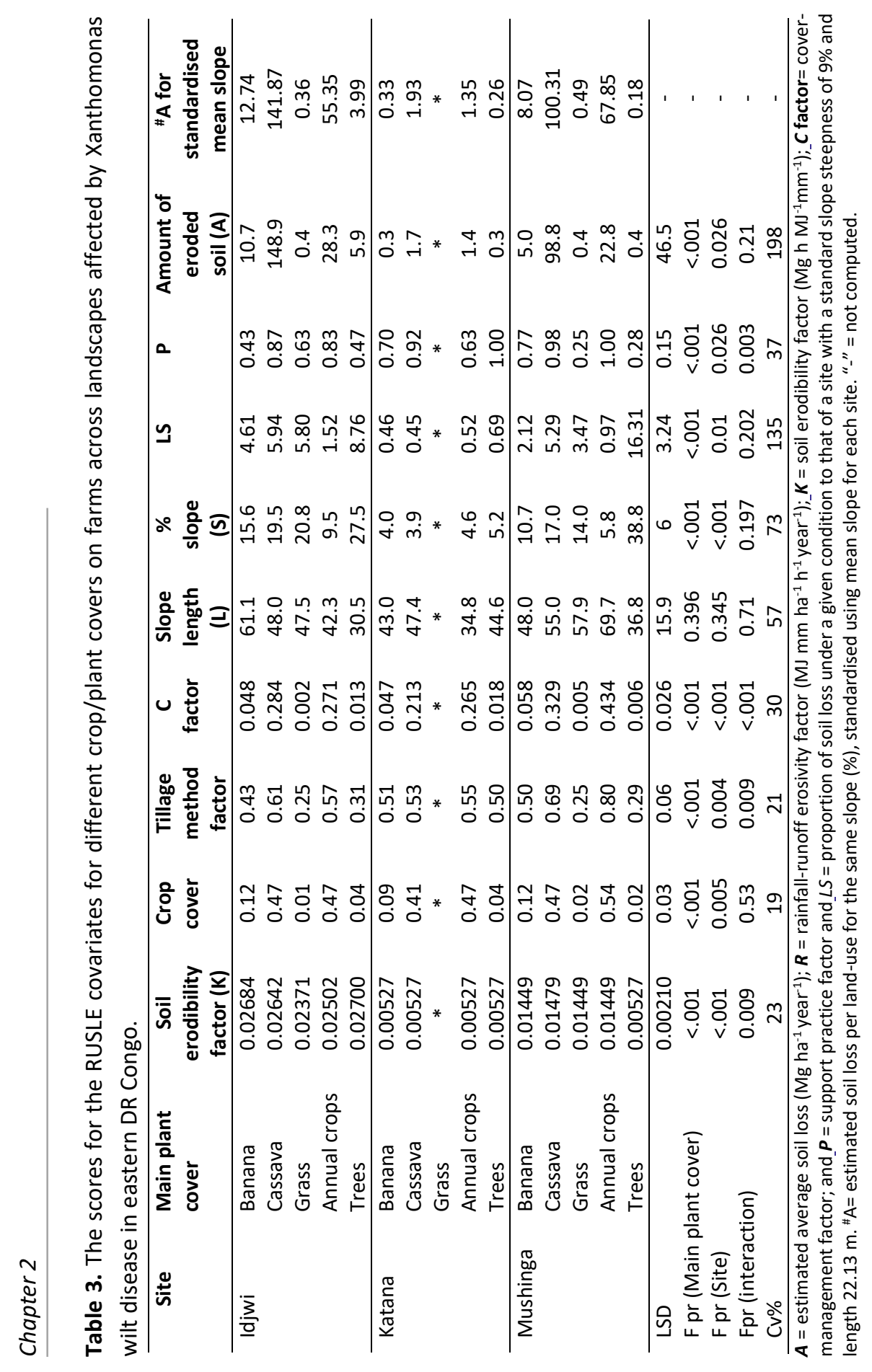

$m$ 


\subsection{Conclusion}

Xanthomonas wilt disease of banana leads to death of affected plants and decay of infected bunches. All the study sites reported XW to severely distress their production systems. Uprooting of entire banana fields, expanding area under other crop species and totally abandoning banana for other crops was common across the landscapes. No changes in crop species richness at landscape level were observed though changes were eminent at farm level, with some farms introducing individual crop species. The overall trend across the sites was to increase the production of crops such as cassava, sweet potato, maize, sugarcane and eucalyptus with the objective of filling the short-term food security and income gaps arising from the loss or low productivity of bananas due to XW disease. Cassava and coffee especially, have already been important food and/or income crops in the region, with better developed market value chains, offering a better option in the short and long term to bridge the food and income gaps left by the banana crop. However, the observed trends in crop diversification in XW affected landscapes needs to be supported through deliberate efforts to improve extension services, seed systems, post-harvest handling and market value chains. Banana is still perceived as the preferred crop due to its multifunctionality in providing food, fodder, fiber, incomes and other ecosystem services in the landscape. The current trajectory in land-use will potentially increase soil loss and negatively affect the productivity and resilience of the soils. Strategies to manage XW and rapidly restore banana production in affected landscapes are necessary. In parallel, efforts are needed to support other land-uses, especially land under cassava so as to mimic the natural ecosystems in the supply of services such as erosion control and nutrient recycling e.g. through planting hedges and grass bands along contours. This study stresses the importance of a holistic approach focused on the entire banana-based agroecosystem in addressing the XW problem and is a good basis/ entry point for interventions to sustainably improve production systems, incomes and food security in XW-affected landscapes.

\subsection{Acknowledgements}

We would like to thank the Directorate General for Development, Belgium for funding this research through the Consortium for Improving Agriculture-based Livelihoods in Central Africa (CIALCA). We would also like to acknowledge the financial contribution of the CGIAR Research Program on Roots, Tubers and Bananas and the CGIAR Fund Donors. 


\section{References}

Abele, S., Twine, E., and Legg, C. (2007). Food Security in Eastern Africa and the great lakes. Crop Crisis Control Project final report. International Institute of Tropical Agriculture, Ibadan, Nigeria.

Angima, S.D., Stott, D.E., O'neill, M.K., Ong, C.K., and Weesies, G.A. (2003). Soil erosion prediction using RUSLE for central Kenyan highland conditions. Agri. Ecosys. Environ. 97(1-3), 295-308.

Baragengana, R. (1985). Banana production and research in Burundi. In: Kirkby, R.A., Ngendayo, D. (eds) Banana Production and Research in Eastern and Central Africa. Proceedings of a Regional Workshop held in Bujumbura, Burundi 14-17 December 1983. IDRC-MR114e, Ottawa, Canada, pp. 23-27.

Beernaert, F.R. (1999). Development of a soil and terrain map/database-Democratic Republic of Congo.

Bekunda, M. (1999). Farmers' responses to soil fertility decline in banana-based cropping systems of Uganda. Managing Africa's Soils, 1999, No. 4. [Available at: http://pubs.iied.org/pdfs/7397IIED.pdf] (Accessed: 24 ${ }^{\text {th }}$ Nov. 2017).

Bekunda, M., and Woomer, P.L. (1996). Organic resource management in banana based cropping systems of the Lake Victoria basin, Uganda. Agric. Ecosyst. Environ.59, 171-180.

Bellon, M.R., and Raneri, J. (2014). Agricultural Biodiversity Assessment: Four Cell Focus Group Methodology, Bioversity International.

Blomme, G., Jacobsen, K., Ocimati, W., Beed, F., Ntamwira, J., Sivirihauma, C., ... and Tinzaara, W. (2014). Fine-tuning banana Xanthomonas wilt control options over the past decade in East and Central Africa. Eur. J. Plant Pathol. 139(2), 271-287.

Bommarco, R., Kleijn, D., and Potts, S.G. (2013). Ecological Intensification: Harnessing Ecosystem Services for Food Security. Trends Ecol. Evol. 28(4), 230-38. [Avaialable at: http://dx.doi.org/10.1016/j.tree.2012.10.012].

Borrelli, P., Robinson, D.A., Fleischer, L.R., Lugato, E., Ballabio, C., Alewell, C., ... and Bagarello, V. (2017). An assessment of the global impact of 21st century land use change on soil erosion. Nat. commun. 8(1), 2013.

Bouyoucos, G.J. (1962). Hydrometer method improved for making particle size analysis of soils. Agron. J., 54, 464-465.

Castellani, E. (1939). Su un marciume dell' Ensete. L'Agricoltura Coloniale, Firenze, 33, 297300.

CIALCA (2009). CIALCA Progress Reports 05, Final Report Phase I - CIALCA January 2006 December 2008.

Cohen, D., and Crabtree, B. (2006). Qualitative research guidelines project. [Available at: http://www.qualres.org/HomeSamp-3702.html]. (Accessed: 20th Nov. 2017).

Dayton, P.K. (1972). Toward an understanding of community resilience and the potential effects of enrichments to the benthos at McMurdo Sound, Antarctica. In: Parker BC (Ed). Proceedings of the colloquium on conservation problems in Antarctica. Lawrence, KS: Allen Press. 
De Taeye, S. (2016). Soil erosion risk mapping using RUSLE in Rwanda.

Desire, R.M., Bahananga, J.B.M., Romain, L., Barhahakana, C., and Amato, S. (2016). Analyse de l'impact socioéconomique du flétrissement bactérien du bananier et réponses paysannes dans la région du Bushi Kivu à l'Est de la République Démocratique du Congo. Int. J. Innov. Appl. Stud. 18(1), 66.

Edmeades, S., Smale, M., Kikulwe, E.M., Nkuba, J., and Byabachwezi, M.S.R. (2007). Characteristics of banana-growing households and banana cultivars in Uganda and Tanzania. Pages 49-74 in: An Economic Assessment of Banana Genetic Improvement and Innovation in the Lake Victoria Region of Uganda and Tanzania. M. Smale and W. K. Tushemereirwe, eds. IFPRI Research Report 155. IFPRI, Washington, DC.

FAO (2012). Banana production systems at risk: Effectively responding to banana wilt disease in the Great Lakes region, FAO banana factsheet. [Available at: http://www.fao.org/fileadmin/user upload/emergencies/docs/FAO\%20BANANA\%20fa ctsheet\%20ENGLISH.pdf] (Accessed on: $22^{\text {nd }}$ Nov. 2017).

FAO (2017). Online statistical database. Food and Agriculture Organization of the United Nations, Rome. [Available at: http://www.fao.org/faostat/en/\#data/QC]. (Accessed: $10^{\text {th }}$ Sept. 2018).

Farrow, A., Busingye, L., and Bagenze, P. (2006). Characterization of Mandate Areas for the Consortium for Improved Agricultural Livelihoods in Central Africa (CIALCA). Bukavu, 132pp.

Food for the Hungry (2013). Annual Results Report FY. P.L. 480 Title II Multi-Year Assistance Program, FFP-A-11-00007. Bukavu, Democratic Republic of Congo.

Gliessman, S.R. (2015). Field and laboratory investigations in Agroecology, $3^{\text {rd }}$ Edition. CRC Press, Taylor and Francis Group, Florida, US., 2015.

Gold, C.S., Karamura, E.B., Kiggundu, A., Bagamba, F., and Abera, A.M.K. (1999). Geographic shifts in highland cooking banana (Musa spp., group AAA-EA) production in Uganda. Int. J. Sust. Dev. World Ecol. 1999, 6, 45-59.

Howeler, R.H., Oates, C.G., Allem, A.C., Chuzel, G., Henry, G., Hershey, C.H., ... and Sriroth, K. (2001). Strategic environmental assessment, an assessment of the impact of cassava production and processing on the environment and biodiversity. In Proceedings of the validation forum on the global cassava development strategy, Vol. 5.

Kalyebara, M.R., Ragama, P.E., Kikulwe, E., Bagamba, F., Nankinga, K.C., and Tushemereirwe, W.K. (2006). Economic importance of the banana bacterial wilt in Uganda. Afr. Crop Sci. J. 14(2), 93-103.

Karamage, F., Zhang, C., Ndayisaba, F., Shao, H., Kayiranga, A., Fang, X., ... and Tian, G. (2016). Extent of cropland and related soil erosion risk in Rwanda. Sustain. 8(7), 609.

Karamura, E.B., Turyagyenda, F.L., Tinzaara, W., Blomme, G., Molina, A., and Markham, R. (2008). Xanthomonas wilt (Xanthomonas campestris pv. musacearum) of Bananas in East and Central Africa. Diagnostic and Management Guide. Fountain Publishers, Kampala, Uganda.

Kassam, A.H., Van Velthuizen, H.T., Mitchell, A.J.B., Fischer, G.W., and Shah, M.M., 1992. Agroecological land resources assessment for agricultural development planning: A case study 
of Kenya resources data base and land productivity, Technical Annex 2. Soil erosion and productivity, FAO/IIASA, Rome, pp. 59

Lufafa, A., Tenywa, M.M., Isabirye, M., Majaliwa, M.J.G., and Woomer, P.L. (2003). Prediction of soil erosion in a Lake Victoria basin catchment using a GIS-based Universal Soil Loss Model. Agr. Syst. 76, 883-894.

Mehlich, A. (1984). Mehlich-3 soil test extractant: a modification of Mehlich-2 extractant. Commun. Soil Sci. Plant Anal. 15(12), 1409-1416.

Mohamoud, Y.M., and Ewing, L.K. (1990). Rainfall interception by corn and soybean residue. Transactions of the ASAE, 33(2), 507-0511.

Ndungo, V., Bakelana, K., Eden-Green, S., and Blomme, G. (2004). An outbreak of banana Xanthomonas wilt (Xanthomonas campestris pv. musacearum) in the Democratic Republic of Congo. InfoMusa, 13, 43-44.

Nkuba, J., Tinzaara, W., Night, G., Niko, N., Jogo, W., Ndyetabula, I., ... and Rwomushana, I. (2015). Adverse impact of banana Xanthomonas wilt on farmers' livelihoods in Eastern and Central Africa. Afr. J. Plant Sci. 9, 279-286.

Nyombi, K., van Asten, P.J.A., Corbeels, M., Taulya, G., Leffelaar, P.A., and Giller, K.E. (2010). Mineral fertilizer response and nutrient use efficiencies of East African highland banana (Musa spp., AAA-EAHB, cv Kisansa). Field Crops Res. 117, 38-50.

Ochola, D., Jogo, W., Ocimati, W., Rietveld, A., Tinzaara, W., Karamura, D.A., and Karamura, E.B. (2013). Farmers' awareness and perceived benefits of agro-ecological intensification practices in banana systems in Uganda. Afr. J. Biotechnol. 12, 4603-4613.

Ocimati, W., Groot, J.C.J., Tittonell, P., Taulya, G., and Blomme, G. (2018). Effects of Xanthomonas wilt and other banana diseases on ecosystem services in banana-based agroecosystems. Acta Hort. 1196, 19-32.

Okech, H.O., Gold, C.S., Abele, S., Nankinga, C.M., Wetala, P.M., van Asten, P., Nambuye, A., and Ragama, P. (2004). Agronomic, pests and economic factors influencing sustainability of banana-coffee systems of Western Uganda and potentials for improvement. Uganda J. Agr. Sci. 9, 432-444.

Panagos, P., Borrelli, P., Meusburger, K., Alewell, C., Lugato, E., and Montanarella, L. (2015). Estimating the soil erosion cover-management factor at the European scale. Land Use Policy, 48, 38-50.

Raneri, J., Turmel, M., Van Zonneveld, M., Dzomeku, B., Termote, C., Bellon, M.R., ... and Staver, C. (2016). Agrobiodiversity 4-Cell Method: a rapid system diagnosis tool. [Available

at: https://cgspace.cgiar.org/bitstream/handle/10568/79396/ABD \%204Cell Poster\%2020 16\%20(2).pdf?sequence=1] (Accessed: Feb., 2016).

Renard, K.G., Foster, G.R., Weesies, G.A., McCool, D.K., and Yoder, D.C. (1997). Predicting soil erosion by water: a guide to conservation planning with the Revised Universal Soil Loss Equation (RUSLE) (Vol. 703). Washington, DC: United States Department of Agriculture. Rishirumuhirwa, T., and Roose, E. (1998). The Contribution of Banana Farming Systems to Sustainable Land Use in Burundi. Adv. GeoEcol. 31, 1197-1204.

Robinson, J.C., and Saúco, V.G. (2010). Bananas and plantains (Vol. 19). CABI. 
Simmonds, N.W. Bananas. 2nd edition. Longmans, London. UK., 1966.

Simmonds, N.W., and Shepherd, K. (1955). The taxonomy and origins of the cultivated bananas. Bot. J. Linn. Soc. 55, 302-312.

Sthapit, B., Rana, R.B., Subedi, A., Gyawali, S., Bajracharya, J., Chaudhary, P., ... and Upadhyay, M.P. (2006). Participatory four cell analysis (FCA) for local crop diversity. Good Practices: On-Farm Management of Agricultural Biodiversity in Nepal. NARC, LI-BIRD, IPGRI and IDRC.

Stone, R.P., and Hilborn, D.P. (2015). Universal Soil Loss Equation (USLE). OMAFRA Factsheet, Order No. 12-051, Queen's Printer for Ontario. [http://www.omafra.gov.on.ca/english/engineer/facts/12-051.htm] (Accessed: 29 ${ }^{\text {th }}$ Feb. 2016)

Tushemereirwe, W., Kangire, A., Ssekiwoko, F., Offord, L.C., Crozier, J., Boa, E., Rutherford, M., and Smith, J.J. (2004). First report of Xanthomonas campestris pv. musacearum on banana in Uganda. Plant Pathol. 53, 802.

UNDP (2009). Profil Resume Pauvrete Et Conditions De Vie Des Menages Programme des Nations Unies pour le développement Unité de lutte contre la pauvreté: Province du SudKivu.

Van Engelen V., Verdoodt A., Dijkshoorn K. and Van Ranst, E. (2006). Soil and Terrain Database of Central Africa - DR Congo, Burundi and Rwanda. SOTERCAF, Version 1.0. ISRIC-UGentFAO.

Vandamme, E. (2008). Nutrient deficiencies in soils of Walungu, South Kivu, Democratic Republic of Congo. Thesis, Katholieke Universiteit Leuven

Vrieling, A., Sterk, G., and de Jong, S.M. (2010). Satellite-based estimation of rainfall erosivity for Africa. J. Hydrol. 395(3-4), 235-241.

VSN International Ltd (2009). GenStat $12^{\text {th }}$ Edition. [www.vsni.co.uk.]

Wall, G.J., Coote, D.R., Pringle, E.A., and Shelton, I.J. (2002). RUSLEFAC - Revised Universal Soil Loss Equation for Application in Canada: A Handbook for Estimating Soil Loss from Water Erosion in Canada. Research Branch, Agriculture and Agri-Food Canada. Ottawa. Contribution No. AAFC/AAC2244E, $117 \mathrm{pp}$.

Wischmeier, W.H., and Smith, D.D. (1978). Predicting rainfall erosion losses. A Guide to conservation planning. United States Department of Agriculture, Agricultural Research Service (USDA-ARS) Handbook No. 537. United States Government Printing Office, Washington, DC.

Wood, S., Sebastian, K., and Scherr, S.J. (2000). Agroecosystems. International food policy research Institute. [Available at: https://www.researchgate.net/profile/Kate Sebastian2/publication/237596137 Agroe cosystems/links/53fb51dd0cf27c365cf09c9c.pdfl (Accessed: March 2016). 


\section{Chapter 3}

\section{Effects of Xanthomonas wilt disease of banana on ecosystem services in banana-based agroecosystems}

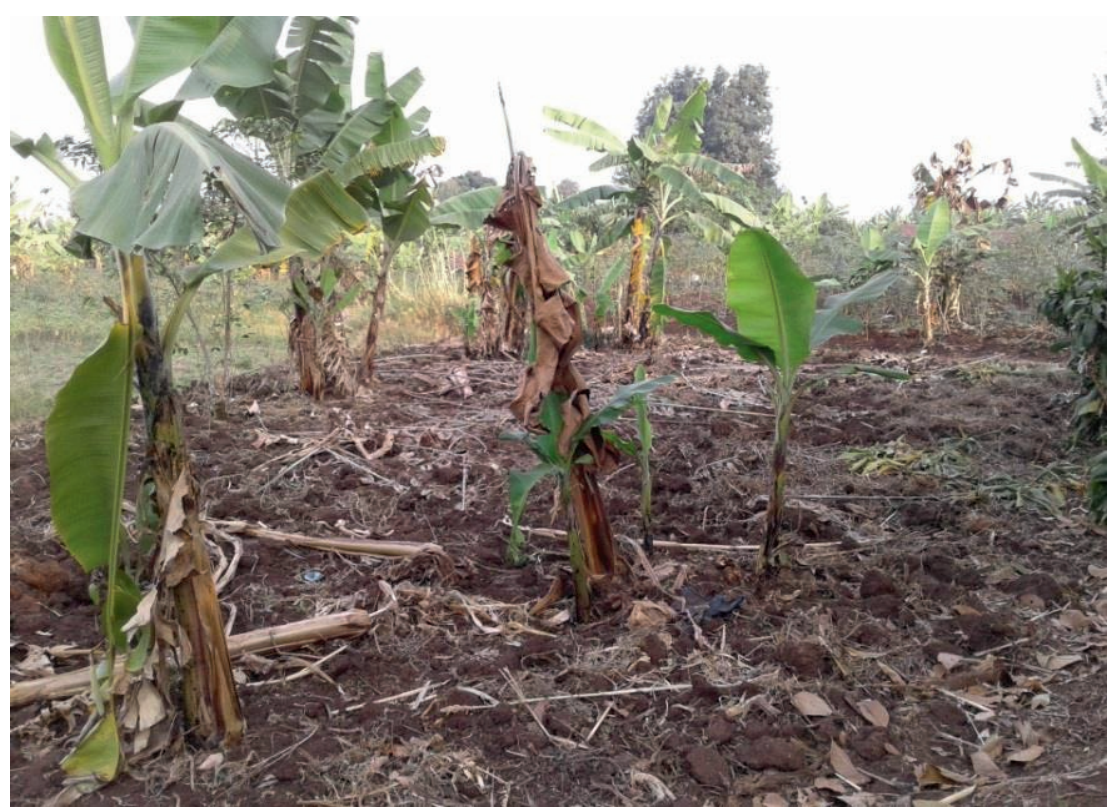

Published as:

Ocimati, W., Groot, J.C.J., Tittonell, P., Taulya, G., and Blomme, G. (2016). Effects of Xanthomonas wilt and other banana diseases on ecosystem services in bananabased agroecosystems. In X International Symposium on Banana: ISHS-ProMusa Symposium on Agroecological Approaches to Promote Innovative Banana 1196 (pp. 19-32). 


\begin{abstract}
Banana plantations are multifunctional agroecosystems that besides their main provisioning service also deliver a range of supporting, regulatory and cultural services that are largely unvalorized. Banana is perennial in nature with plantations as old as 50 years reported in the African Great Lakes region. Banana is cultivated in a wide range of agroecologies (from sea level to 2400 m.a.s.I.) and cropping systems, where it contributes to various ecosystem services (ES). These include regulating soil erosion, water cycles and quality, and nutrient recycling. However, the outbreak of Xanthomonas wilt of banana (XW) along with some of its management practices, such as uprooting mats/entire fields, is devastating banana production and rendering landscapes bare and prone to degradation. Yet this process is also leading to diversification of agroecosystems in over $70 \%$ of farms in the African Great Lakes region with unknown but potentially positive consequences for resilience and adaptation, as well as for local diets. The sustainability of these alternative land-uses is variable. This study reviews the different services offered by banana plantations and the impacts, positive or negative, that $\mathrm{XW}$-driven diversification may have on these services. It suggests the need to consider explicitly the consequences of pests and diseases for the full range of ES provided by the crop and an ES-broad framework for estimation of losses, and planning resources and strategies for disease management. The study also suggests strategies, such as incorporation of shade- and drought-tolerant cover crops, hedges and agroforestry trees, to augment the supply of key ES within XW-affected agroecosystems/landscapes.
\end{abstract}

Keywords: drought tolerance, landscape, multiple functions, provisioning, regulatory, shade tolerance, supporting. 


\subsection{Introduction}

Worldwide, Musa spp. (bananas and plantains, hereafter referred to as banana), with an estimated annual production of 144.6 million tons, rank as the sixth most important source of carbohydrates (FAOSTAT, 2015). About one-third of this production comes from sub-Saharan Africa (FAOSTAT, 2015), where the crop provides over a quarter of food energy requirements for more than 70 million people (Karamura et al., 2008). The African Great Lakes region, covering parts of Burundi, Democratic Republic of Congo (DR Congo), Kenya, Rwanda, Tanzania and Uganda, is the largest producer and consumer of banana in Africa (Smale, 2006). In this region, the crop is also important for cash (Edmeades et al., 2007).

In the African Great Lakes region, banana is predominantly grown by smallholder farmers (<2 ha), who realize low yields of 5-30 $\mathrm{Mg} \mathrm{ha}^{-1}$ year $^{-1}$ (Wairegi et al., 2010; Okumu et al., 2011) when compared with $70 \mathrm{Mg} \mathrm{ha}^{-1}$ year ${ }^{-1}$ reported at experimental stations (van Asten et al., 2004). The low yields are attributed to several factors that include sub-optimal crop management practices, and several abiotic and biotic stresses. Xanthomonas wilt disease of banana and enset (XW, caused by Xanthomonas campestris pv. musacearum) is currently one of the most important constraints to banana production in the African Great Lakes region (Kalyebara et al., 2006; Blomme et al., 2014).

XW indiscriminately infects all banana cultivars in the region (Ssekiwoko et al., 2006). Infected plants die and other attached plants in the mat may also get infected (Ocimati et al., 2013a; 2015). As part of control, or in frustration and anger, farmers uproot infected banana mats or entire fields. XW thus severely compromises livelihoods and food security for the banana-dependent households (Kagezi et al., 2006; Blomme et al., 2014). Potential economic losses varying between US\$ 200 and 295 million/ year were estimated for Uganda if the disease was not managed (Kalyebara et al., 2006; Abele and Pillay, 2008). The estimated economic losses were based on the short-term benefits, i.e. yield and incomes from the fruits (i.e. a provisioning service). Other potential supporting, and regulatory services realized from the crop were not factored in these disease impact calculations.

Banana plants are large perennial herbs characterized by 50 to $100 \mathrm{~cm}$ long sub-horizontal roots that occasionally reach $3 \mathrm{~m}$ in length (Blomme and Ortiz, 2000), and a pseudostem consisting of large overlapping leaf sheaths and broad leaves. These attributes make the crop a conducive supplier of several supporting and regulatory services, such as nutrient recycling, and regulation of soil erosion, water cycles and quality. The current economic loss estimates are thus an under-estimation of the impact of XW disease in the banana-based systems. 
As with the banana crop, most disease-estimation studies in agroecosystems have focused on provisioning services, especially yield. This is also reflected in the definition advanced for agroecosystems, i.e. an ecosystem managed with the intention of producing, distributing and consuming food, fuel and fiber (Cabell and Oelofse, 2012). Cheatham et al. (2009) proposes the ecosystem services (ES) concept as an appropriate means to define successful disease management more broadly, beyond short-term crop yield evaluations. Banana plantations are multifunctional agroecosystems that, besides their main provisioning service, deliver a range of supporting, regulatory and cultural services. This study reviews the different bananabased systems, the potential ES offered by banana plantations and the impacts, positive or negative, that XW-driven land-use diversification and control strategies may have on these services in the African Great Lakes region. It outlines the need for researchers and policy makers to look beyond banana's short-term provisioning role while assessing the impact of diseases and planning resources to invest in disease management. The study also suggests strategies for supporting banana-based agroecosystems to augment the supply of key ES within landscapes affected by XW disease.

\subsection{Banana agroecologies and systems in the African Great Lakes Region}

Banana production systems in the African Great Lakes region are complex and diverse. The complexity derives from the diversity in agroecological conditions as well as the socio-economic variability across the regions (AATF, 2009). The prevailing farming systems also influence farmers' management practices, the prevalence and severity of biotic constraints and strategies for managing the constraints. Bananas are grown from altitudes as low as sea level to above 2000 meters above sea level (Gold et al., 2002; Eledu et al., 2004; Ocimati et al., 2013b), with both bimodal and unimodal annual rainfall patterns between 400 to above $1000 \mathrm{~mm}$ (Eledu et al., 2004). Soils range from low nutrient sandy soils to rich loamy volcanic soils (Eledu et al., 2004).

In the African Great Lakes region, bananas are grown as a permanent vegetation, as a sole crop or in association with various crops and in varying agroecologies and mainly on smallholdings (<2ha). Plantations 30 to 50 years of age are common in the African Great Lakes region (Bekunda, 1999; Gold et al., 1999). Monocropped plantations are almost non-existent in the East and Central African region (AATF, 2009). Bananas are primarily intercropped with beans, coffee and taro (Sebasigari, 1985; AATF, 2009; Ocimati et al., 2013c). Other common intercrops include leafy vegetables, scattered trees and other root and tuber crops such as 
cassava, yams and sweet potato. Plantations are often mulched with grass and other crop residues obtained from elsewhere on the farm. Plantings in home gardens often benefit from kitchen and other household wastes. Tillage practices of banana fields vary from zero tillage to tilling twice annually mainly depending on (i) production objectives, (ii) whether crops are grown in mixtures or as sole crops, and (iii) access to farmland. Most commercial-oriented farms and sole cropped banana plantations are not tilled and instead mulched with grass and/or crop residues. In contrast, most small-scale farmers intercrop banana with other crops due to the limited access to land and as such practice a high level of tillage on farm. External inputs, apart from crop residues and mulch, are used among the better-resourced, market-oriented households. Agroecological intensification practices, such as agroforestry and fallowing, that could improve soil fertility are rarely practiced under these systems due to the high population density, land fragmentation and small size of the plots (Ocimati et al., 2013c).

The East African highland (EAH) cooking and beer bananas (AAA genome) dominate the banana landscapes in the African Great Lakes region, mainly covering the medium to high altitude zones from 1000 to 2000 m.a.s.I. (Gold et al., 2002; Eledu et al., 2004; Ocimati et al., 2013b). The EAH cultivars are often more intensively managed, and bunches can be harvested all year-round. The AAB plantains form an important component of the banana landscape in the lowland humid areas (below 1200 m.a.s.I.) of eastern DR Congo and the Congo basin (Eledu et al., 2004; Ocimati et al., 2013b). The beer banana 'Pisang Awak' (ABB genome) systems are also common in the low-altitude areas, e.g. in central Uganda (Gold et al., 2002). This cultivar is robust even under poor soil and management conditions and is often less intensively managed by farmers (Gaidashova et al., 2005). There are also limited quantities of other cooking ( $A B B$ genome) and dessert types (both $A A A$ and $A A B$ genome groups).

In a nutshell, banana is an important foundation species in several agroecosystems in the East and Central African region. A foundation species is a common or abundant species whose structural or functional attributes create and define an entire ecological community or ecosystem (Dayton 1972; Hanski, 1982). The importance of foundation species has been described for several forest ecosystems in which a single foundation species controls population and community dynamics and modulates ecosystem processes (Orwig et al., 2002; Ellison et al., 2005). The loss of such species can have dramatic effects on our perception of the landscape and broad consequences for associated biota, ecosystem function, and stability (Ellison et al., 2005). 


\subsection{Potential ecosystem services offered by banana-based systems}

Banana plantations or fields serve multiple functions to banana farming households and landscapes, but services other than the provisioning services have often gone unrecognized.

Provisioning services offered by the banana crop: Several studies, such as Singh and Uma (1996); Edmeades et al. (2007); Abele et al. (2007); Karamura et al. (2008); FAOSTAT (2015) and Kamira et al. (2015), have stressed the importance of the banana crop in provisioning of food, fodder (fresh leaves and pseudostems), fuel (dry leaves and leaf sheaths) and fiber (leaf sheaths and flower stalks). All parts of the crop are varyingly beneficial to households in different regions. The crop is an important source of animal feeds, herbal medicine, crafts and ornaments, and construction materials (Singh and Uma, 1996; Kamira et al., 2015). Bananas are consumed as fruit, beverage, vegetable and staple food.

Regulatory services: The characteristics of banana plants make them suitable for the supply of regulatory services, such as soil erosion control, water quality and pollination enhancement in fields and landscapes. The dense network of horizontal roots and thick year-round canopy due to the broad leaves and large number of lateral shoots coupled to the humus from the rotting leaves and trunks protect the ground from soil erosion (Baragengana, 1985; Rishirumuhirwa and Roose, 1998), especially during heavy rainfall seasons and in undulating/hilly terrains, contributing to the resilience of fragile ecosystems. For example, Lufafa et al. (2003) reported much lower $(<30 \%)$ soil erosion levels in fields under permanent banana canopy compared to annual cropped fields. Tillage practices that leave little residue in agricultural fields have been reported to exacerbate soil erosion by wind and water, resulting in reduced top soil and removal of nutrients, air pollution from wind-blown soil and loss of soil structure, leading to reduced infiltration of water and increased runoff (Miller, et al. 1999; Al-Kaisi and Hanna, 2002; With, 2002). Crop residues intercept and retain a certain fraction of rainfall from 2 to 4 times their mass (Mohamoud and Ewing, 1990). Crop residues also reduce runoff by increasing hydraulic roughness, ponding (which slows run off), obstructing and diverting runoff (increasing the length of down slope flow path) thus increasing the time of runoff, allowing for more infiltration (Gilley et al., 1991; Alberts and Niebling, 1994). Thus, the characteristic of the banana plants and plantations (application of mulch and household wastes (more often in backyard plantations)) potentially help improve water infiltration.

Taro (Colocasia spp.), a common food crop in most banana producing households in eastern DR Congo, is also observed to grow well under the shade 
provided by the large banana leaves and canopies. The destruction of banana plantations by XW and XW management practices, and the absence of banana shade, has already been incriminated by farmers in this region for its yield-reducing role in taro (Jules Ntamwira, personal communication, 2016). Rogers and losefa (1993) reported higher plant height, leaf area and an increase in taro plant biomass under $50 \%$ shade compared to full sunlight. Taro corm yields were also not reduced under $50 \%$ shade whereas corm percentage dry matter, a proxy for quality, was higher under $50 \%$ shade compared with full sunlight.

With respect to pollination, the banana crop flowers all year round, though peaking in the wet seasons. The melliferous species are thus able to ensure an allyear supply of pollen and nectar for pollinators, especially in times outside the blooming period of other crops and weeds.

The banana crop can also potentially help with climate regulation through carbon sequestration and minimising temperature extremes. Carbon stock levels (82.5-92.8 Mg ha-1) obtained under selected EAH banana plots (Kamusingize et al., 2017) are comparable or higher than some woody species such as Eucalyptusdominated wood lots (63.8 Mg ha-1; Sirike, 2012 in Kamusingize et al., 2017), tea plantations (69 Mg ha-1) and natural forests (67 Mg ha-1; Twongyirwe et al., 2013) in Uganda and pine plantations ( $87 \mathrm{Mg} \mathrm{ha}^{-1}$ ) in Columbia (Usuga et al., 2010).

Supporting services: Bananas are often grown as a permanent land-use leading to a build-up in crop litter, helping in nutrient recycling and biomass accumulation. In addition, and unlike most other crops, external mulch materials, kitchen refuse and other wastes are often dumped or applied in the banana plantations, thus providing nutrient recycling and biomass accumulation. In eastern DR Congo, most farmers believe that banana plantations can independently support their nutrient recycling needs and thus only apply external inputs onto other crops and in extreme cases were observed to compost and transfer banana residues to other fields. The crop is also an important source of animal feeds (Singh and Uma, 1996; Kamira et al., 2015) whose dung, especially in zero-grazed systems, offers a nutrient circulation benefit.

Cultural services: Common cultural services offered by the banana plant include inspiration for art and spirituality (Singh and Uma, 1996; Kamira et al., 2015). Several cultural values related to birth, marriages, deaths and other special ceremonies and rituals are associated with specific banana cultivars, and as such significant proportions of these cultivars are always maintained in family gardens for these different purposes (Karamura et al., 1998). The traditional knowledge with the respect of conservation, management, use of the cultivars and preparation of banana-based dishes is often passed from generation to generation through parents, uncles and aunts in these systems. There is also a strong sense of identity, self- 
fulfilment and meaning associated with the banana crop and banana-based diets in the banana-consuming communities. For example, the traditional meal made from steamed EAH bananas, "matoke", is synonymous for the word "food" in central Uganda (Karamura et al., 1998). Aesthetic enjoyment can also be realized from the beauty of banana landscapes and the cooler environment they provide.

\subsection{Xanthomonas wilt effects on ecosystem services in banana-based agroecosystems}

The negative effects of $\mathrm{XW}$ disease on food provision and incomes from banana fruits have been well studied and reported (see for example, Kalyebara et al. (2006) and Abele and Pillay (2008)). More recent studies show that, although there was a change in diversity at landscape level, diversity of crops at household level increased due to a complete loss or a significant reduction in banana plot size (Ocimati et al., 2016). Further studies are still needed to determine if the changes in diversity at household level have positively impacted on dietary diversity in the affected households

No studies have been conducted to quantify XW-induced losses in other ES (provisioning, regulatory and cultural). Plant disease effects on supporting and regulating services occur when a plant function is disrupted, and other plant types cannot compensate for the function. These services have received far less research attention (Cheatham et al., 2009).

XW affects ES directly through the removal of plants and/or complete mats. $\mathrm{XW}$ causes premature ripening and rotting of fruits, rapid wilting and eventual death of affected plants. Some of the emerging suckers may eventually show symptoms and die while others emerge with or without latent infections and grow to maturity and bear good fruits (Ocimati et al., 2013a; 2015). The loss of plants, reduced plant density and canopy cover opens the soil to degradation by runoff water, reduced soil water retention and soil sedimentation into community water sources affecting water quality (Cheatham et al., 2009). The loss of plant cover can also affect biomass/crop litter accumulation and nutrient recycling in affected fields and landscapes. Reduced plant cover can also affect the supply of nectar, sap and pollen for pollinators (El-Kazafy, 2007; Bat Conservation Trust, 2017), that play an important ecological role of pollination especially in landscapes where bananas are the predominant suppliers of these services, potentially down-regulating this service and affecting overall yields.

Indirectly, uprooting of infected plants or entire fields, which are among some of the recommended control strategies for managing the disease (Blomme et al., 2014), can affect the supply of key ES (Cheatham et al., 2009). This practice is 
associated with extensive destruction of the soil surface and structure, and exposure of soils to erosion agents, especially rainfall and wind. This practice is often accompanied by export of crop residues from the field, further aggravating soil erosion, reducing soil water infiltration and retention, and negatively affecting nutrient recycling in fields.

As a coping strategy, farmers also often uproot banana plantations for entirely new land-use options or expansion of other existing land-use options. For example, replacement of banana with sweet potatoes and cassava following devastation by XW has been reported in Uganda (Kalyebara et al., 2006). This in part is due to frustration (of being unable to eradicate the disease) and need for alternative sources for food (to maintain a similar whole farm productivity level), and in part due to limited knowledge or importance placed on the regulatory and provisioning services, which are often not tangible to farmers. The effect of the alternative land uses on the multi-functionality of the agroecosystems is not known. The sustainability of the alternative land-use options needs to be assessed to influence policy decisions and mitigation strategies for combating the disease and guiding diversification efforts. It is postulated that some of the alternative land-uses could negatively affect some services, such as erosion regulation, water infiltration and retention, nutrient recycling and weed suppression. In contrast, increased plant biodiversity may reduce disease risk if susceptible host tissue becomes less common (Cheatham et al., 2009). Increased biodiversity at household or landscape level could also improve pollination services and improve household nutrition. However, there is no current evidence to support these arguments in the XW affected banana-based systems. There are ongoing studies to assess the extent of and trajectories of land-use diversification due to XW disease occurrence, the associated trade-offs in ES, and agroecological intensification strategies for recovery of XW-affected landscapes in the South Kivu Province of eastern DR Congo, a hotspot of the disease.

Indirectly, de-budding of male buds, a common practice for preventing insectmediated XW infections could potentially affect pollinator populations, depress pollination services and honey production for bee farmers. These male neuter flowers on male buds are also an important source of pollen, sap and nectar for pollinators such as bats and honey bees (El-Kazafy, 2007; Bat Conservation Trust, 2017), an important ecological function.

Breeding through transgenetics is currently the only breeding mechanism that has yielded XW-resistant banana lines. However, deployment of these lines awaits the establishment of a legal framework in the East and Central African region. Despite these transgenics being a welcome development for enhancing food and income security, their deployment could potentially lead to selection against the susceptible 
cultivars (with other potentially important traits). It is worth noting that it is rather difficult to genetically modify all the commonly-used banana cultivars for XW resistance.

\subsection{An ecosystem-based broad framework for disease impact assessment and management}

The ES concept provides a means to define successful disease management more broadly, beyond short-term crop yield evaluations (Cheatham et al., 2009). Plant disease can affect ES directly, such as through removal of plants providing services, or indirectly through the effects of disease management activities, including pesticide applications, tillage and other methods of plant removal (Cheatham et al., 2009). We recommend a simple ES-based broad framework (Fig. 1) for better estimation of losses and resources to invest for disease management.

This framework describes the interaction of the disease with the crop and the different $E S$, defines the role and interaction between research, policy and extension and management of the disease. The interaction of the disease with the supply of ES has been explicitly described in the above sections. In this section, we define the potential roles played by and interaction between research, policy and extension, and how this could impact disease management by farmers.

Policy actors play the important role of setting priorities and allocating resources for research and extension work. They thus give the strategic direction by setting the agenda for research and extension that will in turn influence the policy guidelines and investment levels (in terms of capacity building, time commitment and finances). In this framework, policy makers will access information from research, extension and/or farming households to guide them in policy formulation. Research outputs can efficiently assist policy-makers in making the right decisions and building up practical, efficient and sustainable policies. 


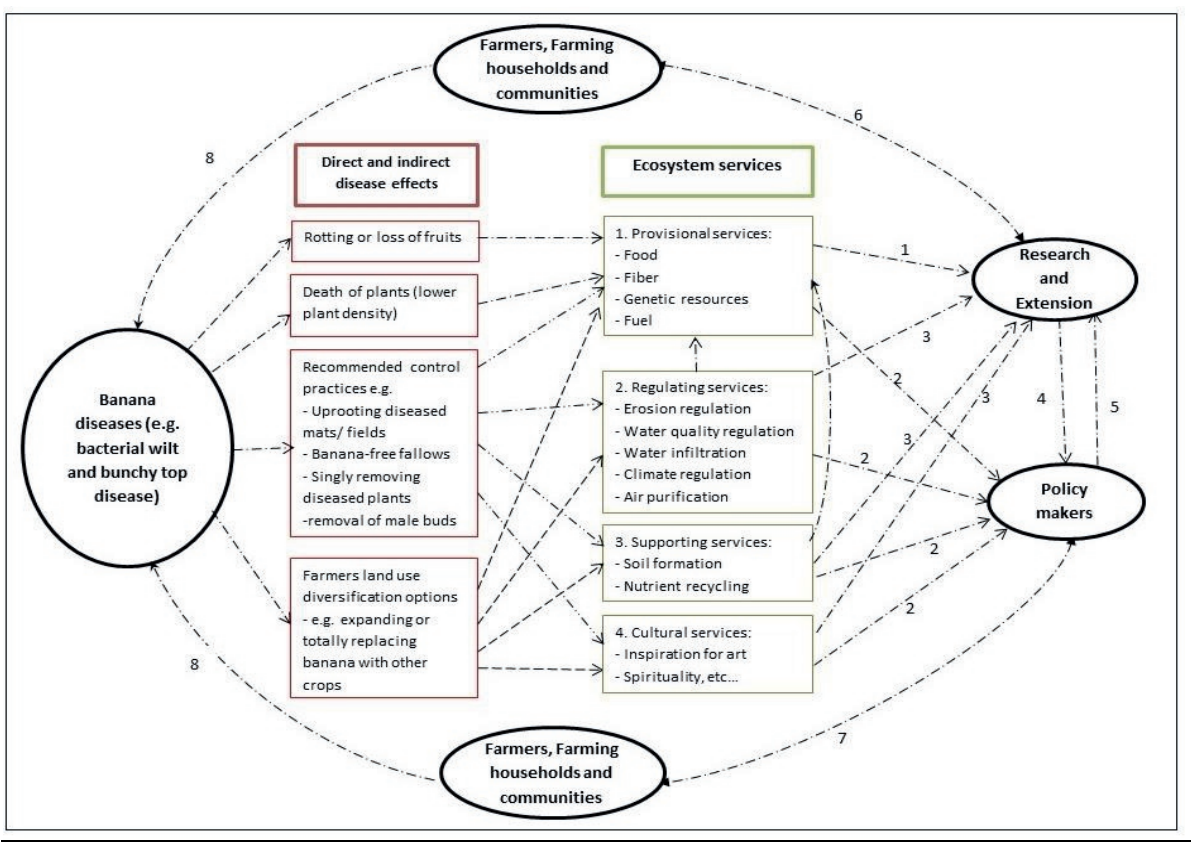

Figure 1. A broad ecosystem-based framework for the more comprehensive assessment and management of banana diseases. 1 = yield assessment and interactions between scientific communities and farmers; 2 = direct observations and feedback from farmers; 3 = assessment of disease impact on ecosystem services (e.g. trade-off analysis); 4 = briefs to policy makers; 5 = policies and investment decisions influencing research and extension priorities; and 6 = research and extension priorities, tools and methodologies; $7=$ policies directly influencing farmers' decisions and activities and direct feedback from farmers to policy makers; and 8 = farmers/farming households/communities decision making and disease management. Arrows denote the flow of information and/or processes, or (intended) influences.

Currently, existing legal policies regarding ecosystems are insufficient and mismatched with the necessary resources to protect ecosystem health and services. Moreover, the role of agroecosystems in supplying key ES has not been highly valued or emphasized, with more focus given to natural ecosystems. Informing decisionmakers of current versus future costs and benefits of ES also requires organizing and translating scientific knowledge to economics, which articulate the consequences of our choices in comparable units of impact on human well-being (Daily et al., 2000). It is the role of the research body to bring to the front the importance of agroecosystems for the supply of ES and to translate this knowledge into economic terms.

Benefits accrued from the ecosystem and their flows are still poorly understood. Thus, landscapes/communities continue to suffer from the so-called 'tragedy of the commons' (Hardin, 1968). It is even more complex to deal with agroecosystems such as banana plantations that are often owned by individuals and 
hence hard to regulate. In a participatory manner with farmers, extension bodies and other stakeholders, researchers therefore, need to generate empirical evidence of the importance of ES, potential services from agroecosystems, impact of diseases on these ES, and strategies for harnessing these services. This calls for stronger linkages between the different stakeholders (research, extension, farming communities (the primary users of the knowledge and information) and the policy makers). Researchers also need to package the information in more user-friendly and accessible alternatives for the different users. The extension bodies on their part have an important role of bridging the gap between researchers and farmers, especially in the traditional extension systems. Policy makers on the other hand need to support the research and extension efforts through generation of socioeconomically relevant and environmentally sound policies.

To bridge the gap between ES supply and demand, payments for environmental services (PES) has emerged as a means of channeling monetary flows from ES beneficiaries to ES providers (Wunder, 2005; Engel et al., 2008). PES is a voluntary transaction where a well-defined environmental service or a land use likely to secure a given service is being 'bought' by the service buyer(s) from the service provider(s) (Wunder, 2005; Engel et al., 2008). PES focus has been on financing of natural resource management actions towards meeting the social demand for ES. Such arrangements have been reported for land uses for natural ecosystems such as forests (Gorriz-Misfud et al., 2016). Similar efforts could be harnessed for valuable agroecosystems. However, for agroecosystems to gain from such arrangements, research needs to generate enough evidence to convince the policy makers and farmers to prioritize investments in protecting the services from the identified valuable land-uses. In the case of banana crop, as PES, potential strategies could involve investment in training in, and promotion of, environment-friendly cultural and cropping practices, and subsidization of seed to enable farmers to immediately restore affected landscapes.

The emphasis on financial valuations of nature as emphasized in the concept of PES has however raised ethical concerns, as it may undermine other forms of valuation based on, for example, moral or cultural values (Child, 2009; Bowles 2008). It has been argued that, many practical applications of the ES concept such as education, land-use planning, strategic policymaking, and in some cases even PES schemes do not require such monetary valuations. Caution therefore must be taken to ensure that the economic framing of ES in general -and their monetary valuation in particular- does not necessarily lead to a denial of the non-use and intrinsic values of nature (Luck et al., 2012). Authors such as Martín-López et al. (2008) and Sagoff (2011) emphasized the importance of place and context in terms of understanding 
the values and trade-offs related to ES. Similar approaches can be applied to the nonuse and intrinsic values. For agricultural systems, this has been demonstrated using multi-objective optimization models (e.g. the explorative Landscape IMAGES) to determine trade-offs in multifunctional land use planning process including environmental, social and economic land-use aspects (Groot et al., 2007; 2010).

\subsection{Potential agroecological intensification strategies for supporting XW infected landscapes}

More comprehensive strategies for managing XW and landscapes affected by XW should look beyond yield and associated incomes to other long-term multiple benefits that can be realized from the banana crop. Conventional intensification approaches to bridge yield gaps have been reported to lead to decline in productivity in the long run and reduced integrity of several natural supporting and regulating services (Bommarco et al., 2013). Instead ecological intensification approaches by optimizing ES in low-input farming systems, with wider yield gaps are recommended by Bommarco et al. (2013), as is the case in most banana-based systems in the East and Central African region. Several farming systems, such as intercropping, agroforestry, shifting cultivation and other traditional farming methods, are reported to mimic natural ecological processes (Altieri, 1999). Agricultural systems can also be designed to make more effective use of sunlight, soil nutrients, rainfall and biological resources (Gliessman, 1995; Altieri, 1999). Agroecosystems could thus be manipulated or managed to optimize the supply of key ES within landscapes. Caution should also be taken to match technologies to farm types.

We suggest some potential agroecological intensification practices that could be incorporated in XW affected landscapes to minimise the effect of the disease.

Hedge crops: Shrub or grass hedges with the ability to produce a large amount of dry matter could be promoted at the edges of farms, homesteads and contour lines of steep slopes. These crops can serve as fodder sources that should promote integration of small ruminants that can potentially improve nutrient recycling. Additional nitrogen inputs by symbiotic fixation can be provided if leguminous species are included. Using the hedges as mulch or green manure will also improve nutrient recycling on the farms. On steep slopes, the hedges will help to slow run-off and reduce soil erosion. Other potential benefits can include the creation of habitats for natural enemies to plant-eating pests, such as carabids, staphylinids (Altieri, 1999; Lichtfouse, 2010), interception of dusts and aerosols (Lichtfouse, 2010) and increasing biodiversity (Risser, 1995; Groot et al., 2010; Lichtfouse, 2010). Despite the risk of some hedges serving as reservoirs for weeds, some plant pests and pathogens, 
benefits of hedges in supporting biological control agents have been reported to outweigh such negative interactions (Lichtfouse, 2010).

Cover crops: The use of Mucuna as a cover crop has been found to be promising for weed suppression and soil fertility improvement when planted in fields using residual soil water at the onset of the dry season in ongoing experiments in eastern DR Congo (Blomme Guy, personal communication, 2016). Mucuna and similar cover crops (e.g. Lablab) could be promoted as cover during dry seasons and in sole banana plots with a good level of light penetration to suppress weeds, improve soil fertility and reduce soil erosion.

Agro-forestry: Though not feasible in most households due to shortage of land, some household types can afford to incorporate trees on their farms. Agroforestry practices could be selectively promoted for enhancing the resilience of the agroecosystems. Coffee-banana intercropping is common and reported as a compatible interaction that improves the resilience of agroecosystems (van Asten et al., 2011) and could thus be promoted in zones currently not growing coffee as a buffer to incomes and ES.

Proper crop residue management: Burning of crop residues and deposition at the edge of farms are common practices on farmers' fields. Extension knowledge on the negative effects of these practices is necessary to improve nutrient recycling on farms.

Banana cultivar mixtures: Differential XW spread has been observed between banana cultivars under natural conditions. High banana cultivar diversity has been reported to suppress banana pests and black leaf streak in Uganda (Mulumba et al., 2012). The potential of cultivar mixtures to suppress XW disease has not been studied, yet dilution and barrier effects provided by cultivars that escape insectmediated infections could be explored to reduce $\mathrm{XW}$-related losses in more susceptible cultivars.

\subsection{Conclusion}

$\mathrm{XW}$ not only reduces yields but also degrades other ecosystem services that often receive less attention in the traditional banana-producing areas, with potentially more severe and long-term effects on the agroecosystem. Policy makers locally, nationally and regionally need to be sensitized on the additional roles that banana can potentially play in the ecosystem. At community or farm level, knowledge and information on the importance of other services other than provisioning services are urgently needed to help farmers appreciate these services and their roles in sustaining the resilience of their agroecosystems. An ES-broad framework is thus 
recommended for better estimation of losses and resources to invest in disease management and development of disease management strategies and approaches. Measurements of provisioning services are often direct and easy, which is not always the case with other ES. Rapid and easy to use methodologies and tools for assessing these other ecosystem services in the banana-based systems are also urgently needed to broaden the framework of assessing the impact of the diseases. We recommend the use of agroecological intensification practices for enhancing or bridging the provision of key ecosystem services in the banana-based agroecosystems affected by XW disease.

\subsection{Acknowledgements}

This review was conducted under the framework of the Roots, Tubers and Banana programme of the CGIAR (CRP RTB) and the Consortium for Improving Agriculturebased Livelihoods in Central Africa (CIALCA) project. We would like to thank the Directorate General for Development, Belgium for funding the CIALCA project and staff time in this review.

\section{References}

AATF [African Agricultural Technology Foundation] (2009). Feasibility Study on Technologies for Improving Banana for Resistance Against Bacterial Wilt in Sub-Saharan Africa. Nairobi, Kenya. http://aatf-africa.org/userfiles/Banana_Bacterial_Wilt_Feasibility_Study.pdf (accessed: August 2013).

Abele, S., Twine, E., and Legg, C. (2007). Food security in Eastern Africa and the Great Lakes. Crop Crisis Control Project Final Report to USAID. Pp. 110. http://c3project.iita.org/Doc/Final\%20report\%20C3P\%20small.pdf (accessed: March 2015).

Abele, S., and Pillay, M. (2007). Bacterial wilt and drought stresses in banana production and their impact on economic welfare in Uganda: Implications for banana research in East African highlands. J. Crop. Improv. 19, 173-191.

Alberts, E.E., and Niebling, W.H. (1994). Influence of crop residues on water erosion. In: Unger, P.W. (ed), Managing agricultural residues. Pp. 19-36.

Altieri, M.A. (1999). The Ecological Role of Biodiversity in Agroecosystems. Agr. Ecosyst. Environ. 74(1-3), 19-31

Al-Kaisi, M.M., and Hanna, M. (2009). Residue management and cultural practices. Publ. No. PM 1901a. lowa State University, Cooperative Extension Service, Ames.

Baragengana, R. (1985). Banana production and research in Burundi. In: Kirkby RA and Ngendayo D (eds) Banana Production and Research in Eastern and Central Africa. Proceedings of a Regional Workshop held in Bujumbura, Burundi 14-17 December 1983. IDRC-MR114e, pp. 23-27. Ottawa, Canada.

Bat Conservation Trust (2017). Why bats matter. [Available at: http://www.bats.org.uk/pages/why bats matter.html] (accessed on $9^{\text {th }}$ March 2017) 
Bekunda, M. (1999). Farmers' responses to soil fertility decline in banana-based cropping systems of Uganda. Managing Africa's Soils No. 4. [Available at: http://pubs.iied.org/pdfs/7397IIED.pdf] (Accessed on 24th Nov. 2016).

Blomme, G., and Ortiz, R. (2000). Preliminary assessment of root systems morphology in Musa. In: Craenen, K., Ortiz, R., Karamura, E.B., Vuylsteke (Eds.) Proceedings of the International Conference on Banana and Plantain for Africa. Acta Hort. 540, 259-266.

Blomme, G., Jacobsen, K., Ocimati, W., Beed, F., Ntamwira, J., Sivirihauma, C., ... and Karamura, E. (2014). Fine-tuning banana Xanthomonas wilt control options over the past decade in East and Central Africa. Eur. J. Plant Pathol. 139, 265-281.

Bommarco, R., Kleijn, D., and Potts, S.G. (2013). Ecological Intensification: Harnessing Ecosystem Services for Food Security. Trends Ecol. Evol. 28, 230-38.

Bowles, S. (2008). Policies designed for self-interested citizens may undermine "the moral sentiments": Evidence from economic experiments. Sci. 320, 1605-1609.

Cabell, J.F., and Oelofse, M. (2012). An indicator framework for assessing agroecosystem resilience. Ecol. Soc. 17, 18. http://dx.doi.org/10.5751/ES-04666-170118

Cheatham, M.R., Rouse, M.N., Esker, P.D., Ignacio, S., Pradel, W., Raymundo, R., ... and Garrett, K.A. (2009). Beyond yield: Plant disease in the context of ecosystem services. Phytopathol. 99, 1228-1236.

Child, M.F. (2009). The Thoreau ideal as a unifying thread in the conservation movement. Conserv Biol. 23, 241-243.

Daily, G.C., Söderqvist, T., Aniyar, S., Arrow, K., Dasgupta, P., Ehrlich, P.R., ... and Levin, S. (2000). The value of nature and the nature of value. Sci. 289(5478), 395-396.

Dayton, P.K. (1972). Toward an understanding of community resilience and the potential effects of enrichments to the benthos at McMurdo Sound, Antarctica. In: Parker BC (Ed). Proceedings of the colloquium on conservation problems in Antarctica. Lawrence, KS: Allen Press

Edmeades, S., Smale, M., Kikulwe, E.M., Nkuba, J., and Byabachwezi, M.S.R. (2007). Characteristics of banana-growing households and banana cultivars in Uganda and Tanzania. Pages 49-74 in: An Economic Assessment of Banana Genetic Improvement and Innovation in the Lake Victoria Region of Uganda and Tanzania. M. Smale and W. K. Tushemereirwe, eds. IFPRI Research Report 155. IFPRI, Washington, DC.

Eledu, C.A., Karamura, E.B., and Tushemereirwe, W.K. (2004). Agroecological distribution of banana systems in the Great Lakes region. Afr. Crop Sci. J. 12, 33-42.

El-Kazafy, A. (2007). Importance of banana Musa sp. (Musaceae) for honey bee Apis mellifera L. (Hymenoptera: Apidae) in Egypt. Bull. Ent. Soc. Egypt 2, 125-133.

Ellison, A.M., Bank, M.S., Clinton, B.D., Colburn, E.A., Elliott, K., Ford, C.R., ...and Webster, J.R. (2005). Loss of foundation species: consequences for the structure and dynamics of forested ecosystems. Front. Ecol. Environ. 3(9), 479-486.

FAOSTAT, (2015). http://faostat3.fao.org/browse/Q/*/E. Accessed on 22 $2^{\text {nd }}$ March 2015.

Gaidashova S.V., Okech, S.H.O., Gold, C.S., and Nyagahungu, I. (2005). Why beer bananas? The case for Rwanda. InfoMusa 14(1), 2-6.

Gilley, J.E., Kowttwitz, E.R., and Wieman, G.A. (1991). Roughness coefficients for selected residue materials. J. Irrig. Drain. Eng. 114, 503.

Gliessman, S.R. 1(995). Sustainable agriculture: an agroecological perspective. Adv. Plant Pathol. 1, 45-57

Gold, C.S., Karamura, E.B., Kiggundu, A., Bagamba, F., and Abera, A.M.K. (1999). Geographic shifts in highland cooking banana (Musa spp., group AAA-EA) production in Uganda. Int. J. Sust. Dev. World Ecol. 6, 45-59. 
Gold, C.S., Kiggundu, A., Abera, A.M.K., and Karamura, D. (2002). Diversity, Distribution and Farmer Preference of Musa Cultivars in Uganda. Exp. Agric. 38, 39-50

Górriz-Mifsud, E., Varela, E., Piqué, M., and Prokofieva, I. (2016). Demand and supply of ecosystem services in a Mediterranean forest: computing payment boundaries. Ecosyst. Serv. 17, 53-63.

Groot, J.C.J., Rossing, W.A.H., Jellema, A., Stobbelaar, D.J., Renting, H., and Van Ittersum, M.K. (2007). Exploring multi-scale trade-offs between nature conservation, agricultural profits and landscape quality -a methodology to support discussions on land-use perspectives. Agr. Ecosyst. Environ. 120, 58-69.

Groot, J.C.J., Jellema, A., and Rossing, W.A.H. (2010). Designing a hedgerow network in a multifunctional agricultural landscape: Balancing trade-offs among ecological quality, landscape character and implementation costs. Eur. J. Agron. 32, 112-119.

Hanski, I. (1982). Dynamics of regional distribution: the core and satellite species hypothesis. Oikos, 210-221.

Hardin, G. (1968). "The Tragedy of the Commons". Sci. 162 (3859), 1243-1248.

Kagezi, G.H., Kangire, A., Tushmereirwe, W., Bagamba, F., Kikulwe, E., Muhangi, J., ... and Ragama, P. (2006). Banana bacterial wilt incidence in Uganda. Afr. Crop Sci. J. 14, 83-91.

Kamusingize, D., Majaliwa, J. M., Komutunga, E., Tumwebaze, S., Nowakunda, K., Namanya, P., and Kubiriba, J. (2017). Carbon sequestration potential of East African Highland Banana cultivars (Musa spp. AAA-EAHB) cv. Kibuzi, Nakitembe, Enyeru and Nakinyika in Uganda. J. Soil Sci. Environ. Manage. 8(3), 44-51.

Kalyebara, R., Ragama, P.E., Kagezi, G.H., Kubiriba, J., Bagamba, F., Nankinga, K.C., and Tushemereirwe, W. (2006). Economic importance of the banana bacterial wilt in Uganda. Afr. Crop Sci. J. 14, 93-103.

Kamira, M., Sivirihauma, C., Ntamwira, J., Ocimati, W., Katungu, M.G., Bigabwa, J.B., Vutseme, L., and Blomme G. (2015). Household uses of the banana plant in eastern Democratic Republic of Congo. J. Appl. Biosci. 94, 8915 - 8929

Karamura, E., Frison, E., Karamura, D.A., and Sharrock, S. (1998). Banana production systems in eastern and southern Africa. Bananas and food security. INIBAP, Montpellier, 401-412.

Karamura, E.B., Turyagyenda, F.L., Tinzaara, W., Blomme, G., Molina, A., and Markham, R. (2008). Xanthomonas wilt of Bananas in East and Central Africa. Diagnostic and Management Guide. Bioversity International. Fountain Publishers, Kampala, Uganda.

Lichtfouse, E. (Ed.). (2010). Biodiversity, biofuels, agroforestry and conservation agriculture (Vol. 5). Springer Science \& Business Media.

Lufafa, A., Tenywa, M.M., Isabirye, M., Majaliwa, M.J.G., and Woomer, P.L. (2003). Prediction of soil erosion in a Lake Victoria basin catchment using a GIS-based Universal Soil Loss Model. Agri. Syst. 76, 883-894.

Luck, G.W., Chan, K.M.A., Eser, U., Gómez-Baggethun, E., Matzdorf, B., Norton, B., and Potschin, B.M. (2012). Ethical considerations in on-ground applications of the ecosystem services concept. Biosci. 62, 1020-1029.

Martín-López, B., Montes, C., and Benayas, J. (2008). Economic valuation of biodiversity conservation: The meaning of numbers. Conserv. Biol. 22, 624-635.

Miller, G A., Amemiya, M., Jolly, R.W., Melvin, S.W., and Nowak, P.J. (1999). Soil Erosion and the lowa Soil 2000 Program. Publ. No. PM-1056. lowa State University Cooperative Extension Service, Ames. 66

Mohamoud, Y.M., and Ewing, L.K. (1990). Rainfall interception by corn and soybean residue. Trans. Am. Soc. Agri. Eng. 33, 507. 
Mulumba J.W., Nankya, R., Adokorach, J., Kiwuka, C., Fadda, C., De Santis, P., and Jarvis, D.I. (2012). A risk-minimising argument for traditional crop varietal diversity use to reduce pest and disease damage in agricultural ecosystem of Uganda. Agr. Ecosyst. Environ. 157, 70-86.

Ocimati, W., Groot, J.C.J., Ntmwira, J., Bahati, L., Tittonell, P.A., Taulya, G., ... and Blomme, G. (2016). Land use/cropping pattern changes in retrospect across Xanthomonas wiltinfected landscapes. In International Symposium on Banana/ISHS-ProMusa symposium: Agroecological approaches to promote innovative banana production systems.

Ocimati, W., Karamura, D., Rutikanga, A., Sivirihauma, C., Ndungo, V., Adheka, J., ... and Blomme, G. (2013b). Musa germplasm diversity status across a wide range of agroecological zones in Rwanda, Burundi and eastern Democratic Republic of Congo. In: Blomme, G. et al. (eds). Banana systems in the humid highlands of Sub-Saharan Africa: enhancing resilience and productivity. Wallingford, UK: CAB International, 8-21 ISBN:9781780642314.

Ocimati, W., Karamura, D., Rutikanga, A., Sivirihauma, C., Ndungo, V., Ntamwira, J., ... and Blomme, G. (2013c). Agronomic practices for Musa across different agro-ecological zones in Burundi, Eastern Democratic Republic of Congo and Rwanda. In: Blomme G, Vanlauwe B, van Asten P, eds. Banana Systems in the Humid Highlands of Sub-Saharan Africa: Enhancing Resilience and Productivity. Wallingford, UK: CAB International, 175-190 ISBN:9781780642314.

Ocimati, W., Nakato, G.V., Fiaboe, K.K.M., Beed, F., and Blomme, G. (2015). Incomplete systemic movement of Xanthomonas campestris pv. musacearum and the occurrence of latent infections in Xanthomonas wilt-infected banana mats. Plant Pathol. 64, 81-90.

Ocimati, W., Ssekiwoko, F., Karamura, E., Tinzaara, W., Eden-Green, S., Blomme, G. (2013a). Systemicity of Xanthomonas campestris pv. musacearum and time to disease expression after inflorescence infection in East African highland and Pisang Awak bananas in Uganda. Plant Pathol. 62, 777-785.

Okumu, M.O., van Asten, P.J.A., Kahangi, E., Okech, S.H.J., Jefwa, J., and Vanlauwe, B. (2011). Production gradients in smallholder banana (cv. Giant Cavendish) farms in central Kenya. Sci. Hort. 127, 475-481.

Orwig, D.A., Foster, D.R., and Mausel, D.L. (2002). Landscape patterns of hemlock decline in New England due to the introduced hemlock woolly adelgid. J. Biogeogr. 29, 1475-87.

Engel, S., Pagiola, S., and Wunder, S. (2008). Designing payments for environmental services in theory and practice: An overview of the issues. Ecol. Econ. 65(4), 663-674.

Rishirumuhirwa, T., and Roose, E. (1998). The Contribution of Banana Farming Systems to Sustainable Land Use in Burundi. Adv. GeoEcol. 31, 1197-1204.

Risser, P.G. (1995). The status of the science examining ecotones. BioSci. 45(5), 318-325.

Rogers, S., and losefa, T. (1993). Potentials for shade management in agroforestry systems for taro cropping. In: Ferentinos L, (ed). Proceedings of the Sustainable Taro Culture for the Pacific Conference; 1992 Sept 24-25; Honolulu, Hawaii. Honolulu (HI): University of Hawaii. Pp. 62-65.

Sagoff, M. (2011). The quantification and valuation of ecosystem services. Ecol. Econ. 70, 497502

Sebasigari, K. (1985). Overview of banana cultivation and constraints in the Economic Community of the Great Lakes States (CEPGL). In: Kirby, R. and Ngendahayo, D. (eds), Banana production and research in eastern and central Africa. Proceedings of a Regional Workshop held in Bujumbura, Burundi 14-17 December 1983. IRAZ/ IDRC. IDRC-MR114e. pp. 9-22. 
Smale, M. (2006). Assessing the impact of crop genetic improvement in sub-Saharan Africa: Research context and highlights. In: Melinda, S., Edmeades, S., De Groote (Eds.). Promising Crop biotechnologies for smallholder farmers in East Africa: Bananas and Maize. Genetic Resources Policies Briefs 19-2006

Singh H.P. and Uma, S. (1996). Banana cultivation in India. NRCB Publication, pp. 16-37

Southwood, R.E., and Way, M.J. (1970). Ecological background to pest management. In: Rabb, R.C., Guthrie, F.E. (Eds.), Concepts of Pest Management. North Carolina State University, Raleigh, NC, pp. 6-29.

Ssekiwoko, F., Taligola, H.K., and Tushmereirwe, W.K. (2006). Xanthomonas campestris pv. musacearum host range in Uganda. Afr. Crop Sci. J. 14, 111-120.

Twongyirwe, R., Sheil, D., Majaliwa, J.G.M., Ebanyat, P., Tenywa, M.M., van Heist, M., and Kumar, L. (2013). Variability of Soil Organic Carbon stocks under different land uses: A study in an afro-montane landscape in southwestern Uganda. Geoderma, 193, 282-289.

van Asten, P.J.A., Gold, C.S., Okech, S.H.O., Gaidashova, S.V., Tushemereirwe, W., and De Waele, D. (2004). Soil quality problems in East African banana systems and their relation with other yield loss factors. InfoMusa 13, 20-25.

van Asten, P.J.A., Wairegi, L.W.I., Mukasa, D., and Uringi, N.O. (2011). Agronomic and economic benefits of coffee-banana intercropping in Uganda's smallholder farming systems. Agr. Syst. 104, 326-334.

Wairegi, W.I.L., van Asten, J.A.P., Tenywa, M.M., and Bekunda, A.M. (2010). Abiotic constraints override biotic constraints in East African highland banana systems. Field Crops Res. 117, 146-153

With, K.A. (2002). The landscape ecology of invasive spread. Conserv. Biol. 16, 1192-1203.

Wunder, S. (2005). Payments for environmental services: some nuts and bolts (No. CIFOR Occasional Paper no. 42, p. 24p).

Usuga, J.C.L., Toro, J.A.R., Alzate, M.V.R., and Tapias, Á.D.J.L. (2010). Estimation of biomass and carbon stocks in plants, soil and forest floor in different tropical forests. For. Ecol. Manage. 260(10), 1906-1913. 


\section{Chapter 4}

\section{Banana Xanthomonas wilt disease hotspots, fronts and vulnerable landscapes}

\section{Published as:}

Ocimati, W., Bouwmeester, H., Groot, J.C.J., Tittonell, P., Brown, D., and Blomme, G. (2019). The risk posed by Xanthomonas wilt disease of banana: Mapping of disease hotspots, fronts and vulnerable landscapes. PloS one, 14(4), e0213691.

https://doi.org/10.1371/journal.pone.0213691 


\section{Abstract}

Banana production landscapes in the African Great Lakes Region (AGLR) have been under immense pressure from Xanthomonas wilt (XW) disease over the past two decades. XW, first reported on banana in central Uganda and eastern DR Congo in 2001, has since spread to the entire AGLR. XW is currently spreading westwards from hot spots in eastern DR Congo highlands, putting the plantain (Musa AAB genome) belt of central and west Africa at risk. In-depth understanding of the key variables responsible for disease spread, current hotspots, and vulnerable landscapes is crucial for disease early warning and management. We mapped aggregated disease distribution and hotspots in the AGLR and identified vulnerable landscapes across African banana production zones. Available data on disease prevalence collected over 11 years was regressed against environmental and expert developed covariates to develop the AGLR XW hotspots map. For the Africa-wide risk map, precipitation, distance to hotspots, degree of trade in fresh banana products, production zone interconnectedness and banana genotype composition were used as covariates. In the AGLR, XW was mainly correlated to precipitation and disease/banana management. Altitude and temperature had unexpectedly low effects, possibly due to an overriding impact of tool-mediated spread which is part of the management covariate. In the AGLR, the eastern part of DR Congo was a large hotspot with highest vulnerability. Apart from endemic zones in the AGLR and Ethiopia, northern Mozambique was perceived as a moderate risk zone mainly due to the predominance of 'Bluggoe' (Musa ABB type) which is highly susceptible to insectvectored transmission. Presence of XW hotspots (e.g. eastern DR Congo) and vulnerable areas with low (e.g. north-western Tanzania) or no disease (e.g. Congo basin, western DR Congo and northern Mozambique) pressure suggest key areas where proactive measures e.g. quarantines and information sharing on $\mathrm{XW}$ diagnosis, epidemiology, and control could be beneficial.

Key words: covariates, cultivar, indicator regression kriging, surveillance, vulnerable landscapes 


\subsection{Introduction}

More than one third of Africa's banana (Musa spp.) production, or nearly $11 \%$ of world production, comes from the African Great Lakes region (AGLR), i.e., Burundi, Democratic Republic of Congo (DR Congo), Kenya, Rwanda, Tanzania, and Uganda (FAO, 2017), which is a centre of diversity of East African highland bananas and plantains (Simmonds and Shepherd, 1955; Simmonds, 1966). Banana provides 30 $60 \%$ of food energy needs for over 70 million people in this region (Abele et al., 2007; Karamura et al., 2008) and contributes to incomes of farm households and businessmen along the value chain of the crop (Okech et al., 2004; Edmeades et al, 2007). Since two decades, banana production landscapes in the AGLR have been subjected to immense pressure from pests and diseases on top of several abiotic constraints. The outbreak of Xanthomonas wilt disease of banana (XW) has drawn the greatest attention due its rapid rate of spread and severe impact on production. The disease was first observed on banana in 1974 in Ethiopia (Yirgou and Bradbury, 1974). In the AGLR, it was first observed in 2001 in central Uganda (Tushemereirwe et al., 2004) and eastern DR Congo (Ndungo et al., 2006) and has over a period of a decade spread to the whole AGLR (Reeder et al., 2007; Tripathi et al., 2009; Carter et al., 2010; Blomme et al., 2013). Within the affected countries, the disease has spread to new zones at rates dependent on the agroecological conditions and the characteristics of the production systems. High spread rates have been reported in lower altitude areas ( $<1500 \mathrm{~m}$ ) of central Uganda (Tushemereirwe et al., 2006) with slower rates reported at high elevations (>1500 m) of eastern DR Congo (Ndungo et al., 2006). The disease is currently spreading westwards from the current hot spots in eastern DR Congo, towards the Congo basin, putting the plantain belt of central and west Africa at risk. XW disease results in severe yield losses reaching as high as $100 \%$ if control is delayed, severely compromising food and income security of households and communities (Kalyebara et al., 2006; Blomme et al., 2014; 2017). Potential economic losses between US\$ 200 and 295 million a year due to delayed intervention have been estimated for Uganda (Kalyebara et al., 2006; Blomme et al., 2017; Abele et al., 2007; Okech et al., 2004). In Tanzania and Rwanda, a 35\% drop in sales and doubling of prices due to XW were reported (Nkuba et al., 2015). In Uganda, (FAO, 2017) reports 50\% less production for 2014, compared to 2002 while area under banana declined by $39 \%$.

Over the past 15 years, various research and extension efforts have been put in place to manage and contain the disease. For example, several XW epidemiology studies have been conducted and control strategies fine-tuned (Blomme et al., 2005, 2017b; Ssekiwoko et al., 2006; Tinzaara et al., 2006; Ocimati et al., 2013a, b, 2015; 
Nakato et al., 2015; Ochola et al., 2014, 2015) farmers sensitized and trained; and bylaws and task forces formed to foster control (Blomme et al., 2014; Tinzaara et al., 2011; Kubiriba et al., 2012). No disease quarantines have been set up in the region to contain the disease. If attempted, low success rates are anticipated due to lack of efficient detection tools at border points, porous nature of borders and common ethnicities at borders with some households being separated by the borders (Blomme et al., 2014). Once established, landscape-wide XW control is difficult and total eradication is impossible (Eden-Green, 2004). Ocimati et al. (2013a) reported long incubation periods of up to 24 months and latent infections. Though helpful for reducing disease incidence and recovery of yields, the current measures have been reactive and are not adequate for containing the disease, especially not from spreading to new locations.

Knowledge of the vulnerable landscapes and disease fronts could prevent or minimise negative effects due to the disease. Here we aim to map XW incidence and identify the XW disease fronts and the vulnerable landscapes across Africa. Making XW spatially explicit can guide the design of interventions for disease management and containment. Maps will be important for surveillance; risk assessment; priority setting and resource allocation; and strategizing for disease management and containment. Mapping will also allow identification of vulnerable sites for a more pro-active disease prevention strategy, rather than the commonly applied reactive strategy. Our objectives were (i) to map the spatial spread of XW disease and the vulnerable landscapes of the AGLR, collating available disease incidence survey data and environmental and social co-variates from the various countries in the region, and (ii) to develop a first, coarse $\mathrm{XW}$ disease risk map for the rest of Africa. Deliberating on these XW spatial risk maps with stakeholders is anticipated to proactively guide decisions and strategies for $\mathrm{XW}$ prevention and management at landscape and regional level. This study will build on existing XW mapping exercises in the region (Tripathi et al., 2009; Tushemereirwe et al., 2006; Ndungo et al., 2008; Bouwmeester et al., 2016; Shimwela et al., 2017) that have often been region- or country-specific.

\subsection{Materials and methods}

\subsubsection{Study area}

The study area (Fig. 1) consists of two geographical zones. The first zone is the African Great Lakes region (AGLR) and measures about $1000 \times 1000 \mathrm{~km}^{2}$. The area includes Rwanda, Burundi, the main banana growing areas in western Kenya, Uganda, northern Tanzania and the eastern DR Congo. The East African highlands are part of 
the African Rift System with Lake Victoria as the central basin. The area has a diverse agroecology, resulting from a large variation in altitude (550-4600 m above sea level; CGIAR-CSI, 2008), mean annual rainfall (500-2300 mm; Hijmans et al., 2005) and mean annual temperature (from 3 to $26^{\circ} \mathrm{C}$; Hijmans et al., 2005). A large part of the area is very suitable for growing crops such as banana and plantains, maize and cassava because of fertile soils and high rainfall. Agriculture in the region can predominantly be characterized as subsistence farming with complex mixed cropping. This zone is dominated by the east African highland bananas. Plantains ( $A A B$ genome) can be found in high abundance in parts of eastern DR Congo while the $A B B$ types can be found localized in patches across this zone, with higher concentrations in central Uganda. All surveys were carried out in this zone.

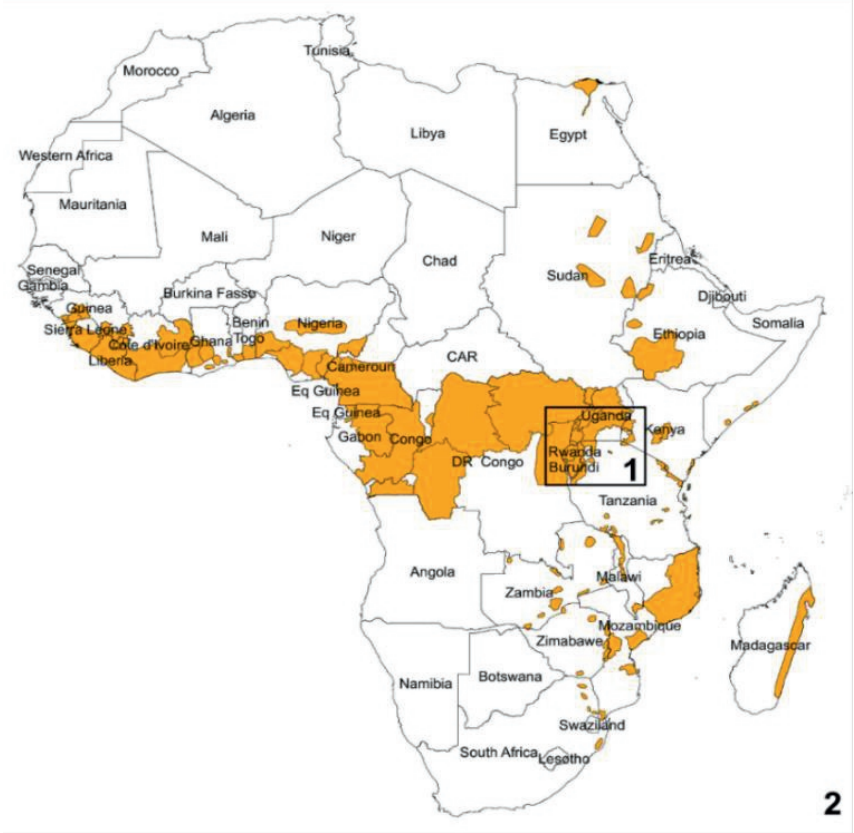

Figure 1. Study areas: 1) African Great Lakes region and 2) entire Africa. Shaded are the main banana growing areas (Source: www.crop-mapper.org).

The second (much larger) zone covers all the banana growing zones in Africa, including the AGLR. The area covers 28 tropical or subtropical countries in Africa with a very diverse agroecology resulting from its sheer size and the African Rift System that cuts it in two (Fig. 1). It borders two oceans, has several mountain ranges, river systems/basins and extensive forested areas. The areas in the west and central Africa are dominated by plantains while the east and central African highlands (AGLR) are 
dominated by the east African highland banana (AAA genome). Other AAA genomes (e.g. Cavendish types) are prevalent in the central, east and southern parts of Africa. Both study areas are delimited using administrative boundaries (Global Administrative Areas vs. 2.8; www.gadm.org).

\subsubsection{Methodology for zone 1 (i.e. AGLR)}

Data collection: Survey datasets: The data set for mapping the AGLR was collated from nine ground-based surveys conducted between 2005 and 2016 across the zone 1 (Figs 1 and 2) and comprised of a total of 4,760 farms. An ellipse is added for each survey to show its geographic extent (Fig. 2). The smallest extent is that of survey $E$, where all samples lie within a $3 \mathrm{~km}$ distance. The largest one is survey $H$, where the samples lie within $1000 \mathrm{~km}$ distance. Only survey $\mathrm{H}$ covers the entire area of interest. $\mathrm{XW}$ incidence/ distribution was recorded through farmer interviews and diagnosis of banana farms/fields. The coordinates of the sample locations were recorded with a handheld GPS with an error margin of about $10 \mathrm{~m}$. The surveys measured XW as binominal (present or absent) or categorical values (percentage incidence of infected plants in a farm (i.e. 0 to $100 \%)$ ). For uniformity, all measurements were transformed to binominal values ( $1=$ present or $0=$ absent $)$.

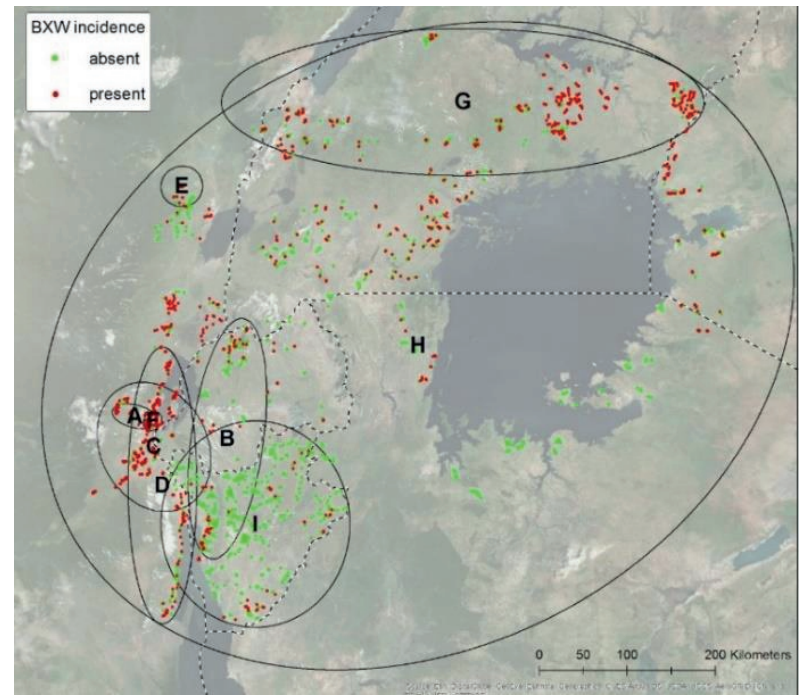

Figure 2. Incidence of XW for all nine surveys indicated with letters $A$ to $H$. An ellipse/circle shows the geographic extent of a survey. 
Dataset of covariates: Most of the area of interest for the AGLR risk mapping is devoid of samples. Environmental variables (e.g. altitude, rainfall, temperature) and banana cultivar composition have a relationship with XW disease (Blomme et al., 2005; 2014; Biruma et al., 2007; Bouwmeester et al., 2016; Shimwela et al., 2017). Precipitation, temperature and altitude influence insect vector activity and thus the incidence and severity of XW disease (Blomme et al., 2005; Shimelash et al., 2008; Rutikanga et al., 2015). The ABB banana types are particularly prone to insectmediated infections due to their non-persistent neuter flowers (Blomme et al., 2017), as such depending on their concentrations and farm management practices, landscapes containing them tend to be more prone to XW infection. Environmental characteristics/banana types can thus help to predict the incidence of $\mathrm{XW}$ or the risk of infection at the unobserved locations. The environmental variables (e.g. topography, vegetation, temperature, precipitation) and major markets were obtained from publicly available predictor maps. Data on the distribution and abundance of ABB types in the AGLR was obtained through literature review and expert knowledge. The level and organization of extension services and thus disease management also plays a key role in the spread, incidence and severity of the disease. To capture this, through expert judgement, management was incorporated as an additional covariate using a scale varying between 0 and 1 , ' 0 ' denoting no efforts to manage XW disease and ' 1 ' strong research, extension and management efforts to control XW. Table 1 lists all environmental variables that have been used for mapping the AGLR and Figure 3 illustrates them as maps.

Table 1. Sixteen covariates used for the regression analysis and for making the infection risk map of the African Great Lakes Region.

\begin{tabular}{|c|c|c|c|}
\hline Var. & Description & Resolution & Source \\
\hline Lon & Longitude & 30 arc s & - \\
\hline Lat & Latitude & $30 \operatorname{arcs}$ & - \\
\hline Alt & Altitude above sea level (m) & 30 arc s & $\frac{\text { http://srtm.csi.cgiar.org (Jarvis et }}{\text { al., 2008). }}$ \\
\hline Prec & Annual precipitation (mm) & 30 arc s & WorldClim V1 (Hijmans et al., 2005) \\
\hline Precsq & - & 30 arc s & - \\
\hline precmin & Precipitation driest month (mm) & $30 \operatorname{arcs}$ & WorldClim V1 (Hijmans et al., 2005) \\
\hline precvar & Precipitation seasonality (-) & $30 \operatorname{arcs}$ & WorldClim V1 (Hijmans et al., 2005) \\
\hline Temp & Mean annual temperature $\left({ }^{\circ} \mathrm{C}\right)$ & 30 arc s & WorldClim V1 (Hijmans et al., 2005) \\
\hline Tempsq & - & $30 \operatorname{arcs}$ & - \\
\hline tempmin & $\begin{array}{l}\text { Mean temperature coldest month } \\
\left({ }^{\circ} \mathrm{C}\right)\end{array}$ & 30 arc s & WorldClim V1 (Hijmans et al., 2005) \\
\hline tempvar & Temperature seasonality & 30 arc s & WorldClim V1 (Hijmans et al., 2005) \\
\hline Market & Market access (hr) & 30 arc s & www.forobs.jrc.ec.europa.eu \\
\hline Veg & Vegetation cover & $30 \operatorname{arcs}$ & ESA CCI landcover map V1 \\
\hline Vegsq & - & 30 arc s & - \\
\hline Man & Management Factor (-) & 30 arc s & Expert knowledge \\
\hline$a b b$ & Distribution of ABB banana types & $30 \operatorname{arcs}$ & Expert knowledge \\
\hline
\end{tabular}




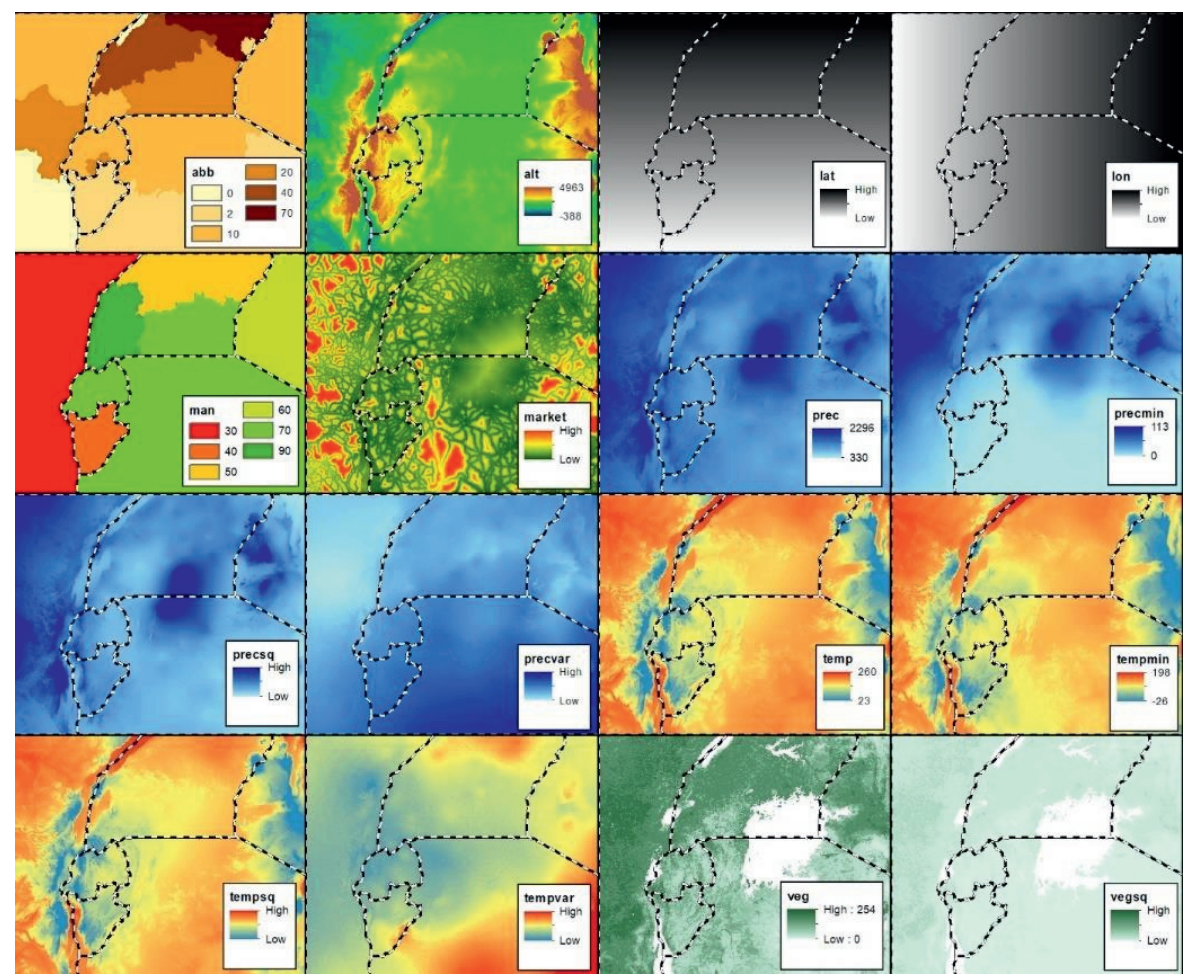

Figure 3. Covariate maps that served as input for the regression model for developing the spatial map of Xanthomonas wilt disease in the African Great Lakes Region.

Indicator regression kriging: To develop the XW disease map for the AGLR, the indicator regression kriging method was used. Indicator regression kriging is a geostatistical interpolation method that spatially interpolates a response variable, making use of point observations of the target variable and auxiliary data (Goovaerts, 1997; Webster and Oliver, 2007). Bouwmeester et al. (2016), used the method to map XW in the East African highlands. In this study, the same technique was applied, but multiple merged survey datasets were used, instead of just one, and hence the spread of XW was predicted for a larger area. Bouwmeester et al. (Bouwmeester et al., 2016) used data of 2006/7 only, and since then the disease has spread to other areas in the region. The methodology involves two stages. In the first stage, the binary survey variables are regressed to auxiliary environmental (e.g., terrain, climate, land cover) and social (e.g. management) covariates. In the second stage, the regression residuals are interpolated using simple kriging and added to the regression map to further improve the spatial prediction of XW incidence across the entire region. 
Regression analysis: Regression models predict at the unobserved locations using the relationship between the observed locations and the environmental auxiliary covariates. We used 16 auxiliary covariates (Table 1 ) that were thought to have a plausible and significant relationship with XW or its vectors and for which spatially exhaustive maps in the public domain or literature and knowledge were available. An overlay of the survey locations and covariates resulted in a database with XW presence and 16 covariates. This database served as input for fitting the regression models. We applied logistic regression because the dependent variable (XW presence) is binary, either 1 for present or 0 for absent. The theory and practical application of logistic regression is well explained by (Hosmer and Lemeshow, 2000) and by Bouwmeester et al. (2016) and therefore only briefly described it in this article. The general logistic regression model was built in four steps:

1. All 16 covariates (Table 1 ) were entered into a univariate logistic regression model. Covariates with a significance level less than 0.25 were included in further analysis because these may be significant in two-way interactions.

2. The 16 covariates (Table 1 ) were then entered into a multivariate logistic regression model. With stepwise regression, the covariates that were not significant at the $p=0.05$ level were removed one at a time.

3. Two-way-interactions between covariates were included to check for combined effects that improve the likelihood ratio. Initially, all possible covariate interactions were examined. All interactions with a $p$-value less than 0.05 are deemed significant and included in the model, again using a stepwise approach.

4. The goodness-of-fit of the final model was assessed in terms of deviance and compared to the null model (i.e., the model without covariates) using the likelihood ratio test.

Finally, the derived logistic regression model was used on the covariate maps and yields a regression prediction map for zone 1 of the study area.

The R Statistical software (R Core Team, 2017) and the Raster package (Hijmans, 2017) were used for the regression analysis.

Spatial interpolation: In most cases, the regression model will only describe part of the variation in the response variables. Through regression kriging, the regression residuals were interpolated with kriging and used to correct the estimate of the regression model. Kriging predicts at unobserved locations by taking a weighted average of the surrounding observations, where the kriging weights depend on the spatial autocorrelation between the variable at the prediction and observation locations. The spatial autocorrelation is characterized by the semivariogram that 
plots the semivariance, i.e., a measure of the degree of variation, as a function of geographical distance (Goovaerts, 1997). In regression kriging, the residuals from the regression analysis are used instead of the observations directly. We estimated the semivariogram model parameters based on visual interpretation of the semivariance plot. Next, simple kriging of the regression residuals was applied since the regression residuals have zero mean (Webster and Oliver, 2007). Finally, the simple kriging method yields a kriging prediction map for zone 1 of the study area. The GSTAT package in R (Pebesma, 2004) was used for this.

$\mathbf{X W}$ prediction map: To predict the XW incidence of the entire region, the regression prediction map was simply added to the kriging prediction map. Cells were set to zero if the sum of the regression- and the kriging-value was negative, and cells were set to 1 if the sum exceeded 1 .

\subsubsection{Methodology for zone $\mathbf{2}$ (banana growing areas in Africa)}

For the development of XW infection risk map at the Africa-wide level, we cannot directly rely on the current surveys because they cover only the AGLR. Therefore, variation in environmental covariates is beyond the range of the samples, and the calculated relationships for study area 1 will not hold. Also, XW is currently not present in the lowland plantain growing zones of west and central Africa and not in the Cavendish (AAA genome) growing zones in eastern and southern Africa. Management as a covariate would also not work for the Africa wide context due to the absence of the disease.

To overcome this challenge, a prediction of infection risk was estimated by calculating a background risk level to all banana growing zones in Africa based on the relationship between $\mathrm{XW}$ disease and selected covariates (environmental and expert generated). This background risk was then corrected based on expert knowledge. The expert assessment of covariates was attained through a two-step procedure. In the first step, a questionnaire was administered to 14 experts on XW epidemiology, to determine the importance of ten suggested covariates on a scale of 1-5 (Fig. 4). Rank ' 1 ' stands for not important while rank ' 5 ' denotes very important in influencing $\mathrm{XW}$ disease. Table 2 lists the covariates that were finally used for the Africa wide XW risk map. Subsequently, and using the selected covariates, three experts with good understanding of XW disease epidemiology and the banana production zones, independently ranked the risk scores for each production zone/ country. 


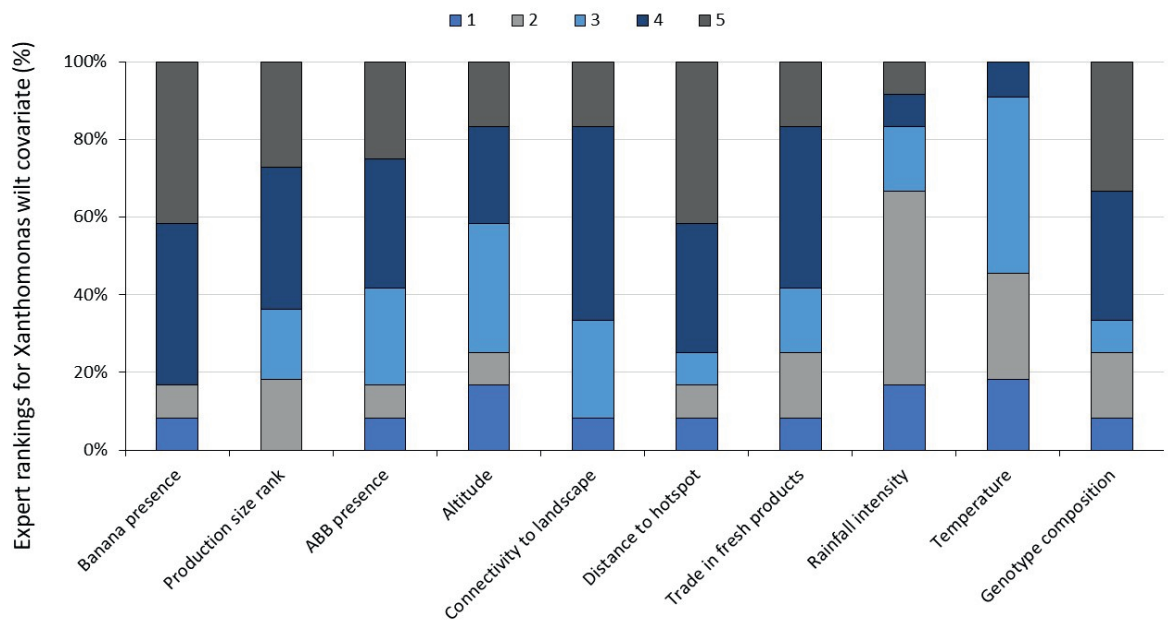

Figure 4. The percentage of experts giving different ranks for 10 potential covariates influencing risk of Xanthomonas wilt disease spread and severity. Covariates were ranked at a scale of 1 to 5, "1" denoting that a covariate does not influence XW disease while " 5 " has a very important influence on XW disease. Fourteen experts participated in ranking of the covariates.

Most of the banana production zones for which the XW infection risk was calculated were downloaded from the crop-mapper application (www.crop-mapper.org). The zones were modified using ArcGIS (2014) because some zones were 1) overlapping, 2 ) were entered twice, 3) were split into small polygons or 4) were displaced. In some countries, zones were added because they were missing in the crop-mapper application despite having significant banana production (FAO, 2017). The geographic location of these missing zones was based on the maps of MapSPAM V2 (You et al., 2017) banana production.

After editing there were 121 zones within 28 African countries. In some countries there were many zones with a maximum in Guinea of 15 , whereas in other countries like Madagascar there was only one zone. To each zone relevant covariate data were added. The relevance was determined through expert assessments and by interpreting correlation coefficients between environmental data and XW samples in the East African Highlands (Table 2). 
Table 2. The covariate data used for developing the Xanthomonas wilt of banana risk map for production zones in Africa.

\begin{tabular}{|c|c|c|c|c|c|}
\hline Covariate & Detail & Source(s) & $\mu$ & $\Sigma$ & Weight \\
\hline Zones & Banana production zone & $\begin{array}{l}\text { www.crop-mapper.org; } \\
\text { http://mapspam.info }\end{array}$ & $(-)$ & $(-)$ & $(-)$ \\
\hline Genotype & $\begin{array}{l}\text { Banana genotype composition. } \\
\text { ABB types are prone to insect } \\
\text { vector-mediated infections } \\
\text { predisposing landscapes to XW } \\
\text { (Tripathi et al., 2009). }\end{array}$ & $\begin{array}{l}\text { www.crop-mapper.org } \\
\text { Various banana experts } \\
\text { and authors. }\end{array}$ & 1.3 & 0.6 & +1 \\
\hline Connectivity & $\begin{array}{l}\text { Interconnectedness to hot spots - } \\
\text { Isolated areas have a lower } \\
\text { exposure to XW. Could be } \\
\text { influenced by a common border, } \\
\text { main road axis, water body or } \\
\text { forests. }\end{array}$ & $\begin{array}{l}\text { Various banana experts } \\
\text { and authors. }\end{array}$ & 0.3 & 0.4 & +1 \\
\hline Trade & $\begin{array}{l}\text { Trade with hotspots in fresh } \\
\text { fruits. Spread along trade routes } \\
\text { has been reported (Ocimati et al., } \\
\text { 2015; Nakato et al., 2013). }\end{array}$ & $\begin{array}{l}\text { Various banana experts } \\
\text { and authors. }\end{array}$ & 0.4 & 0.5 & +1 \\
\hline Distance & $\begin{array}{l}\text { Actual distance to hotspots - } \\
\text { closer a site is to a hotspot the } \\
\text { higher the XW risk }\end{array}$ & $\begin{array}{l}\text { Various banana experts } \\
\text { and authors. }\end{array}$ & 14 & 13 & -1 \\
\hline Precipitation & $\begin{array}{l}\text { Annual precipitation ( } \mathrm{mm} \text { )- higher } \\
\text { number of infections reported in } \\
\text { the wet seasons. }\end{array}$ & $\begin{array}{l}\text { WorldClim V1 (Hijmans } \\
\text { et al., 2005) }\end{array}$ & 1333 & 597 & +1 \\
\hline
\end{tabular}

The values of the covariates had very different ranges (Table 2). To make comparisons possible all values were standardized. To calculate the infection risk of each zone, five covariates (genotype, connectivity, trade, precipitation and distance) were simply summed. Four other covariates (e.g. production zone size, production level, temperature and altitude) were also considered but not used in the end because the resulting maps suggested a non-useful relation. It was assumed that the covariates genotype, connectivity, trade and precipitation increase risk, whereas distance decreases risk. It was also assumed that all covariates have an equal weight in determining risk.

\subsection{Results}

\subsubsection{Correlation of covariates to XW occurrence in AGLR}

Pearson's correlation between XW incidence and all covariates were significant at the $p=0.05$ level, except for the two covariates market and vegetation squared (Vegsq) (Table 3). Three covariates (precipitation squared, precipitation and management) had an absolute correlation coefficient of 0.35 or higher, suggesting a higher contribution to the observed variation in XW disease occurrence. All 
precipitation covariates, except the variability in precipitation, were positively correlated to XW. This suggests XW incidence is higher during the wet/humid seasons. In contrast, the disease management factor was negatively correlated with the XW incidence. Thus, a higher occurrence of XW is expected in landscapes that either had no access to management information or in which disease was poorly managed.

Table 3. Pearson's correlation coefficients between XW incidence and covariates used for the African Great Lakes Region map, ordered from highest positive to high negative.

\begin{tabular}{llcc}
\hline $\begin{array}{l}\text { Variable } \\
\text { code }\end{array}$ & Variable name & $\begin{array}{c}\text { Pearson correlation } \\
\text { coefficient }(\mathbf{r})\end{array}$ & p-value \\
\hline Precsq & Precipitation squared & 0.41 & $2.2 \mathrm{e}-16$ \\
Prec & Annual precipitation $(\mathrm{mm})$ & 0.40 & $2.2 \mathrm{e}-16$ \\
Alt & Altitude above sea level $(\mathrm{m})$ & 0.14 & $2.2 \mathrm{e}-16$ \\
Precmin & Precipitation driest month $(\mathrm{mm})$ & 0.09 & $1.6 \mathrm{e}-10$ \\
Veg & Vegetation cover & 0.09 & $6.9 \mathrm{e}-10$ \\
Abb & Distribution of ABB banana types & 0.03 & 0.035 \\
Market & Market access $(\mathrm{hr})$ & 0.02 & 0.142 \\
Vegsq & Vegetation cover squared & 0.02 & 0.112 \\
Lat & Latitude & -0.09 & $2.8 \mathrm{e}-09$ \\
Tempmin & Mean temperature coldest month $\left({ }^{\circ} \mathrm{C}\right)$ & -0.10 & $2.3 \mathrm{e}-11$ \\
Tempsq & Temperature squared & -0.14 & $2.2 \mathrm{e}-16$ \\
Temp & Mean annual temperature $\left({ }^{\circ} \mathrm{C}\right)$ & -0.15 & $2.2 \mathrm{e}-16$ \\
Precvar & Precipitation seasonality $(-)$ & -0.17 & $2.2 \mathrm{e}-16$ \\
Tempvar & Temperature seasonality & -0.18 & $2.2 \mathrm{e}-16$ \\
Lon & Longitude & -0.22 & $2.2 \mathrm{e}-16$ \\
Man & Management Factor $(-)$ & -0.35 & $2.2 \mathrm{e}-16$ \\
\hline
\end{tabular}

\subsubsection{Regression analysis and spatial interpolation}

The deviance of the regression model was $25.9 \%$ smaller than the deviance of the null model, which indicates the covariates (S1 Appendix) improved the goodness of fit of the model and explain a larger part of the variation than the null model. The covariates management ('man'), precipitation seasonality ('precvar'), precipitation in the driest month ('precmin') and precipitation ('prec') (S1 Appendix) had relatively high absolute values, just like the correlation values (Table 3). Similar to observations with the correlations, this suggests that the management and the precipitation related covariates had the highest contribution to the observed variation in the model, thus XW occurrence. A shift in the sign for 'prec' and relative importance of covariates is observed in the regression coefficients (S1 Appendix) in comparison with correlation values (cf. Table 3). These changes may be explained by the fact that the covariates are themselves correlated, which is very much the case between 'prec' and 'precsq' with a correlation efficient close to 1 . In the regression model all 
covariates and interactions are lumped together in multivariate model, whereas the correlations are univariate. In the multivariate regression model the contribution of a specific covariate may entirely be covered by another one, as is probably the case for 'prec'. With the final regression model a regression map was calculated (Fig. 5a).
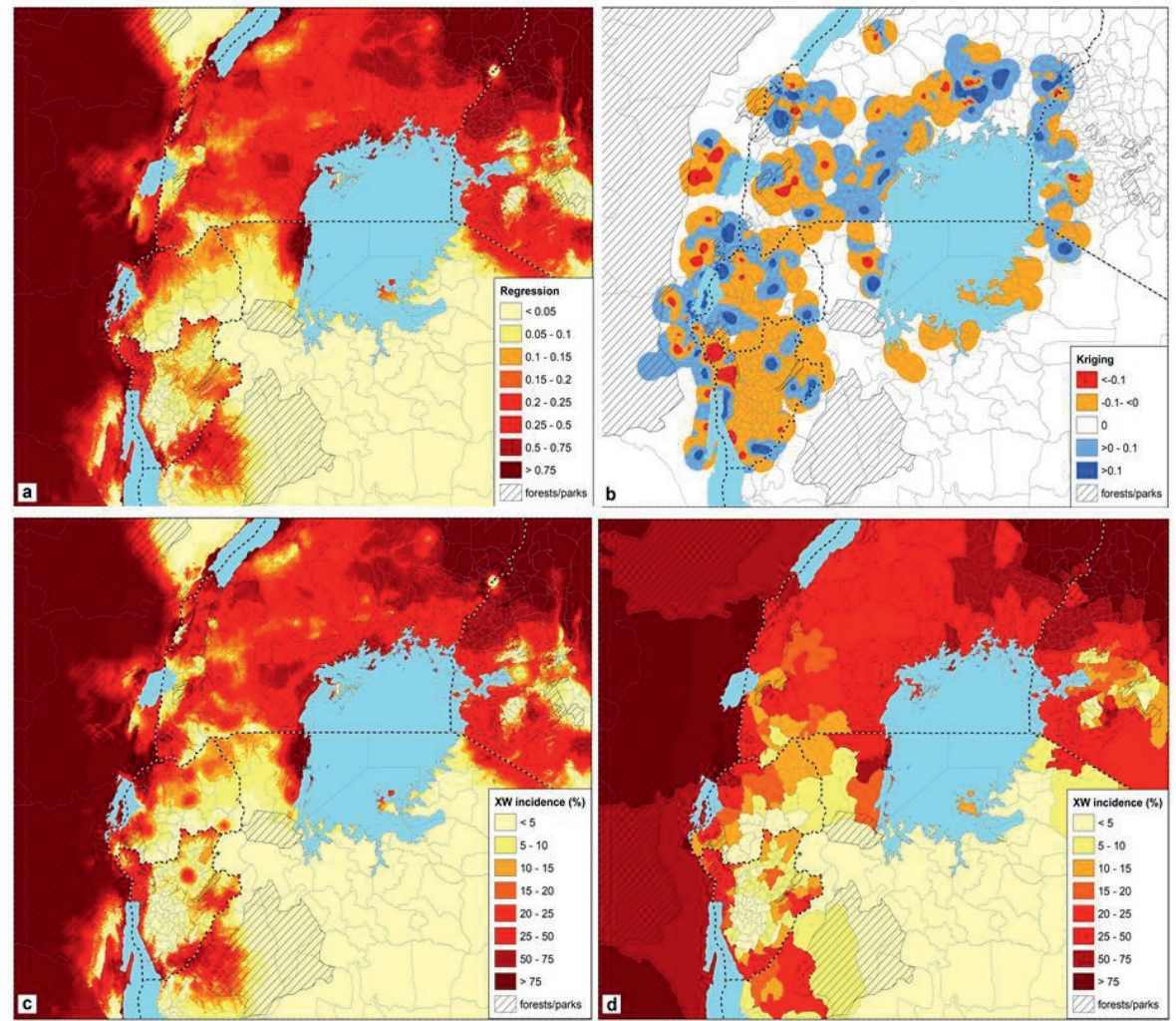

Figure 5. The XW incidence in the AGLR (c) is the sum of the regression prediction map (a) and kriging prediction map (b) and is aggregated by administrative boundaries (d). Large lakes are shaded blue. Areas deemed unsuitable for banana production, above $2500 \mathrm{~m}$, forests and or national parks are denoted by black stripes/ dashed lines and correspond to masked areas.

The kriging prediction map was calculated from the regression residuals. First a semivariogram was calculated (S2 Appendix). It is a near nugget variogram, meaning that there is little spatial autocorrelation between residuals. With the semivariogram a kriging prediction map was calculated (Fig. 5b). The map consists of different colour shades around the samples representing relatively small positive or negative prediction values. In the blue areas the sample kriging prediction values were higher than the regression model predictions (i.e. $>0$ ) whereas in the red areas the values were lower (i.e. $<0$ ). The kriging prediction value in most parts of the study area is 
zero, the average value of the residuals, i.e. the kriging predictions were the same as the regression predictions.

\subsubsection{XW incidence map of the African Great Lakes region}

The XW incidence map of the East African Great Lakes region (Fig. 5c) is the sum of the regression predictions (Fig. 5a) and the kriging predictions (Fig. 5b). The areas with black stripes/ dashed lines correspond to masked areas, where the altitude is above $2500 \mathrm{~m}$, forests or national parks and deemed unsuitable for banana production. The resulting high-resolution map had a cell size of approximately $1 \mathrm{~km}$, which may be too detailed and difficult to translate into clear-cut policy decisions or recommendations. Therefore, an aggregated map showing the XW incidence per district was created by calculating the average value for all cells in a district (Fig. $5 \mathrm{~d}$ ).

Both, the high resolution and aggregated XW incidence maps strongly resemble the regression map as the influence of the kriging is limited and local. The maps show that the risk XW spreads beyond the original data points (Fig. 2) given the biophysical conditions and management is high. The disease has a high likelihood of being in all districts of Uganda and eastern DR Congo. The eastern part of DR Congo is a potential large hotspot with high XW occurrence. Uganda has a moderate to high XW occurrence/incidence. Clusters of potential XW hotspots were also visible in the Kagera region of north-western Tanzania, western parts of Burundi and Rwanda, southern Burundi and in western Kenya at the border with Uganda. Large portions of Burundi, Rwanda and the banana producing zones in Tanzania, have low levels of or no likelihood of appearance of XW. However, large portions of the survey regions were devoid of data (as surveys did not cover all banana production regions), though could potentially be having the disease.

\subsubsection{XW infection risk in tropical Africa}

The XW infection risk for all banana production zones in tropical Africa derived from expert developed covariates (Fig. 6) shows one zone in Tanzania, two zones in Ethiopia and the infected zones in the AGLR to have a very high risk ( $>4.5)$ due to the presence of the disease in these zones. A high-risk score of 2.1-4.5 was observed for one production zone in Mozambique, a large zone stretching from north easterncentral DR Congo, a zone in northern Ethiopia, zones in Kenya and Tanzania. Production zones in Egypt, Sudan, South Africa, Guinea, Togo, Ghana and Cote d'Ivoire had the least risk to XW infection. 


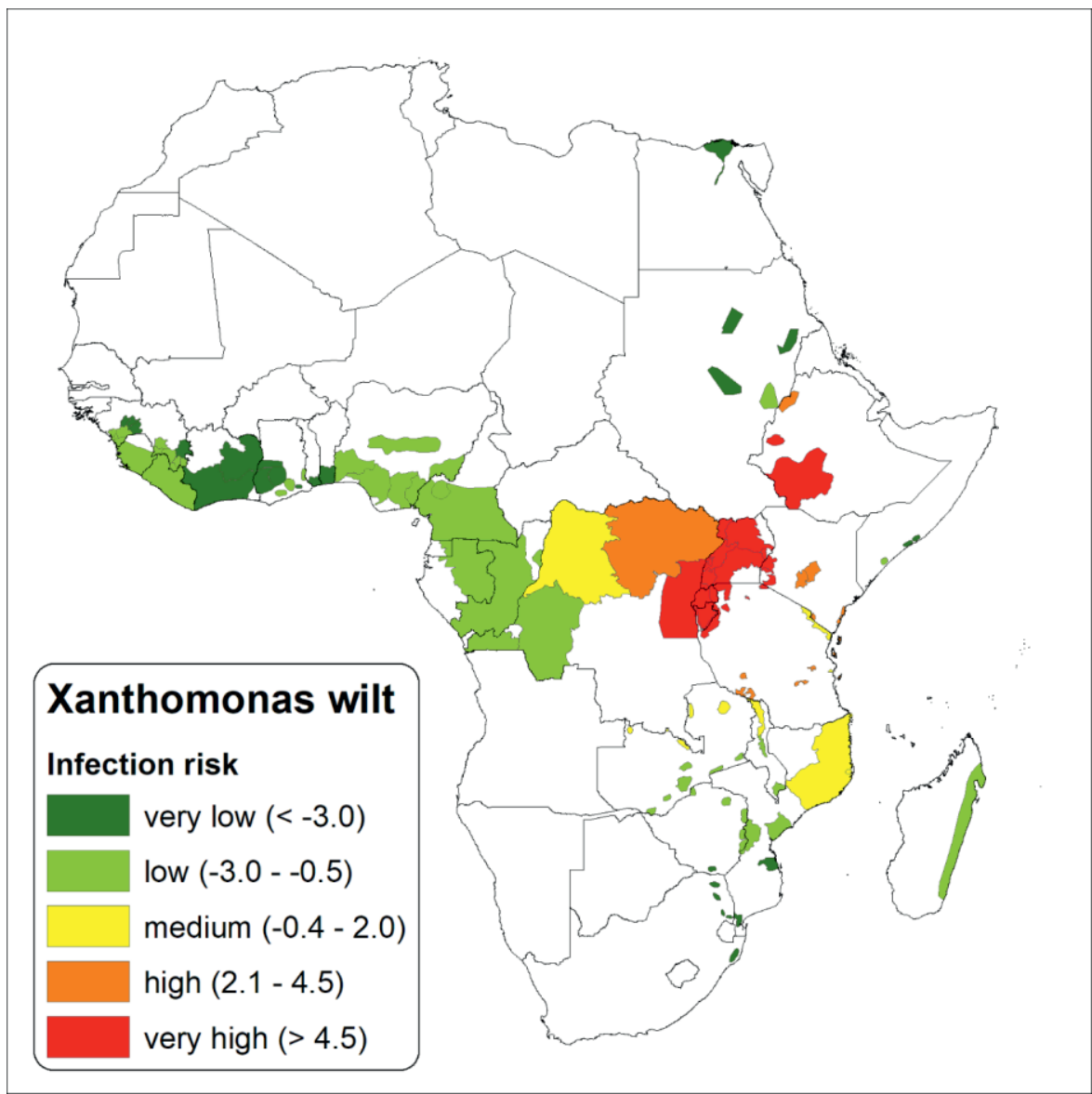

Figure 6. Infection risk of Xanthomonas wilt in tropical Africa developed using five expert generated covariates i.e. banana genotype, connectivity to disease hotspots, trade with an infected zone or country, precipitation and distance from a hotspot.

Banana genotype effects on the landscape risk of XW were strong in Mozambique and parts of the AGLR (Fig. 7). Connectivity of landscapes and inter country trade also had strong contributions to the XW risk in the AGLR. Presence of the ABBgenotypes that are prone to insect-mediated infections, connectivity to a hotspot, and trade increase the risk of exposure to XW disease. Risk variability in the western part of Africa was mainly influenced by the distance from the hotspots and the level of precipitation (Fig. 7). A long distance from the hot spot(s) and a low precipitation is associated with a lower risk. Risk in the northern parts of Africa were mainly influenced by the low amounts of precipitation. 


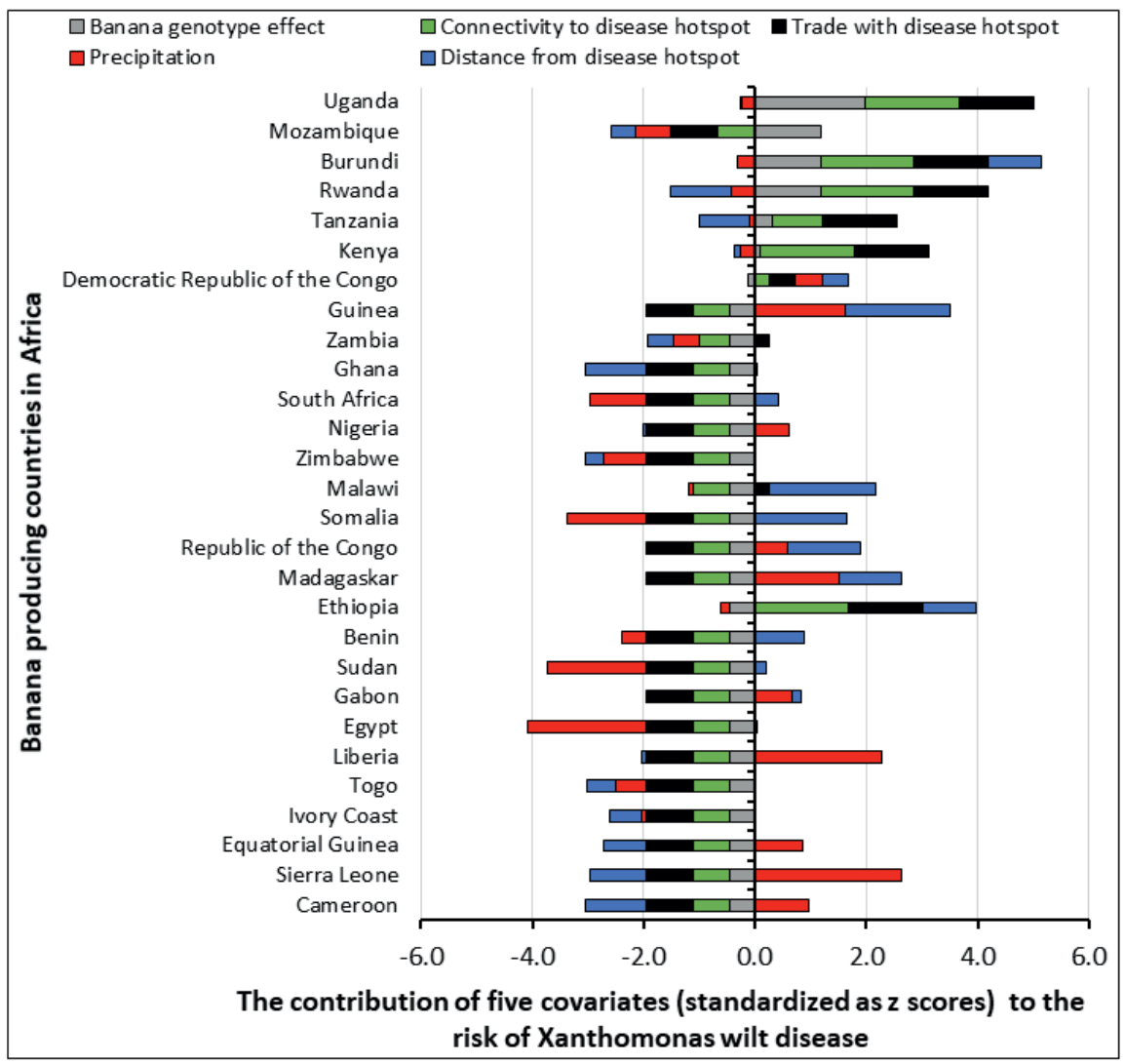

Figure 7. The contribution of five expert developed covariates (i.e. trade with a disease hotspot, connectivity to a disease hotspot, precipitation, distance from a disease hotspot and banana genotype composition) to the Xanthomonas wilt disease risk levels of different countries that grow banana in Africa. Covariate scores have been standardized as $Z$ scores.

\subsection{Discussion}

Xanthomonas wilt disease of banana has rapidly spread across the AGLR and the plantain belt of central and west Africa is currently at risk. This study developed risk maps showing the aggregated spatial XW disease distribution and hotspots in the $A G L R$, and vulnerable landscapes across African banana and plantain production zones (Figs 5 and 6). 


\subsubsection{XW occurrence and incidence in endemic zones of the African Great Lakes region}

In the endemic zones of the AGLR the occurrence and incidence of the XW disease was largely explained by precipitation and management (cf. Table 3, S1 Appendix). The occurrence of XW increased with precipitation and declined with increasing level of disease/banana management.

High precipitation offers a conducive environment for both the pathogen (Xanthomonas campestris pv. musacearum (Xcm)) and the host (Agrios, 2005). Higher XW severity and incidence has often been reported on farms during the rainy season in contrast to the drier seasons (Biruma et al., 2007; Tripathi et al., 2009). Using Maxent and regression, (Shimwela et al., 2017) also reported precipitation to be positively correlated to $\mathrm{XW}$ and to predominantly explain $\mathrm{XW}$ development in Tanzania. Rainfall and water availability can affect the survival, vigor, multiplication, spore production, inoculum dispersion, spore germination and penetration of a pathogen (Hirano, 2000; Agrios, 2005; Kang et al., 2010; Aung et al., 2018).

A humid microclimate within the crop can result in stomatal opening allowing microbes to enter the plant apoplast (Aung et al., 2018) and also modulate bacterial population and disease incidence (Mina and Sinha, 2008; Xin et al., 2016; Aung et al., 2018). Xcm bacteria are in the group of proteobacteria, that are sensitive to desiccation (Saddler and Bradbury, 2005; Taketani et al., 2017) and thus likely to be favored by high humidity in plant tissues. Results from (Ochola et al., 2014) show banana plants that receive an adlib supply of water to be more susceptible than those that received a moderate water stress, and that banana plants tended to remain in a latent state when moisture in the soil was deficient. High humidity has been associated with suppression of R gene mediated Hypersensitive Response that involves rapid plant cell death at point of infection in some plant species (Wang et al., 2005), though not yet investigated or reported for $\mathrm{Xcm}$.

Shimwela et al. (2017) suggests the short distance spread of XW causing bacteria through rain splashes as the possible explanation for the higher correlation of XW infections to high rainfall or the rainy season. Infections through rain splashes would however be feasible in the presence of wounds on healthy plants and bacterial ooze on the ground and inflorescences, that would be most likely associated with farm management practices or pest damage. For example, $\mathrm{Xcm}$ has been reported to infect plants and cause disease when it comes in contact with fresh wounds on the roots or corms resulting from nematode or tool damage (Shehabu et al., 2010; Ocimati et al., 2013b).

Management plays a crucial role at regulating disease pressure on farms. XW is spread over both short (at field level and between close fields and farms) and long 
distances mainly through contaminated farm tools, insect vectors and infected planting material and occasionally through fruit/nectar feeding birds and bats (Blomme et al., 2014). To prevent spread or reduce disease inoculum and incidence, tool sterilization, early male bud removal using forked sticks (prevents insectmediated infections), removal of infected bunches, plants and or mats are recommended. Where these practices have been applied, the disease has been contained or kept to lower levels of severity or incidence (Blomme et al., 2005, 2014, 2017a, b; Kubiriba et al., 2012; Eden-Green, 2004; Biruma et al., 2007). Increased use of farm tools most often without sterilization in the rainy season during field preparation, pruning of leaves to introduce annual crops could also contribute to the higher incidence in the rainy season (Tripathi et al., 2009; Blomme et al., 2014, 2017).

Altitude and temperature have also been reported to influence XW spread, mainly through their effect on insect vector activity. Insect vector numbers and population activity is lower at higher and cooler altitudes resulting in a lower disease occurrence and severity (Shimelash et al., 2008; Rutikanga et al., 2015). But unexpectedly low correlation and regression coefficients were obtained between $\mathrm{XW}$ and temperature and altitude, possibly due to the larger impact of tool-mediated XW spread (captured in the disease management covariate - cf. Table 3, S1 Appendix). More so, the endemic AGLR sites are dominated by the east African highland banana types that are not very prone to insect-mediated $\mathrm{XW}$ transmission due to their persistent male floral bracts and flowers (Tripathi et al., 2009).

In the AGLR, multiple disease hotspots were observed in the entire study area (Fig. 5). The eastern part of DR Congo was a large hotspot, while Tanzania had most of its production zones XW free (cf. Fig. 5). The XW status in eastern DR Congo could be attributed to the lower level of control/ management efforts due to a weaker extension support system. A recent study in eastern DR Congo reported a low adoption of XW management practices, while only $32.3 \%$ of farmers had accessed some training on XW management over the past five years (Bioversity International, 2017). The distribution of this training was skewed with some regions having zero access. The eastern DR Congo also has high precipitation that has been shown in this study and studies of Bouwmeester et al. (2016) and Shimwela et al. (2017) to be correlated with high infection levels. In contrast, Rwanda had a strong extension effort, including a mandatory government driven effort to uproot swathes of plantations in disease hotspots in western Rwanda with plans to reintroduce the crop after a few years of fallow (Rutikanga et al., 2016). In contrast, production zones in Tanzania are distant from each other, preventing XW spread.

Clusters of XW hotspots were also visible in the Kagera region of Tanzania, central and eastern regions of Uganda, the western part of Burundi and in the 
western part of Kenya on the border with Uganda. This could be attributed to the rapid rate of spread over short distances (e.g. though contaminated farm tools, insect vectors, small ruminants, infected planting materials and rain splashes/floods).

\subsubsection{XW infection risk in tropical Africa}

Apart from the endemic zones in the AGLR and Ethiopia, northern Mozambique was perceived to be at a very high risk mainly due to the omnipresence in backyards of 'Bluggoe' (Musa ABB type) which is highly susceptible to insect, bird and batvectored transmission. Ocimati et al. (2018), observed a significant association between the presence/absence of the XW-susceptible $A B B$ types with disease incidence on a farm. The ABB banana types have also been blamed for the rapid spread of XW in Uganda (period 2003 till 2006) from the initial point of infection in Luwero district in Central Uganda. Proactive preventive measures in both the southern part of Tanzania and northern part of Mozambique and Malawi will be crucial for preventing a southward spread of the disease. These could include community awareness to improve surveillance and introduction of infected planting materials or fresh products and installation of quarantine measures. Similar measures are also needed to prevent the westward spread of the disease into the Congo basin and the plantain growing belt of west Africa.

\subsubsection{Reflection on the methods}

The surveys carried out in the AGLR were an accurate method of scouting for XW disease. However, their reach was limited by the need of a high financial investment, time constraints and limited access to some of the study locations (leading to convenience sampling). The study shows that geostatistical approaches can overcome the above challenges and use limited surveys or data points to make valid and precise predictions beyond the surveyed areas. Bouwmeester et al. (2016), through cross-validation reported regression kriging to yield unbiased predictions of $\mathrm{XW}$ occurrence. The regression model however suffers some limitations and may not as such capture part of the variation in XW. First, not all underlying processes that cause spatial variation in XW incidence e.g., mode of transmission, distribution of susceptible host types and level of disease management are known or can be effectively represented by covariates in the model. The mode of spread of XW is complex, involving mainly farming tools, insect vector spread and planting materials. Spread through these modes can be minimised through cultural management practices. In the current study, a management covariate based on expert knowledge and available literature was incorporated to capture some of these aspects (cf. Table 
1, Fig. 3). The ABB Musa types are also known to be highly susceptible and a covariate on the distribution of ABB Musa types (cf. Table 1, Fig. 3) was as such incorporated based on expert knowledge and available literature. These covariates based on expert knowledge may suffer from errors due to failure to capture minor details e.g. variations over short distances and a lack appropriate scale but give valid predictions over large geographical scopes. For the Africa-wide risk map, a prediction of infection risk was estimated based on the relationship between XW disease and selected environmental and expert developed covariates because the variation in environmental covariates outside of the AGLR was beyond the scope of the surveys. These covariates could as such suffer from errors and or lack appropriate scale. However, this exercise gives us the first coarse XW disease risk map for the rest of Africa that can offer a platform to pro-actively make decisions and strategies for containing the disease to the currently affected zones.

\subsection{Conclusion}

$\mathrm{XW}$ is spread across most of the AGLR. All banana landscapes in this region are vulnerable. Efforts in the region could focus on managing/reducing the disease and its damage on productivity. Landscapes with high precipitation are hotspots of XW or highly vulnerable to XW infection. Management plays a crucial role on the current $\mathrm{XW}$ incidence and prevalence. Improving extension services is crucial for the management of the disease in the AGLR. Extension efforts should be concentrated to such landscapes to curb or reduce the XW pandemic. Production zones in northern Mozambique and central lowland DR Congo are potential gateways for the spread of XW southwards and eastwards, respectively. Proactive measures are crucial for the prevention of the disease to these production zones. Possible actions could include the institution of quarantine measures and provision of relevant information and training on diseases diagnosis and epidemiology. The integration of expert judgement in development of covariates that are not readily available yet capture underlying processes that cause spatial variation was crucial in improving the regression outcomes.

\subsection{Acknowledgments}

This study was supported by the CGIAR Research Program on Roots, Tubers and Bananas (RTB). We thank the RTB Program Management Unit that supported this study through complementary funding and CGIAR Fund Donors who support RTB 
(www.cgiar.org/who-we-are/cgiar-fund/fund-donors-2). We also extend our gratitude to the different partners that willingly shared their data for this work.

\section{References}

Abele, S., and Pillay, M. (2007). Bacterial wilt and drought stresses in banana production and their impact on economic welfare in Uganda: Implications for banana research in East African highlands. J. Crop Improv. 19, 173-191.

Abele, S., Twine, E., and Legg, C. (2007). Food security in Eastern Africa and the Great Lakes. Crop Crisis Control Project Final Report to USAID; pp. 110.

Agrios, G.N. (2005). Plant diseases caused by fungi. Plant Pathol. 4.

Aung, K., Jiang, Y., He, S.Y. (2018). The role of water in plant-microbe interactions. The Plant J. 93(4), 771-780.

Bioversity International (2017). Xanthomonas wilt of banana in South Kivu, eastern Democratic Republic of Congo. Kampala (Uganda). Pp. 103. ISBN: 978-92-9255-066-0

Biruma, M., Pillay, M., Tripathi, L., Blomme, G., Abele, S., Mwangi, M., ... and Eden-Green, S. (2007). Banana Xanthomonas wilt: a review of the disease, management strategies and future research directions. Afr. J. Biotechnol. 6(8), 953-962.

Blomme, G., Dita, M., Jacobsen, K.S., Pérez Vicente, L., Molina, A., Ocimati, W., ... and Prior, P. (2017a). Bacterial diseases of bananas and enset: Current state of knowledge and integrated approaches toward sustainable management. Front. Plant Sci. 8, 1290.

Blomme, G., Jacobsen, K., Ocimati, W., Beed, F., Ntamwira, J., Sivirihauma, C., ... and Karamura, E. (2014). Fine-tuning banana Xanthomonas wilt control options over the past decade in East and Central Africa, Eur. J. Plant Pathol. 139, 265-281.

Blomme, G., Mukasa, H., Ssekiwoko, F., and Eden-Green, S.J. (2005). On-farm assessment of banana bacterial wilt control options. Afr. Crop Sci. Proceed. 7, 317-320.

Blomme, G., Ocimati, W., Sivirihauma, C., Vutseme, L., Mariamu, B., Kamira, M., ... and Ntamwira, J. (2017b). A control package revolving around the removal of single diseased banana stems is effective for the restoration of Xanthomonas wilt infected fields. Eur. J. Plant Pathol. 1-16. DOI 10.1007/s10658-017-1189-6.

Blomme, G., Ploetz, R., Jones, D., De Langhe, E., Price, N., Gold, C., ... and Buddenhagen, I. (2013). A historical overview of the appearance and spread of Musa pests and pathogens on the African continent: highlighting the importance of clean Musa planting materials and quarantine measures. Ann. Appl. Biol. 162, 4-26.

Bouwmeester, H., Heuvelink, G.B.M., and Stoorvogel, J.J. (2016). Mapping crop diseases using survey data: The case of bacterial wilt in bananas in the East African highlands. Eur. J. Agron. 74, 173-184.

Carter, B.A., Reeder, R., Mgenzi, S.R., Kinyua, Z.M., Mbaka, J.N., Doyle, K., .... and Simth, J.J. (2010). Identification of Xanthomonas vasicola (formerly $X$. campestris pv. musacearum), causative organism of banana Xanthomonas wilt, in Tanzania, Kenya and Burundi. Plant Pathol. 59(2), 403-403.

Desktop ESRI ArcGIS (2014). Release 10.2. 2. Redlands, CA, USA: Environmental Systems Research Institute.

Eden-Green, S. (2004). Focus on bacterial wilt. How can the advance of banana Xanthomonas wilt be halted? InfoMusa. 13, 38-41.

Edmeades, S., Smale, M., Kikulwe, E.M., Nkuba, J., and Byabachwezi, M.S.R. (2007). Characteristics of banana-growing households and banana cultivars in Uganda and 
Tanzania. An Economic Assessment of Banana Genetic Improvement and Innovation in the Lake Victoria Region of Uganda and Tanzania. M. Smale and WK Tushemereirwe, eds. IFPRI Research Report. 155, 49-74.

FAO (2017). FAOSTAT Data: Crops; 2017 http://www.fao.org/faostat/en/\#data/QC (Accessed on: $16^{\text {th }}$ Nov. 2017).

Goovaerts, P. (1997). Geostatistics for Natural Resources Evaluation. Oxford University Press, New York, USA.

Hijmans, R.J. (2017). Geographic Data Analysis and Modeling. [Available at: https://cran.rproject.org/web/packages/raster/raster.pdf].

Hijmans, R.J., Cameron, S.E., Parra, J.L., Jones, P.G., and Jarvis, A. (2005). Very high-resolution interpolated climate surfaces for global land areas. Int. J. Climatol. 25(15), 1965-1978.

Hirano, S.S., and Upper, C.D. (2000). Bacteria in the leaf ecosystem with emphasis on Pseudomonas syringae-a pathogen, ice nucleus, and epiphyte. Microbiol. Mol. Biol. Rev. 64, 624-653.

Hosmer, D.W., and Lemeshow, S. (2000). Special topics. Applied Logistic Regression, Second Edition, pp. 260-351.

Jarvis, A., Reuter, H.I., Nelson, A., and Guevara, E. (2008). Hole-filled seamless SRTM data V4, International Centre for Tropical Agriculture (CIAT). Available from at: http://srtm.csi.cgiar.org.

Kalyebara, M.R., Ragama, P.E., Kikulwe, E., Bagamba, F., Nankinga, K.C., and Tushemereirwe, W.K. (2006). Economic importance of the banana bacterial wilt in Uganda. Afr. Crop Sci. J. 14(2), 93-103.

Kang, W.S., Yun, S.C., and Park, E.W. (2010). Nonlinear regression analysis to determine infection models of Colletotrichum acutatum causing anthracnose of chili pepper using logistic equation. Plant Pathol. J. 26(1), 17-24

Karamura, E.B., Turyagyenda, F.L., Tinzaara, W., Blomme, G., Molina, A., and Markham, R. (2008). Xanthomonas wilt of Bananas in East and Central Africa. Diagnostic and Management Guide, (Kampala, Uganda: Bioversity International, Fountain Publishers).

Kubiriba, J., Karamura, E.B., Jogo, W., Tushemereirwe, W.K., and Tinzaara, W. (2012). Community mobilization: a key to effective control of banana Xanthomonas wilt. J. Dev. Agr. Econ. 4(5), 125-131.

Mina, U., and Sinha, P. (2008). Effects of Climate Change on Plant Pathogens. Environ. News 14(4), 6-10.

Nakato, G.V., Beed, F., Ramathani, I., Rwomushana, I., and Opio, F. (2013). Risk of banana Xanthomonas wilt spread through trade. J. Crop Prot. 2(2), 151-161.

Nakato, G.V., Ocimati, W., Blomme, G., Fiaboe, K.K.M., and Beed, F. (2015). Comparative importance of infection routes for banana Xanthomonas wilt and implications on disease epidemiology and management. Can. J. Plant Pathol. 36(4), 418-427.

Ndungo, V., Eden-Green, S., Blomme, G., Crozier, J., and Smith, J.J. (2006). Presence of banana Xanthomonas wilt (Xanthomonas campestris pv. musacearum) in the Democratic Republic of Congo (DRC). Plant Pathol. 55(2), 294-294.

Ndungo, V., Komi, F., and Mwangi, M. (2008). Banana Xanthomonas wilt in the DR Congo: impact, spread and management. J. Appl. Biosci. 1, 1-7.

Nkuba, J., Tinzaara, W., Night, G., Niko, N., Jogo, W., Ndyetabula, I., ... and Karamura, E. (2015). Adverse impact of banana Xanthomonas wilt on farmers livelihoods in Eastern and Central Africa. Afr. J. Plant Sci. 9(7), 279-286. 
Ochola, D., Ocimati, W., Tinzaara, W., Blomme, G., and Karamura, E. (2014). Interactive effects of fertilizer and inoculum concentration on subsequent development of Xanthomonas wilt in banana. Afr. J. Agr. Res. 9(35), 2727-2735.

Ochola, D., Ocimati, W., Tinzaara, W., Blomme, G., and Karamura, E.B. (2015). Effects of water stress on the development of banana Xanthomonas wilt disease. Plant Pathol. 64(3), 552558.

Ocimati, W., Nakato, G.V., Fiaboe, K.M., Beed, F., and Blomme, G. (2015). Incomplete systemic movement of Xanthomonas campestris pv. musacearum and the occurrence of latent infections in Xanthomonas wilt-infected banana mats. Plant Pathol. 64(1), 81-90.

Ocimati, W., Ssekiwoko, F., Karamura, E., Tinzaara, W., Eden-Green, S., and Blomme, G. (2013a). Systemicity of Xanthomonas campestris pv. musacearum and time to disease expression after inflorescence infection in East African highland and Pisang Awak bananas in Uganda. Plant Pathol. 62(4), 777-785.

Ocimati, W., Ssekiwoko, F., Karamura, E.B., Tinzaara, W., and Blomme, G. (2013b). Does Xanthomonas campestris pv. musacearum colonize banana cord root tissue? Acta Hort. 986, 103-109. Doi: 10.17660/ActaHortic.2013.986.8

Ocimati, W., Were, E., Groot, J.C.J., Tittonell, P., Nakato, V.N., and Blomme, G. (2018). Risks posed by intercrops and weeds as alternative hosts to Xanthomonas campestris pv. musacearum in banana fields. Front. Plant Sci. Doi: 10.3389/fpls.2018.01471

Okech, S.H.O., Gold, C.S., Abele, S., Nankinga, C.M., Wetala, P.W., van Asten, P., ... and Ragama, P. (2004). Agronomic, pests and economic factors influencing sustainability of banana-coffee systems of Western Uganda and potentials for improvement. J. Agr. Sci. 9(1), 437-444.

Pebesma, E.J. (2004). Multivariable geostatistics in S: the gstat package. Comput. Geosci. 30, 683-691.

R Core Team (2017). R: A language and environment for statistical computing. R Foundation for Statistical Computing, Vienna, Austria. URL: https://www.R-project.org/

Reeder, R.H., Muhinyuza, J.B., Opolot, O., Aritua, V., Crozier, J., and Smith, J.J. (2007). Presence of banana bacterial wilt (Xanthomonas campestris pv. musacearum) in Rwanda. Plant Pathol. 56(6), 1038-1038.

Rutikanga, A., Night, G., Tusiime, G., Ocimati, W., and Blomme, G. (2015). Spatial and temporal distribution of insect vectors of Xanthomonas campestris pv. musacearum and their activity across banana cultivars grown in Rwanda. In: Marčić, D., Glavendekić, M. and P. Nicot, (eds.) Proceedings of the 7th Congress on Plant Protection. Plant Protection Society of Serbia, IOBC-EPRS, IOBC-WPRS, Belgrade, pp. 139-153.

Rutikanga, A., Sivirihauma, C., Ocimati, W., Night, G., Murekezi, C., Ndungo, V., ... and Blomme, G. (2016). Breaking the cycle of Xanthomonas campestris pv. musacearum in infected fields through the cultivation of annual crops and disease control in adjacent fields. $J$. Phytopathol. 164(9), 659-670.

Saddler, G.S., and Bradbury, J.F. (2005). Xanthomonadales ord. nov. Bergey's Manual of Systematic Bacteriology XIV(III), 63-122.

Shehabu, M., Addis, T., Mekonen, S., De Waele, D., and Blomme, G. (2010). Nematode infection predisposes banana to soil-borne Xanthomonas campestris pv. musacearum transmission. Tree For. Sci. Biotechnol. 4, 63-64.

Shimelash, D., Alemu, T., Addis, T., Turyagyenda, F.L., and Blomme, G. (2008). Banana Xanthomonas wilt in Ethiopia: occurrence and insect vector transmission. Afr. Crop Sci. J. $16,75-87$. 
Shimwela, M.M., Blackburn, J.K., Jones, J.B., Nkuba, J., Narouei-Khandan, H.A., Ploetz, R., ... and van Bruggen, A.H.C. (2017). Local and regional spread of banana Xanthomonas wilt (BXW) in space and time in Kagera, Tanzania. Plant Pathol. 66(6), 1003-1014.

Simmonds, N.W. (1966). Bananas. Tropical agricultural series.

Simmonds, N.W. and Shepherd, K. (1955). The taxonomy and origins of the cultivated bananas. Bot. J. Linn. Soc. 55(359), 302-312.

Ssekiwoko, F., Tushemereirwe, W.K., Batte, M., Ragama, P.E., and Kumakech, A. (2006). Reaction of banana germplasm to inoculation with Xanthomonas campestris pv. musacearum. Afr. Crop Sci. J. 14(2).

Taketani, R.G., Lanconi, M.D., Kavamura, V.N., Durrer, A., Andreote, F.D., and Melo, I.S. (2017). Dry season constrains bacterial phylogenetic diversity in a semi-arid rhizosphere system. Microb. Ecol. 73, 153-161.

Tinzaara, W., Gold, C.S., Ssekiwoko, F., Bandyopadhyay, R., Abera, A., and Eden-Green, S.J. (2006). Role of insects in the transmission of banana bacterial wilt. Afr. Crop Sci. J. 14(2), 105-110.

Tinzaara, W., Karamura, E.B., Blomme, G., Jogo, W., Ocimati, W., Rietveld A., ... and Opio, F. (2013). Why sustainable management of Xanthomonas wilt of banana in east and central Africa has been elusive. Acta Hort. 986, 157-164.

Tripathi, L., Mwangi, M., Abele, S., Aritua, V., Tushemereirwe, W.K., and Bandyopadhyay, R. (2009). Xanthomonas wilt: a threat to banana production in East and Central Africa. Plant Dis. 93(5), 440-451.

Tushemereirwe, W., Kangire, A., Ssekiwoko, F., Offord, L.C., Crozier, J., Boa, E., ... and Smith, J.J. (2004). First report of Xanthomonas campestris pv. musacearum on banana in Uganda. Plant Pathol. 53(6), 802-802.

Tushemereirwe, W.K., Okaasai, O.O., Kubiriba, J., Nankinga, C., Muhangi, J., Odoi, N. ... and Opio, F. (2006). Status of banana bacterial wilt in Uganda. Afr. Crop Sci. J. 14(2), 73-82.

Wang, C., Cai, X., and Zheng, Z. (2005). High humidity represses Cf-4/Avr4-and Cf-9/Avr9dependent hypersensitive cell death and defence gene expression. Planta 222(6), 947956.

Webster, R., and Oliver, M.A. (2007). Geostatistics for Environmental Scientists, $2^{\text {nd }}$ ed. John Wiley \& Sons Ltd, Chichester, UK.

Xin, X.F., Nomura, K., Aung, K., Velasquez, AC, Yao J, Boutrot F, ... and He, S.Y. (2016). Bacteria establish an aqueous living space in plants crucial for virulence. Nature, 539: 524-529.

Yirgou, D., and Bradbury, J.F. (1974). A note on wilt of banana caused by the enset wilt organism Xanthomonas musacearum. East Afr. Agr. For. J. 40(1), 111-114.

You, L., Wood-Sichra, U., Fritz, S., Guo, Z., See, L., and Koo, J. (2017). Spatial Production Allocation Model (SPAM) 2005 v3.2. [Available at: http://mapspam.info]. 


\section{Supporting information}

S1 Appendix. Estimates and standard errors of coefficients of the logistic regression model. Interactions are indicated with the ':' sign.

\begin{tabular}{|c|c|c|}
\hline Term & Estimate & Std. Error \\
\hline (Intercept) & $-1.44 \mathrm{E}+02$ & $6.56 \mathrm{E}+01$ \\
\hline Lon & $3.09 E-05$ & $1.86 \mathrm{E}-05$ \\
\hline Lat & $-7.65 E-05$ & $4.79 E-05$ \\
\hline Alt & $6.41 \mathrm{E}-02$ & $2.03 E-02$ \\
\hline Prec & $-9.08 \mathrm{E}-02$ & $2.73 \mathrm{E}-02$ \\
\hline Precsq & $3.97 E-05$ & $1.08 \mathrm{E}-05$ \\
\hline Precmin & $1.08 \mathrm{E}-01$ & $3.13 \mathrm{E}-01$ \\
\hline Precvar & $3.31 \mathrm{E}-01$ & 7.17E-02 \\
\hline Tempsq & $2.65 \mathrm{E}-03$ & $7.75 \mathrm{E}-04$ \\
\hline Market & $-6.24 \mathrm{E}-04$ & $3.51 \mathrm{E}-04$ \\
\hline Vegsq & $-5.09 E-05$ & $2.16 \mathrm{E}-05$ \\
\hline Man & $2.29 \mathrm{E}-01$ & $1.88 \mathrm{E}-01$ \\
\hline Ion:lat & $1.40 \mathrm{E}-11$ & $5.24 \mathrm{E}-12$ \\
\hline lon:alt & $-1.18 \mathrm{E}-08$ & 6.49E-09 \\
\hline Ion:tempsq & $-4.45 \mathrm{E}-10$ & $2.47 \mathrm{E}-10$ \\
\hline Ion:tempvar & $1.10 \mathrm{E}-08$ & $5.23 E-09$ \\
\hline lat:alt & $5.73 \mathrm{E}-08$ & $1.10 \mathrm{E}-08$ \\
\hline lat:prec & $-1.59 E-07$ & $5.08 \mathrm{E}-08$ \\
\hline lat:precsq & $6.17 \mathrm{E}-11$ & $2.03 \mathrm{E}-11$ \\
\hline lat:precmin & $-5.28 \mathrm{E}-07$ & $9.55 \mathrm{E}-08$ \\
\hline lat:precvar & $-2.17 \mathrm{E}-07$ & $1.12 \mathrm{E}-07$ \\
\hline lat:tempsq & $2.19 \mathrm{E}-09$ & $4.14 \mathrm{E}-10$ \\
\hline lat:tempvar & $-2.03 E-08$ & $6.90 \mathrm{E}-09$ \\
\hline alt:precmin & $-2.34 \mathrm{E}-04$ & $7.15 \mathrm{E}-05$ \\
\hline alt:tempvar & $-2.05 \mathrm{E}-05$ & $4.83 \mathrm{E}-06$ \\
\hline alt:vegsq & $3.68 \mathrm{E}-08$ & $1.47 \mathrm{E}-08$ \\
\hline alt:man & $-1.13 \mathrm{E}-04$ & 4.01E-05 \\
\hline prec:precmin & $9.12 \mathrm{E}-04$ & $3.35 \mathrm{E}-04$ \\
\hline prec:tempvar & $3.75 \mathrm{E}-05$ & $2.51 \mathrm{E}-05$ \\
\hline prec:man & $5.82 \mathrm{E}-04$ & $2.05 E-04$ \\
\hline
\end{tabular}




\begin{tabular}{|l|r|r|}
\hline Term & Estimate & Std. Error \\
\hline recsq:precmin & $-3.14 \mathrm{E}-07$ & $1.28 \mathrm{E}-07$ \\
\hline precsq:tempvar & $-1.95 \mathrm{E}-08$ & $9.80 \mathrm{E}-09$ \\
\hline precsq:man & $-2.57 \mathrm{E}-07$ & $8.13 \mathrm{E}-08$ \\
\hline precmin:tempsq & $-9.79 \mathrm{E}-06$ & $2.70 \mathrm{E}-06$ \\
\hline precmin:man & $-8.26 \mathrm{E}-04$ & $4.45 \mathrm{E}-04$ \\
\hline precvar:tempvar & $-1.31 \mathrm{E}-04$ & $7.73 \mathrm{E}-05$ \\
\hline precvar:man & $-4.21 \mathrm{E}-03$ & $8.43 \mathrm{E}-04$ \\
\hline tempsq:tempvar & $-7.82 \mathrm{E}-07$ & $1.87 \mathrm{E}-07$ \\
\hline tempsq:man & $-7.09 \mathrm{E}-06$ & $1.66 \mathrm{E}-06$ \\
\hline man:tempvar & $2.49 \mathrm{E}-04$ & $4.12 \mathrm{E}-05$ \\
\hline
\end{tabular}

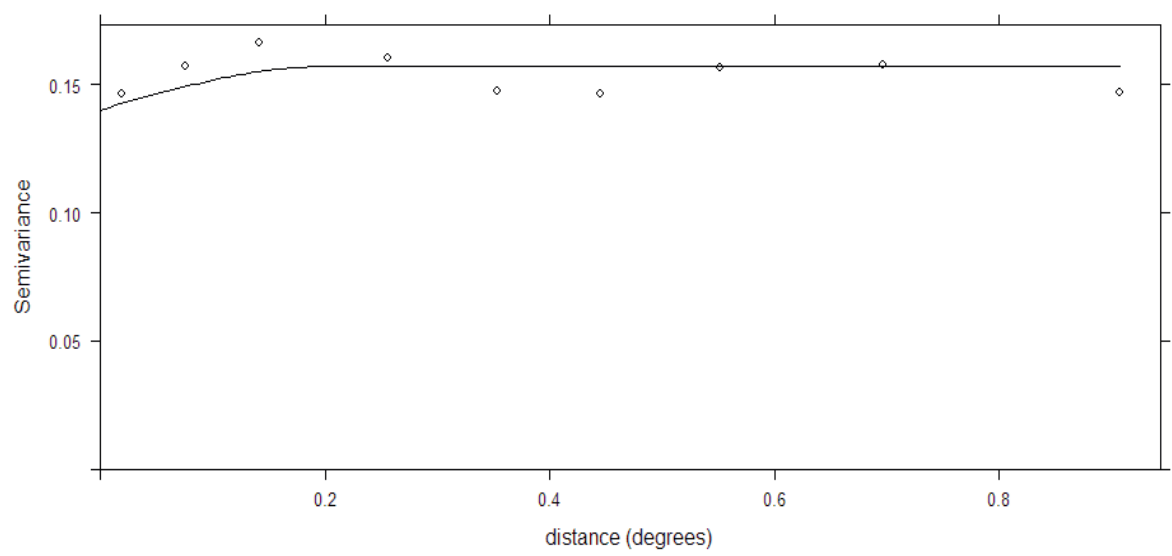

S2 Appendix. The semivariogram of the regression residuals (nugget $=0.14$, sill $=0.17$, range $=0.2$ degrees). The line depicts the variogram model, with little spatial autocorrelation until a distance of 0.2 degrees where it flattens out. 


\section{Chapter 5}

Field level risk of Xanthomonas wilt - an assessment of the potential role of alternative host plants

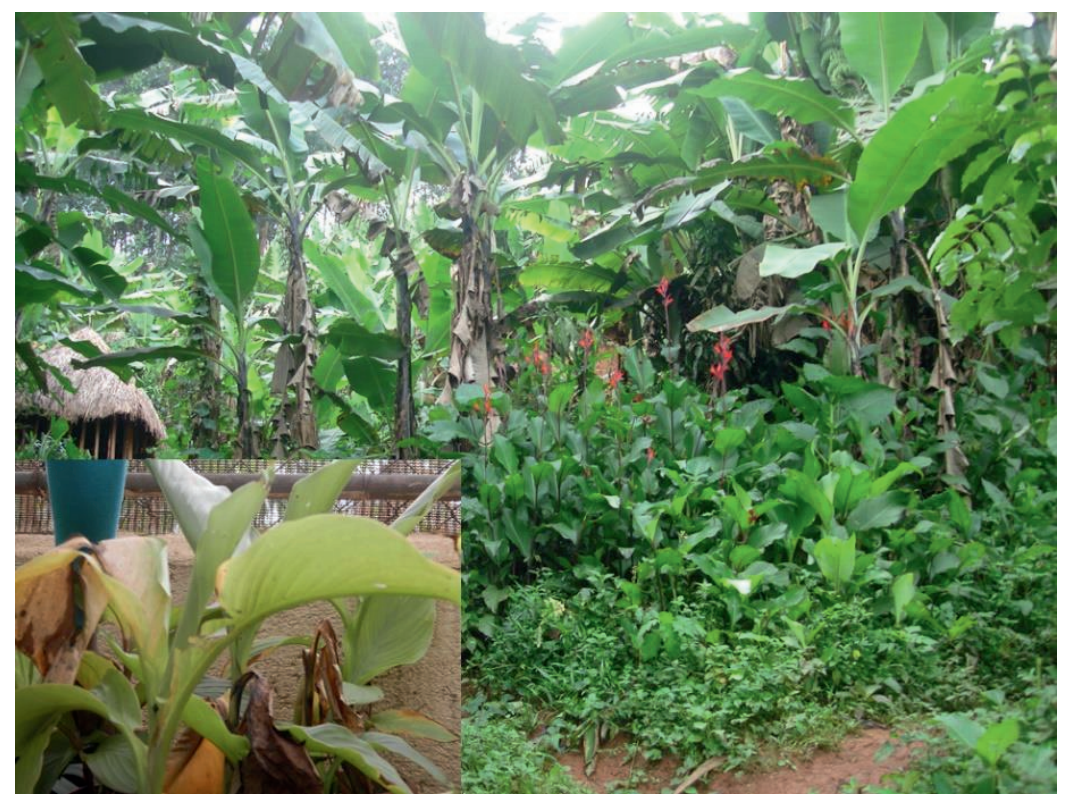

\section{Published as:}

Ocimati, W., Were, E., Groot, J.C., Tittonell, P., Nakato, G.V. and Blomme, G., 2018. Risks posed by intercrops and weeds as alternative hosts to Xanthomonas campestris pv. musacearum in banana fields. Front. Plant Sci. 9, 1471 


\section{Abstract}

Alternative host plants are important in the survival and perpetuation of several crop pathogens and have been suspected to play a role in the survival of Xanthomonas campestris pv. musacearum $(\mathrm{Xcm})$ and perpetuation of Xanthomonas wilt (XW) disease of banana and enset. This study determined the potential risk posed by two weeds (Canna spp. and wild sorghum) and common banana intercrops (maize, millet, sorghum, taro and sugarcane) as alternative hosts to $\mathrm{Xcm}$. The study employed screenhouse experiments, laboratory procedures and diagnosis of banana fields in $\mathrm{XW}$-affected landscapes. Typical XW symptoms were only observed in artificially inoculated Canna sp., with an incidence of $96 \%$. Leaf lesions characteristic of xanthomonads occurred on millet (50\%) and sorghum (35\%), though the plants recovered. No symptoms occurred in maize, sugarcane, taro or wild sorghum. However, Xcm was recovered from all these plant species, with higher recoveries in Canna sp. (47\%), millet (27\%), sugarcane (27\%) and wild sorghum (25\%). Only isolates recovered from Canna sp., millet, sorghum and wild sorghum caused disease in banana plantlets. The presence and incidence of XW on-farm was positively associated with the presence of susceptible ABB Musa genotypes and negatively with number of banana cultivars on farm and household access to training on XW management. Only $0.02 \%$ of field sampled Canna spp. plants had Xcm. Risk posed by Canna spp. on-farm could be limited to tool transmission as it has persistent floral bracts that prevent insect-mediated infections. Given the high susceptibility, perennial nature and propagation through rhizomes of Canna sp., it could pose a moderate-high risk, thus warranting some attention in the management of $\mathrm{XW}$ disease. Sugarcane could offer a low-moderate risk due to its perennial nature and propagation through rhizomes while risk from maize, millet and sorghum was deemed zero-low due to their annual nature, wind-mediated mode of pollination and propagation through seed. Understanding the interactions of a crop pathogen with other plants is thus important when diversifying agroecosystems. The study findings also suggest other factors such as cultivar composition and management of the disease at farm and landscape level to be important in the perpetuation of XW disease.

Key words: Alternative host, banana, Canna spp., maize, millet, sorghum, Xanthomonas campestris pv. musacearum, Xanthomonas wilt 


\subsection{Introduction}

Xanthomonas wilt (XW) disease of banana (Musa spp.) and enset (Ensete ventricosum) caused by the bacteria Xanthomonas campestris pv. musacearum $(X \mathrm{~cm})$ has severely affected the production of banana and plantain in the east and central African (ECA) region. Host range studies have shown all the edible Musa spp. and enset cultivars in this region to be susceptible, though the level of susceptibility has been observed to vary with genotypes (Ssekiwoko et al., 2006a; Michael et al., 2006; Kebede and Gemmeda, 2017). Only Musa balbisiana, a wild Musa sp., has been reported to be resistant (Ssekiwoko et al., 2006a). The potential inoculum sources of $\mathrm{Xcm}$ have been reported to include infected plants, infected planting materials, infected plant residues, traded banana products (fruits and leaves) and contaminated soils and water (Eden-Green, 2004; Karamura et al., 2008; Nakato et al., 2014). Efforts to manage XW disease in ECA have mainly focused on the banana crop, yet banana grows in association with other crop and weed species. Weed fallows and some food and/or fodder crops such as common beans (Phaseolus vulgaris), cassava (Manhot esculent), maize (Zea mays), taro (Colocasse spp.), sweet potato (Ipomea batatas), sorghum (Sorghum bicolor), tobacco (Nicotiana tobacum) and Napier grass (Pennisetum purpureum) have also been recommended for breaking the cycle of the banana Xanthomonas wilt (Mwangi et al. 2006). Some of the weeds and crops in association with banana could potentially influence the XW dynamics either through inhibiting spread and survivial of the pathogen or supporting pathogen survival and perpetuation of the disease. Understanding the nature of interactions of plants in the survival of pathogens and disease dynamics are thus important. Field level crop diversification of agroecosystems has been reported as a promising strategy for suppressing pests and diseases (Letourneau et al., 2011; Boudreau, 2013; Poeydebat et al., 2017). Intercrops affect disease dynamics by altering wind, rain, and vector dispersal; modifying the microclimate (mainly temperature and moisture); altering host morphology and physiology; and directly inhibiting the pathogen (Boudreau, 2013). In contrast, other plants in an agroecosystem could exacerbate and perpetuate the diseases of certain crops, especially when acting as alternative host plants.

Alternative hosts have been reported to play a crucial role in the perpetuation of several diseases in different crop species. For example, the Indian tomato leaf curl virus was identified in 13 common weed species through symptoms and TAS-ELISA and was effectively transmitted by Bemisia tabaci from these weeds to tomato (Ramappa et al., 1998). Similarly, Ocimati et al. (2017) reported sorghum to be affected by Pythium spp. causing root rots in beans, thus exacerbating the bean root 
rot problem in southwestern Uganda. In banana, $R$. syzygii subsp. celebesensis strains that cause banana blood disease, a wilt of banana, is associated with some Heliconia species (Elphinstone, 2005; Blomme et al., 2017a). Ralstonia solanacearum that causes Moko/Bugtok wilt in banana has a wide host range (Belalcazar et al., 2004) and was also isolated from Heliconia species in the Coto valley virgin forests of southwest Costa Rica, leading to the suggestion that Moko could have originally been endemic in these rainforests (Sequeira and Averre, 1961). R. solanacearum strains causing Moko/Bugtok disease are associated with Solanaceaous hosts thus compromising the efficiency of fallow periods in disease management. Therefore, the removal of weeds that are alternative hosts is recommended (Romo et al., 2012).

Pathogenic Xanthomonas species have also been reported in some crops such as maize (De Cleene, 2008), sugarcane (Saccharum spp.) (Destefano et al., 2003), sorghum (Reddy, 2012), common beans (Mkandawire et al., 2004; Todorović et al., 2008) and sweet potato (Hernandez and Trujillo, 1990), all of which are commonly grown in the banana-based systems of ECA. Xcm has also been shown to be phylogenetically similar to Xanthomonas vasicola pv. vasculorum (Xvv) that is pathogenic to sorghum, maize and sugarcane (Aritua et al., 2008; Lang et al., 2017). A number of studies have been conducted to understand how other plant species (weeds and cultivated crops) in the environment of banana and enset interact with Xcm (e.g. Yirgou and Bradbury, 1974; Ashagari, 1985; Ssekiwoko et al., 2006b; Aritua et al., 2008; Karamura et al., 2015; Chala et al., 2016). Whereas studies consistently report Canna spp., a common weed, to develop XW characteristic symptoms similar to those in banana after inoculation with Xcm (Ssekiwoko et al., 2006b; Chala et al., 2016), they give a mixed and less clear picture regarding the interaction of $X \mathrm{~cm}$ with the cereals, especially with maize.

Yirgou and Bradbury (1974), Ashagari (1985) and Ssekiwoko et al. (2006b) observed no symptoms in cereals after inoculation with $\mathrm{Xcm}$ isolates from enset and banana. In contrast, Aritua et al. (2008) reported a hypersensitive response (pathogenic reaction) at the inoculation points of maize while Karamura et al. (2015) reported characteristic Xanthomonas wilt symptoms in sugarcane but not in maize. These two studies were able to isolate $X \mathrm{~cm}$ from the maize plants 5 weeks after the inoculations. Rutikanga et al. (2016) reported the isolation of $X \mathrm{~cm}$ from maize, beans and sweet potato plant parts and soils around these crops, and mixed weed fallow. The most common weed species in the Rutikanga et al. (2016) weed fallow sites included Bidens pilosa L., Tithonia diversifolia (Hemsl.) A Gray, Bothriocline ugandensis (S. Moore) M.G. gilbert, Leonotis nepetifolia (L.) R Br, Coleus/Plectranthus kilimandschari Gurke ex Engl, Ricinus communis (L.), Crassocephalum vitellium Benth, Canna indica (L.), Galisonga ciliate (Raf.) Blake, 
Comelina diffusa Burm. F. and Crassocephalum montuosum (S. Moore) Milne-Redh. Though the Rutikanga et al. (2016) isolates were confirmed to be Xcm with PCR, they did not cause disease when inoculated into tissue cultured banana plantlets.

A more recent study by Chala et al. (2016) using three $\mathrm{Xcm}$ isolates obtained from cultivated enset, wild enset and banana reported typical disease symptoms 2 to 3 weeks after the inoculations with incidences of $40-67 \%$ in maize, $25-50 \%$ in sorghum, $13 \%$ in wild sorghum and $1-17 \%$ in millet (Eleusine coracana). However, some of the above studies did not report re-isolation of $\mathrm{Xcm}$ from these alternative host plants while Koch's postulates were not reported in all the studies. Yet some plant species can act as symptomless carriers or non-hosts of pathogens (Katan, 1971; Schaad and Dianese, 1981; Gitaitis et al. 1998; Fassihiani, 2000). For example, naturally-occurring weeds including Amaranthus sp., Chenopodium album, and aubergines were colonized to various degrees and determined as symptomless carriers of Fusarium oxysporum f. sp. Lycopersici that is pathogenic to tomato (Fassihiani, 2000). In addition to clarifying the above observations, the risk posed by these crop species under on-farm situations also needs to be examined.

The current study built on to the above studies by i) determining the potential risk of selected weeds (Canna spp. and wild sorghum) and common banana intercrops (maize, millet, sorghum, sugarcane and taro (Colocasia esculenta)) to harbour and / or succumb to Xcm in controlled experiments; ii) the potential of Xcm isolates from these putative alternative hosts to re-infect banana plants and iii) the potential importance of the putative alternative hosts in the perpetuation of XW in banana in farmers' fields. Synthesis of these findings will be helpful in informing the management of XW disease on farms in the ECA region.

\subsection{Materials and methods}

This study was conducted through laboratory, screenhouse and field studies. Screenhouse and laboratory studies were conducted at the National Agricultural Research Laboratories (NARL) located at Kawanda in central Uganda in 2015/2016. The screen house and laboratory studies were complemented through farm diagnostic studies in central Uganda, a hot spot for XW disease.

\section{Screenhouse studies}

A total of eight plant species that included five common banana intercrops (maize, millet, sorghum, sugarcane and taro) and two weeds (Canna sp. and wild sorghum (Sorghum versicolor)) previously reported or suspected to harbour or succumb to $\mathrm{Xcm}$ infection under controlled screenhouse conditions were used in this 
experiment. Two months old east African highland (EAHB) banana cv. 'Musakala' (AAA genome) plantlets were used as the positive control. The choice of the banana cultivar to use was based on availability of tissue culture plantlets, as all banana cultivars in the region are susceptible to XW disease following infection by the $\mathrm{Xcm}$ pathogen. For each species, 60 plants were raised from either seed (maize, millet and sorghum); rhizome/corm bits (taro), cuttings (sugarcane), rhizome (Canna spp.), small plantlets (wild sorghum) or tissue culture plantlets (banana). To rule out any latent $\mathrm{Xcm}$-infection in vegetatively propagated plants, cross sections from the stems and or leaves were sampled, total DNA extracted as described by Mahuku (2004) and checked with PCR using Xcm GspDm-specific primers (Adriko et al., 2012). The plants were then grown in small pots ( $3 \mathrm{~L}$ in size) filled $3 / 4$ full with pre-sterilized forest top soil mixed with sand in a ratio of 2:1 over a period of 1-2 months (depending on the crop species) before treatment application. Sand was added to improve drainage and aeration while the plants were regularly watered to provide adequate moisture for growth.

Inoculum preparation: $\mathrm{Xcm}$ for the screenhouse study was isolated from a fresh sample of a banana pseudostem obtained from a plant that had only recently developed XW symptoms (not older than two days) in an infested field at NARL, Kawanda. One gram of the sample was aseptically cut off from the middle and inner portion of the pseudostem tissue and macerated with a mortar and pestle in $3 \mathrm{~mL}$ of sterile distilled water, serially diluted four-fold and $10 \mu \mathrm{L}$ of each dilution plated on Yeast Peptone Glucose Agar (YPGA, Mwangi et al., 2007) media in Petri plates. Plates were sealed and incubated at $28{ }^{\circ} \mathrm{C}$ for a period of 72 hours. Single colonies with $\mathrm{Xcm}$-characteristics (yellow, mucoid and dome shaped) were carefully picked, streaked on fresh media and incubated as above. Resultant colonies were confirmed using Xcm-specific primers (Adriko et al., 2012) using PCR, and a suspension of the bacteria adjusted to $0.5 \mathrm{OD}_{600}\left(\sim 1 \times 10^{8}\right.$ colony forming units) using a Nanodrop spectrophotometer (Thermo Fisher Scientific Inc., Pittsburgh, PA, USA) for the inoculation of plants.

Inoculation of plants: Thirty maize, sorghum, millet, bean, Canna spp. and wild sorghum plants were inoculated after one month from emergence or potting while sugarcane, taro and banana were inoculated at two months after establishment An equal number of plants served as un-inoculated controls. Inoculations were done by injecting $100 \mu \mathrm{L}$ of fresh $\mathrm{Xcm}$ inoculum using a sub-dermal syringe into the stem tissues at $15-20 \mathrm{~cm}$ height. Twelve inoculated plants per species were routinely observed for symptoms typical of XW whereas the remaining 18 plants were routinely sampled for laboratory analysis. An equal number of un-inoculated plants were respectively kept for observation and sampling. The screenhouse plants were 
observed for a 60 days period corresponding to the life span of the annual crops and covering adequately the time period in which XW symptoms in banana plantlets are manifested. Data collected included symptom characteristics, time from inoculation to symptom expression (i.e. incubation period) and symptom incidence. Mean incubation was computed as sum of $\mathrm{XW}$ incubation period for the individual symptomatic plants divided by the total number of symptomatic plants, while incidence was determined as the percentage of plants that showed XW symptoms over the study period.

Replications: The experiment was repeated thrice over the period of the study. Isolates for inoculation of plants in the three screenhouse experiments were obtained from the same field and thus assumed to be homogenous. The Xcm isolates for the first screenhouse experiment could not be used in subsequent experiments due to a possible change in their virulence associated with repeated culturing and long storage in the laboratory (Tripathi Leena., personal communication, 2017).

Sampling of plants: Three inoculated plants per species in the screenhouse were sampled at an interval of 7 days starting at 14 days and ending at 49 days post inoculation for $\mathrm{Xcm}$ isolation in the laboratory. Samples were destructively collected in an aseptic manner by sterilizing knives and gloves with a solution of $15 \%(\mathrm{v} / \mathrm{v})$ sodium hypochloride $(\mathrm{NaOCl})$ between samples to prevent cross contamination. Further precaution was taken to sample the un-inoculated controls first, followed by the potential alternative host species and lastly the already known / susceptible Xcm host (i.e. banana). For each plant species, samples were obtained from the stems/leaves and below ground parts. Samples were stored separately in labelled plastic bags and transferred to the laboratory where they were processed immediately or stored at $4{ }^{\circ} \mathrm{C}$ for later isolation.

\section{Laboratory studies}

Isolation of Xcm: Samples from the field were separately washed in running water, surface sterilized using $15 \% \mathrm{v} / \mathrm{v} \mathrm{NaOCl}$ to eliminate any epiphytes and external $\mathrm{Xcm}$ contamination, rinsed with distilled water to remove excess $\mathrm{NaOCl}$ and blotted dry using paper towels. Approximately $3 \mathrm{~g}$ of each plant part/sample were cut and homogenized with a sterile mortar and pestle in $3 \mathrm{~mL}$ of sterile distilled water. $1 \mathrm{~mL}$ of this homogenate was serially diluted to $10^{-3}$, from which a $20 \mu \mathrm{L}$ aliquot was spread plated on triplicate Petri plates of YPGA- containing antibiotics 5-fluorouracil and cephalexin (Mwangi et al., 2007). Plates were sealed, incubated at $28^{\circ} \mathrm{C}$ for 3 days and scored for presence or absence of colonies with $\mathrm{Xcm}$ characteristics. All $\mathrm{Xcm}$-like colonies were streaked on fresh YPGA media and incubated as above to 
obtain pure cultures and confirmed through PCR using Xcm GspDm-specific primers (Adriko et al., 2012).

Genomic DNA extraction from Xcm and Polymerase Chain Reaction (PCR): Genomic DNA was extracted from Xcm-like colonies as described by Mahuku, (2004). The integrity (concentration and purity) of DNA samples was determined using the NanoDrop 2000C spectrophotometer (Thermo Fisher Scientific Inc., Pittsburgh, PA, USA) and adjusted to $50 \mathrm{ng} / \mu \mathrm{L}$, for PCR. The gDNA extracted from Xcm-like colonies was used as template in a PCR reaction using 265 bp GspDm-specific Xcm primers (Adriko et al., 2012). Amplification reactions were carried out in a $20 \mu \mathrm{L}$ reaction volume with a final concentration of $0.3 \mu \mathrm{M}$ of each of the forward and reverse primers, $1.5 \mathrm{mM} \mathrm{MgCl}_{2}, 0.2 \mu \mathrm{M}$ of each dNTPs (Promega, Madison WI, USA), 1× PCR green buffer, 1 unit of HotStarTaq Plus DNA polymerase (Qiagen, Canada) and $2 \mu \mathrm{L}$ of genomic DNA (50 ng/ $\mu \mathrm{L}$ ). The PCR amplification reactions were performed in the Eppendorf Mastercycler (Eppendorf AG, Hamburg, Germany) using the following program: an initial denaturation at $95^{\circ} \mathrm{C}$ for $3 \mathrm{~min} ; 35$ cycles consisting of $92^{\circ} \mathrm{C}$ for 20 $\mathrm{s}$, annealing at $64^{\circ} \mathrm{C}$ for $15 \mathrm{~s}$, extension at $72^{\circ} \mathrm{C}$ for $15 \mathrm{~s}$; and a single final extension at $72^{\circ} \mathrm{C}$ for $3 \mathrm{~min}$ before cooling and holding at $4^{\circ} \mathrm{C}$. Amplified PCR products were separated by electrophoresis in $1.5 \% \mathrm{w} / \mathrm{v}$ agarose gel in $1 \times$ TAE buffer at $150 \mathrm{~V}$ for $45 \mathrm{~min}$. The gel was stained with ethidium bromide $\left(0.5 \mu \mathrm{g} \mathrm{mL}^{-1}\right)$ and the image captured using the GBOX Syngene gel documentation system (SYNGENE, UK). Samples with a 265-bp amplicon were selected and preserved on $2 \mathrm{~mm}$ glass beads in $80 \% \mathrm{v} / \mathrm{v}$ glycerol at $-80^{\circ} \mathrm{C}$ for further studies.

Koch postulate trials: Koch's postulate trials were conducted to determine if the Xcmlike bacterial isolates recovered from the potential alternative host plants inoculated with $\mathrm{Xcm}$ could cause disease in the original host (banana plantlets). Koch's postulates are a stringent criterion that provides a framework for thinking about the proof of microbial disease causation and are widely used in plant pathology (Liu et al., 2016). The key elements include a specific association of the microbe with the disease state, scientific consistence of microbiological and pathological evidence, isolation of the microbe on culture media, and reproduction of disease following inoculation of the cultured organism into a host. To fulfill Koch's postulate, Xcm-characteristic colonies re-isolated from the alternative host plants in the study that were confirmed positive for Xcm with PCR were sub-cultured and inoculated into 2 months old East African highland banana (cv. 'Musakala') banana plantlets using the procedures described above. Five banana plantlets of the same age, each having a total of four leaves were inoculated per Xcm inoculum source/ isolate. Five banana plantlets inoculated with $\mathrm{Xcm}$ isolated from banana plantlets served as controls. All inoculated banana plantlets were regularly monitored for disease symptoms, time to symptom 
expression and symptom incidence as in the section above. XW severity at a scale of $0-1,0$ being no disease symptom and 1 being the highest severity score, was also assessed for some of the $\mathrm{Xcm}$ isolates used for the Koch postulate trials. The severity $\mathrm{S}$ for a given isolate was assessed as below.

$$
\begin{aligned}
& S=\frac{s P_{1}+s P_{2}+----+s P_{n}}{N p} \\
& s P=\frac{L i}{L N}
\end{aligned}
$$

Where: $\mathrm{S}=$ severity score for a given $\mathrm{Xcm}$ isolate inoculated into a total of "Np" plants; $\quad \mathrm{SP}=\mathrm{XW}$ severity score for a single plant, with the number of plants inoculated with a single isolate varying from " 1 " to " $n$ " plants; $N p=$ total number of plants inoculated with a given $\mathrm{Xcm}$ isolate; $\mathrm{Li}=$ number of symptomatic leaves at the time of data recording; and $\mathrm{LN}=$ the total number of leaves per plant at inoculation.

\section{Assessment of the field risk/relative importance of the potential alternative host plants of Xanthomona campestris pv. musacearum on farm}

The potential risk and relative importance of crops or weeds that either showed XW symptoms in the controlled experiments or from which active $\mathrm{Xcm}$ could be isolated were assessed on-farm through diagnosis of 63 randomly selected banana farms in XW endemic districts (Mukono, Wakiso, Kayunga and Luwero) in central Uganda and expert knowledge. On farms, data was collected on: XW presence and incidence; presence of Canna spp. and wild sorghum in banana fields; and presence of common banana intercrops (maize, millet, sorghum, sugarcane, and taro) in banana fields and or farm. XW incidence on each farm was scored on mat (i.e., an underground banana rhizome from which one or more shoots emerge) basis at a scale of 0 to $100 \%$. Data was also collected on other potential factors that could influence XW presence and incidence, and these included: presence of banana cultivars with $A B B$ genome, the diversity of banana cultivars and presence of agroforestry trees. Banana cultivars with $\mathrm{ABB}$ genome are highly susceptible to insect-mediated XW infections (Tripathi and Tripathi, 2009; Blomme et al., 2017a) whereas, a high diversity of banana cultivars and presence of agroforestry trees were anticipated to cause a dilution effect and reduce insect vector access to the susceptible ABB banana types. XW management practices also play a crucial role in influencing disease presence and incidence on farm. Thus, information on management of banana fields (e.g. weeding, removal of male buds, and removal of excess suckers), the history of $X W$, household access to training on XW management, and key XW cultural control practices applied on farm were also collected using farmer interview schedules. The on-farm studies sought to determine if a cause-effect relationship existed between the presence of the potential alternative host plant(s) of interest as an independent variable and i) 
the presence/absence of $\mathrm{XW}$ and ii) the incidence of $\mathrm{XW}$ on banana farms as response variables. Other possible explanatory variables to the above two response variables assessed on-farm included the time of exposure to $\mathrm{XW}$, key $\mathrm{XW}$ management practices (male bud removal, single diseased stem removal (SDSR), complete banana mat removal (CMU)), number of banana cultivars on farm/field, presence/absence of $A B B$ banana types, presence of agroforestry trees, banana intercropping, access to information on XW and farmer/ household access to training on XW management. During field diagnosis, Canna spp. plants were aseptically sampled for laboratory isolation and identification of $\mathrm{Xcm}$ as described in sections above. Priority was given to sample Canna spp. plants that exhibited suspicious Xanthomonas characteristic wilting symptoms.

Expert knowledge from five scientists with at least seven years of experience on XW epidemiology and management was used to develop XW risk scores varying between 0 (no risk) to 5 (high risk) for the different potential alternative host crops. In addition to the results of the experiments in this study, key plant species characteristics used for assessing the risk from the alternative host plants included their mode of pollination, persistence or non-persistence of floral bracts and male neuter flowers, potential for tool mediated $\mathrm{Xcm}$ spread, mode of reproduction and life span (annual vs. perennial). XW is also spread by insects that visit for pollen and nectar, thus plant species pollinated by insects were deemed a risk to XW spread while banana plants with persistent neuter flower and floral bracts have been found to escape the disease. Plants that reproduce through rhizomes can potentially pass the bacteria or disease to subsequent generations while susceptible perennial plant species are likely to offer a higher risk to the banana crop than the annual crops.

\section{Statistical analysis}

Data were compiled in MS Excel. The GenStat v. 12 statistical software (VSN International Ltd, 2009) was then used to obtain the analysis of variance ANOVA and to separate means (at 5\% Least Significant Difference (LSD)) of the laboratory and screenhouse data. The R-Statistical package (R Core Team, 2013) was used to separately conduct a regression analysis between the response variables and the explanatory variables. A general logistic regression model was used to explore the relationship between the presence/absence of XW on-farm with the above explanatory variables, except the XW management practices and exposure time. XW management practices (SDSR and CMU) were not used as explanatory variables because they can either be introduced on-farm in response to XW presence or influence XW presence. A linear model was used to explore the relationship between $\mathrm{XW}$ incidence with the explanatory variables. The explanatory variables for each 
response variable were reduced to a few that significantly influenced the observed response through a backward stepwise regression process, each step dropping explanatory variables that contributed least to the observed response.

\subsection{Results}

\section{Screenhouse and laboratory studies}

Occurrence of Xanthomonas wilt symptoms: Characteristic symptoms similar to those of XW disease in banana (Fig 1. B) i.e. progressive yellowing and wilting of leaves were only visible in Canna sp. plants (Fig. 2B and C). In most of the cases, leaf necrosis and yellowing in Canna sp. started either in the middle part or edge of a leaf, subsequently progressing to the whole leaf and plant. Severely affected Canna sp. plants also had their leaf margins turning black, progressing rapidly to the entire leaf and plant (Fig. 2D). The affected Canna sp. plants collapsed and rotted. Cut Canna sp. pseudostems released a yellow bacterial ooze (Fig. 2E) similar to cut XW infected banana stems (Fig. 1C). Infections were also observed in some of the attached suckers following the inoculation of the parent Canna sp. plants (see figure 2D) whereas other suckers from inoculated Canna sp. mats did not show symptoms. None of these symptoms occurred in the uninoculated controls.
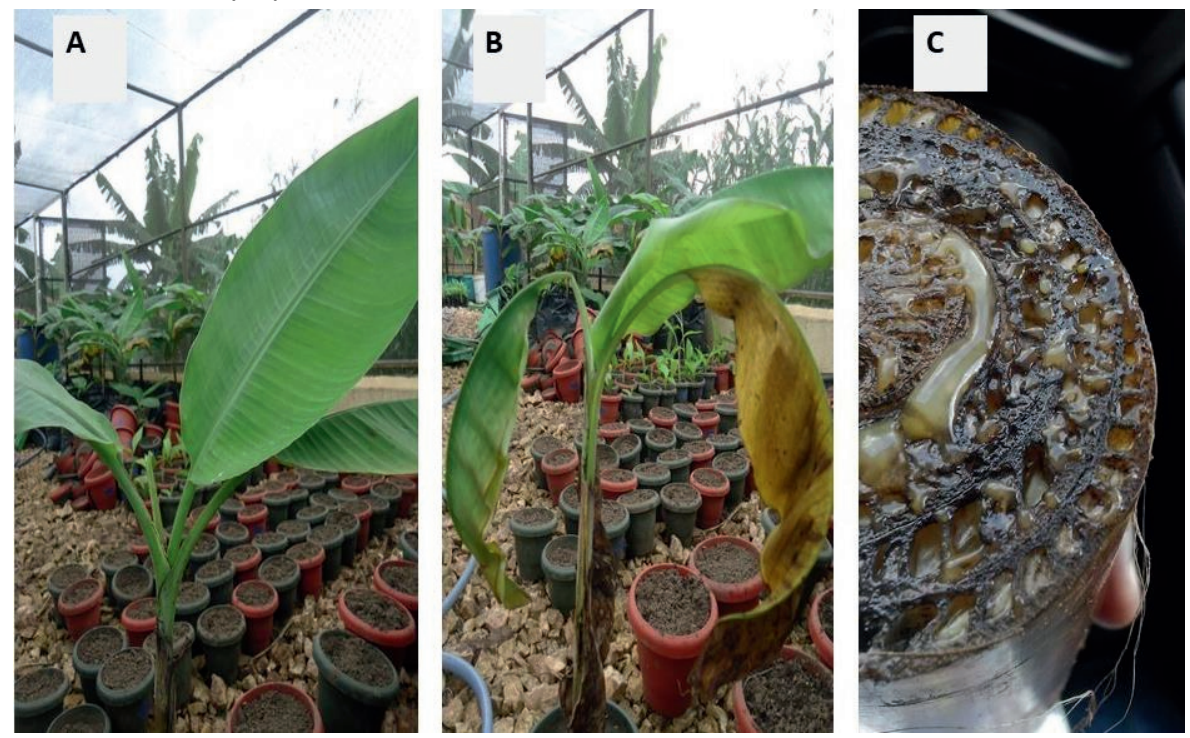

Figure 1. A) A disease-free banana plant, B) a banana plant showing Xanthomonas wilt symptoms after inoculation with Xanthomonas campestris pv. musacearum, and C) a cut pseudostem of a XW infected banana plant showing yellow $\mathrm{Xcm}$ ooze. 

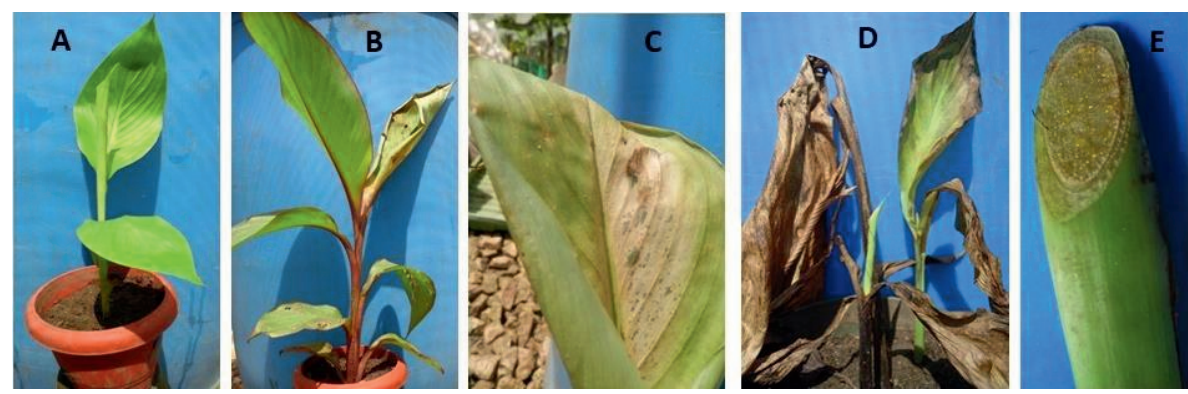

Figure 2. Photos of Canna sp. showing: A) an un-inoculated control plant, B) an inoculated plant and C) a symptomatic leaf, D) a severely affected mat showing the dead parent plant (middle) and symptomatic shoots (foreground and behind), and E) yellow bacterial ooze on a cut stem surface.

Leaf necrosis (whitish to light green lesions) along the parallel veins were observed on leaves of inoculated sorghum (Fig. 3B and C) and millet (Fig. 3E and F) plants, 7 days after inoculation. No symptoms occurred in the control plants (Fig. 3A and 3D). However, these symptoms were observed to disappear over time and new emerging millet and sorghum leaves presented no leaf symptoms, suggesting that the plants recovered from the $\mathrm{Xcm}$ infection. No Xanthomonas-characteristic symptoms were observed in the controls or inoculated plants of maize, sugarcane, wild sorghum, beans or taro.
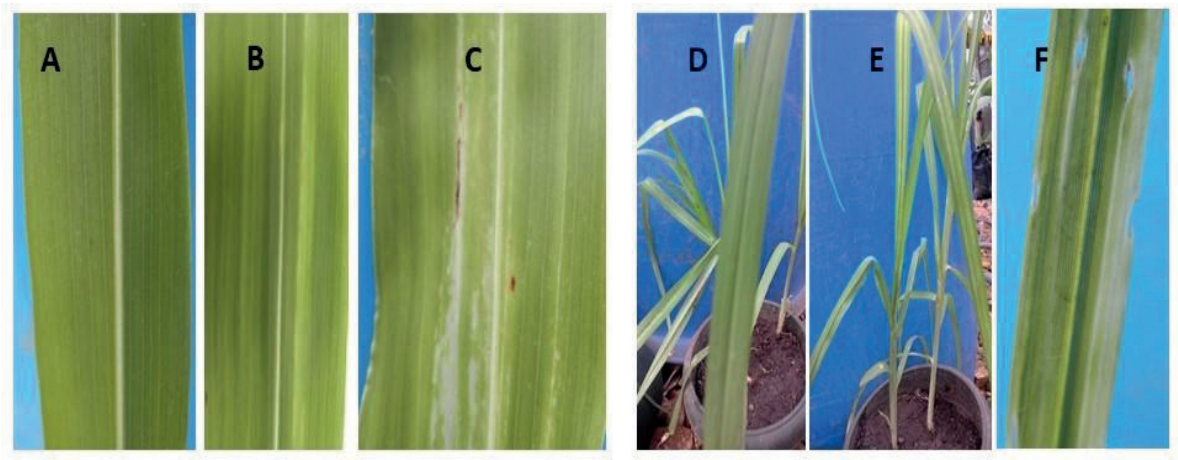

Figure 3. A) The leaf of an un-inoculated control sorghum plant, B) and C) inoculated sorghum leaves with whitish lesions, D) leaf of an un-inoculated millet plant, and E) and F) leaves of inoculated millet plants with white lesions. Photos depict plants/leaves at about 12 days after trial initiation/inoculation. 


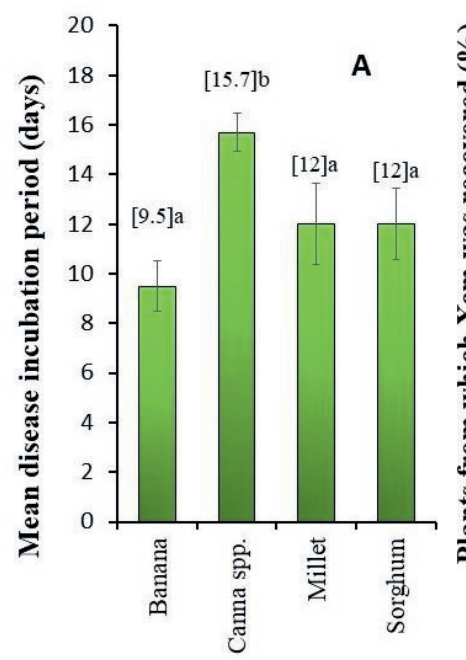

Plant species

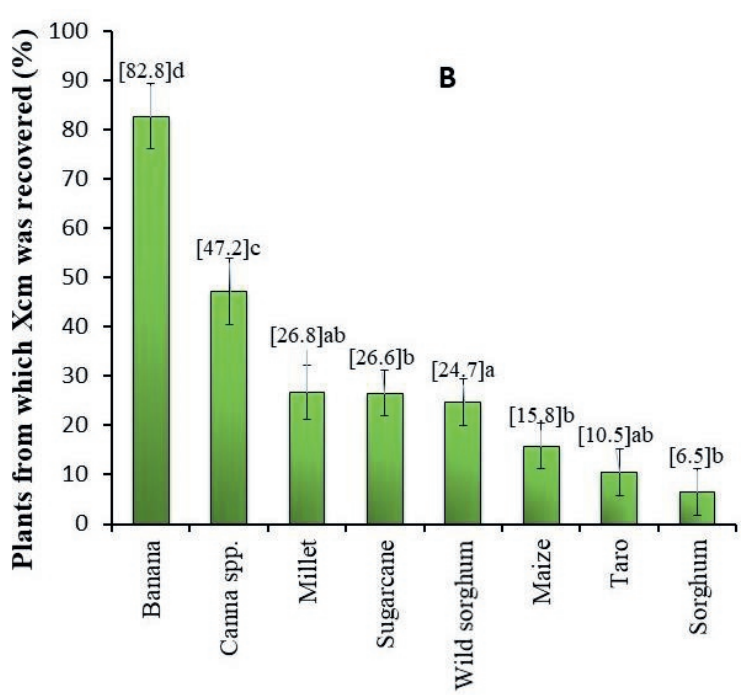

Plant species

Figure 4 A). Mean incubation period (i.e. time for the appearance of symptoms characteristic of Xanthomonas wilt) in different plant species and B). the proportion of plants from different plant species from which Xanthomonas campestris pv. musacearum was recovered following a deliberate artificial inoculation. Vertical bars denote standard errors. Significant differences were observed between the species means at $\mathrm{P}<0.001$. Mean values followed by the same letter are not significantly different at $\mathrm{P}=$ $5 \%$.

$X W$ incubation period, incidence and occurrence of $X c m$ in plant tissues: The mean incubation period (number of days from time of inoculation to first symptom observation) was greatest for Canna sp. and did not differ significantly between banana, millet and sorghum (Fig. 4). The XW symptom incidence in Canna sp. was $96 \%$, while banana had $100 \%$ of potted plants showing symptoms. Millet had symptom incidence of $50 \%$ and sorghum $35 \%$. 

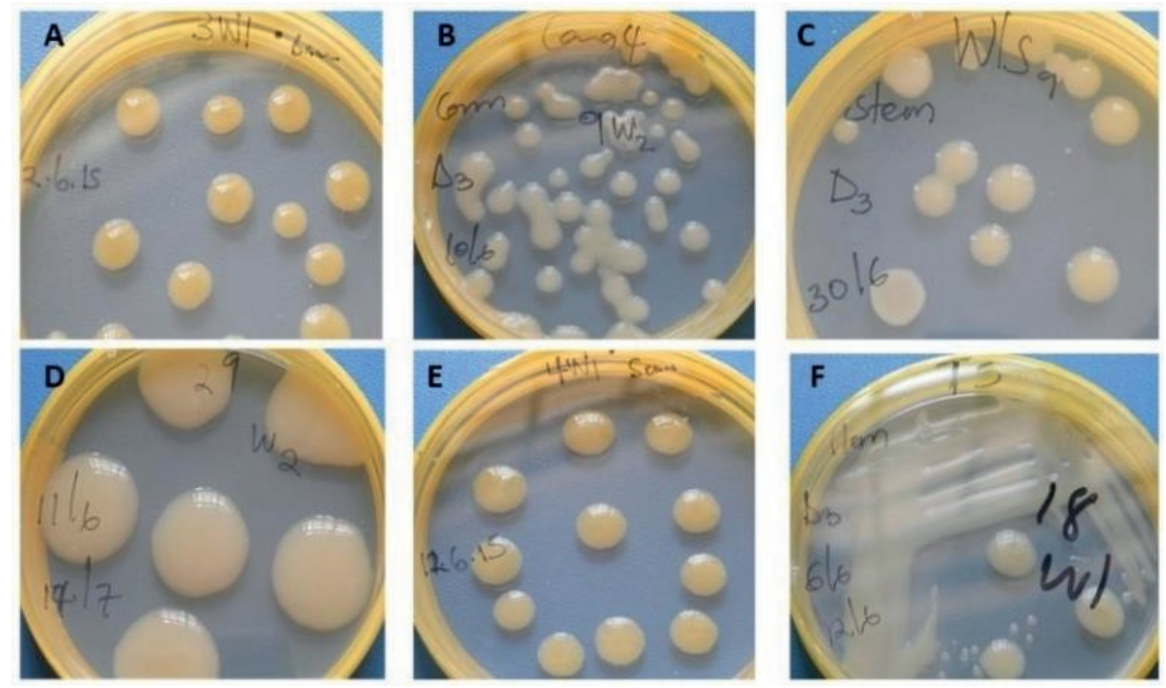

Figure 5. Xanthomonas campestris pv. musacearum $(\mathrm{Xcm})$ like colonies (on Yeast Peptone Glucose Agar) recovered from different crop species artificially inoculated with $\mathrm{Xcm}$. $\mathrm{A}=$ banana, $\mathrm{B}=\mathrm{Canna}$ sp., $\mathrm{C}=$ wild sorghum, $\mathrm{D}=$ sorghum, $\mathrm{E}=$ sugarcane and $\mathrm{F}=$ taro.

Xcm-like colonies (Fig. 5) were re-isolated from both symptomatic and symptomless Canna sp., sorghum and millet plants and confirmed to be positive with a PCR using Xcm GspDm-specific primers (Fig. 6; Adriko et al., 2012). Despite the absence of symptoms Xcm was also recovered from wild sorghum, sugarcane, maize and taro and similarly confirmed with the GspDm-specific primers (Fig. 5, 6). Adriko et al. (2012) reported the GspDm-specific primers to be specific to Xcm based on a $265 \mathrm{bp}$ amplicon. To our knowledge there are no other published primers other than GspDm reported to be specific for molecular diagnosis of $\mathrm{Xcm}$. However, when we performed an in silico analysis with Primer-BLAST (https://www.ncbi.nlm.nih.gov/tools/primerblast/primertool.cgi?ctg time $=1532089551$ \&job key=wsgdcVNWXv55wFvFVqV 9yvbsUBrXXYAA\&CheckStatus=Check), GspDm primers generated a specific amplicon of 265 bp with Xvv and non-specific amplicons (>3000 bp) with other Xanthomands (nonpathogens of banana). This suggests that the GspDm primers may also amplify Xvv that causes bacterial leaf streak in maize, sugarcane and sorghum. The fact that a $265 \mathrm{bp}$ amplicon was not observed in the genomic DNA of tissues from maize, sugarcane and other plant species used in this study prior to inoculation gives us confidence that the plants used for the screenhouse experiments were Xvv free and amplicons obtained with Gspdm primers were $X \mathrm{~cm}$.

The frequency of $X \mathrm{~cm}$ presence in the plant parts significantly $(p<0.001)$ varied between the crop species (Fig. 4B). Xcm was recovered in $83 \%$ of the banana plant samples compared with $47 \%$ in Canna sp. plants. Xcm incidence in plant parts of the 
other crops was significantly lower than that in Canna sp. and varied between $6.5 \%$ in sorghum to $27 \%$ in millet (Fig. $4 \mathrm{~B}$ ). For the period of $\mathrm{Xcm}$ isolation (13-39 days after inoculation), no consistent relationship was observed between the proportion of plants from which $\mathrm{Xcm}$ was recovered and the age of plants or time of Xcm reisolation.

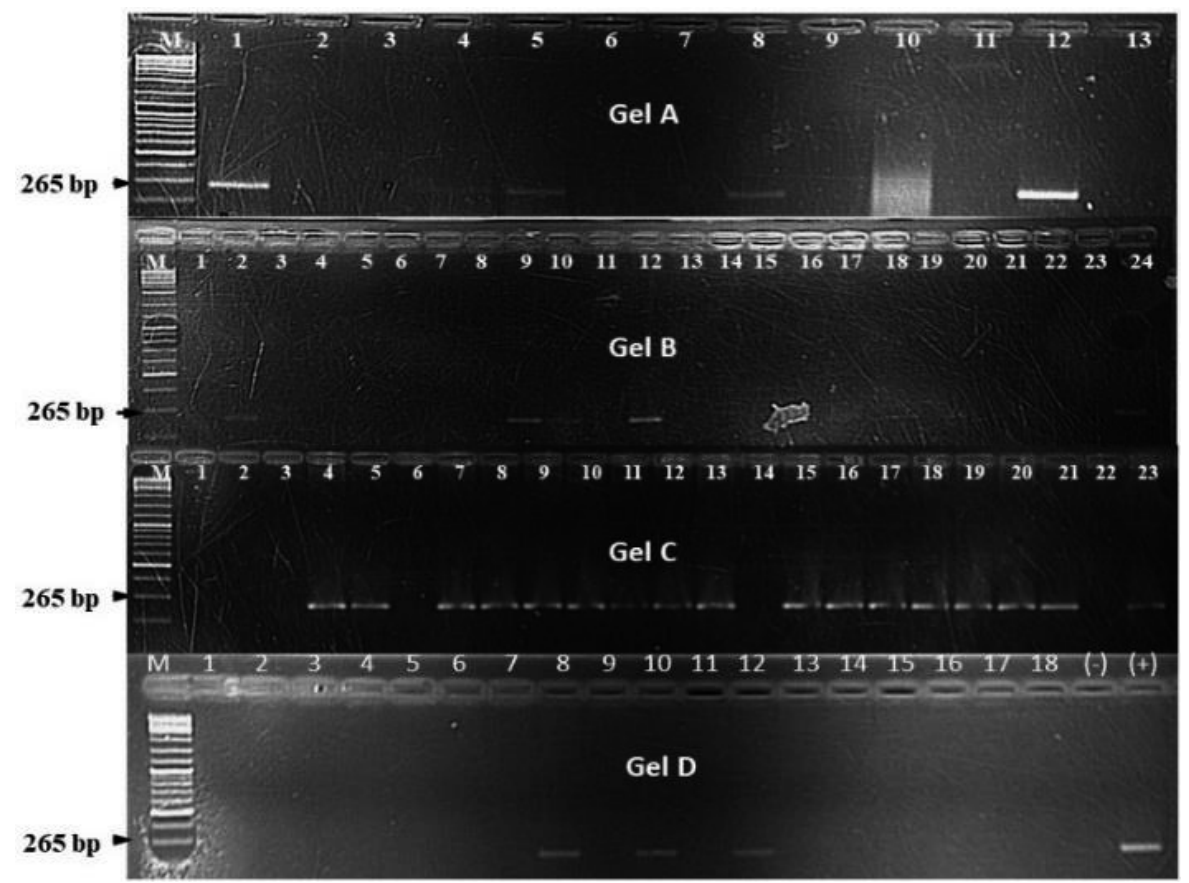

Figure 6. DNA bands on agarose gel for different Xanthomonas campestris pv. musacearum (Xcm) like isolates from different plant species after being inoculated with $\mathrm{Xcm}$ isolated from banana. On gel $\mathbf{A}, 1=$ Canna sp., 2, 3, 8= banana; 4, 5, 10, 11= sugarcane; 6, 7= taro; $9=$ maize; $12=$ positive control and $13=$ negative control. On gel B, 1, 2, 7-9, 13= wild sorghum; 3, 4,5, 16= maize; 6, 10, 12, 17-21= Canna sp.; 11, 14= sorghum; $15=$ sugarcane; $22=$ taro; $23=$ negative control; $24=$ positive control. Gel C, 1, 2= sugarcane; 3,5-7, 18,21 = wild sorghum; 4, 16, 20= taro; 8-10, 12, 13, 15, 17, 19= banana; 11 = Canna sp.; 14= sorghum; $22=$ negative control and $23=$ positive control. On gel D, 1-18 = millet. " $M$ " on all the gels denotes the DNA ladder. The experiments were conducted at the Kawanda laboratory in central Uganda.

\section{Koch's postulates using pathogens re-isolated from non-host plants}

Koch's postulates were performed using the isolates recovered from the different artificially inoculated crop species. Isolates recovered from banana, Canna sp., millet, wild sorghum and sugarcane caused XW symptoms in banana plantlets with incidences of $100 \%$ for those from banana, $60 \%$ for those from Canna sp., $80 \%$ for those from millet, $40-100 \%$ for those from wild sorghum and $40 \%$ for those from sugarcane. Isolates from maize and taro did not cause disease in banana while 
isolates from sorghum were not introduced into the banana plants. Finger-prints were obtained for some of the isolates from banana, sugarcane, Canna sp. and taro. Similar finger-print patterns were observed for the banana and Canna sp. isolates that caused disease in banana plantlets, while a different pattern was observed for the taro and sugarcane isolates that did not cause disease in banana plantlets (Fig. 7).

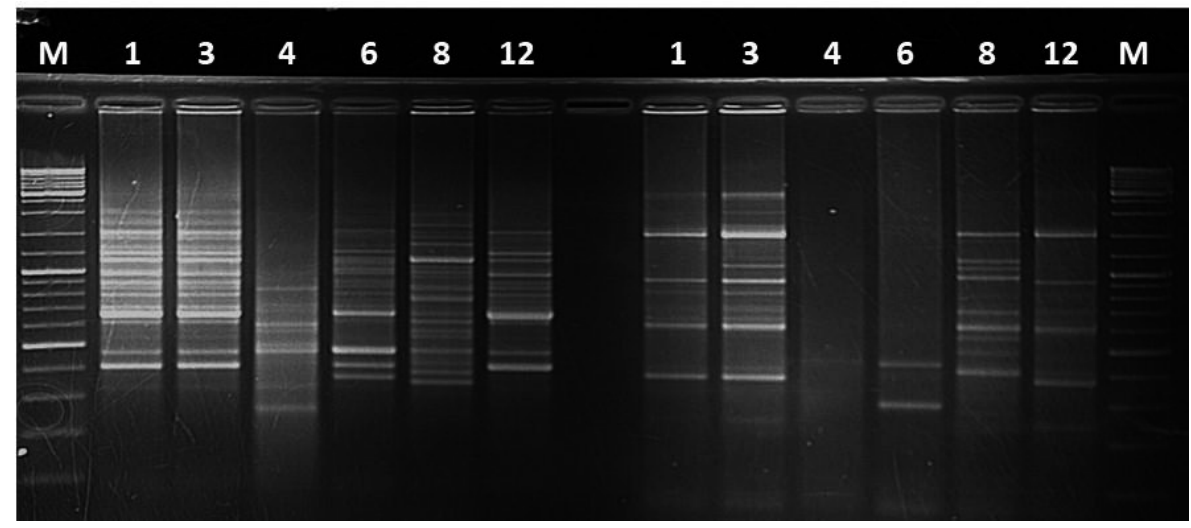

Figure 7. DNA finger prints on agarose gel for different Xanthomonas campestris pv. musacearum (Xcm) like isolates from: 1 = Canna sp., 3 and $8=$ banana, $4=$ sugarcane, $6=$ Taro, $12=\mathrm{Xcm}$ positive control. The initial $\mathrm{Xcm}$ isolate was obtained from a symptomatic banana plant at Kawanda research station, central Uganda. Isolates 1, 3, 8 caused disease in banana plantlets while 4 and 6 did not.

Four of the $\mathrm{Xcm}$ isolates recovered from the potential alternative hosts were compared for their virulence on banana plantlets (Fig. 8A and B). One isolate from wild sorghum was highly virulent causing up to $100 \%$ incidence with a correspondingly high severity score of 1 (1 being the highest score and 0 being no disease). A second isolate from wild sorghum and the isolate from sugarcane were the least virulent while the isolate from millet was moderately virulent. 


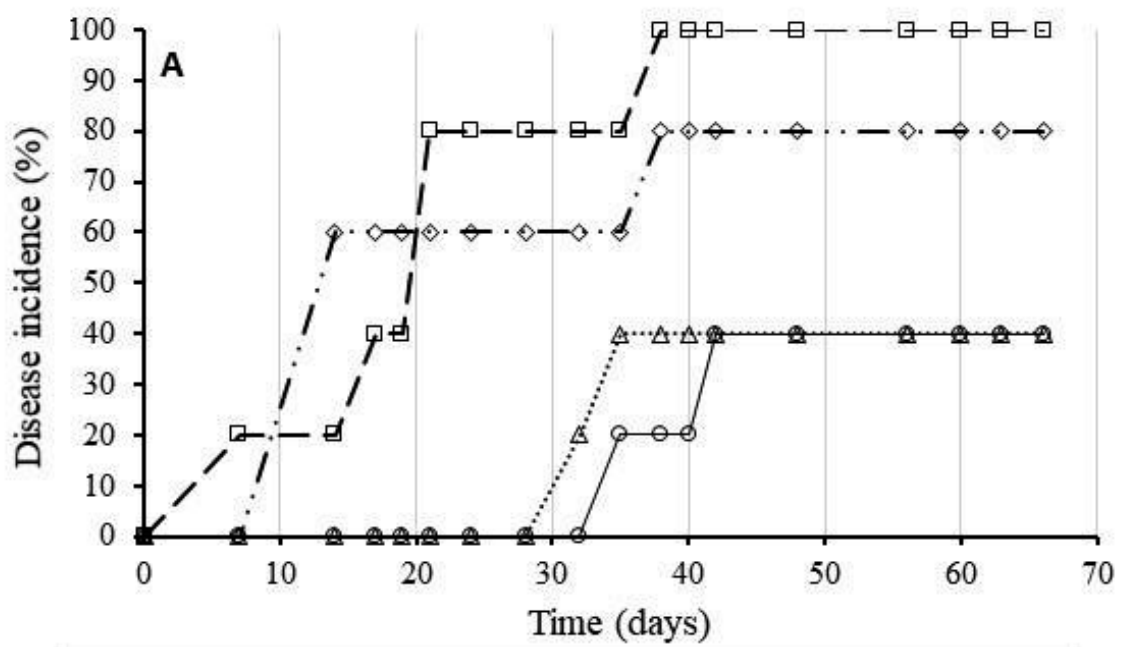

$\neg-$ Wild sorghum $1 \longrightarrow$. Millet $\rightarrow$ Sugarcane $\cdots \triangleq \cdots$ Wild sorghum 2

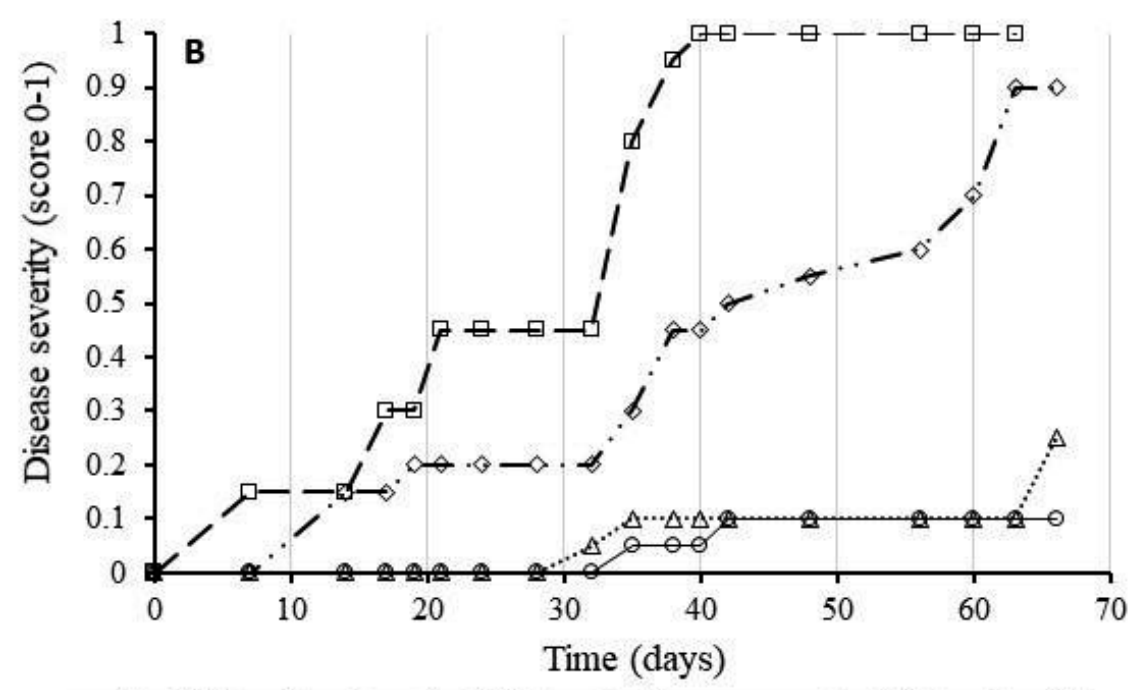

$\rightarrow$-Wild sorghum $1 \rightarrow$. Millet $\rightarrow$ Sugarcane $\cdots . \cdots$ Wild sorghum 2

Figure 8. Xanthomonas wilt incidence $(A, \%)$ and $(B)$ severity scores over time in banana plantlets inoculated with Xanthomonas campestris pv. musacearum re-isolated from different $\mathrm{Xcm}$ non-host plant species. A total of five banana plantlets were inoculated per isolate. Severity was scored at a scale of 0 to 1, 0 being no disease and 1 being the highest severity scores.

\section{Xanthomonas wilt field risk drivers}

XW was present in $92 \%$ of the surveyed farms with a mean mat disease incidence and time of exposure to XW of $21 \%$ and 4.7 years, respectively. The number of Musa cultivars on farm varied between 1 and 11 , while the ABB types were present on $95 \%$ 
of the banana farms (Table 1). Agroforestry trees and intercropping were practiced on all the surveyed farmers. Between $32 \%$ and $84 \%$ of the farmers practiced different XW control measures while between $5 \%$ and $76 \%$ of the farmers reported to have accessed information and or training from different sources. Farmers were the main source of information (75\%) on XW disease (Table 1).

Table 1. Distribution of response and explanatory variables explored on Xanthomonas wilt (XW) infected farms in central Uganda. In parenthesis are minimum and maximum values of the variables. A total of 63 farms were surveyed.

\begin{tabular}{|c|c|}
\hline Variable & Mean value \\
\hline XW presence on farms (\%) & 91.9 \\
\hline XW mat incidence score (\%) & $21.3(0-80)$ \\
\hline Time of exposure to XW disease (years) & $4.7(0-20)$ \\
\hline Area under banana (hectares) & $0.61(0.10-4.05)$ \\
\hline Number of banana cultivars on farm & $4.4(1-11)$ \\
\hline Farms with ABB types of banana (\%) & 94.6 \\
\hline Presence of agroforestry trees (\%) & 100 \\
\hline Farms intercropping banana (\%) & 100 \\
\hline Farms applying complete mat uprooting (CMU) (\%) & 37.8 \\
\hline Farms applying single diseased stem removal (SDSR) (\%) & 32.4 \\
\hline Farmer accessing information on XW from other farmers (\%) & 75.7 \\
\hline Farmer accessing information on XW from extension agents (\%) & 5.4 \\
\hline Farmer accessing information on XW from media (\%) & 46.0 \\
\hline Households accessing training (\%) & 32.4 \\
\hline Farms on which Canna sp. was present (\%) & 59.5 \\
\hline \multicolumn{2}{|l|}{ Who accesses information in household (\%) } \\
\hline - Men & 48 \\
\hline - Women & 41.7 \\
\hline - Children & 10.4 \\
\hline Male headed households (\%) & 83.8 \\
\hline Commercially oriented farms (\%) & 13.5 \\
\hline
\end{tabular}

Canna spp. was observed on $59.5 \%$ of the farms surveyed in central Uganda (Table 1). The abundance of Canna spp. on farms could not always be easily ascertained as most farmers had cleaned their fields using mainly hand hoes and/or herbicides in a few cases. In some farms, (see example of Figure 9B), Canna spp. are very abundant. Out of 46 Canna spp. samples analyzed in the laboratory, only one plant ( $0.02 \%)$ had colonies characteristic of $\mathrm{Xcm}$ that were also confirmed positive using $\mathrm{Xcm}$ specific primers. The other samples either had no Xcm-like colonies or were negative on PCR with the specific primers. 

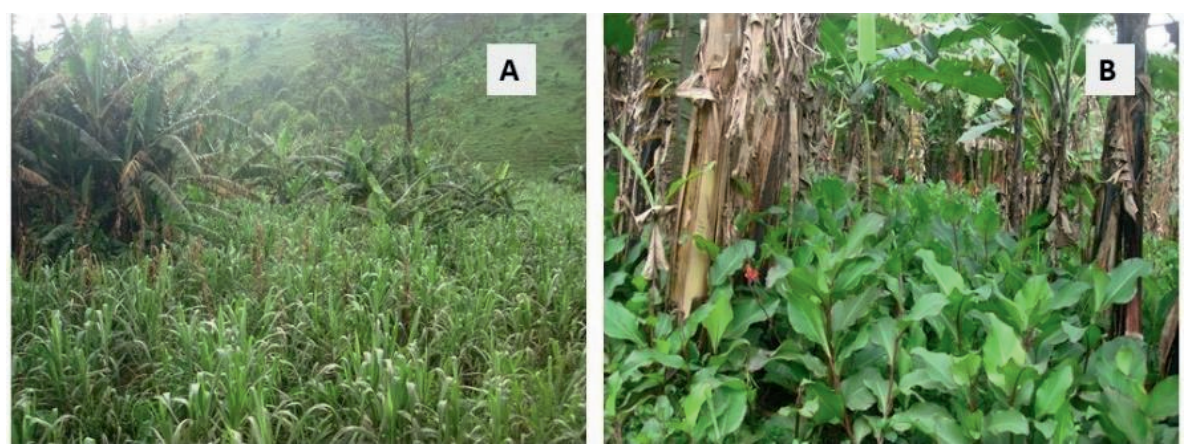

Figure 9. A) Banana being intercropped with sugarcane, B) a banana field with a high density of Canna sp.

A logistic regression model of XW presence/ absence on farm only selected farmers access to training and the presence of $A B B$ banana cultivar types as explanatory factors that significantly influenced disease presence/absence on farm. Access to training had a negative and significant $(P=0.009)$ influence on $X W$ presence on farm, suggesting that the $8 \%$ of the farms without XW were also those that had received training on XW management. In contrast, $92 \%$ of the farms with $\mathrm{XW}$ had a high likelihood of having the susceptible ABB banana cultivar types ( $P=0.029)$ (Table 2). A linear regression model for XW plant incidence on-farm selected the number of banana cultivars, as the key factor influencing XW incidence on a farm (Table 2).

Table 2. Model outcomes of regressions of Xanthomonas wilt (XW) presence (as binary scores) and Xanthomonas wilt incidence on farm as response variables with different explanatory variables. SDSR denotes 'single diseased stem removal'

\begin{tabular}{lcccc}
\hline & $\begin{array}{c}\text { Parameter } \\
\text { estimate }\end{array}$ & $\begin{array}{c}\text { Standard } \\
\text { error }\end{array}$ & $\begin{array}{c}\mathbf{t} \\
\text { value }\end{array}$ & $\operatorname{Pr}(>|\mathbf{t}|)$ \\
\hline Xanthomonas presence on farm & & & & \\
Intercept & 0.62 & 0.17 & 3.53 & $0.0012^{* *}$ \\
Presence of ABB banana types & 0.40 & 0.17 & 2.29 & $0.0286^{*}$ \\
Household access to training & -0.23 & 0.08 & -2.76 & $0.0094^{* *}$ \\
& & & & \\
Xanthomonas wilt incidence on farm & & & & \\
Intercept & 21.17 & 17.81 & 1.19 & 0.2431 \\
Number of banana cultivars on-farm & -4.62 & 2.25 & -2.06 & $0.0478^{*}$ \\
Presence of ABB banana types & 26.01 & 16.83 & 1.55 & 0.1318 \\
Application of SDSR & -13.48 & 8.12 & -1.66 & 0.1064 \\
\hline Significance COdes: $0^{* * * \prime 0} 0.001^{* * * \prime} 0.01^{* * \prime} 0.05$ & & & &
\end{tabular}

The number of cultivars on farm and the application of SDSR, one of the recommended control practices led to a decline in $\mathrm{XW}$ incidence, while incidence was increased on farm by the presence of the susceptible ABB banana types. However, only the number of cultivars had a significant effect at $P=0.05$. The logistic 
regression and the linear regression models respectively, explained 29.3\% (null deviance: 2.7569 on 36 degrees of freedom (d.f.) and residual deviance: 1.9503 on 34 d.f.) and $18.1 \%$ (model p-value of 0.083 ) of the variation in XW presence/absence and incidence on farm, suggesting likely landscape effects not explored in this study played an important role in XW incidence on farm.

\section{Synthesis of the risk posed by potential alternative host plants}

Table 3 summarizes the different risk criteria and how they ranked across the crops in this study based on laboratory, screenhouse and field observations; and expert knowledge. In the screenhouse pot trials only Canna sp. was found to be highly susceptible whereas other crops were resistant (Table 3). The risk to/from Canna sp. and sugarcane could be increased by their perennial nature and propagation through the rhizome. Overall, the risk from Canna spp. could be ranked as moderate-high while low-moderate for sugarcane and none-very low for the other crop species in this study.

Table 3. Ranking of the risk of the different crops/weeds to perpetuate Xanthomonas wilt disease on banana plants on farms. For the different criteria, rank 0 denotes no risk while 5 denotes a high risk.

\begin{tabular}{|c|c|c|c|c|c|c|c|}
\hline Criteria & Canna sp. & \begin{tabular}{|c|}
$\begin{array}{c}\text { Wild } \\
\text { sorghum }\end{array}$ \\
\end{tabular} & Millet & Sorghum & Taro & Maize & Sugarcane \\
\hline $\begin{array}{l}\text { Susceptibility to } \\
\text { Xcm (based on } \\
\text { ability to induce } \\
\text { symptoms) }\end{array}$ & 5 & 0 & 2 & 2 & 0 & 0 & 0 \\
\hline $\begin{array}{l}\text { Recovery of } X \mathrm{~cm} \\
\text { from tissues }\end{array}$ & 5 & 2 & 2 & 1 & 1 & 1 & 2 \\
\hline Life span & \begin{tabular}{|l}
5 (Perennial \\
- high risk of \\
sustaining \\
infection)
\end{tabular} & $\begin{array}{c}0 \\
\text { (annual) }\end{array}$ & $\begin{array}{c}0 \text { (Annual. } \\
\text { No risk) }\end{array}$ & $\begin{array}{c}0 \\
\text { (Annual) }\end{array}$ & $\begin{array}{c}0 \\
\text { (Perennial } \\
\text { but not a } \\
\text { suitable } \\
\text { host) }\end{array}$ & $\begin{array}{c}\text { Not annual. } \\
\text { Not a } \\
\text { suitable } \\
\text { host) }\end{array}$ & 5 (Perennial) \\
\hline $\begin{array}{l}\text { Mode of } \\
\text { propagation }\end{array}$ & $\begin{array}{l}5 \text { (Dispersed } \\
\text { through the } \\
\text { rhizome, } \\
\text { thus able to } \\
\text { pass } \\
\text { infection to } \\
\text { plantlets) }\end{array}$ & $\begin{array}{c}0 \text { (Seed } \\
\text { dispersal) }\end{array}$ & $\begin{array}{c}0 \text { (Seed } \\
\text { dispersal) }\end{array}$ & $\begin{array}{c}0 \text { (Seed } \\
\text { dispersal) }\end{array}$ & $\begin{array}{l}0 \text { (Not a } \\
\text { suitable } \\
\text { host) }\end{array}$ & $\begin{array}{c}0 \text { (Seed } \\
\text { dispersal) }\end{array}$ & $\begin{array}{l}4 \text { (Dispersed } \\
\text { through the } \\
\text { rhizome and } \\
\text { cuttings. Can } \\
\text { possibly pass } \\
\text { infection to } \\
\text { plantlets) }\end{array}$ \\
\hline $\begin{array}{l}\text { Risk of spread } \\
\text { though tools }\end{array}$ & 5 & 1 & 1 & 1 & 0 & 1 & 3 \\
\hline $\begin{array}{l}\text { Presence in banana } \\
\text { fields (Likely to vary } \\
\text { from place to place) }\end{array}$ & $\begin{array}{l}3 \text { (52\% of } \\
\text { farms in } \\
\text { Uganda) }\end{array}$ & 2 & 1 & 2 & 3 & 3 & 3 \\
\hline Field assessment & \begin{tabular}{|c|}
1 (isolated \\
from $0.02 \%$ \\
of field \\
plants) \\
\end{tabular} & $\begin{array}{c}\text { Not } \\
\text { assessed }\end{array}$ & $\begin{array}{c}\text { Not } \\
\text { assessed }\end{array}$ & $\begin{array}{c}\text { Not } \\
\text { assessed }\end{array}$ & $\begin{array}{c}\text { Not } \\
\text { assessed }\end{array}$ & $\begin{array}{c}\text { Not } \\
\text { assessed }\end{array}$ & Not assessed \\
\hline Overall risk rating & \begin{tabular}{|c|}
$\begin{array}{c}\text { Moderate- } \\
\text { high }\end{array}$ \\
\end{tabular} & $\begin{array}{c}\text { None - } \\
\text { very low }\end{array}$ & $\begin{array}{c}\text { None - } \\
\text { very low }\end{array}$ & $\begin{array}{c}\text { None - } \\
\text { very low }\end{array}$ & None & $\begin{array}{c}\text { None - } \\
\text { very low }\end{array}$ & $\begin{array}{c}\text { Low - } \\
\text { moderate }\end{array}$ \\
\hline
\end{tabular}




\subsection{Discussion}

Alternative host plants play an important role in the spread and perpetuation of several plant pests and diseases. Several crop and weed species have been suspected to potentially play a role in the spread or survival of the XW disease-causing pathogen, $\mathrm{Xcm}$.

In the current study, Xcm caused symptoms similar to those in banana in $96 \%$ of Canna sp. plants. This confirms the findings of Ssekiwoko et al. (2006b) and Chala et al. (2016), who observed symptoms in Canna spp. after inoculation with $\mathrm{Xcm}$. The longer incubation period in Canna sp. plants could be attributed to the fact that fully grown Canna sp. plants were used in contrast to the other plants species. In the current study, Xcm was successfully re-isolated from $47 \%$ of the Canna sp. plants in the screenhouse study and confirmed with Xcm specific primers, a component not present in previous studies. Given the high symptom incidence in Canna sp. (96\%), the observed level of Xcm recovery/re-isolation (47\%) in Canna sp. was relatively low, a fact that could be attributed to the growth of saprophytes in the severely affected and decomposing plants which were assessed at later stages of sampling. Isolation of $\mathrm{Xcm}$ from banana plants with advanced disease symptoms has also been reported to be low due to the onset of decomposition and competition from saprophytes (Mwebaze et al., 2006; Were et al., 2015). Koch's postulates showed however that the isolates from Canna sp. could induce disease in banana plantlets. These laboratory and screenhouse findings coupled with the high prevalence of this weed on banana farms in east and central Africa suggests that Canna spp. could pose a risk to the management of the $\mathrm{XW}$ disease.

Yet, in the field assessment only $0.02 \%$ of the field-grown Canna plants had $\mathrm{Xcm}$. Moreover, presence/absence and incidence of XW on the studied farms was not influenced by the presence of Canna spp. on farm. A close examination of the Canna spp. plants in the field revealed that they have persistent floral bracts. In banana, cultivars with semi or persistent male/neuter flowers have been reported to escape insect-mediated infections (Tripathi and Tripathi, 2009; Blomme et al., 2014). Thus, the risk of Canna spp. on farm is likely to be limited to tool transmission mostly during weeding. The use of farm tools has been reported to potentially spread the $\mathrm{Xcm}$ bacteria from an infected banana plant to disease-free plants within or across fields (Ocimati et al., 2013). The weeding/ land preparation periods (including banana leaf and sucker trimming) have been reported to be often followed by higher incidences of XW disease (Mgenzi Byabachwezi, 2016, personal communication). Canna spp. can propagate through the underground rhizome and as such $\mathrm{Xcm}$ infections can spread from one plant to other attached plants leading to disease 
persistence on a farm. In the current study, the attached suckers and sprouts in some of the symptomatic or dead Canna sp. plants, for example, were observed to succumb to the inoculation of the parent plants whereas in other pots the attached lateral shoots did not show disease symptoms even after death of parent plants. Based on the above findings we therefore rated the risk of Canna spp. to perpetuate $\mathrm{XW}$ on-farm as moderate to high.

Among the cereals inoculated with $\mathrm{Xcm}$, symptoms were only observed in millet and sorghum plants, though the plants eventually recovered. The recovery suggests that the resistance mechanisms of these species could overcome the pathogen. Pathogen virulence is often directly correlated with pathogen replication, with higher levels of replication resulting in increased damage to the host (Ebert and Bull, 2008). However, virulence and pathogen replication can be decoupled (Margolis and Levin, 2008), especially if the host mounts an appropriate immune response against novel pathogens (Graham et al., 2005). Chala et al. (2016) also reported typical Xanthomonas wilt symptoms after $\mathrm{Xcm}$ inoculations into sorghum and millet. The appearance of symptoms in cereals and the taxonomic similarity of $X \mathrm{~cm}$ to $X$. vasicola, a pathogen of sorghum, maize and sugarcane should be a source of concern as this suggests a potential risk of a jump from one host to another. We however rate the risk of $\mathrm{Xcm}$ to these crops and from these crops to banana to be low mainly due to i) the short annual cycle of these crops and the inability of Xcm to survive in absence of the host, ii) the lack of infection arising from insects, iii) their dispersal through seeds and other criteria in table 7. These cereals, unlike banana that is exposed to XW spread through insects foraging for nectar and pollen (a key mode of XW spread) are wind and/or self-pollinated. No symptoms were observed in maize and sugarcane. The absence of symptoms in maize and sugarcane agrees with earlier findings by Yirgou and Bradbury (1974) or Ashagari (1985) but contrasts findings from Karamura et al. (2015) and Chala et al. (2016) who reported typical Xanthomonas symptoms in sugarcane and maize, respectively, following inoculation with $\mathrm{Xcm}$. No symptoms were also observed in wild sorghum contrary to reports by Chala et al. (2016). Taro a common banana intercrop reported to suffer from wilts by farmers in XW landscapes did not succumb to Xcm inoculation, suggesting that it is resistant.

Differences in results between the above studies could potentially arise from the differences in the varieties used and differences in virulence of $\mathrm{Xcm}$ isolates. Karamura et al. (2015) used six different isolates from different sites in the east and central African region, while Chala et al. (2016) used three isolates arising from banana, wild enset and domesticated enset. Chala et al. (2016) reports different levels of susceptibility of banana, enset and the potential alternative hosts to these 
three isolates. This is strengthened by the fact that four isolates recovered from millet, wild sorghum ( 2 isolates) and sugarcane in this study had different levels of virulence, with a higher virulence observed in one of the isolates from wild sorghum, followed by that in millet and the least in the second wild sorghum isolate (cf. Figure 8). Evaluating a wide range of isolates from different geographical setups would therefore be vital. We rate the risk of wild sorghum and maize to be very low due to their short annual cycle and mode of pollination (i.e., wind pollinated) that prevents insect-mediated infections (Table 3). Sugarcane like other cereals are wind pollinated but are perennial and reproduce through cuttings and the underground rhizomes. Thus, in case $\mathrm{Xcm}$ gets adapted to it, it could be of importance in perpetuation of the problem of XW disease in banana. With tool-mediated XW spread and the observed increase in cases of banana-sugarcane intercrops (e.g. fig. 10A), sugarcane could potentially gain importance as an alternative host to $\mathrm{Xcm}$. Based on the screenhouse and laboratory results, the characteristics of the sugarcane and its management, would propose a low -moderate risk score from/for sugarcane (Table 3).

$\mathrm{Xcm}$ was isolated from all the plant species after artificial inoculation with an $\mathrm{Xcm}$ isolate from banana in this study, irrespective of presence or absence of symptoms. Xcm re-isolation has also been reported for maize (Aritua et al., 2008, Karamura et al., 2015) and sugarcane (Karamura et al., 2015). In this study, isolates from maize and taro did not cause disease in banana plantlets. Rutikanga et al. (2016) also reported the isolation of $\mathrm{Xcm}$ from maize, beans and sweet potato plant parts and soils around the stems of these plants. The isolates though confirmed to be Xcm with PCR did not cause disease in banana plantlets (Rutikanga et al., 2016). The multiplication of bacterial pathogens in planta irrespective of the plant being a nonhost or a host has been reported (Hodson et al., 1995; Vidhyasekaran, 2002; Canteros et al., 1991). The bacteria in non-hosts have been reported to however remain static or to decline after some time (Canteros et al., 1991; Vidhyasekaran, 2002). Novel host-pathogen interactions have not been under direct selection (Antonovics et al., 2013), and hence the degree of pathogen virulence is likely to be maladaptive for both the novel host and the pathogen. Host phylogeny has been considered a key factor in determining the susceptibility of novel hosts (de Vienne et. al., 2009; Gilbert and Webb, 2007) because species closely related to the natural host of a pathogen tend to be more susceptible since the pathogen develops specialized adaptations to its natural host such as binding to host receptors, avoiding immune responses or utilizing host resources, and these break down if the environment provided by the novel host is too different (Longdon et al., 2014). We postulate that the failure of $\mathrm{Xcm}$ isolates from non-host plants to cause $\mathrm{XW}$ symptoms in banana may be due to loss or modification of key genes involved in 
virulence in the pathogenicity island of the $\mathrm{Xcm}$ genome. The loss of such loci could be attributed to the variation in fingerprint patterns compared to the original isolate (control). The ability of $\mathrm{Xcm}$ re-isolations from sugarcane and wild sorghum to cause disease in banana even though they did not show any symptoms raises a big concern for the management of the disease as several plant species have been reported to act as symptomless hosts to pathogens. Age of plants (time of re-isolation) did not affect the recovery of the bacteria from the inoculated plants.

The observation of symptoms in some of the non-host plants in this study and earlier studies could be a cause for concern as several plant pathogens have been reported to evolve by host jumps followed by specialization (Grünwald and Flier, 2005; Raffaele et al., 2010). Species in the Phytophthora clade 1c are reported to have evolved through host jumps and subsequent adaptive specialization on plants from four dissimilar botanical families (Grünwald and Flier, 2005). In the group of xanthomonads, Coutinho et al. (2015) reported a significant host jump of Xanthomonas vasicola from sugarcane to eucalyptus. It is also not known for how long such pathogens need to survive in the non-host plants to warrant concern for management, especially given the reported closeness of $X \mathrm{~cm}$ to pathogens such as $X$. vasicola that are pathogens to some of these non-host cereal plants. For example, Peixoto et al. (2007) isolated Xanthomonas campestris pv. viticola from non-host plants such as Alternanthera tenella, Amaranthus sp., and Glycine max. These plants and grapevine (host) developed typical symptoms of bacterial canker when they were inoculated with the recovered isolates. However, the plant/ crop spp. in this study were not reinoculated with isolates recovered from them.

$X W$ presence and incidence on farm increased with the ABB banana types on farm. The ABB types, in addition to attracting many insect vectors, have floral bracts and neuter flowers that readily fall off leaving open fresh wounds on the rachis/flower stalk that are easily colonized by bacteria accidentally deposited by foraging insects (Blomme et al., 2014; 2017a). XW incidence also declined with increasing number of banana cultivars on farm. Crop or cultivar mixtures have been reported to impede disease and pest spread and damage (Poeydebat et al., 2016; Vidal et al., 2017; Li et al., 2018). High diversity of banana cultivars has been reported to suppress banana weevils, nematodes and black sigatoka in Uganda (Mulumba et al., 2012). The effect of mixtures on diseases can be through a dilution effect/ decrease in the susceptible host, change in microclimate, pathogen dispersal rate and vector population and behaviour, host alteration, and pathogen inhibition (Boudreau, 2013; Vidal et al., 2017). This study for the first time suggests a possible role of cultivar mixtures in reducing or slowing XW spread on farm. This effect of banana cultivars can be attributed to the effect of dilution on the susceptible ABB 
types and a reduced insect vector access to susceptible cultivars. XW incidence on farm was also influenced by singly removing diseased stems/plants on farm i.e. SDSR application. SDSR is one of the recommended practices for managing XW disease on farms. SDSR has been reported to drastically reduce XW incidence and lead to recovery of infected banana fields if regularly and consistently applied (Blomme et al., 2017b). No associations were observed between XW presence/ incidence with crop mixtures and agroforestry practices, possibly due to the homogeneity of the farms in the study region. The models only explained between 18 and $29 \%$ of the observed variation on-farm. This could be attributed to the fact that other factors responsible for disease spread on farm such as use of contaminated tools and uncertified seed were homogenous across farms. Landscape level factors could have also possibly dominated the studied factors within the individual farms. At landscape level, XW spread, incidence and severity has been reported to be influenced by altitude, temperature, precipitation, trade in diseased fresh products and the level of collective application of disease control measures among others.

\subsection{Conclusion}

In the current study, despite a low recovery (0.02\%) of Xcm from field-based Canna spp. plants, the high susceptibility of Canna sp. to Xcm in the screenhouse coupled to the pathogenicity of the $\mathrm{Xcm}$ isolates recovered from these plants to banana makes them suitable alternative hosts to $X \mathrm{~cm}$. More still, given the perennial nature of Canna spp. and its propagation through the rhizome, even at low incidences, Canna spp. could act as a reservoir of Xcm and perpetuate XW disease, leading to a low-moderate risk from this weed. Isolates recovered from sugarcane and wild sorghum (another important weed species) also caused disease in banana though these plants were resistant following inoculation with $\mathrm{Xcm}$. Given sugarcane and some species of wild sorghum e.g. Johnson grass (Sorghum halepense (L.) Pers) are perennial and reproduce through the rhizome, they could potentially become important alternative hosts if the bacteria gets adapted to them. Efforts for managing XW will thus need to be broadened to management of some of the alternatives host plants, especially Canna spp. In contrast, the risk from the grain cereals is deemed as none to very low, give the grain cereals were resistant, are annual in nature and propagate through seed. More still, XW cannot survive in decomposing or dry host tissues. Efforts to diversify agroecosystems therefore need to consider the interaction of pathogens of given crops with other plants in the system. On farmers' fields, XW presence and incidence had no association with the potential alternative hosts, especially Canna spp. but rather with the presence of 
susceptible ABB Musa genotypes, number of cultivars on farm and access to training on XW management. The models accounted for only between $18-29 \%$ of the variation in $\mathrm{XW}$ presence on farm, suggesting a possible role of other factors on farm. There is also need for in-depth study of the genomes of the $\mathrm{Xcm}$ isolates retrieved from the potential alternative host plants.

\subsection{Acknowledgements}

We acknowledge the financial contribution of the CGIAR Research Program on Roots, Tubers and Bananas and the CGIAR Fund Donors.

\section{References}

Adriko, J., Aritua, V., Mortensena, C. N., Tushemereirwe, W.K., Kubiriba, J., and Lund, O. S. (2012). Multiplex PCR for specific and robust detection of Xanthomonas campestris pv. musacearum in pure culture and infected plant material. Plant Pathol. 61, 489-497.

Antonovics, J., Boots, M., Ebert, D., Koskella, B., Poss, M., and Sadd, B.M. (2013). The origin of specificity by means of natural selection: evolved and nonhost resistance in hostpathogen interactions. Evol. 67, 1-9.

Aritua, V., Parkinson, N., Thwaites, R., Heeney, J.V., Jones, D.R., Tushemereirwe, W., ... and Smith, J. (2008). Characterization of the Xanthomonas sp. causing wilt of enset and banana and its proposed reclassification as a strain of $X$. vasicola. Plant Pathol. 57, 170177.

Ashagari, D. (1985). Studies on the bacterial wilt of enset (Ensete ventricosum) and prospects for its control. Ethiopian J. Agr. Sci. 7(1), 1-14.

Belalcazar, S.C., Rosales, F.E., and Pocasangre, L.E. (2004). "El Moko del banano y el plátano y el rol de las plantas hospederas en su epidemiología," in Proceedings of the XVI International ACORBAT Meeting. September 26-October 1, eds M. Orozco-Santos, J. Orozco-Romero, M. Robles-Gonzalez, J. Velazquez-Monreal, V. Medina-Urrutia, and J. A. Hernandez-Bautista (Oaxaca: Artturi), 16-35.

Blomme G., Dita, M., Jacobsen, K. S., Pérez Vicente, L., Molina, A., Ocimati, W., ... and Prior, P. (2017a). Bacterial diseases of bananas and enset: Current state of knowledge and integrated approaches toward sustainable management. Front. Plant Sci. 8, 1290.

Blomme, G., Jacobsen, K., Ocimati, W., Beed, F., Ntamwira, J., Sivirihauma, C., ... and Karamura, E. (2014). Fine-tuning banana Xanthomonas wilt control options over the past decade in East and Central Africa. Eur. J. Plant Pathol. 139, 265-281.

Blomme, G., Ocimati, W., Sivirihauma, C., Vutseme, L., Mariamu, B., Kamira, M., ... and Ntamwira, J. (2017b). A control package revolving around the removal of single diseased banana stems is effective for the restoration of Xanthomonas wilt infected fields. Eur. J. Plant Pathol. 149, 385-400.

Boudreau, M.A. (2013). Diseases in intercropping systems. Annu. Rev. Phytopathol. 51,499519. 
Canteros, B., Minsavage, G., Bonas, U., Pring, D., and Stall, R. (1991). The cloning and characterization of a gene from Xanthomonas campestris pv. vesicatoria that determines avirulence in tomato. Mol. Plant-Microbe Interact. 4, 628-632.

Chala, A., Kebede, T., and Blomme, G. (2016). Natural occurrence and pathogenicity of Xanthomonas bacteria on selected plants. Afr. J. Biotechnol. 15(39), 2146-2155.

Coutinho, T.A., van der Westhuizena, L., Rouxa, J., McFarlaneb, S.A., and Ventera, S.N. (2015). Significant host jump of Xanthomonas vasicola from sugarcane to a Eucalyptus grandis clone in South Africa. Plant Pathol. 64, 576-58.

De Cleene, M. (2008). Scanning electron microscopy of the establishment of compatible and incompatible Xanthomonas campestris pathovars on the leaf surface of Italian ryegrass and maize. EPPO Bulletin 19, 81-88.

de Vienne, D.M, Hood, M.E., and Giraud, T. (2009). Phylogenetic determinants of potential host shifts in fungal pathogens. J. Evol. Biol. 22, 2532-2541.

Destefano, S.A.L., Almeida, I.M.G., Rodrigues Neto, J., Ferreira, M., and Balani, D.M. (2003). Differentiation of Xanthomonas species pathogenic to sugarcane by PCR-RFLP analysis. Eur. J. Plant Pathol. 109, 283-288.

Ebert, D., and Bull, J.J. (2008). The evolution and expression of virulence. In: Stearns SC, Koella JC, editors. Evolution in Health and Disease. $2^{\text {nd }}$ ed. Oxford: Oxford University Press. pp. 153-167.

Eden-Green, S.J. (2004). How can the advance of banana Xanthomonas wilt be halted? InfoMusa 13, 38-41.

Elphinstone, J.G. (2005). "The current bacterial wilt situation: a global view," in bacterial wilt disease and the Ralstonia solanacearum Species complex, eds C. Allen, P. Prior, and A. C. Hayward (St. Paul, MN: APS Press), 9-28.

Fassihiani, A. (2000). Symptomless carriers of the causal agent of tomato wilt pathogen. J. Agr. Sci. Tech. 2, 27-32.

Gilbert, G.S., and Webb, C O. (2007). Phylogenetic signal in plant pathogen-host range. Proceedings of the National Academy of Sciences of the United States of America 104, 4979-4983. PMID: 17360396.

Graham, A.L., Allen, J.E., and Read, A.F. (2005). Evolutionary causes and consequences of immunopathology. Ann. Rev. Ecol. Evol. Syst. 36, 373-397.

Grünwald, N.J. and Flier, W.G. (2005). The biology of Phytophthora infestans at its center of origin. Annu. Rev. Phytopathol. 43, 171-190.

Hernandez, Y., and Trujillo, G.E. (1990). A new leaf disease in sweet potato caused by Xanthomonas campestris. J. Agron. Trop. Venezuela, 40, 291-307.

Hodson, A., Smith, A., and Hignett, R. (1995). Characterization of an outer membrane preparation of Pseudomonas syringae pv. mors-prunorum and its biological activities in planta. Physiol. Mol. Plant Pathol. 47, 159-172.

Karamura, E.B., Turyagyenda, F.L., Tinzaara, W., Blomme, G., Molina, A., and Markham, R. (2008). Xanthomonas wilt (Xanthomonas campestris pv. musacearum) of bananas in East and Central Africa: diagnostic and management guide. Kampala, Uganda: Fountain Publishers.

Karamura, G., Smith, J., Studholme, D., Kubiriba, J., and Karamura, E. (2015). Comparative pathogenicity studies of the Xanthomonas vasicola species on maize, sugarcane and banana. Afr. J. Plant Sci. 9(9), 385-400.

Kebede, T., and Gemmeda, L. (2017). Evaluation of banana genotype resistant to Xanthomonas wilts disease (Xanthomonas campestris pv. musacearum) in south east of Ethiopia. Afr. J. Microbiol. Res. 11(15), 603-612. 
Lang, J.M., DuCharme, E., Ibarra Caballero, J., Luna, E., Hartman, T., Ortiz-Castro, M., ... and Leach, J. E. (2017). Detection and Characterization of Xanthomonas vasicola pv. vasculorum (Cobb 1894) comb. nov. Causing Bacterial Leaf Streak of Corn in the United States. Phytopathol. 107(11), 1312-1321.

Letourneau, D.K., Armbrecht, I., Rivera, B.S., Lerma, J.M., Carmona, E.J., Daza, M.C., ... and Mejía, J. L. (2011). Does plant diversity benefit agroecosystems? A synthetic review. Ecol. Appl. 21(1), 9-21.

Li, X., de Boer, W., Zhang, Y., Ding, C., Zhang, T., and Wang, X. (2018). Suppression of soil-borne Fusarium pathogens of peanut by intercropping with the medicinal herb Atractylodes lancea. Soil Biol. Biochem. 120-130, doi.org/10.1016/j.soilbio.2017.09.029.

Liu, P., Xue, S., He, R., Hu, J., Wang, X., Jia, B., ... and Zhu, L. (2016). Pseudomonas syringae pv. actinidiae isolated from non-kiwifruit plant species in China. Eur. J. Plant Pathol. 145(4), 743-754.

Longdon, B., Brockhurst, M.A., Russell, C.A., Welch, J.J., and Jiggins, F.M. (2014). The Evolution and Genetics of Virus Host Shifts. PLoS Pathog. 10: e1004395. doi: 10.1371/journal.ppat.1004395 PMID: 25375777.

Mahuku, G.S. (2004). A simple extraction method suitable for PCR-based analysis of plant, fungal, and bacterial DNA. Plant Mol. Biol. Rep. 22, 71-81.

Margolis, E., and Levin, B.R. (2008). The evolution of bacteria-host interactions: virulence and the immune over-response. In: Gutirrez, J.Q., Baquero, F., editors. Introduction to the evolutionary biology of bacterial and fungal pathogens. Washington D.C.: ASM Press.

Michael, G.W., Bobosha, K., Blomme, G., Addis, T., Mekonnen, S., and Mengesha, T. (2006). Screening banana cultivars for resistance to bacterial Xanthomonas wilt. InfoMusa, 15(1/2), 10-12.

Mkandawire, A.B., Mabagala, R.B., Guzmán, P., Gepts, P. and Gilbertson, R.L. (2004). Genetic diversity and pathogenic variation of common blight bacteria (Xanthomonas campestris pv. phaseoli and $X$. campestris pv. phaseoli var. fuscans) suggests pathogen coevolution with the common bean. Phytopathol. 94, 593-603.

Mulumba, J.W., Nankya, R., Adokorach, J., Kiwuka, C., Fadda, C., De Santis, P., and Jarvis, D.I. (2012). A risk-minimising argument for traditional crop varietal diversity use to reduce pest and disease damage in agricultural ecosystems of Uganda. Agr. Ecosyst. Environ. 157, 70-86.

Mwangi, M., Mwebaze, M., Bandyopadhyay, R., Aritua, V., Eden-Green, S., Tushemereirwe, W., \& Smith, J. (2007). Development of a semiselective medium for isolating Xanthomonas campestris pv. musacearum from insect vectors, infected plant material and soil. Plant Pathol. 56(3), 383-390.

Mwebaze, J. M., Tusiime, G., Teshemereirwe, W.K., and Kubiriba, J. (2006). The survival of Xanthomonas campestris pv. musacearum in soil and plant debris. Afr. Crop Sci. J. 14(2).

Nakato, G.V., Ocimati, W., Blomme, G., Fiaboe, K.K.M., and Beed, F. (2014). Comparative importance of infection routes for banana Xanthomonas wilt and implications on disease epidemiology and management. Can. J. Plant Pathol. 36, 418-427.

Ocimati, W., Ssekiwoko, F., Karamura, E.B., Tinzaara, W., and Blomme, G. (2013). Does Xanthomonas campestris pv. musacearum colonize banana cord root tissue? Acta Hort. 986, 103-109. doi: 10.17660/Acta Hortic.2013.986.8

Ocimati, W., Tusiime, G., Opio, F., Ugen, M.A., and Buruchara, R. (2017). Sorghum (Sorghum bicolor) as a bean intercrop or rotation crop contributes to the survival of bean root rot pathogens and perpetuation of bean root rots. Plant Pathol. 66(9), 1480-1486. 
Peixoto, A.R., Mariano, R.L.R., Moreira, T.J.O., and Viana, I.O. (2007). Alternative hosts of Xanthomonas campestris pv. viticola. Fitopatol. Bras. dx.doi.org/10.1590/S010041582007000200012

Poeydebat, C., Carval, D., De Lapeyre de Bellaire, L., and Tixier, P. (2016). Balancing competition for resources with multiple pest regulation in diversified agroecosystems: a process-based approach to reconcile diversification and productivity. Ecol. Evol. 6(23), 8607-8616.

Poeydebat, C., Tixier, P., Chabrier, C., de Bellaire, L.D.L., Vargas, R., Daribo, M.O. and Carval, D. (2017). Does plant richness alter multitrophic soil food web and promote plantparasitic nematode regulation in banana agroecosystems? Appl. Soil Ecol. 117, 137-146.

R Core Team (2013). R: A language and environment for statistical computing. R Foundation for Statistical Computing, Vienna, Austria. http://www.R-project.org/.

Raffaele, S., Farrer, R.A., Cano, L.M., Studholme, D.J., MacLean, D., Thines, M., ... and Meyers, B.C. (2010). Genome evolution following host jumps in the Irish potato famine pathogen lineage. Sci. 330(6010), 1540-1543.

Ramappa, H.K., Muniyappa, V., and Colvin, J. (1998). The contribution of tomato and alternative host plants to tomato leaf curl virus inoculum pressure in different areas of South India. Annals Appl. Biol. 133(2), 187-198.

Reddy, JR. (2012). Detection of Xanthomonas campestris pv. holcicola in sorghum by dot immunobinding assay. Epubs,icar.org.in 43, 1990

Romo, J.P., Morales Osorio, J.G., and Yepes, M.S. (2012). Identification of new hosts for Ralstonia solanacearum (Smith) race 2 from Colombia. Rev. Prot. Veg. 27, 151-161.

Rutikanga, A., Sivirihauma, C., Ocimati, W., Night, G., Murekezi, C., Ndungo, V., ... and Blomme G. (2016). Breaking the cycle of Xanthomonas campestris pv. musacearum in infected fields through the cultivation of annual crops and disease control in adjacent fields. J. Phytopathol. 164, 659-670.

Salazar-Jaramillo, L., Paspati, A, van de Zande, L., Vermeulen, C.J., Schwander, T., ... and Wertheim, B. (2014). Evolution of a cellular immune response in Drosophila: a phenotypic and genomic comparative analysis. Genome Biol. Evol. 6(2), 273-289

Sequeira, L., and Averre, C. (1961) Distribution and pathogenicity of strains of Pseudomonas solanacearum from virgin soils in Costa Rica. Plant Dis. Rep. 45, 435-440.

Ssekiwoko, F., Taligoola, K., and Tushemereirwe, W.K. (2006b). Xanthomonas campestris pv. musacearum host range in Uganda. Afr. Crop Sci. J. 14, 111-120.

Ssekiwoko, F., Tushemereirwe, W., Batte, M., Ragama, P.E, and Kumakech, A. (2006a). Reaction of banana germplasm to inoculation with Xanthomonas campestris pv. musacearum. Afr. Crop Sci. J. 14, 151-155.

Todorović, B., Milijašević, S., Rekanović, E., Potočnik, I., and Stepanović, M. (2008) Susceptibility of bean genotypes to Xanthomonas campestris pv. phaseoli in screenhouse conditions. Pestic Phytomed (Belgrade) 23, 167-173.

Tripathi, L., and Tripathi, J.N. (2009). Relative susceptibility of banana cultivars to Xanthomonas campestris pv. musacearum. Afr. J. Biotechnol. 8, 5343-5350.

Vidal, T., Boixel, A., Durand, B., de Vallavieille-Pope, C., Huber, L., and Saint-Jean, S. (2017). Reduction of fungal disease spread in cultivar mixtures: Impact of canopy architecture on rain-splash dispersal and on crop microclimate. Agr. For. Meteorol. 246, 154-161.

Vidhyasekaran, P. (2002). Bacterial disease resistance in plants: molecular biology and biotechnological applications. Food Products Press, Binghamton, NY. Pp. 6-11.

VSN International Ltd. (2009). GenStat $12^{\text {th }}$ Edition. http://www.vsni.co.uk 
Were, E., Nakato, G.V., Ocimati, W., Ramathani, I., Olal, S., and Beed, F. (2015). The banana weevil, Cosmopolites sordidus (Germar), is a potential vector of Xanthomonas campestris pv. musacearum in bananas. Can. J. Plant Pathol. 37(4), 427-434.

Yirgou, D., and Bradbury, J. F. (1974). A note on wilt of banana caused by the enset wilt organism Xanthomonas musacearum. East Afr. Agric. For. J. 40, 111-114. 


\section{Chapter 6}

\section{Banana-legume intensification: pruning banana canopy to intercrop legumes in the East African highlands}

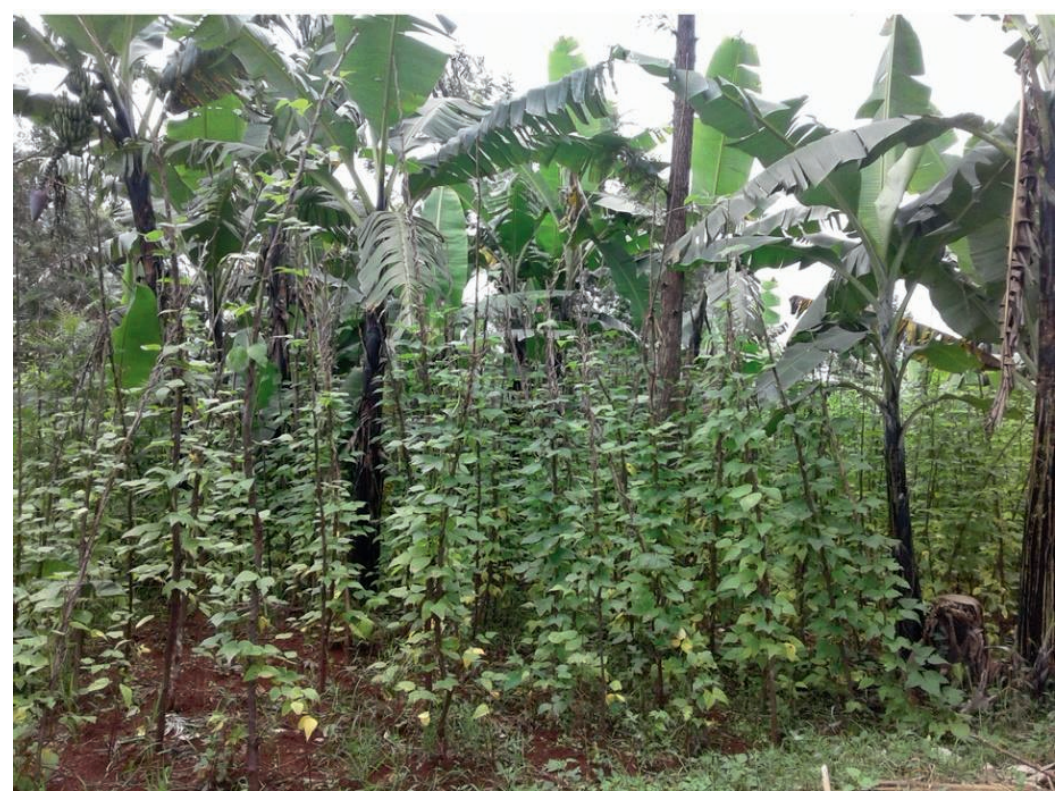

Published as:

Ocimati, W., Ntamwira, J., Groot, J. C. J., Taulya, G., Tittonell, P., Dhed'a, B., ... and Blomme, G. (2019). Banana leaf pruning to facilitate annual legume intercropping as an intensification strategy in the East African highlands. Eur. J Agron., 110, 125923. 


\section{Abstract}

Banana leaf pruning is a common practice to facilitate intercropping with legumes on farmers' fields. It is however not clear if this practice improves farmers land-use and economic efficiency, especially after full canopy formation. To analyse pruning effects, three legumes viz. bush bean (Phaseolus vulgaris L), climbing bean (Phaseolus vulgaris L) and soybean (Glycine max), were planted under three banana leaf pruning levels in which four, seven and all fully grown leaves were retained. Sole banana or legume plots served as controls. Each treatment combination was replicated three times. Banana growth and yield attributes were measured for the plant and first ratoon crops while legume biomass and yields determined over five consecutive cropping seasons. Significant $(\mathrm{P}<0.001)$ reductions in banana growth and yield were associated with leaf pruning. Banana yield reductions of $31 \%$ and $10 \%$ for the four- and seven-leaf retention treatments, respectively occurred. The vigorous intercrops (climbing beans and soybeans) more often depressed the growth and yield of banana. Legume grain and biomass yields increased with leaf pruning levels. Weed biomass and associated management costs increased with decline in shade intensity. The land-use efficiency measured using the land equivalence ratio (LER) was far lower in the treatment with four-leaves (1.10) compared to when all leaves were retained (1.4) but higher (1.54) for the seven-leaf treatment. Severe banana leaf pruning could thus be detrimental to banana performance and inefficient. Moderate banana leaf pruning could however be promoted were land is limiting and farmers want to maximise diversity/nutrition. However, the highest values for gross revenue and benefit-cost ratio were realized for sole banana-all-leaf retention treatment due to a higher labour productivity and lower input costs attributed to the perennial nature of banana. The higher economic efficiency in sole banana plots suggests that reliance on LER only may be insufficient for guiding intercropping decisions.

Keywords: banana, intercrop, leaf pruning, legume, LER, revenue. 


\subsection{Introduction}

Banana-legume intercropping is important in several countries of the African Great Lakes region (AGLR) including Uganda, Rwanda, Burundi, Democratic Republic of Congo (DR Congo) and north-western Tanzania (Wortmann and Sengooba, 1993; Nzawele et al., 2009; Ntamwira et al., 2013a, b; 2014). Banana-legume intercropping is widely practiced due to high population pressure on the land. The region is characterized by high population densities estimated at between 300 and 350 inhabitants per km² (DSRP, 2005; CIALCA, 2010), with each household typically living on less than 0.5 hectare of land. The incorporation of food and/or fodder legumes into banana cropping systems in AGLR could increase the use efficiency of land (Sileshi et al., 2007) and other resources in smallholder banana farms (Ouma, 2009). It is aimed at maximising productivity and minimising risks related to, for example, climate change, pests and diseases (Nyabyenda, 2006; Dapaah et al., 2003; Zinsou et al., 2004) and helps in suppression of weeds (Amanullah et al., 2007). Furthermore, intercropping with nitrogen-fixing legumes may also be a strategy to offset the depletion of soil nitrogen (Chakeredza et al., 2007), thereby contributing to increasing productivity of the system. For example, intercropping with grain legumes (common beans, cowpea, groundnut, pigeon pea or soybean) has been reported to increase productivity with land equivalent ratios of 1.2-1.9 (Pypers et al., 2010).

Wortmann and Sengooba (1993) compared the performance of 16 nonclimbing bean genotypes intercropped with East African highland banana with that in their respective sole crop systems. Intercropping reduced the bean yields to only $50 \%$ of the sole bean yields yet the intercrop bean density was $68 \%$ of the sole crop. This incongruous response to reduction in the bean density in the intercrop compared with that in the sole crop suggests that the banana-bean intercrops were affected by competition for light, water and nutrients, which if well understood can guide the optimization of the system for productivity. Below ground competition for moisture and nutrients in the banana-bean intercrop probably limits bean productivity since both banana and bean species are shallow-rooted (Wortmann and Sengooba, 1993) and require large amounts of nitrogen (N), phosphorus (P) and potassium (K) for growth and development (Maria et al., 2002; Ganeshamurthy et al., 2011; Marschner, 2011; McGrath et al., 2013). Above ground shading of the shorter legume plants by the banana canopy could reduce light interception, growth and yield of the legumes (Nyambo et al., 1982; Davis et al., 1987). Consequently, farmers e.g. in eastern Democratic Republic of Congo, often prune banana leaves to enhance sunlight penetration to the understory component crop so as to improve their growth and yield (Mirindi, 2011; Ntamwira et al., 2013a, b; 2014; Ocimati et al., 
2013; Blomme et al., 2017). However, leaf pruning perpetuates the spread of the bacterial wilt disease of banana (Blomme et al., 2017) and is potentially detrimental to the banana yield (Robinson et al., 1992), hence the need to analyze the leaf pruning effects in banana-legume intercrop systems.

Ntamwira et al. (2013a; 2014) observed no significant differences in banana yield when leaves of fully-grown plants were reduced to seven on farmers' fields and five in controlled field experiments compared with non-pruned controls over four annual cropping seasons. In these experiments, leaves were only cut once when plants were at the flowering stage. In contrast, significant declines in banana plant crop growth and yield were observed when leaves were reduced to four or 7 leaves starting from the third month of planting in controlled field experiments (Ntamwira et al., 2013b). The different legume species (soybeans, bush and climbing beans) performed better when banana leaves were pruned across the three experiments. The Ntamwira et al. (2013b) study reported findings of two bean cropping seasons and the banana plant crop (i.e. first crop established from plantlets or suckers) planted at a spacing of $2 \mathrm{~m} \times 2 \mathrm{~m}$. Our work builds on Ntamwira et al. (2013b) taking into account the significantly higher growth vigour and canopy cover of the banana ratoon crops (new shoots in a banana stool retained for the following crops) compared to those of the plant crop (e.g. Robinson et al., 1993). This study analysed the interaction of the annual crops with the banana crop under different pruning levels over three a three years period (i.e. two banana cropping seasons). Higher shade and competition levels were anticipated in additional season compared to those observed by Ntamwira et al. (2013b).

The specific objective of this study was to determine the requisite banana leaf pruning intensity to optimize productivity of the intercrops. It was hypothesized that there is no effect of banana leaf pruning intensity on the overall land use efficiency and net returns from banana-legume intercropping regardless of banana crop cycle and component legume species. The findings of this study could be relevant for guiding farmers' decisions on banana intercropping and leaf pruning practices.

\subsection{Materials and methods}

\subsubsection{Study location description}

This study was conducted at the Institut National d'Etudes et Recherches Agronomiques (INERA), Mulungu research station in the South Kivu Province in eastern of the Democratic Republic of Congo. Banana is an important food and cash crop in eastern DR Congo, accounting for $70 \%$ of the total crop production landscape (Bakelana and Ndungo, 2004). In this region, the crop is predominantly cultivated on 
smallholdings and in mixtures, with bush beans and taro as the predominant intercrops. To integrate the shorter annual crops such as beans, different levels of leaf pruning (retaining 4 to 7 leaves) is a common practice on farms in the wet seasons (J. Ntamwira personal communication, 2013). The experiments were located at $02^{\circ} 20.042^{\prime} \mathrm{S}, 028^{\circ} 47.311^{\prime} \mathrm{E}$, and an altitude of 1,707 meters above sea level. The soils are volcanic Andosols with: $\mathrm{pH} 8.5$ (read from a 1:2.5 soil:water extract), soil organic matter content 4.9\%, N 0.25\% (using salicylate method (Kempers and Zweers, 1986)), P 126 ppm, exchangeable K 748.8 ppm, exchangeable Ca 23.85 $\mathrm{cmol}(+) / \mathrm{kg}$ and exchangeable $\mathrm{Mg} 1.41 \mathrm{cmol}(+) / \mathrm{kg}$. P, K, Ca and $\mathrm{Mg}$ were extracted using the Mehlich 3 extraction method (Melich, 1984). The mean annual rainfall at the site is $1,500 \mathrm{~mm}$ distributed over two rainy seasons (February to May and September to December). The experimental field had been under banana cultivation for three years. All banana mats were uprooted, and plant debris spread out as mulch across the field one week prior to establishing the intercropping experiment.

\subsubsection{Experimental design and management}

The treatments consisted of combinations of three different banana leaf pruning levels i.e. maintaining i) four, ii) seven and iii) all fully expanded leaves per plant applied to banana monocrops and banana-legume intercrops. On average, the 'all leaves' treatment had nine leaves per plant, while four leaves represented the worstcase scenarios often observed on farmers' fields during intercrops. For the intercrops three different legume species were used: bush bean (cv. MLB49), climbing bean (Phaseolus vulgaris L, cV. AND10) and soybean (Glycine max, cv. SB24). The monocrops of banana and the three legumes served as controls. The banana plants of the East African highland cooking cultivar 'Barhabesha' (genome AAA) were planted on the $13^{\text {th }}$ December 2009. The legume crops were planted among the banana plants at 3 ( $8^{\text {th }}$ March 2010), 9 ( $9^{\text {th }}$ Sept. 2010), 15 (12 ${ }^{\text {th }}$ March 2011), 21 (12 ${ }^{\text {th }}$ Sept. 2011) and 27 ( $9^{\text {th }}$ March 2012) months after banana planting and data were collected during five consecutive legume cropping seasons starting with the MarchJune 2010 season and ending with the March-June 2012 season.

A total of 15 treatments were randomized within four blocks resulting in a randomized complete block design with four replications per treatment and a total of 60 plots. Each plot $\left(120 \mathrm{~m}^{2}\right)$ contained 30 banana mats, in five rows of six mats each, spaced at $2 \mathrm{~m} \times 2 \mathrm{~m}$. Legumes were planted in lines $50 \mathrm{~cm}$ apart, thus giving 20 lines of legumes per plot. Each line of legumes was $12 \mathrm{~m}$ long and the intra-line spacing was $20 \mathrm{~cm}$ for bush bean, $25 \mathrm{~cm}$ for climbing bean and $10 \mathrm{~cm}$ for soybean plants. Senesced banana leaves were removed regularly from legume planting until legume harvest. No banana leaf cutting was carried out during the dry seasons, to 
mimic farmers practice. Leaf cutting is mainly done during the rainy season to allow for adequate sunlight to reach the shorter crops planted within banana fields (Ntamwira et al. 2012, 2013a, b). Weeding was carried out monthly, while desuckering was done at the beginning of the annual cropping season. Farmyard manure was only applied for banana in the planting hole at planting. No additional fertilizer was applied.

\subsubsection{Data collection and measurements}

Data were collected during two banana crop cycles, i.e. the plant crop (first crop cycle or crop resulting from plantlets used to establish plantation) and the first ratoon crop cycle (first suckers allowed to grow to maturity), equivalent to 5 legume crop cycles. Banana and legume data were collected in centrally-located net plots, which comprised 12 banana plants and a $6 \times 4 \mathrm{~m}^{2}$ section of legume crop. Measurements on banana plants for both the plant and first ratoon crop were conducted at flowering and harvest. At flowering stage, data collected included pseudostem circumference (PCSL) at soil level, number of hands and fingers on the second lowest hand.

At banana bunch harvest, data were collected on the weight of the second lowest hand $(\mathrm{kg})$ of the bunch, the length of the middle finger of the second lowest hand, time to harvest (days) and bunch weight $(\mathrm{kg})$. Bunches were harvested when the fruits were deep green, full and rounded (Dadzie and Orchard, 1997). Yield ( $\mathrm{Mg} / \mathrm{ha}$ /year) was computed from the bunch weight $(\mathrm{kg})$ and time to harvest (days), using a cropping density of 2500 banana plants per hectare (i.e. $2 \mathrm{~m} \times 2 \mathrm{~m}$ spacing). Time to harvest for the plant crop was considered as the time from planting to harvest, whereas the time to harvest for the first ratoon crop was calculated as the time from harvest of the plant crop bunch to harvest of the first ratoon crop bunch. Bunch yield ( $\mathrm{Y}$; Mg/ha/year) was determined using a modification of the formula described by Gaidashova et al. (2008) as below:

$$
Y=\frac{W}{T} \cdot D \cdot P \cdot c
$$

Where:

$$
\begin{aligned}
& \mathrm{W}=\text { bunch weight }(\mathrm{kg} / \mathrm{plant}) ; \\
& \mathrm{T}=\text { time to harvest (days); } \\
& \mathrm{D}=\text { number of days in a year ( } 365 \text { days/year); } \\
& \mathrm{P}=\text { plant density }(2500 \text { plants per ha); } \\
& \mathrm{C}=\text { conversion factor from } \mathrm{kg} \text { to } \mathrm{Mg}(1 / 1000) .
\end{aligned}
$$


Legume biomass yield was assessed when $50 \%$ of legumes had formed pods, in a $1 \mathrm{~m} \times 1 \mathrm{~m}$ section located in a corner of each legume net plot, while legume grain yield was assessed in the net plot of $23 \mathrm{~m}^{2}$. Legume biomass was not returned to the plots to mimic the common practices of the smallholder farmers in the study location.

Weed biomass was also assessed during the third (when banana plants were 15 months old) and fourth legume cropping cycle ( $21^{\text {st }}$ month) under the different banana leaf pruning and legume treatments. Weed biomass was assessed before legume planting (coinciding with the time of land preparation) and at legume flowering in a $1 \mathrm{~m} \times 1 \mathrm{~m}$ section located in a corner of each legume net plot. In the banana monocrop plots, weed biomass was similarly assessed in a corner of the banana net plot.

An ACCUPAR photometer probe (Model LP-80, Decagon Devices, Pullman, WA, USA; Decagon Devices, 2004) was used to measure the photosynthetically active radiation (PAR, $\mu \mathrm{mol} / \mathrm{m}^{2} / \mathrm{s}$ ) received by the leguminous crops under the different treatments. The PAR measurements were taken, from the second to the fifth legume cropping seasons, on clear days between mid-day and $2 \mathrm{pm}$, when (i) $50 \%$ of legumes had flowered, (ii) $50 \%$ of legumes had formed pods and (iii) $50 \%$ of legumes had reached full maturity. Twelve light measurements were taken below the banana canopy at $50 \mathrm{~cm}$ height in the legume net plot for each legume treatment and at each of the three legume physiological stages. The legume monocrop and intercrop plots were also visually monitored for the presence and severity of common diseases such as leaf spots and viruses.

Banana and grain legume yield across all treatments were compared using the land equivalent ratio (LER) (Willey, 1985), defined as the amount of mono-cultured land needed to produce the same yield as the specified intercrops. For each crop, the relative yield (RY) was calculated to determine the partial LER for that crop and then the partial LERs were summed to give the total LER for the intercrop (Mazaheri et al., 2006).

$L E R=R Y_{1}+R Y_{2}=\frac{I_{1}}{M_{1}}+\frac{I_{2}}{M_{2}}$

Where:

$R Y_{1}=$ partial LER of crop $1(-)$;

$\mathrm{RY}_{2}=$ partial LER of crop $2(-)$;

$\mathrm{I}_{1}=$ Yield of crop 1 grown as intercrop $\left(\mathrm{kg} \mathrm{ha}^{-1}\right.$ year $\left.^{-1}\right)$;

$\mathrm{M}_{1}=$ Yield of crop 1 grown as monocrop $\left(\mathrm{kg} \mathrm{ha}^{-1} \mathrm{year}^{-1}\right)$; 


$$
\begin{aligned}
& \mathrm{I}_{2}=\text { Yield of crop } 2 \text { grown as intercrop }\left(\mathrm{kg} \mathrm{ha}^{-1} \text { year }^{-1}\right) ; \\
& \mathrm{M}_{2}=\text { Yield of crop } 2 \text { grown as monocrop }\left(\mathrm{kg} \mathrm{ha}^{-1} \text { year }^{-1}\right) .
\end{aligned}
$$

An LER value of 1.0 indicates no difference in relative yield between the intercrop and the collection of monocultures. A total LER greater than 1.0 indicates the presence of positive interactions among the varieties or crops in the mixture and means that any negative interaction that exists in the mixture is not as great as may occur in the monocultures (Mazaheri et al., 2006).

Banana and bean net revenues, i.e. net present value (NPV, US\$/ha) were calculated as the difference between the revenues from legume grain and banana bunch sales and the input costs (labour cost for field preparation, digging planting holes, manure application, banana and legume planting, weeding, banana leaf pruning, banana de-suckering, cost of propping banana and staking climbing beans, and cost of harvesting and post-harvest handling) for the period of the study. Legume gross revenues were estimated using the local market prices for grains (i.e. $1.0 \mathrm{U} \$ / \mathrm{kg}$ while banana gross revenue was estimated using the market price for cooking banana bunches at the closest market to Mulungu research station i.e. 0.15 US\$/kg. Revenues for the different cropping cycles were adjusted upwards or downwards from the computed annual yields/ha using the duration to harvest for the respective treatments. High quality legume seeds and banana suckers were bought at the INERA research station, respectively at $2.5 \mathrm{US \$} / \mathrm{kg}$ and 1 US\$ per sucker. Land preparation or weeding was costed at a wage of 1.33 US\$ per $100 \mathrm{~m}^{2}$, while digging a banana planting hole of $60 \times 60 \times 60 \mathrm{~cm}$ was costed at 0.11 US\$. The stakes for propping climbing beans were bought at 2.22 US\$ per bundle of 100 sticks. A benefit cost ratio (BCR) and the labour productivity for the cropping options were also computed as indices of risk to investment and guidelines for investment decisions. BCR is the ratio of the value of a project to the money spent in undertaking it. BCR provides a value of benefits and costs in actual dollars spent and gained and was computed using the net present values (NPV) of the cropping options. The labour productivity was computed as the ratio of the net present values (NPV) to the cost (US\$) of labour invested in a cropping option (US\$).

\subsubsection{Statistical analysis}

The R statistical software (R Core Team, 2018) and Imer function from the Ime4 package (Winter et al., 2013; Bates et al., 2015) were used to perform a linear mixed model analysis of the relationship between banana/ legume yield growth and yield parameters and the management options. The linear mixed model was used due to the presence of random effects within the experimental treatments. The random 
effects were attributed to the blocks (4 levels) and the banana crop cycles (2 levels). The differences between and within the blocks were predominantly significant $(p<0.05)$ following preliminary analysis of variance using the GenStat v. 12 statistical software (VSN International Ltd., 2009). In contrast, the crop cycles were set as random effects because of potential variations in the environment within the different years of experimentation and influence from the remains of mother plants and other attached shoots in the ratoon crop. The remains of the banana mother plants in a mat following harvest have been reported to support the growth and development of the ratoon crops (Walmsley and Twyford 1968), an effect lacking for the plant crop. The random effects were entered as nested random effects with intercepts. The fixed effects include banana leaf pruning (3 leaf pruning levels), intercrop options ( 4 treatment levels), and the interaction term between the two effects. The above full model and its null and reduced forms were fit to the same data using the maximum likelihood criterion and compared using combinations of the model-fit statistics. The model fit by maximum likelihood generates several model-fit statistics that include the Akaike's Information Criterion (AIC) (Sakamoto et al., 1986); Bayesian Information Criterion (BIC) (Schwarz, 1978); the log-likelihood and deviance of the parameter estimates; chi-square and p-values. The model with smaller values of BIC, AIC and deviance are recommended. For this study, models with the smallest $\mathrm{BIC}$ were selected for subsequent analysis. Where two or more models had more or less the same values of BIC, the AIC, deviance and $p$-values values were also considered. $P$ values were considered significant when $<0.05$. The best model was subsequently refit with the restricted maximum likelihood criterion (REML) which is default for Imer (Bates, 2010) to determine the random and fixed effects in the model. The ImerTest package was used to give the Imer4 package an extended output of the summary consisting of degrees of freedom using the Satterthwaite's (Kenward-Roger's) approximations for the test and corresponding p-values (Kuznetsova et al., 2017). These p-values jointly with the treatment effects were used for comparison of the fixed effects.

For the legumes, the blocks had a zero variance and thus only the seasons that accounted for a greater part of the variance were retained as random effects. The banana canopy levels increased with subsequent seasons and legume performance was thus expected to be affected by this seasonal variation in canopy. Differences were also anticipated for other environmental variables such as nutrient levels, moisture and cloud cover of the different seasons. Only banana leaf pruning levels were considered as the fixed effect. A comparison between the legumes and legume interaction with the banana leaf pruning levels were not considered relevant given 
the inherent differences between the legume species. Further analysis was as for the banana crop above.

Data visualization was attained using the $\mathrm{R}$ statistical software (R Core Team, 2018) and statistical packages devtools (Wickham and Chang, 2018), ggplot2 (Wickham, 2016), ggpubr (Kassambara, 2018) and patchwork (Pedersen, 2017) were used. The residual plots were visually inspected for obvious deviations from linearity, homoscedasticity or normality, and when necessary log transformed. GenStat v. 12 was also used to compute linear regressions with groupings (with the bush bean as the reference level) between PAR and legume grain or biomass yield.

\subsection{Results}

\subsubsection{Banana plant characteristics at flowering and harvest}

Table 1 shows that the reduced model was the best predictor for the banana plant characteristics (i.e. the lowest value for $\mathrm{BIC}$ and $\mathrm{p}<0.05$ for significance of difference with the null model) and was thus used in the subsequent determination of the fixed effects. The fixed effects did not profoundly affect the time to harvest in banana plants (Table 1). Despite this observation, a lower mean time to harvest was observed in banana plants in which four leaves had been retained (Fig. 1a) while the banana monocrop relative to the intercrop treatments had a lower median and mean score (Fig. 1b).

The fixed effects (i.e. banana leaf pruning levels and intercrop options) generally had profound effects on banana pseudostem circumference at soil level, the number of hands on bunch and the number of fingers on the second lowest hand (Table 2). Banana leaf pruning significantly $(p<0.001)$ reduced all the above parameters measured at flowering, with higher effects realized for the severe banana leaf pruning i.e. to four leaves (Table 2, Figs. 2a-2c). For example, the intercepts of pseudostem circumference were 3.2 and $8.8 \mathrm{~cm}$ smaller in the seven and four-leaf treatments, respectively, compared to the situation without banana leaf pruning (Table 2). 
Table 1. The Bayesian Information Criterion (BIC) for null, reduced and full linear mixed models fit on the same banana growth and yield data. The model fixed effects include three levels of banana leaf pruning and four banana-legume intercrop treatments while the random effects are the blocks and banana crop cycles. For a given dependent variable, the best fit model is the one with the lowest BIC value.

\begin{tabular}{lccc}
\hline Dependent variable & $\begin{array}{c}\text { Null } \\
\text { model }\end{array}$ & $\begin{array}{c}\text { Reduced } \\
\text { model }\end{array}$ & $\begin{array}{c}\text { Full } \\
\text { model }\end{array}$ \\
\hline Pseudostem circumference at soil level & 6763.1 & 6456.0 & 6476.9 \\
Number of hands on bunch & 2565.8 & 2448.5 & 2469.1 \\
Fingers on second hand & 2150.6 & 2089.1 & 2091.5 \\
Time to harvest & 10089.0 & 10104.0 & 10133.0 \\
Finger length & 4507.1 & 4282.9 & 4310.9 \\
Bunch weight & 5445.1 & 5069.2 & 5092.6 \\
Yield & -492.6 & -682.1 & -673.6 \\
\hline
\end{tabular}

Null model: $y \sim 1+\left(1 \mid\right.$ block/cycle); reduced model: $y \sim x_{1}+x_{2}+\left(1 \mid\right.$ block/cycle); and full model: $y \sim x_{1}{ }^{*} x_{2}$ $+\left(1 \mid\right.$ block/cycle). ' $y$ ' is the dependent variable (i.e. measured parameter), ' $x_{1}$ ' and ' $x_{2}$ ' respectively, the de-leafing treatments and the intercrop option that are the fixed effects. Block (treatment blocks) and cycle (crop cycles) are the random effects of the model.

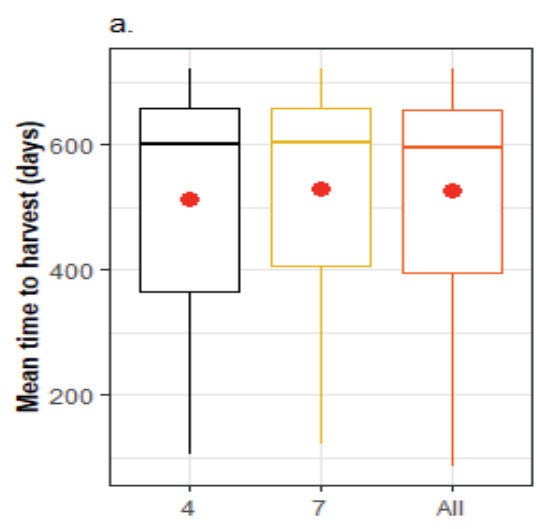

No. banana leaves retained

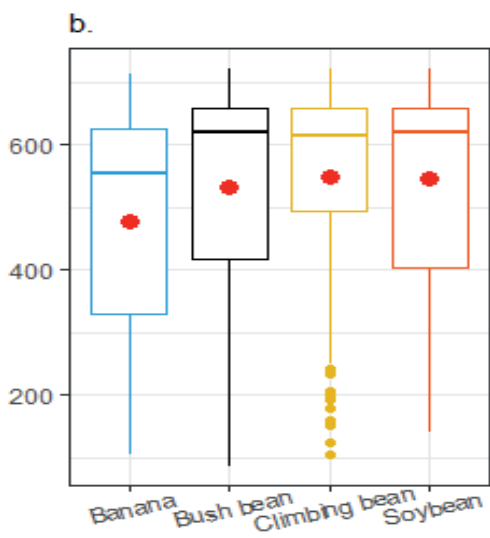

Intercrop treatments

Figure 1. Mean time to harvest banana bunches under different leaf pruning levels (a) and intercrop options (b). " 4 ", "7" and "All", respectively, denote four, seven and all fully open leaves retained on the banana plants. The horizontal line within each box is the median while the red diamond shape is the mean. The lower and upper boundaries of the boxes are respectively, the $25^{\text {th }}$ and $75^{\text {th }}$ percentile; the bars/whiskers below and above the box the $10^{\text {th }}$ and $90^{\text {th }}$ percentile and points beyond $10^{\text {th }}$ and $90^{\text {th }}$ percentiles are outliers. 
Table 2. Experiment to understand the effect of banana leaf pruning to integrate legumes on the performance of the component crops. Fixed effects of three banana leaf pruning levels (i.e. retaining 4, 7 and all fully open leaves) and intercrops of bush bean (cv. MLB49), climbing bean (cv. AND10) and soybeans on pseudostem circumference at soil level (cm), number of hands on bunch and fingers on second lowest hand. The experiment was established under controlled conditions at the Institut National d'Etudes et Recherches Agronomiques, Mulungu research station in eastern Democratic Republic of Congo.

\begin{tabular}{llcccc}
\hline $\begin{array}{l}\text { Banana } \\
\text { parameter }\end{array}$ & Effects & Estimate & S. E & $\begin{array}{c}\mathbf{t} \\
\text { value }\end{array}$ & $\operatorname{Pr}(>|\mathbf{t}| \mathbf{)}$ \\
\hline Pseudostem & (Intercept) & 80.83 & 1.17 & 68.80 & $1.5 \mathrm{E}-13$ \\
circumference & 7 leaves & -3.22 & 0.45 & -7.13 & $1.9 \mathrm{E}-12$ \\
at soil level & 4 leaves & -8.81 & 0.45 & -19.53 & $<2.0 \mathrm{E}-16$ \\
& Banana-climbing bean intercrop & 0.75 & 0.52 & 1.45 & 0.1483 \\
& Banana-bush bean intercrop & 1.19 & 0.51 & 2.33 & 0.0203 \\
& Banana-soybean intercrop & -0.96 & 0.51 & -1.87 & 0.0622 \\
\hline Number of & (Intercept) & 7.80 & 0.09 & 83.96 & $3.5 \mathrm{E}-13$ \\
hands on & 7 leaves & -0.12 & 0.06 & -1.90 & 0.0582 \\
bunch & 4 leaves & -0.75 & 0.06 & -11.66 & $<2.0 \mathrm{E}-16$ \\
& Banana-climbing bean intercrop & -0.17 & 0.07 & -2.27 & 0.0235 \\
& Banana-bush bean intercrop & -0.10 & 0.07 & -1.40 & 0.1610 \\
& Banana-soybean intercrop & -0.08 & 0.07 & -1.09 & 0.2753 \\
\hline Number of & (Intercept) & 7.94 & 0.08 & 103.18 & $<2.0 \mathrm{E}-16$ \\
fingers on the & 7 leaves & -0.11 & 0.05 & -2.04 & 0.0415 \\
second lowest & 4 leaves & -0.47 & 0.05 & -8.90 & $<2.0 \mathrm{E}-16$ \\
hand & Banana-climbing bean intercrop & -0.15 & 0.06 & -2.48 & 0.0134 \\
& Banana-bush bean intercrop & -0.20 & 0.06 & -3.31 & 0.0010 \\
& Banana-soybean intercrop & -0.09 & 0.06 & -1.41 & 0.1585 \\
\hline
\end{tabular}

Bush and climbing bean intercrops resulted in larger pseudostems compared to the banana monocrop whereas soybean intercrop depressed the size of the pseudostem (Table 2, Fig. 2b). However, the effect of climbing beans and soybean did not result in pseudostem circumferences that were significantly $(P>0.05)$ different from that of the banana monocrop. The intercrops negatively affected the number of hands, though this was only significant $(P=0.0235)$ for the climbing beans. Similarly, the number of fingers on the second lowest hand of the bunch were depressed by all intercrops, though only significantly in the bush $(P=0.0010)$ and climbing beans ( $P=0.0134)$ (Table 2$)$. 
a.

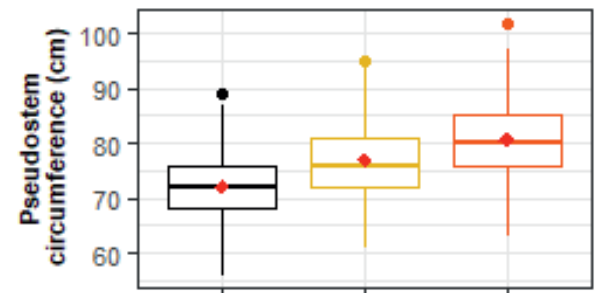

C.

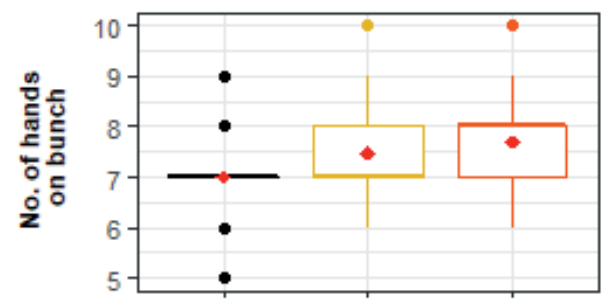

e.

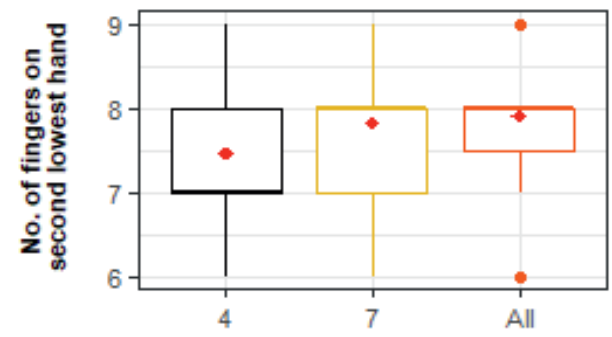

No. of banana leaves retained b.

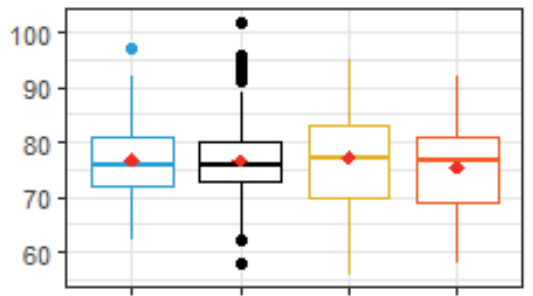

d.

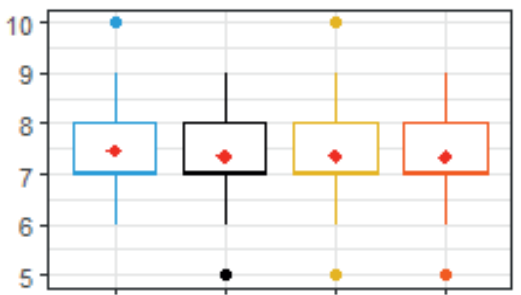

f.

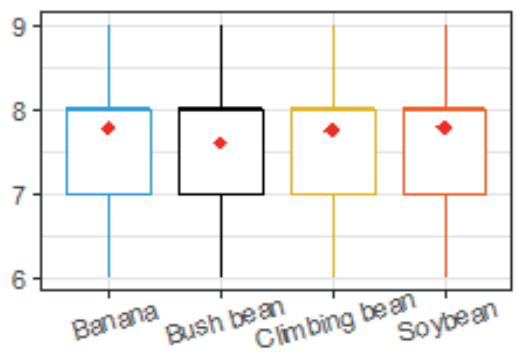

Intercrop treatments

Figure 2. Banana pseudostem circumference at soil level, number of hands on the bunch and number of fingers on the second lowest hand of bunch for different leaf pruning levels and intercrop options. "4", "7" and "All", respectively, denote four, seven and all fully open leaves retained on the banana plants. The horizontal line within each box is the median while the red diamond shape is the mean. The lower and upper boundaries of the boxes are respectively, the $25^{\text {th }}$ and $75^{\text {th }}$ percentile; the bars/whiskers below and above the box the $10^{\text {th }}$ and $90^{\text {th }}$ percentile and points beyond $10^{\text {th }}$ and $90^{\text {th }}$ percentiles are outliers.

Leaf pruning and the legume intercrops also affected the finger length, bunch weight and overall banana yield measured at harvest (Table 3, Figs. 3a, 3c, 3e). Finger length, bunch weight and yield significantly decreased $(P<0.01)$ with the increasing level of leaf pruning (Table 3, Figs. 3a, 3c and 3e). For example, the finger length intercepts for the seven and four-leaf treatments dropped by 0.56 and $2.93 \mathrm{~cm}$, respectively, from an intercept of $20.68 \mathrm{~cm}$ in the all leaf treatment. 
The intercrops, except for the bush bean crop that resulted in increased finger length $(P=0.0005)$, generally depressed finger length, bunch weight and banana yield (Table 3, Figs. 3b, 3d, 3e). Significant negative effects were however only caused by the climbing bean intercrop on bunch weight $(\mathrm{P}=0.0038)$ and banana yield $(P<0.0001)$ and by soybean on banana yield $(P<0.0001)$ (Table 3$)$.

Table 3. Experiment to understand the effect of banana leaf pruning to integrate legumes on the performance of the component crops. Fixed effects of three levels of banana leaf pruning (i.e. retaining 4, 7 and all leaves) and legume intercrops (i.e. bush bean (cv. MLB49), climbing bean (cv. AND10) and soybean) on finger length, bunch weight and yield of banana. The experiment was established under controlled conditions at the Institut National d'Etudes et Recherches Agronomiques, Mulungu research station in eastern Democratic Republic of Congo.

\begin{tabular}{|c|c|c|c|c|c|}
\hline $\begin{array}{l}\text { Banana } \\
\text { parameter }\end{array}$ & Effect & Estimate & S. E. & $\begin{array}{c}\mathbf{t} \\
\text { value }\end{array}$ & $\operatorname{Pr}(>|t|)$ \\
\hline \multirow{6}{*}{$\begin{array}{l}\text { Finger } \\
\text { length }\end{array}$} & (Intercept) & 20.68 & 0.31 & 66.10 & $<2.0 \mathrm{e}-16$ \\
\hline & 7 leaves & -0.56 & 0.19 & -2.97 & 0.0031 \\
\hline & 4 leaves & -2.93 & 0.19 & -15.52 & $<2 \mathrm{e}-16$ \\
\hline & Banana-climbing bean intercrop & -0.12 & 0.22 & -0.56 & 0.5781 \\
\hline & Banana-bush bean intercrop & 0.75 & 0.21 & 3.52 & 0.0005 \\
\hline & Banana-soybean intercrop & -0.31 & 0.22 & -1.44 & 0.1504 \\
\hline \multirow{6}{*}{$\begin{array}{l}\text { Bunch } \\
\text { weight }\end{array}$} & (Intercept) & 18.23 & 0.70 & 25.88 & $<0.0001$ \\
\hline & 7 leaves & -1.37 & 0.27 & -5.00 & $6.8 \mathrm{E}-07$ \\
\hline & 4 leaves & -5.87 & 0.27 & -21.48 & $<2.0 \mathrm{E}-16$ \\
\hline & Banana-climbing bean intercrop & -0.91 & 0.31 & -2.90 & 0.0038 \\
\hline & Banana-bush bean intercrop & -0.14 & 0.31 & -0.44 & 0.6575 \\
\hline & Banana-soybean intercrop & -0.58 & 0.32 & -1.83 & 0.0675 \\
\hline \multirow{6}{*}{$\begin{array}{l}\log _{10} \\
\text { (Yield) }\end{array}$} & (Intercept) & 1.626 & 0.08 & 21.61 & $6.4 \mathrm{E}-08$ \\
\hline & 7 leaves & -0.048 & 0.01 & -3.66 & 0.0003 \\
\hline & 4 leaves & -0.190 & 0.01 & -14.51 & $<2.0 \mathrm{e}-16$ \\
\hline & Banana-climbing bean intercrop & -0.063 & 0.01 & -4.26 & $2.3 \mathrm{E}-05$ \\
\hline & Banana-bush bean intercrop & -0.022 & 0.01 & -1.49 & 0.1374 \\
\hline & Banana-soybean intercrop & -0.058 & 0.01 & -3.94 & $9.0 \mathrm{E}-05$ \\
\hline
\end{tabular}


a.

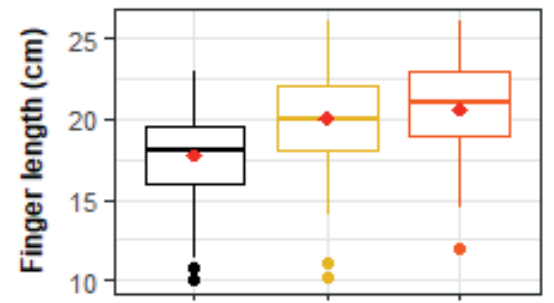

C.

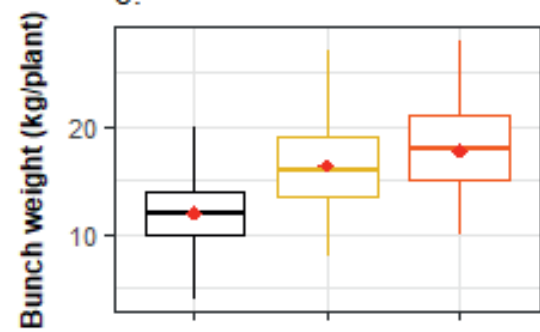

e.

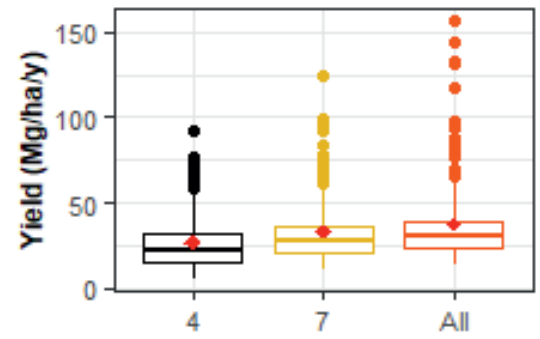

No. of banana leaves retained b.

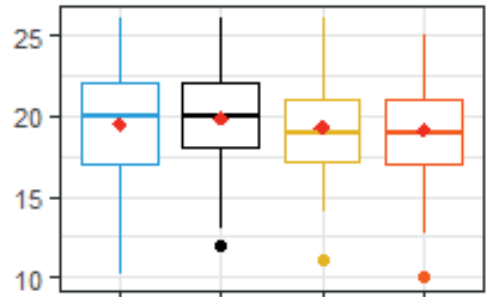

d.

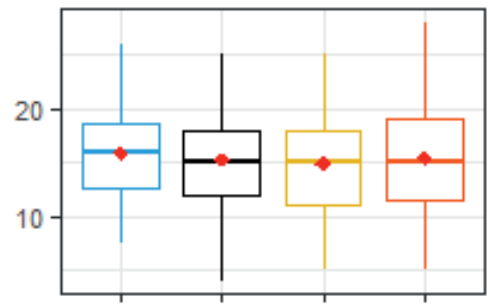

f.

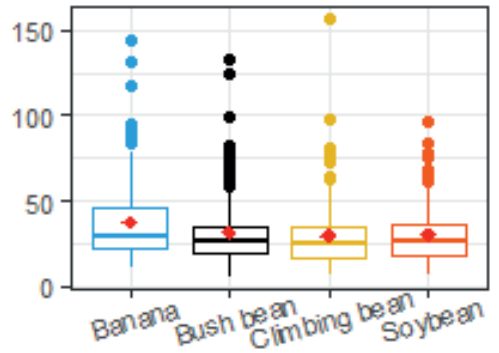

Intercrop treatments

Figure 3. Banana finger length, bunch weight and yield for different leaf pruning levels and intercrop options. "4", "7" and "all", respectively, denote four, seven and all fully open leaves retained on the banana plants. The horizontal line within each box is the median while the red diamond shape is the mean. The lower and upper boundaries of the boxes are respectively, the $25^{\text {th }}$ and $75^{\text {th }}$ percentile; the bars/whiskers below and above the box the $10^{\text {th }}$ and $90^{\text {th }}$ percentile and points beyond $10^{\text {th }}$ and $90^{\text {th }}$ percentiles are outliers.

\subsubsection{Light interception, weed biomass, legume grain and biomass yields}

Retaining a larger number of banana leaves adversely affected light transmission to the underlying legumes in the intercrop systems. The amount of PAR intercepted at $1 \mathrm{~m}$ height significantly increased with the level of leaf pruning (Fig. 4a). However, PAR under the four-leaf treatment was significantly $(P<0.001)$ lower than that above the sole legume crop (Fig. 4a). 

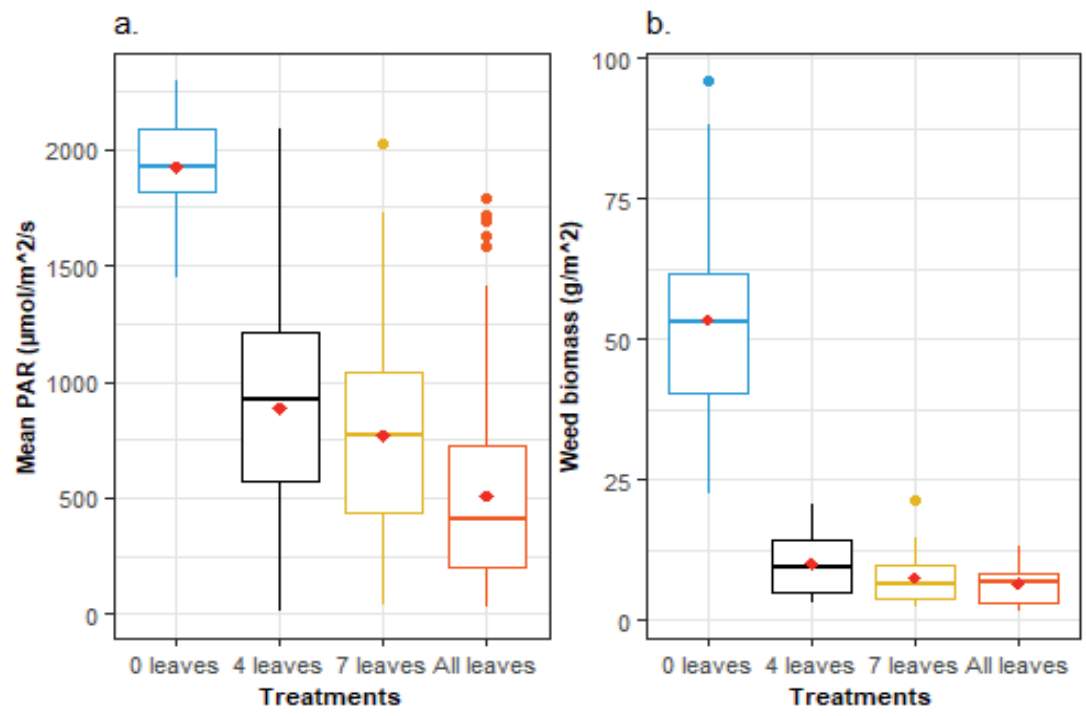

Figure 4. Photosynthetically active radiation (PAR) (a) and weed biomass (b) above/in legume monocrop field (i.e. 0 leaves) and under banana at three leaf pruning levels. "4 leaves", "7 leaves" and "All leaves", respectively, denote four, seven and all fully open leaves retained on the banana plants. The horizontal line within each box is the median while the red diamond shape is the mean. The lower and upper boundaries of the boxes are respectively, the $25^{\text {th }}$ and $75^{\text {th }}$ percentile; the bars/whiskers below and above the box, the $10^{\text {th }}$ and $90^{\text {th }}$ percentile and points beyond $10^{\text {th }}$ and $90^{\text {th }}$ percentiles are outliers.

The effect of PAR was clearly visible on the growth of weeds. Weed biomass yields were significantly higher $(P<0.05)$ in the legume monocrop fields compared with the fields that had banana, irrespective of the intercrop legume component crop or the number of leaves retained on the banana plants (Fig. 4b). Weed biomass significantly $(P<0.05)$ increased with a decline in the number of leaves retained on the banana plants (Fig. 4b).

The cycle (seasonal) effects accounted for $52-55 \%$ of the variance in the random effects on the legume biomass and grain yield while the blocks accounted for $0 \%$ of the variance. Leaf pruning significantly $(P<0.01)$ affected legume biomass and grain yields. Consistently the legume biomass and grain yields were significantly lower in the banana-legume intercrop fields compared with the legume monocrops and increased with increasing leaf pruning levels (Table 4, Fig. 5). The leaf pruning effects on legume biomass and grain yield did not however profoundly differ between the 7-leaf and the all-leaf treatments. Regression analysis showed that the PAR accounted for about $72 \%$ and $78 \%$ of the observed variation in biomass and grain yields respectively. 
Table 4. Experiment to understand the effect of banana leaf pruning to integrate legumes on the performance of the component crops. Fixed effects of three levels banana leaf pruning (i.e. retaining 4, 7 and all leaves) and a control of legume monocrops as a fixed effect on legume biomass and grain yield. The experiment was established under controlled conditions at the Institut National d'Etudes et Recherches Agronomiques, Mulungu research station in eastern Democratic Republic of Congo

\begin{tabular}{lcccc}
\hline Legume parameters/ Effects & Estimate & S. E. & t value & $\operatorname{Pr}(>|\mathrm{t}|)$ \\
\hline Legume biomass yield $(\mathrm{kg} / \mathrm{ha})$ & & & & \\
(Intercept) & 2252.5 & 443.6 & 5.08 & 0.0057 \\
4 leaves & -957.0 & 144.8 & -6.61 & $2.6 \mathrm{E}-10$ \\
7leaves & -1226.7 & 144.8 & -8.47 & $2.8 \mathrm{E}-15$ \\
All leaves & -1410.0 & 144.8 & -9.74 & $<2.0 \mathrm{E}-16$ \\
\hline Legume grain yield $(\mathrm{kg} / \mathrm{ha})$ & & & & \\
(Intercept) & 748.4 & 120.6 & 6.20 & 0.0024 \\
4 leaves & -332.0 & 44.3 & -7.50 & $1.4 \mathrm{E}-12$ \\
7leaves & -452.2 & 44.1 & -10.26 & $<2.0 \mathrm{E}-16$ \\
All leaves & -500.8 & 44.1 & -11.36 & $<2.0 \mathrm{E}-16$ \\
\hline
\end{tabular}
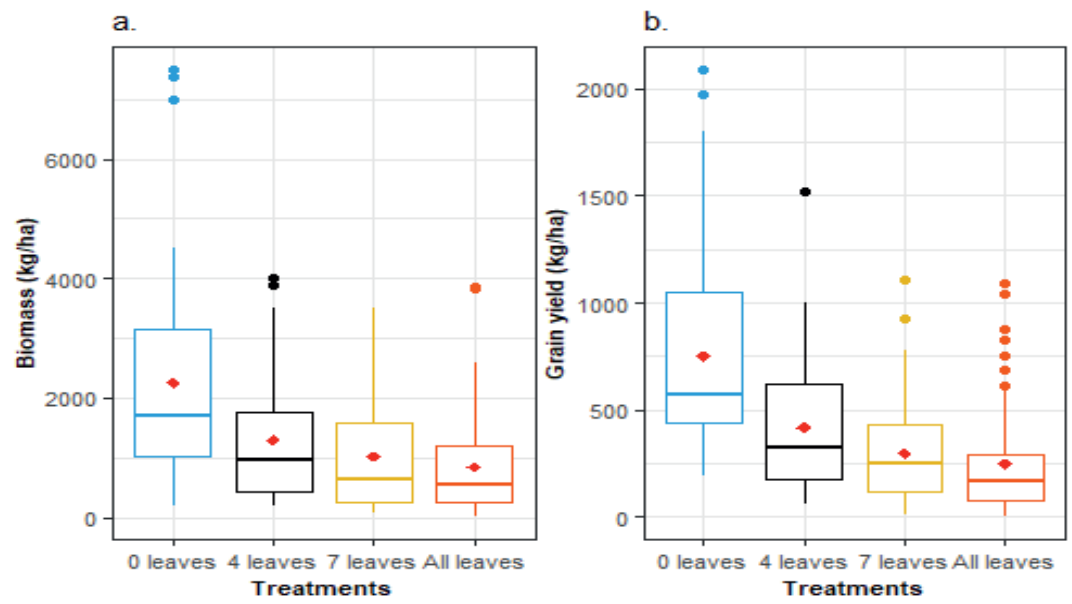

Figure 5. Legume biomass (a) and grain yield (b) in a legume monocrop (i.e. 0 leaves) and under three banana leaf pruning levels (i.e. 4, 7 and All leaves). "4 leaves", "7 leaves" and "all leaves", respectively, denote four, seven and all fully open leaves retained on banana plants. The horizontal line within each box is the median while the red diamond shape is the mean. The lower and upper boundaries of the boxes are respectively, the $25^{\text {th }}$ and $75^{\text {th }}$ percentile; the bars/whiskers below and above the box, the $10^{\text {th }}$ and $90^{\text {th }}$ percentile and points beyond $10^{\text {th }}$ and $90^{\text {th }}$ percentiles are outliers.

Septoria brown spot caused by the fungus Septoria glycines and angular leaf spot caused by Phaeoisariopsis griseola were observed on soybean and bush/climbing beans, respectively. The severity of these two diseases was higher in 
the legume monocrop plots, while in the intercropped plots, legume disease severity increased with increasing level of leaf pruning.

\subsubsection{The land equivalent ration (LER), income and risk of investment analysis} Agronomic yield advantage measured in terms of LER (i.e. LER $>1$ ), was observed for all the banana-legume intercrops (Table 5). LER values varied between 1.54 in the banana-seven-leaf soybean intercrop and 1.10 in the banana with four leaves intercropped with climbing bean. In all cases, a higher LER value was obtained in the seven-leaf treatment when compared with the treatment in which all banana leaves were retained. In contrast, the four-leaf treatments under-performed in comparison to the all-leaf treatment (Table 5).

The gross revenue calculations revealed a high gap between the four, seven and all-leaf treatments across the banana monocrop and the banana-legume intercrops. For a given legume intercrop, gross revenues consistently declined with increasing level of leaf pruning. The banana monocrop average gross revenue varied between 8788 and 11429 US\$/ha for the period of study (i.e. 30 months) in the sole banana four-leaf and all-leaf treatments respectively, while it varied between 9212 and 13042 US\$/ha/annum in the banana-legume intercrop treatments (Table 5). The gross revenues from the sole banana and banana-intercrops were far higher than those from the sole legume crops (2907-4615 US\$/ha) due to the higher production per ha and monetary value of banana in the market. However, input and the labour costs where higher for the banana-legume intercrops compared to the sole banana crop resulting in lower net revenues for the banana-legume intercrops. The net revenue for the sole banana crop varied between 5432 US\$/ha for the four-leaf and 8103 US\$/ha for all-leaf treatments over a 30 months period compared with 3504 and 7366 US\$/ha for the four-leaf and all-leaf banana-climbing bean and bananabush bean intercrops, respectively (Table 5). For the intercrop treatments, the banana-bush bean intercrop was more profitable than the banana-soybean and climbing bean intercrops (Table 5 ). A benefit cost ratio (BCR) revealed a higher return for every unit cost invested in the banana monocrop plots (1.6-2.4) compared with the intercrops (0.6-1.4) (Table 5). Higher returns were also realized for the all-leaf treatments (1.2-1.4) compared with 1.0-2.2 for the seven-leaf and 0.6-1.6 for the four-leaf treatments. A higher return for labour (i.e. 9.8-15.4 US\$/ unit labour cost) was also observed for the banana monocrop fields compared to the sole legume (0.30.9) and legume-banana intercrop (1.6-3.6) fields (Table 5). 


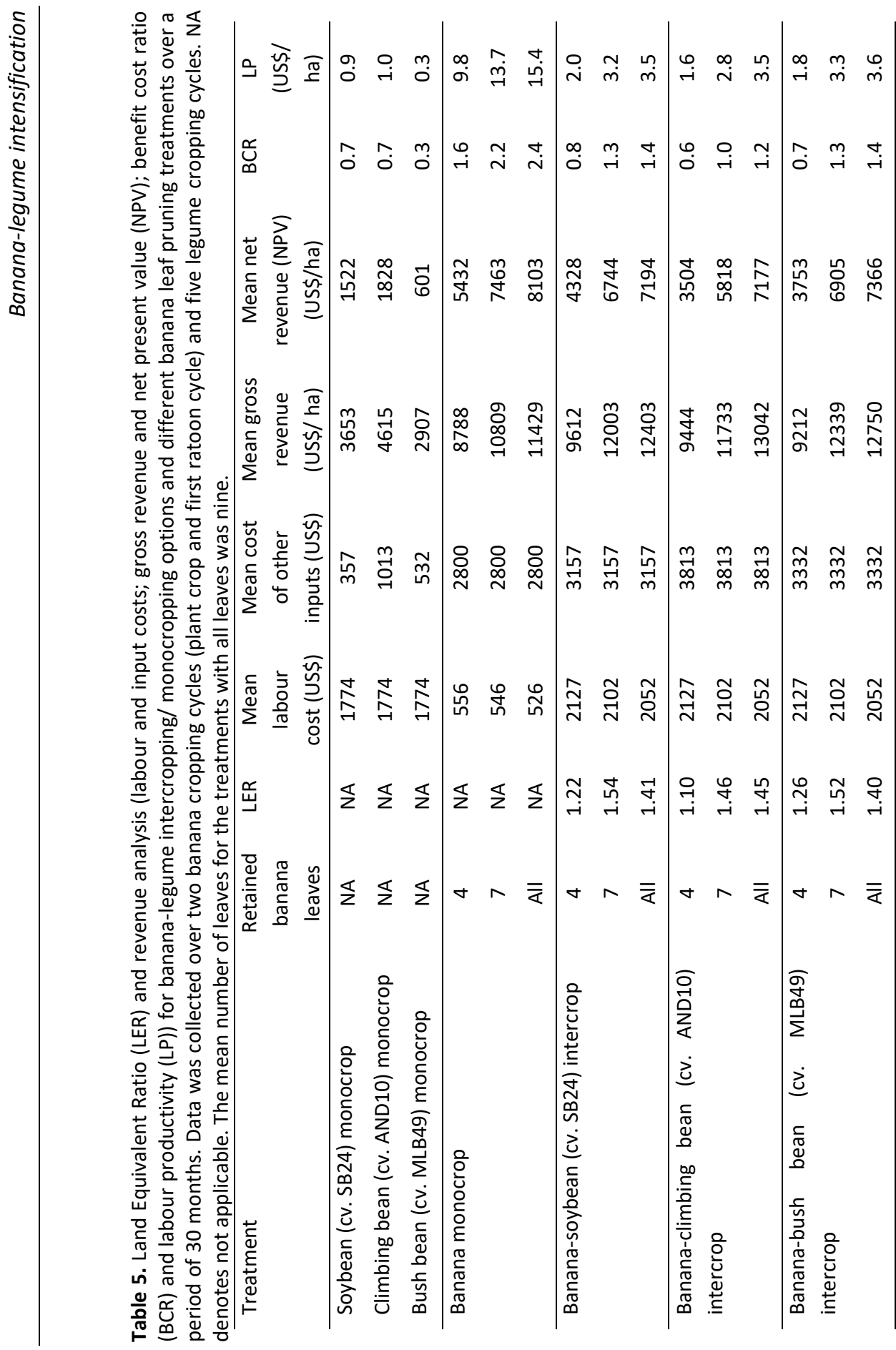

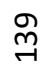




\subsection{Discussion}

Intercropping of bananas in East Africa has increased due to the currently increasing land pressure (Bekunda and Woomer, 1996; Bekunda, 1999; Ntamwira et al., 2013b; Ocimati et al., 2013; Tittonell and Giller, 2013). To intercrop shorter crops such as the legume crops within banana fields, pruning banana leaves is one of the intensification practices applied by smallholder farmers, mainly to meet their household food security and nutritional needs. This practice is aimed at increasing the efficiency of using the limited area of available land. Despite its role in the spread of the Xanthomonas wilt (XW) disease of banana (Blomme et al., 2017) it persists, especially in the eastern part of DR Congo. This study explored the effect of this practice on the performance of the component crops and overall productivity and profitability of the system.

In the current study, with exception of the time to harvest, negative effects on banana growth and yield attributes occurred with increasing levels of banana leaves pruned. The time to harvest was not significantly $(P>0.05)$ affected by both the banana leaf pruning treatments and the intercrops. This is consistent with finding by Ntamwira et al. (2013) for banana-legume intercrops in which banana leaves were reduced to 5 and 7 . The reduced performance of the banana crop attributes with the subsequent reduction in number of functional leaves could be primarily due to the reduced photosynthetic capacity and production of assimilates for growth and partitioning into the storage organs and increase in evapotranspiration with declining canopy cover. Leaf area is often used to estimate the photosynthetic capacity and to predict the performance of a banana crop (Stover and Simmonds, 1987; Echeverry, 2001). A strong positive relationship between leaf area and bunch weight has been reported for east African Musa spp. genotypes (Mukasa et al., 2005). Leaf pruning could have also led to a reduced root mass, leading to a lower supply of water and nutrients for photosynthesis, growth and development. A significant reduction in root system and above ground plant growth following leaf pruning in banana has been reported (Blomme et al., 2001). In this study, the retention of four leaves on banana plants mimicked the worst-case scenario observed commonly on some farms in the annual cropping season. This practice severely depressed bunch weights, yields and the overall performance of plants (cf. Fig. $3 c, f$ and Table 1 ). In contrast, the performance of the banana plants with seven leaves were profoundly different from those with all leaves. Robinson et al. (1992) reported a $35 \%$ increase in $\mathrm{CO}_{2}$ uptake and a greater photosynthetic efficiency in retained leaves after pruning banana leaves of $\mathrm{cv}$. Williams. This could explain the lower yield depression in the banana plants when mildly pruned (e.g. to seven 
leaves). Krishnamoorthy et al. (2004) reported seven to eight functional leaves as a requirement for optimal bunch formation and fruit filling at flowering. In contrast, Balbín and Zapata (2001) also reported five healthy leaves at flowering to be enough for bunch development. Retention of five and seven leaves were also confirmed not to significantly depress the yield of banana by Ntamwira et al. (2013a, b and 2014).

The banana yields obtained in this study (32-46 $\mathrm{Mg} \mathrm{ha}^{-1}$ year $^{-1}$ ) were comparable to yields reported for banana-legume intercrops on farmers' fields (31$42 \mathrm{Mg} \mathrm{ha}^{-1}$ year $^{-1}$ ) in study region by Ntamwira et al. (2014) but higher than those on farmers' fields (6-42 $\mathrm{Mg} \mathrm{ha}^{-1}$ year $^{-1}$ ) in other regions in the AGLR (e.g. Okumu et al., 2011; Ndabamenye et al., 2013; van Asten et al., 2011). This performance is however still lower than the achievable yields of $60-70 \mathrm{Mg} \mathrm{ha}^{-1}$ year ${ }^{-1}$ under recommended practices (Tushemereirwe et al., 2001; Smithson et al., 2001). The relatively good performance of banana plants even when leaves had been pruned in the current study despite not adhering to recommended soil input levels can be attributed to the high fertility level at the site. Different responses could potentially have been obtained for these treatments under varying soil fertility conditions. For example, in Rwanda, Ndabamenye et al. (2013) observed Ca, Mg and K to limit plant density at Rubona that had a lower soil fertility while increasing plant density did not always result in nutrient imbalance at Ruhengeri that had a high soil fertility level.

In general, the intercrops reduced the performance of banana, though often non-significantly at $P=0.05$. The bush beans (cv. MLB49) that have a smaller stature and biomass had the least effect on bunch weight and yields, suggesting a potential effect of competition for the below ground resources from the more robust climbing beans (cv. AND10) and soybeans. Similar observations were reported by Mclntyre et al. (2001) and Ntamwira et al. (2012; 2013a, b, 2014) for banana-legume intercrops.

Nitrogen is one of the key yield-limiting nutrients for banana (Nyombi et al., 2010; Taulya, 2013) and the integration of legumes that biologically fix $\mathrm{N}$ into the soil has often been recommended as a strategy for offsetting soil $\mathrm{N}$ balance and improving yields of other component crops. However, the heavy shading under the all- and seven-leaf treatments do not seem to offer conducive conditions for $\mathrm{N}$ fixation by the legumes, as such this benefit may not be fully harnessed and needs to be further explored. Shading has been reported to cause a marked loss of roots and nodules, and subsequently biological nitrogen fixation by different legume species (Butler et al., 1959; Fujita et al., 1992). Dry matter (DM) allocation plasticity suggests that more DM gets allocated to the shoots when light or carbondioxide is limiting and to the roots when water or nutrients are limiting (Bloom et al., 1985; McCarthy and Enquist, 2007). In the current situation, more DM in the legumes under the heavily shaded plots would be allocated to the shoots resulting into poorly 
developed and less competitive legume-root systems and thus a depression in the activity of the symbiotic bacteria (Bloom et al., 1985). Similar situations of dry matter plasticity have been reported in vines (Grechi et al., 2007), Cryptomeria japonica (McCarthy and Enquist, 2007) and Lindera melissifolia seedlings (Lockhart et al., 2012). Grechi et al. (2007) observed that vine leaves under shade had an increased specific leaf area (i.e. thinner leaves); a significantly reduced dry weight and a low root to shoot biomass ratio. In the above situation, the banana plants with fourleaves would possibly not also benefit from the increased $\mathrm{N}$ fixation arising from the increased light penetration and improved legume root development due to a poorly developed root system and reduced photosynthetic capacity. Apart from $\mathrm{N}$ fixation, plants also compete for water and other essential minerals such as potassium and phosphorus. Integration of legumes would thus be effective when these other resources are not limiting in the system.

Legume grain and biomass yields as expected increased with leaf pruning levels and amount of PAR received by the legume crops, PAR accounting to over $70 \%$ of the observed variation in legume yield. The PAR values declined by approximately $36 \%$ in the four-leaf treatments and $74 \%$ in the all leaf treatments compared to the legume monocrops. Akyeampong et al. (1999) showed a $27 \%$ decrease in PAR not to affect bean yields in a banana-tree-bean experiment, although a further decrease to $42 \%$ of total PAR decreased dry bean grain yield by $27 \%$ compared with the control. The current decline in PAR values are above the $27 \%$ in Akyeampong et al. (1999) and result in yield declines varying between 56 and $86 \%$ in the four and all-leaf treatments respectively. In contrast, increasing the amount of light penetration to the annual crops under the banana canopy, led to increased weed growth and frequency of weeding and thus raising the labour costs for weed management. Weeds also increase competition for water and nutrients.

Higher severities of septoria brown spot and angular leaf spot were observed in the legume monocrop plots, and to increase with increasing levels of leaf pruning in the banana-legume intercrop plots. This suggests a positive effect of the banana canopy on reducing their spread. The role of crop or cultivar mixtures in disease and pest suppression has been reported in several studies (Boudreau, 2013; Vidal et al., 2017; Li et al., 2018; Mulumba et al., 2012; Ocimati et al., 2018). The mechanisms for disease suppression in mixtures include: a change in the microclimate, vector population and behaviour; pathogen dispersal rate; host alteration; dilution effect due to decrease in the susceptible host; and pathogen inhibition (Boudreau, 2013; Vidal et al., 2017). Septoria brown spot and angular leaf spot are mainly favoured by presence of infested plant debris, volunteer crops and infected seed (Celleti et al., 2006; Allen et al., 2017). Rainfall events help to splash their spores from plant debris 
into the plant canopies, leading to infection (Celleti et al., 2006; Allen et al., 2017). The observed trend in the severity of these two diseases in the current study could be attributed to the increasing impact of rain drops with declining leaf canopy levels. Understanding the potential influence of banana-legume intercropping on the prevalence of pests and diseases in a system is thus also important.

The agronomic advantage for banana-legume intercrop combinations measured as LER, was greater than one across all leaf pruning treatments but highest for intercrops in which seven leaves had been retained. This suggests a higher land use efficiency in intercrops compared with sole crops (Prasad and Brook, 2005). The LER values suggest that area planted to monocultures would need to be larger than the current area planted to the intercrops by 10 to $54 \%$ to produce the same value as realized from the intercrops. The observed LER values agree with values (1.2-1.9) reported by Pypers et al. (2010) for banana-grain legume intercrops. LER in bananabased systems may thus be increased by incorporating food and/or fodder legumes within the banana fields. High LER values of 1.5 and 2.5 reported for banana intercrops with Robusta and Arabica, respectively (van Asten et al. 2011) also offer a good case for improving the productivity of banana systems through intercropping of banana with other species. In all cases in the current study, a higher LER value was obtained in the seven-leaf treatment when compared with the treatment in which all banana leaves were retained. In contrast, the four-leaf treatment was less efficient compared to the all-leaf treatment. This practice also increased weed growth and labour costs needed for weeding. Extreme cutting of leaves also negatively affected the quality of the banana bunch and fruits as shown by the reduced number of hands, fingers and finger length (cf. Table 1, 2), and this could potentially lead to lower prices in the markets. The observed potential negative effect of severe leaf pruning (e.g. to four) on the agronomic efficiency of the system offers a good basis for discouraging this practice that currently also plays a big role in the spread of the XW disease of banana in the study region.

Despite a higher LER for the intercrops, higher profit, benefit cost ratio and labour productivity were realized for the sole banana and all leaf treatments compared with the sole annual crops and banana-legume intercrops. This can be attributed to the high market value of banana fruits compared with that for the grain legumes. Labour costs for banana production are also only high at establishment. Given its perennial nature plantations are not frequently re-established, with plantations in areas with low disease and pest pressure lasting even for decades. For example, plantations that are over 30 years old are common in East Africa (Bekunda, 1999). The investments are often low in the first and subsequent ratoon crops compared with the plant crop because of lower input costs, lack of costs associated 
with banana seed purchase, land preparation and weeding. The large canopy after full establishment suppresses weed growth and labour associated with weed management is therefore reduced. This can be shown by the higher weed biomass in the monocrop plots especially at the start of the season (cf. Fig. 4b). In contrast, for the intercrops, costs associated with the intercrops such as land preparation, weeding, staking, de-leafing are incurred seasonally. Of the intercrops, the bananabush bean intercrops were more profitable than other legumes across all leaf pruning treatments. This could be because they offered less competition compared with soybean and climbing beans. Ntamwira et al. (2012) also reported a bananabush bean intercrop as giving a larger net revenue compared to banana-climbing bean intercrop. Careful selection of intercrops will also be helpful for realizing optimal benefits from banana-legume/annual crop intercrops.

Despite the higher benefits from banana monocrops, few farmers cultivate these monocrops due to a very high population pressure on the land (estimated at 300-350 inhabitants per $\mathrm{km}^{2}$ ) given the small land holdings (less than 0.5 ha per household) in the study region. Most production is thus focused on ensuring diversity for nutrition and insurance of food security against production risks. The observed trends could also be due to farmers' lack of knowledge of the performance of the monocrops in comparison to the intercrops. Armed with knowledge on the performance of the monocrops in comparison with the intercrops, farmers' choice to intercrop and/or prune would need to be consciously balanced out with farmers' production objectives and access to land. Possible objectives could include maximisation of income; farm/crop diversity and nutrition; and soil fertility improvement. Farmers aiming at maximising profits could allot all or a large portion of their land to banana monocrop and lesser to annual crops, whereas those aiming at nutritional security could differently apportion their land to other crops/intercrops. Farmers with large parcels of land in contrast can afford to grow banana or legumes as monocrops on large areas without affecting their nutritional and food security needs. Model-based approaches that integrate biophysical and socio-economic aspects of production are recommended for tailoring such management decisions to farm types, production goals and resource endowments.

This study was however, conducted over a short period of time i.e. two production cycles (i.e. 4 years) and at a single experimental site with a single replication in time. Longer term environmental effects such as changes in soil fertility, build-up of pests and diseases and changes in the weather and climate conditions on banana leaf pruning and intercrops could thus not be ascertained. Interactions of the treatments with site conditions (e.g. different soils, environmental and management and biotic scenarios) could not be assessed, 
whereas could have varied with site conditions. Thus, the application of the study findings in other context needs to be done with caution.

\subsection{Conclusion}

Banana leaf pruning despite its current role in the spread of XW disease of banana, is a common practice to allow for banana-legume intercropping and mainly driven by the small land/farm sizes. Leaf pruning improved light penetration to legumes and their yield while it negatively affected the growth and yield of the banana crop. More severe yield reductions occurred when only four leaves were retained, a practice that also resulted in the least land use efficiency compared to when all leaves are retained. Moderate leaf pruning (7 leaves) however, did not in most cases significantly depress yields and resulted in a higher land use efficiency than the banana monocrop all-leaf treatment. However, higher net revenues and labour productivity realized for sole banana and all leaf retention treatments suggests that growing banana as a sole crop is more profitable and moderate leaf- pruning, preferably bending the older leaves to avoid spread of XW could promoted when intercropping is necessary. Intensification decisions should thus go beyond the assessment of the land use efficiency of the systems to determining economic value (net revenues) of the systems. Depending on farmers' production objectives they can decide whether to diversify their farms or target higher incomes. Given the findings of this study, it is recommended for a farmer interested in fostering food security, diversity and nutrition to go for moderate leaf pruning (7 leaves). In contrast, a farmer interested in improving immediate incomes could go for a sole banana crop. Intensification decisions (e.g. pruning banana leaves to integrate legumes) should also look at a broader range of production constraints. For example, where land is not limiting, it is recommended to cultivate the banana and the legumes as sole crops. Where land is limiting, minimal pruning to e.g. seven leaves can be applied with minimal damage. In the current study, annual crops were labour intensive compared to the banana crop, and as such a farmer constrained by labour could go for the sole banana crop. Taking such intensification decision is knowledge intensive, thus rigorous/regular knowledge extension to farmers will be crucial. Bioeconomic models (e.g. FarmDESIGN, Groot et al., 2009) that address multiple constraints, decision variables and objectives would be handy in guiding farmers' decision with respect to such intensification options. 


\subsection{Acknowledgements}

We are grateful for the financial support from the Belgian Directorate General for Development through the Consortium for Improving Agriculture-based Livelihoods in Central Africa. This research was conducted in the framework of the Roots, Tubers and Banana program of the CGIAR (CRP RTB).

\section{References}

Akyeampong, E., Hitimana, L., Torquebiau, E., and Munyemana, P.C. (1999). Multistrata agroforestry with beans, bananas and Grevillea robusta in the highlands of Burundi. Exp. Agr. 35, 357-369.

Allen, T.W., Bradley, C.A., Sisson, A.J., Byamukama, E., Chilvers, M.I., Coker, C.M., ... and Esker, P.D. (2017). Soybean yield loss estimates due to diseases in the United States and Ontario, Canada, from 2010 to 2014. Plant Health Progress, 18(1), 19-27.

Amanullah, M.M., Somasundaram, E., Vaiyapuri, K., and Sathyamoorthi, K. (2007). Intercropping in cassava. Agr. Rev. 28, 179-187.

Balbín, L.A.G., and Zapata, J.C. (2001). Integrated management of black and yellow Sigatoka diseases in plantain cv. Africa. InfoMusa 10(2), 3-7.

Bakelana, K., and Ndungo, V. (2004). La maladie de Bwere: une bactériose dévastatrice de la culture de la banane dans la province du Nord Kivu en République Démocratique du Congo, Rapport de mission FAO, 1 pp

Bates, D.M. (2010). Ime4: Mixed-effects modeling with R.

Bekunda, M. (1999). Farmers' responses to soil fertility decline in banana-based cropping systems of Uganda. Managing Africa's Soils No. 4. [Available at: http://pubs.iied.org/pdfs/7397|lED.pdf] (Accessed on 24 $4^{\text {th }}$ Nov. 2016).

Bekunda, M.A., and Woomer, P.L. (1996). Organic resource management in banana-based cropping systems of the Lake Victoria Basin, Uganda. Agri. Ecosyst. Environ. 59(3), 171180.

Bates, D., Maechler, M., Bolker, B., and Walker, S. (2015). Fitting Linear Mixed-Effects Models Using Ime4. J. Stat. Softw. 67(1), 1-48. doi:10.18637/jss.v067.i01.

Bloom, A.J., Chapin III, F.S., and Mooney, H.A. (1985). Resource limitation in plants-an economic analogy. Annu. Rev. Ecol. Syst. 16, 363-392.

Blomme, G., Ocimati, W., Sivirihauma, C., Vutseme, L., Mariamu, B., Kamira, M., ... and Ntamwira, J. (2017). A control package revolving around the removal of single diseased banana stems is effective for the restoration of Xanthomonas wilt infected fields. Eur. J. Plant Pathol. 149(2), 385-400.

Blomme, G., Tenkouano, A., and Swennen, R. (2001). Influence of leaf removal on shoot and root growth in banana (Musa spp.). InfoMusa 10(2), 10-13.

Boudreau, M.A. (2013). Diseases in intercropping systems. Annu. Rev. Phytopathol. 51, 499519. doi: 10.1146/annurev-phyto-082712-102246 
Butler, G.W., Greenwood, R.M., and Soper, K. (1959). Effects of shading and defoliation on the turnover of root and nodule tissue of plants of Trifolium repens, Trifolium pratense, and Lotus uliginosus. New Zeal. J. Agr. Res. 2(3), 415-426.

Celetti, M.J., Melzer, M.S., and Boland, G.J. (2006). Angular leaf spot of snap beans. Ontario, Ministry of Agriculture, Food and Rural Affairs.

Chakeredza, S., Hove, L., Akinnifesi, F.K., Franzel, S., Ajayi, O.C., and Sileshi, G. (2007). Managing fodder trees as a solution to human-livestock food conflicts and their contribution to income generation for smallholder farmers in southern Africa. Nat. Resour. Forum 31, 286-296.

CIALCA (2010). CIALCA Baseline Survey Report. Consortium for Improving Agriculture-based Livelihoods in Central Africa $129 \mathrm{p}$.

Dapaah, H.K., Asafu-Agyei, J.N., Ennin, S.A., and Yamoah, C. (2003). Yield stability of cassava, maize, soya bean and cowpea intercrops. J. Agr. Sci. 140, 73-82.

Davis, J.H.C., Smithson, J.B., Arregoses, O., and Maria, L.M. (1987). Principes de la culture du haricot en association avec d'autres espèces. CIAT. Series. 04-FB-12.05, 42 p.

Dadzie, B.K., and Orchard, J.E. (1997). Routine Post Harvest Screening of Banana/Plantain Hybrids: Criteria and Methods. INIBAP Technical Guidelines 2. International Plant Genetic Resources Institute, Rome, Italy; International Network for the Improvement of Banana and Plantain, Montpellier, France; ACP-EU Technical Centre for Agricultural and Rural Cooperation, Wageningen, The Netherlands.

Decagon Devices (2004). ACCUPAR Model LP80 Operators Manual. Decagon Devices Pullman, WA, USA.

DSRP (2005). Document de Stratégie de Réduction de la Pauvreté Province du Sud-Kivu République Démocratique du Congo. Ministère du Plan. Unité de Pilotage de Processus du DSRP Kinshasa. $96 \mathrm{p}$.

Echeverry, N.E. (2001). The production of fire-softened plantain leaves for the agrifood industry. Agro-economics production and use of leaves. InfoMusa 10(1), 9-12.

Fujita, K., Ofosu-Budu, K.G., and Ogata, S., (1992). Biological nitrogen fixation in mixed legumecereal cropping systems. Plant and Soil, 141(1-2), 155-175.

Gaidashova, S.V., Karemera, F., and Karamura, E.B. (2008). Agronomic performance of introduced banana varieties in lowlands of Rwanda. Afr. Crop Sci. J. 16(1).

Ganeshamurthy, A.N., Satisha, G.C., and Prakash, P. (2011). Potassium nutrition on yield and quality of fruit crops with special emphasis on banana and grapes. Karnataka J. Agric. Sci. 24(1), 29-38.

Grechi, I., Vivin, P.H., Hilbert, G., Milin, S., Robert, T., and Gaudillère, J.P. (2007). Effect of light and nitrogen supply on internal C:N balance and control of root-to-shoot biomass allocation in grapevine. Environ. Exper. Bot. 59(2), 139-149.

Groot, J.C.J., Rossing, W. A., Tichit, M., Turpin, N., Jellema, A., Baudry, J., ... and Van de Ven, G. W. (2009). On the contribution of modelling to multifunctional agriculture: learning from comparisons. J. Environ. Manage. 90, S147-S160.

Kassambara, A. (2018). ggpubr: 'ggplot2' based publication ready plots. R package version 0.2 .999. http://www.sthda.com/english/rpkgs/ggpubr 
Kempers, A.J., and Zweers, A. (1986). Ammonium determination in soil extracts by the salicylate method. Commun Soil Sci. Plant Anal. 17(7), 715-723.

Krishnamoorthy, V., Kumar, N., Angappan, K., and Soorianathasundaram, K. (2004). Evaluation of new banana hybrids against black leaf streak disease. InfoMusa 13(1), 25-27.

Kuznetsova, A., Brockhoff, P.B., and Christensen, R.H.B. (2017). "ImerTest Package: Tests in Li near Mixed Effects Models." J. Stat. Softw. 82(13), 1-26. doi: 10.18637/jss.v082.i13. htt p://doi.org/10.18637/iss.v082.i13).

Li, X., de Boer, W., Zhang, Y., Ding, C., Zhang, T., and Wang, X. (2018). Suppression of soil-borne Fusarium pathogens of peanut by intercropping with the medicinal herb Atractylodes lancea. Soil Biol. Biochem. 116, 120-130.

Lockhart, B.R., Gardiner, E.S., Stautz, T., and Leininger, T.D. (2012). Development and plasticity of endangered shrub Lindera melissifolia (Lauraceae) seedlings under contrasting light regimes. Plant Spec. Biol. 27(1), 30-45.

Maria, C.T.F., David, M.E., and Jonathan, P.L. (2002). Lack of evidence for programmed root senescence in common bean (Phaseolus vulgaris) grown at different levels of phosphorus supply. New Phytol. 153, 63-71.

Marschner, H. (2011). Marschner's mineral nutrition of higher plants. Academic press.

Mazaheri, D., Madani, A., and Oveysi, M. (2006). Assessing the land equivalent ratio (LER) of two corn [Zea mays L.] varieties intercropping at various nitrogen levels in Karaj, Iran. J. Cent. Eur. Agr. 7(2), 359-364.

McCarthy, M.C., and Enquist, B.J. (2007). Consistency between an allometric approach and optimal partitioning theory in global patterns of plant biomass allocation. Funct. Ecol. 21(4), 713-720.

McGrath, C., Wright, D., Mallarino, A.P., and Lenssen, A.W. (2013). Soybean Nutrient Needs. Agriculture and Environment Extension Publications. Book 189. http://lib.dr.iastate.edu/extension ag pubs/189 (Accessed on: $5^{\text {th }}$ May 2017).

McIntyre, B.D., Gold, C.S., Kashaija, I.N., Ssali, H., Night, G., and Bwamiki, D.P. (2001). Effects of legume intercrops on soil-borne pests, biomass, nutrients and soil water in banana. Biol. Fertil. Soils 34, 342-348.

Mehlich, A. (1984). Mehlich 3 soil test extractant: A modification of Mehlich 2 extractant. Commun. Soil Sci. Plant Anal. 15(12), 1409-1416.

Mirindi, J.B. (2011). Contribution a la connaissance des pratiques paysannes dans une association bananier haricot et de l'utilisation de différentes parties du bananier en territoires de Kabare et de Walungu. BSc thesis Université Catholique de Bukavu. DR Congo. $47 \mathrm{p}$.

Mukasa, H.H., Ocan, D., Rubaihayo, P.R., and Blomme, G. (2005). Relationships between bunch weight and plant growth characteristics of Musa spp. assessed at farm level. MusAfrica $16,2-4$.

Mulumba, J.W., Nankya, R., Adokorach, J., Kiwuka, C., Fadda, C., De Santis, P., ... and Jarvis, D.I. (2012). A risk-minimising argument for traditional crop varietal diversity use to reduce pest and disease damage in agricultural ecosystems of Uganda. Agri. Ecosyst. Environ. 157, 70-86. doi: 10.1016/j.agee.2012.02.012. 
Ndabamenye, T., van Asten, P.J.A., Blomme, G., Vanlauwe, B., Uzayisengae, B., Annandale, J.G., and Barnard, R.O. (2013). Nutrient imbalance and yield limiting factors of low input East African highland banana (Musa spp. AAA-EA) cropping systems. Field Crops Res. 147, 68-78

Ntamwira, J., Pypers, P., Van Asten, P., Vanlauwe, B., Ndungo, V., Badesire, A., and Blomme, G. (2012). Effect of banana leaf pruning on banana and bean yield in an intercropping system in eastern Democratic Republic of Congo. Afr. J. Plant Sci. Biotechnol. 7(1), 32-35.

Ntamwira, J., Pypers, P., van Asten, P., Vanlauwe, B., Ndungo, V., Badesire, A., Lepoint, P., and Blomme, G. (2013a). Effect of banana leaf pruning on banana and bean yield in an intercropping system in Eastern Democratic Republic of Congo. Afr. J. Plant Sci. Biotechnol. 7(1), 32-35.

Ntamwira, J., Pypers, P., van Asten, P., Vanlauwe, B., Ruhigwa, B., Lepointe, P., and Blomme, G. (2013b). Effect of leaf pruning of banana on legume yield in banana-legume intercropping systems in eastern Democratic Republic of Congo. In: Blomme G, van Austen P and Vanlauwe B (eds) Banana Systems in the Humid Highlands of Sub-Saharan Africa: enhancing resilience and productivity. $\mathrm{CABI}$, Wallingford, Oxfordshire, UK, pp. 158165.

Ntamwira, J., Pypers, P., van Asten, P., Vanlauwe, B., Ruhigwa, B., Lepoint, P., ... and Blomme, G. (2014). Effect of banana leaf pruning on banana and legume yield under intercropping in farmers' fields in eastern Democratic Republic of Congo. J. Hortic. For. 6(9), 72-80.

Nyabyenda, P. (2006). Les plantes cultivées en régions tropicales d'altitude d'Afrique. Les presses agronomiques de Gembloux. Gembloux. Belgium. Pp. 22-24.

Nyambo, D.B., Matimati, T., Komba, A.L., and Jana, R.K. (1982). Influence of plant combinations and planting configurations on three cereals (maize, sorghum, millet) intercropped with two legumes (soybean, green-gram). In: Keswani $\mathrm{CL}$ and Ndunguru BJ (eds) Proceedings of the Second Symposium on Intercropping in Semi-Arid Areas. Morogoro, Tanzania, 4-7 August 1980. IDRC Publication (Canada). No 186e, pp. 56-62.

Nyombi, K., Van Asten, P.J., Corbeels, M., Taulya, G., Leffelaar, P.A., and Giller, K.E. (2010). Mineral fertilizer response and nutrient use efficiencies of East African highland banana (Musa spp., AAA-EAHB, cv. Kisansa). Field Crops Res. 117(1), 38-50.

Nzawele, D.B., Rweyemamu, C.L., and Maerere, A.P. (2009). Banana (Musa spp.) cropping systems, production constraints and cultivar preferences in eastern Democratic Republic of Congo. J. Anim. Plant Sci. 4, 341-356.

Ocimati, W., Karamura, D., Rutikanga, A., Sivirihauma, C., Ndungo, V., Ntamwira, J., ... and Blomme, G. (2013). Agronomic practices for Musa across different agro-ecological zones in Burundi, eastern Democratic Republic of Congo and Rwanda. Banana Systems in the Humid Highlands of Sub-Saharan Africa, p.175.

Ocimati, W., Were, E., Groot, J.C., Tittonell, P., Nakato, G.V., and Blomme, G. (2018). Risks posed by intercrops and weeds as alternative hosts to Xanthomonas campestris pv. musacearum in banana fields. Front. Plant Sci. 9, 1471. 
Okumu, M.O., van Asten, P.J.A., Kahangi, E., Okech, S.H., Jefwa, J., and Vanlauwe, B. (2011). Production gradients in smallholder banana (cv. Giant Cavendish) farms in central Kenya. Sci. Hortic. 127, 475-481.

Ouma, G. (2009). Intercropping and its application to banana production in East Africa: a review. J. Plant Breed. Crop Sci. 1, 13-15.

Pedersen, T.L. (2017). Patchwork: The Composer of Ggplots. R package version 0.0.1. https://github.com/thomasp85/patchwork

Prasad, R.B., and Brook, R.M. (2005). Effect of varying maize densities on intercropped maize and soybean in Nepal. Expl. Agric. (41), 365-382.

Pypers, P., Sanginga, J., Kasereka, B., Walangululu, M., and Vanlauwe, B. (2010). Increased productivity through integrated soil fertility management in cassava-legume intercropping systems in the highlands of Sud-Kivu, DR Congo. Field Crops Res. 120(1), 76-85.

$R$ Core Team (2018). R: A language and environment for statistical computing. $R$ Foundation $f$ or Statistical Computing, Vienna, Austria. https://www.R-project.org/.

Robinson, J.C., Fraser, C., and Eckstein, K. (1993). A field comparison of conventional suckers with tissue culture banana planting material over three crop cycles. J. Hortic Sci. 68(6), 831-836.

Robinson, J.C., Anderson, T., and Eckstein, K. (1992). The influence of functional leaf removal at flower emergence on components of yield and photosynthetic compensation in banana. J. Hortic. Sci. 67(3), 403-410.

Sakamoto, Y., Ishiguro, M., and Kitagawa, G. (1986). Akaike information criterion statistics. Dordrecht, The Netherlands: D. Reidel, 81.

Schwarz, G. (1978). Estimating the dimension of a model. Ann. Stat. 6(2), 461-464.

Sileshi, G., Akinnifesi, F.K., Ajayi, O.C., Chakeredza, S., Kaonga, M., and Matakala, P.W. (2007). Contributions of agroforestry to ecosystem services in the Miombo eco-region of eastern and southern Africa. Afr. J. Environ. Sci. Technol. 1, 68-80.

Smithson P.C., McIntyre, B.D., Gold, C.S., Ssali, H., and Kashayij, I.N. (2001). Nitrogen and potassium fertilizers vs. nematode and weevil effects on yield and foliar nutrient status of banana in Uganda. Nutr. Cycl. Agroecosyst. 59, 239-250.

Stover, R.H., and Simmonds, N.W. (1987). Bananas $\left(3^{\text {rd }} \mathrm{Ed}^{\mathrm{n}}\right)$, Tropical Agricultural Series, Longman, Essex, UK, $468 \mathrm{p}$.

Taulya, G. (2013). East African highland bananas (Musa spp. AAA-EA) 'worry' more about potassium deficiency than drought stress. Field Crops Res. 151, 45-55

Tittonell, P., and Giller, K.E. (2013). When yield gaps are poverty traps: The paradigm of ecological intensification in African smallholder agriculture. Field Crops Res. 143, 76-90.

Tushemereirwe, W.K., Karamura, D., Ssali, H., Bwamiki, D., Kashaija, I., Nankinga, C., ... and Ssebuliba, R. (2001). Bananas (Musa spp.) in Uganda. In: Mukiibi, J.K. (Ed.), Agriculture, vol. II: Crops. Fountain Publishers, Kampala, Uganda, pp. 281-321.

van Asten, P.J., Wairegi, L.W.I., Mukasa, D., and Uringi, N.O. (2011). Agronomic and economic benefits of coffee-banana intercropping in Uganda's smallholder farming systems. Agr. Syst. 104(4), 326-334. 
Vidal, T., Boixel, A., Durand, B., de Vallavieille-Pope, C., Huber, L., and Saint-Jean, S. (2017). Reduction of fungal disease spread in cultivar mixtures: impact of canopy architecture on rain-splash dispersal and on crop microclimate. Agr. For. Meteorol. 246, 154-161.

VSN International Ltd. (2009). GenStat $12^{\text {th }}$ Edition. www.vsni.co.uk.

Walmsley, D., and Twyford, I.T. (1968). The translocation of phosphorus within a stool of Robusta bananas. Tropical Agriculture (Trinidad) 45, 229-233.

Willey, R.W. (1985). Evaluation and presentation of intercropping advantages. Exp. Agric. 21, 119-133.

Wickham, H. (2016). ggplot2: elegant graphics for data analysis. Springer-Verlag New York.

Wickham, H., and Chang, W. (2018). devtools: Tools to make developing R Packages easier. R package version 1.13.6. https://CRAN.R-project.org/package=devtools

Winter, B. (2013). Linear models and linear mixed effects models in $\mathrm{R}$ with linguistic applications. arXiv:1308.5499. [http://arxiv.org/pdf/1308.5499.pdf]

Wortmann, C.S., and Sengooba, T. (1993). The banana-bean intercropping systems - bean genotype $\mathrm{x}$ cropping systems interactions. Field Crops Res. 31, 19-25.

Zinsou, V., Wydra, K., Ahohuendo, B., and Hau, B. (2004). Effects of soil amendments, intercropping and planting time in combination on the severity of cassava bacterial blight and yield in two ecozones of West Africa. Plant Pathol. 53, 585-595. 


\section{Chapter 7}

\section{Trade-offs and synergies due to banana leaf pruning to intercrop legumes in eastern DR Congo}

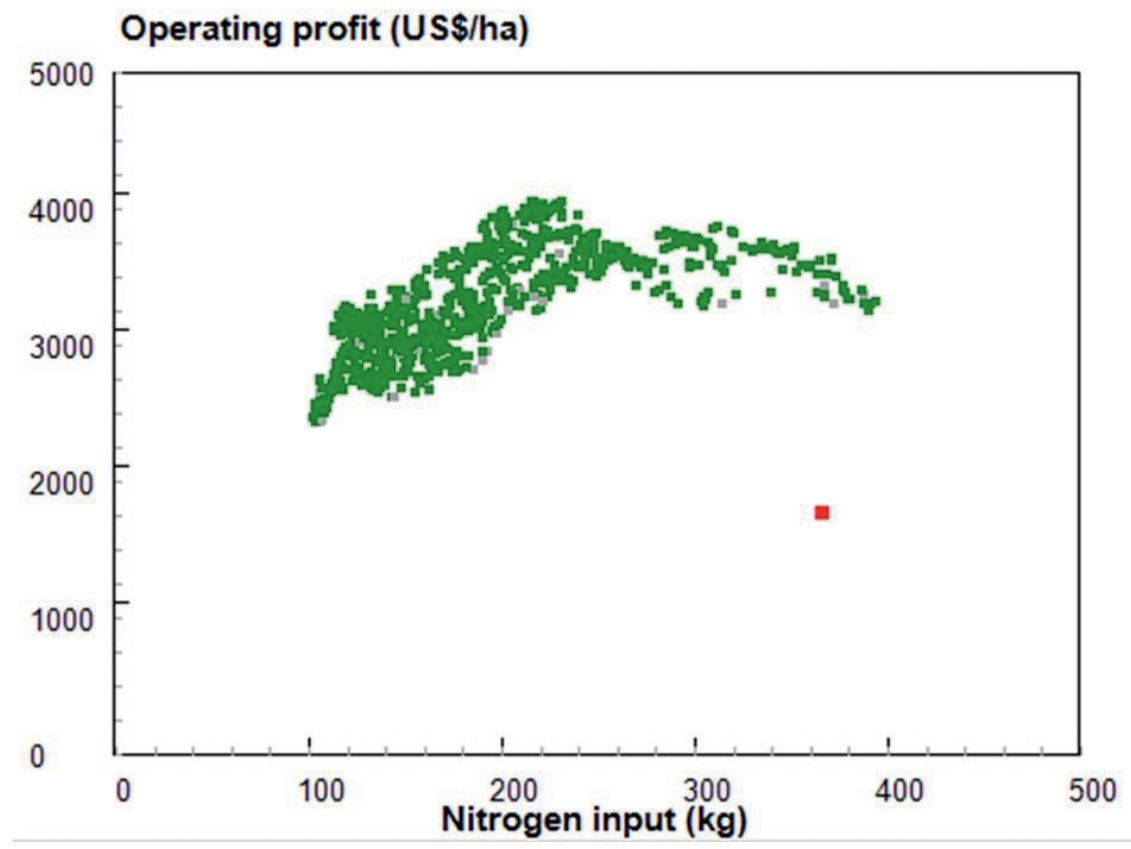

To be published as:

Ocimati, W., Groot, J.C.J, Taulya, G., Remans, R., Ntamwira, J., and Tittonell, P. Field level exploration of banana-canopy management options to facilitate legume intercropping using a multi-objective optimization model. 


\section{Abstract}

Smallholder farmers in the African Great Lakes region frequently intercrop banana with other crops, especially legumes. This is often accompanied with varying levels of banana leaf pruning to illuminate the understory crop(s). Banana leaf pruning reduced fresh bunch weight, enhances the risk of spreading bacterial wilt disease of banana and reduces the overall farm profitability. The impact of farmers' practices on the environmental and nutritional production objectives are challenging to determine yet could guide farm decision making. We used data from a field experiment that assessed three banana leaf pruning intensities (i.e. retaining all, seven and four leaves) to integrate bush beans as input for a multi-objective optimization and exploration of trade-offs and synergies among economic, nutritional, and environmental objectives. Banana monocrops at the three leafpruning treatment levels and bush bean monocrops served as checks. Retention of only four functional banana leaves mimicked a worst-case scenario of leaf pruning. The model optimized for maximisation of operating profit, nutritional yields, soil organic matter (SOM) and minimisation of external nitrogen $(\mathrm{N})$ input. The model explored a range of scenarios that included: i) business as usual (BaU, farmyard manure only applied at planting), ii) addition of hedges, iii) addition of inorganic fertilizers, iv) combination of hedges with goat manure, v) hedges with inorganic fertilizer, vi) inorganic fertilizer with goat manure and vii) a combination of hedges with inorganic fertilizer and goat manure. No profound improvements in the system were realised for $\mathrm{BaU}$ and addition of hedges alone. Addition of inorganic fertilizer profoundly improved the performance of the system for operating profit, $\mathrm{N}$ input and protein yield. Goat manure improved SOM balance and increased $\mathrm{N}$ input in the system. For BaU and hedges, land was predominantly allocated to an intercrop of bush bean with pruned bananas and/or sole bush beans. In contrast, the model allocated land predominantly to the un-pruned banana-bush bean intercrop and/ or sole un-pruned banana crop at the Pareto-optimal frontiers when inorganic fertilizers and/ or goat manure was introduced. Farmers' practice of leaf pruning could thus be indirectly reducing nutrient uptake/ depletion thus fostering the systems adaptive capacity. Discouraging the practice of leaf pruning will thus require efforts towards improving access and use of external input sources. The FarmDESIGN model optimization also made the trade-offs and synergies between the different objectives explicit and is helpful for field-level decision making in the system.

Keywords: banana, FarmDESIGN, multi-objective, Pareto-optimal, trade-offs 


\subsection{Introduction}

Banana (Musa spp.) is an important food and income crop across a wide range of agroecological zones and cropping systems in the African Great Lakes region (AGLR) (FAO, 2018). This region produces about one third of the crop in the world (FAO, 2018). The crop provides 30-60\% of dietary energy requirements for over 70 million people (Abele et al., 2007; Karamura et al., 2008) in this region that comprises of Burundi, Democratic Republic of Congo (DR Congo), Rwanda, Kenya, Tanzania and Uganda.

The AGLR is characterised by a high population density, with the highest population densities of 435 and 470 inhabitants per $\mathrm{km}^{2}$, respectively reported in Burundi and Rwanda (The World Bank Group, 2016). About 70-90\% of the population in this region is employed in agriculture as smallholder farmers (Jagwe et al., 2014; FAO, 2015; IFAD, 2018; Uganda Investment Authority, 2018). This high population density and heavy dependence on agriculture has resulted in small and fragmented farms characterized by declining soil fertility. For example, farm landholdings in banana producing areas of Rwanda, Burundi and eastern DR Congo have been reported to vary between 0.5 and 2 ha (Jagwe et al., 2014). van Asten et al. (2004) report low soil fertility as one of the major constraints to banana production in the region. To compound the problems of ever reducing farm sizes and declining soil fertility, external inputs such as manure, inorganic fertilizers are not widely used in the region (Tinzaara et al., 2018). For example, in Uganda, in 2013 , only $2.8 \%$ of the land under key crops received fertilizers (accounting for $30 \mathrm{~kg} \mathrm{ha}^{-1}$ of fertilizer on the fertilized soils), with banana accounting for $25 \%$ of this land area (Sunday and Ocen, 2015). Moreover, previously important cultural practices for managing soil fertility, and pests and diseases such as crop rotation, agroforestry, shifting cultivation and fallowing are no longer feasible or optimally practiced due to the small farm sizes and more intensive farming systems (Nandwa and Bekunda, 1998; Ocimati et al., 2013). The declining farm sizes and soil fertility have severely impacted banana production in the region. Exploring for sustainable nutrient management options that do not compromise other production objectives is thus critical. Farmers commonly intercrop banana with other annual crops, more specially legumes to optimally use the available land and mitigate potential risks (Ntamwira et al. 2014; Blomme et al., 2018). The incorporation of food and/or fodder legumes within banana fields has been reported to: increase land and resource use efficiency of smallholder banana farms; suppress weeds; and minimise risks related to climate change and pests and diseases (Dapaah et al., 2003; Zinsou et al., 2004; Nyabyenda, 2006; Amanullah et al., 2007; Sileshi et al., 2007; Ouma, 2009; Ocimati et al., 2019; 
Blomme et al., 2018). Intercropping with legumes may also be a strategy to offset soil fertility depletion (Chakeredza et al., 2007; Ouma, 2009). A high functional biodiversity and interaction between crop species has also been reported to enhance agroecosystem sustainability (Vandermeer, 1995). However, the integration of annual crops in banana fields across several landscapes in the AGLR has been hampered by the shading effect from the banana leaf canopy. As a copying strategy, farmers often prune banana leaves to allow for light penetration to the shorter understory crops (Ntamwira et al., 2013; Ocimati et al., 2019). However, leaf pruning has been reported to reduce the productivity of the banana crop (Robinson, 1992; Ntamwira et al., 2013) and overall economic efficiency of the intercrop (Ocimati et al., 2019). This practice additionally enhances the risk for spreading Xanthomonas wilt (XW) of banana, a key constraint to banana production in the AGLR (Blomme et al., 2017). Given the negative effects of leaf pruning and associated risk of spreading XW disease, leaf pruning could undermine the benefits associated with a high level of functional biodiversity.

Several empirical experiments have been conducted to understand the effect of banana leaf pruning and intercropping with different legumes in the region (Ntamwira et al., 2013; 2014; Ocimati et al., 2019). These studies have mainly focused on the effect of farmer's practices on productivity and profitability of the system. However, other potential environmental objectives that support system resilience and productivity and the nutritional objectives given the production constraints were not assessed. For example, though integration of legumes in this system is primarily aimed at meeting household nutritional needs, it is also anticipated to offset the soil nitrogen depletion through biological nitrogen fixation in the system. Understanding the trade-offs and synergies associated with the management of the banana-bush bean system is crucial for generating relevant recommendations for improving the system. Exploring such objectives through empirical experiments can however be challenging and/or require observations over longer time frames/larger durations. Environment related objectives are also knowledge intensive and as such often ignored or difficult to conceptualize, especially by resource poor smallholder farmers. Farm models can overcome limitations associated with dealing with multiple and complex objectives simultaneously, and have been widely used to explore new technologies, management options, innovations and new scenarios (Groot et al., 2007a, b; Janssen and van Ittersum, 2007; Ditzler et al., 2019).

This study complements the above-mentioned empirical experiments on banana canopy management to integrate legumes. This study used the FarmDESIGN model to: i) identify the effect of farmers practice of banana leaf pruning to integrate 
legumes on multiple production objectives (i.e. maximising operating profit, protein yield and soil organic matter balance (SOM), and minimising external nitrogen input), ii) identify potential optimal banana-legume system configurations for the various production objectives, and iii) explore performance of potential scenarios for improving the nutrient balance of the system. The computer-based FarmDESIGN model overcomes the limitation in complexity of systems by coupling a multiobjective optimization algorithm that generates a large set of Pareto-optimal alternative farm/field arrangements to a bio-economic farm model that evaluates productive, economic and environmental farm performance (Groot et al., 2011; 2012). The generated alternatives are Pareto-optimal when they do not perform worse than any other alternatives for all the objectives (Groot et al., 2012).

\subsection{Materials and methods}

This study used data from a field experiment conducted at the Institut National d'Etudes et Recherches Agronomiques (INERA), Mulungu research station in the Democratic Republic of Congo as input for exploring trade-offs and optimization of banana leaf-pruning and banana-legume intercropping options using the FarmDESIGN model. INERA is located at $02^{\circ} 20.042^{\prime} \mathrm{S}, 028^{\circ} 47.311^{\prime} \mathrm{E}$, and at $1,707 \mathrm{~m}$ above sea level. The soils are Andosols with a $\mathrm{pH}$ of 8.5 (1:2.5 soil: water extract), soil organic matter (SOM) of $4.9 \%$, total $\mathrm{N}$ of $0.25 \%$ (using salicylate method (Kempers and Zweers, 1986)), 126 ppm of phosphorus (P), $1921.1 \mathrm{ppm}$ of exchangeable potassium (K), 2385.6 ppm of exchangeable calcium (Ca) and 1411.1 ppm of exchangeable magnesium (Mg). Mehlich 3 extraction method (Mehlich, 1984) was used for the extraction of $\mathrm{P}, \mathrm{K}, \mathrm{Ca}$ and $\mathrm{Mg}$. The site receives $1,500 \mathrm{~mm}$ of annual rainfall distributed over two seasons (February-May and SeptemberDecember).

\section{Field experiment}

The on-station experiment was conducted between December 2009 and March 2012. The field experiment was described by Ocimati et al. (2019). The experiment comprised seven treatments: a bush bean monocrop (T7), banana monocrops at three leaf pruning levels i.e. retaining all (T1), seven (T2) and four (T3) fully expanded functional green leaves per plant, and bush beans intercropped with banana in which all (T4), seven (T5) and four (T6) fully expanded green leaves are retained per plant. Each treatment was replicated four times in a randomized complete block design. The leaf pruning treatments were applied to increase the amount of light reaching the bush bean crop. The 'all leaf' treatment had on average nine leaves while 
retention of four-leaves mimicked the severe banana leaf-pruning scenario often observed on farmers' fields in eastern DR Congo. Sole banana (subjected to the three leaf pruning regimes) and legume plots served as controls. The legumes were introduced under banana plants in the $3^{\text {rd }}, 9^{\text {th }}, 15^{\text {th }}, 21^{\text {st }}$ and $27^{\text {th }}$ months after banana planting, which corresponds with the onset of the rainy seasons. A common cooking east African highland banana cultivar in the area, 'Barhabesha' (genome AAA) was planted at a spacing of $2 \mathrm{~m} \times 2 \mathrm{~m}$ and a common bush bean cultivar (Phaseolus vulgaris L, cv. MLB49) were used in this study. Aboveground biomass (dry weight basis) and yield for two banana cropping cycles and five consecutive legume crops were measured over a 3 years period and mean yields over a one-year period computed (Table 1). The cultivation costs e.g. labour and cost of inputs were recorded. No external inputs were applied on the fields whereas the crop residues were retained and recycled within the plots.

Table 1. Mean yields and aboveground biomass (crop residue) per ha and year of bush bean (cv. MLB49) and banana (cv. 'Barhabesha') in experiments conducted in eastern DR Congo. The experiment was conducted over a period of 3 years (i.e. 5 annual crop harvests and 2 rounds of bunch harvests).

\begin{tabular}{|c|c|c|c|}
\hline \multirow{2}{*}{ Treatments } & \multicolumn{2}{|c|}{ Mean yield (kg/ ha/ y) } & \multirow{2}{*}{ Cultivation costs (US\$)* } \\
\hline & Grain yield & Bean residue & \\
\hline T7 & 1,163 & 2,795 & 922.4 \\
\hline T4 & 562 & 1,731 & $\#$ \\
\hline T5 & 515 & 1,524 & $\#$ \\
\hline \multirow[t]{2}{*}{ T6 } & 408 & 1,098 & $\#$ \\
\hline & Bunch yield & Banana residue & \\
\hline $\mathrm{T} 1$ & 26,720 & 7,600 & 1,382 \\
\hline $\mathrm{T} 2$ & 32,840 & 9,000 & 1,392 \\
\hline T3 & 35,040 & 10,100 & 1,398 \\
\hline $\mathrm{T} 4$ & 23,680 & 7,600 & 2,184 \\
\hline T5 & 33,520 & 9,600 & 2,174 \\
\hline T6 & 36,840 & 10,500 & 2,115 \\
\hline
\end{tabular}

"*" Cultivation costs include the cost of labour (for ploughing, planting, weeding, pruning of leaves and other operations), seed and other inputs; \#Values are lumped together with corresponding costs for the banana crop. T1 to T3 denote monocrops of banana in which all, seven and four fully open green leaves are retained; T4-T6 bush bean intercrop with banana having all, seven and four fully open green leaves; and $\mathrm{T} 7$ a bush bean monocrop.

\section{The FarmDESIGN model}

The FarmDESIGN optimization model links a static bio-economic farm balance model to a multi-objective Pareto-based Differential Evolution algorithm (Groot et al., 2012). The model based on the decision variables e.g. land allocation, management decisions, simultaneously maximises or minimises different objective functions to generate alternative farm configurations, making explicit the trade-offs and synergies between objectives (Groot et al., 2007). Based on the Pareto ranking 
criterion (Goldberg, 1989), configurations that do not violate the constraints and perform equal to or better for at least one of the objectives (i.e. are non-dominated) are retained (Groot et al., 2012). These configurations receive rank 1 and form the trade-off frontier. Through repeating the process, other solution sets are assigned lower ranks 2, 3..., until all solution sets are assigned a rank (Fig. 1). From the tradeoff frontier solution sets that perform better than the original configuration for all objectives can be assigned a superior rank " 0 ". The model through visualization tools makes explicit trade-offs and synergies between the different objectives, leading to an increased knowledge on the interactions between the objectives and agroecosystems (Groot et al., 2012).

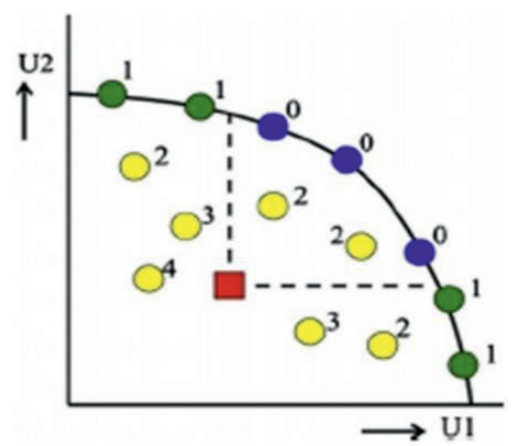

Figure 1. An illustration of a Pareto-based ranking for a solution space of two objectives U1 and $\mathrm{U} 2$ that are maximised. The green and blue circles are the rank 0 and 1 Pareto-optimal solutions while the yellow circles with ranks 2 to 4 are not Pareto-optimal. The Pareto-optimal solutions with rank 0 (blue circles) outperform the original farm configuration (red square) for all objectives (Source: Groot et al., 2012).

\section{Field conceptual model}

FarmDESIGN is based on a farm model consisting a large array of interrelated components of various types including: the biophysical environment, socioeconomic setting, crops and crop groups, crop products, rotations, animals and animal products, on-farm produced manures, imported inputs (e.g. fertilizers, manures, herbicides), buildings and equipment's (Groot et al., 2012). It computes farm resource flows of SOM, carbon, N, P, K and other soil nutrients through and from a farm and the resulting material balances. In addition, farm and household labour balances, household nutrition, economic results (e.g. operating profit, household budgets) are calculated on a yearly basis (Groot et al., 2013; Ditzler et al., 2019).

The current study is however, based on a single field with two crop species, thus a simpler conceptual model (Fig. 2) was developed. The field conceptual model 
was thus conceived as an entity comprising of the soils (biophysical environment), interacting crops (banana and legume) and the management of the crops (pruning of banana leaves, intercropping or monocropping) and fields (e.g. manure application) (Fig. 2). The field components are influenced by the crop management practices, the environment and socio-economic factors such as prices, input and labour costs.

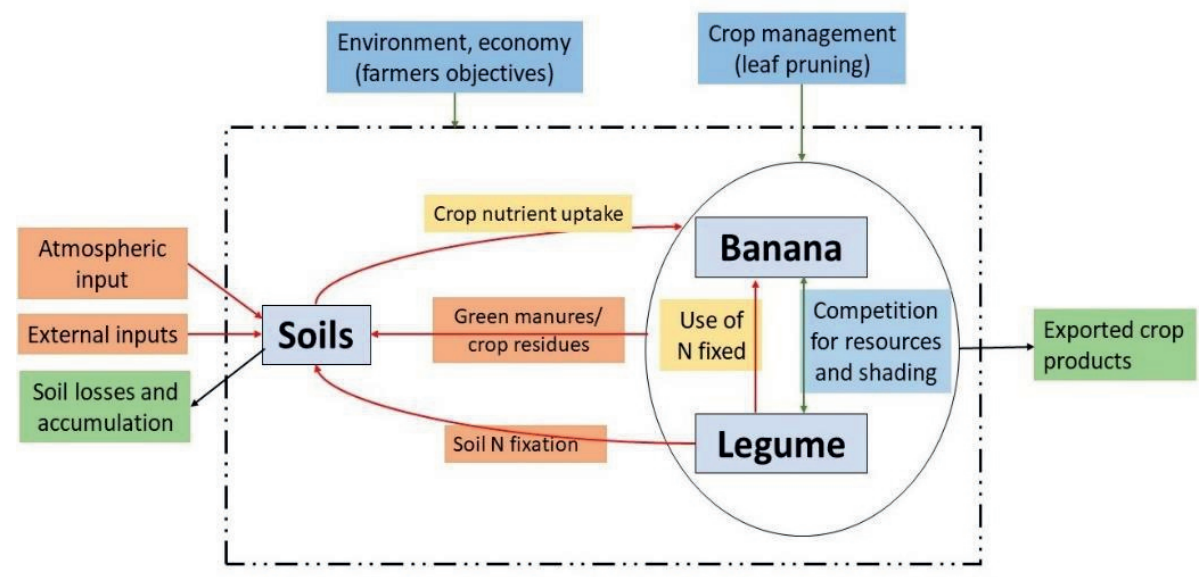

Figure 2. Schematic representation of the original field conceptual model. The solid boxes indicate the field system components; the arrows, the flow of resources (red and black arrows) and influence (green arrows) from management practices, the environment and socioeconomic factors. The dashed lines denote the boundary of the of the field system with the external environment.

\section{Model inputs, outputs and exploration}

The performance of the above field was explored without any additional external inputs (i.e. business as usual, $\mathrm{BaU}$ ) and with alternative improvements for addressing the soil nutrient balances. The different input scenarios are described below.

i. Business as usual ( $\mathrm{BaU})$ : farmyard manure was only applied at planting and no additional inputs added during a 3-year period of the banana crop;

ii. Hedges $(\mathrm{H})$ : border/ alley hedge crops rich in $\mathrm{N}$ and or $\mathrm{K}$ were explored as an alternative for nutrient recycling within the system. The hedge species used in the model are calliandra (Calliandra calothyrsus) and tithonia (Tithonia diversifolia). Calliandra and tithonia have been reported to be good sources of N and K (Orwa et al., 2009; Heuzé et al., 2017) that are often limiting in banana systems; 
iii. Inorganic input source of N, P and K: the model was allowed to chose between different inorganic input sources so as to bridge input gaps in the system (I);

iv. Addition of a combination of inorganic input and the hedge species in (ii) and (iii) $(\mathrm{H}+\mathrm{I})$;

v. Addition of a combination of the hedge species and goat manure $(\mathrm{H}+\mathrm{M})$;

vi. Addition of a combination of the inorganic inputs, the hedge species and goat manure $(\mathrm{H}+\mathrm{I}+\mathrm{M})$;

Model inputs and outputs were explored as decision variables, constraints and objectives (Groot, 2018).

Decision variables: The decision variables used for the explorations included land allocation to the seven banana-bush bean treatments (described in the section on 'field experiment') and two hedge crops (calliandra and tithonia); crop product destinations; five different fertilizer options and their respective amounts and manure from goats. The edible crop products were all assumed to be sold while crop residues were returned as mulch. The fertilizer options included NPK (17\%N, 17\%P

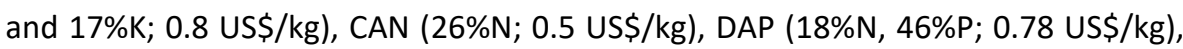
MOP (61\%K; 0.78 US\$ $/ \mathrm{kg}$ ) and Urea $(46 \% \mathrm{~N} ; 0.65 \mathrm{US} \$ \mathrm{~kg})$. The fertilizers also differed in their market prices. The manure from goats $(0.111 \mathrm{US} \$ / \mathrm{kg})$ is included as an alternative source of $\mathrm{N}, \mathrm{P}$ and $\mathrm{K}$ and SOM. The model can thus select either the inorganic fertilizers or/ and the manure and/ or the hedge crops.

Constraints: In the FarmDESIGN model, constraints were set to limit the scarce resources that include the available land area for the crops and soil nutrients, $\mathrm{N}, \mathrm{P}$ and $\mathrm{K}$ balances. The total available land area for each banana-bush bean treatments could vary between 0 and 1 ha whereas the total subsistence land area varied between 0.95 and 1 ha. The land allocated to each of the two hedges was restrained to between 0 and $10 \%$ of the available land area. Before model optimization, computations for the economic, environmental and nutrition outcomes of the alternative treatments were obtained from the Explain window of the FarmDESIGN model for the BaU scenario (Table 2). The $\mathrm{K}$ balance for the treatments with extreme banana leaf pruning i.e. banana with four leaves-bush bean intercrop (T6) that served as starting point for all optimisations was negative $\left(-131 \mathrm{~kg} \mathrm{ha}^{-1}\right.$ year $\left.^{-1}\right)$ while the $\mathrm{N}$ and $\mathrm{P}$ balances were positive (Table 2 ). Soil $\mathrm{K}$ balance was thus constrained to a minimum of $-131 \mathrm{~kg} \mathrm{ha}^{-1}$ year $^{-1}$ for $\mathrm{BaU}$ and $\mathrm{H}$ scenarios and to $0 \mathrm{~kg} \mathrm{ha}^{-1}$ year $^{-1}$ for the other input scenarios that could offset the negative $\mathrm{K}$ balance. The total amounts of the different fertilizers applied were constrained between zero and amounts slightly above the nutrient requirement for banana based on the main nutrient 
supplied by the fertilizer type. These rates were based upon recommended fertilizer rates of $100 \mathrm{~kg} \mathrm{ha}^{-1}$ year-1 of N, $30 \mathrm{~kg} \mathrm{ha}^{-1}$ year ${ }^{-1}$ of $\mathrm{P}$ and $200 \mathrm{~kg} \mathrm{ha}^{-1}$ year ${ }^{-1}$ of $\mathrm{K}$ for East African highland bananas (Nyombi, 2014). NPK, CAN and Urea were targeted at attainment of the soil $\mathrm{N}$ needs and were respectively, allowed to vary to a maximum of 700, 400 and $300 \mathrm{~kg} \mathrm{ha}^{-1}$ year $^{-1}$ of fertilizer input. DAP was aimed at $P$ while MOP at $\mathrm{K}$ supply and the two were respectively, constrained to maximums of 70 and 500 $\mathrm{kg} \mathrm{ha}^{-1}$ year ${ }^{-1}$ of fertilizer input. The amount of manure was varied between 0 and 8 $\mathrm{Mg} \mathrm{ha}^{-1}$ year $^{-1}$.

Table 2. The performance of 7 different banana-banana treatment combinations for different potential production objectives (i.e. income, nutrient yield and environmental) if each was subjected to one hectare of land.

\begin{tabular}{|c|c|c|c|c|c|c|c|}
\hline \multirow[t]{2}{*}{ Variable } & \multicolumn{3}{|c|}{ Banana monocrop } & \multicolumn{3}{|c|}{$\begin{array}{c}\text { Banana-bush bean } \\
\text { intercrop }\end{array}$} & \multirow[t]{2}{*}{ T7 } \\
\hline & T1 & $\mathrm{T2}$ & T3 & T4 & T5 & T6 & \\
\hline Operating profit (US\$/ha-1 year ${ }^{-1}$ ) & 5482 & 4193 & 3794 & 5299 & 4471 & 2575 & -9 \\
\hline $\mathrm{N}$ input $\left(\mathrm{kg} \mathrm{ha}^{-1}\right.$ year $\left.^{-1}\right)$ & 161 & 161 & 161 & 179 & 185 & 188 & 211 \\
\hline Protein yield (persons ha-1 year $^{-1}$ ) & 25 & 21 & 19 & 31 & 29 & 23 & 15 \\
\hline Soil OM balance (kg ha ${ }^{-1}$ year $^{-1}$ ) & 15514 & 14942 & 14152 & 16294 & 16009 & 14962 & 11393 \\
\hline Soil K balance $\left(\mathrm{kg} \mathrm{ha}^{-1}\right.$ year $\left.^{-1}\right)$ & -302 & -216 & -189 & -321 & -261 & -131 & 161 \\
\hline Soil $\mathrm{N}$ balance $\left(\mathrm{kg} \mathrm{ha}^{-1}\right.$ year $\left.^{-1}\right)$ & 47 & 67 & 74 & 45 & 62 & 94 & 164 \\
\hline Soil P balance $\left(\mathrm{kg} \mathrm{ha}^{-1}\right.$ year-1) $^{-1}$ & 105 & 107 & 108 & 102 & 104 & 107 & 114 \\
\hline
\end{tabular}

T1 to T3 denote monocrops of banana in which all, seven and four fully open green leaves are retained; T4-T6 bush bean intercrop with banana having all, seven and four fully open green leaves; and T7 a bush bean monocrop.

Input data: Input data for the FarmDESIGN model were obtained from the field experiment, local markets, FarmDESIGN repository and other secondary data. Input data obtained from the empirical experiment included crop yields ( $\mathrm{kg} / \mathrm{ha} / \mathrm{year}$ ) (Table 1); cultivation costs (cost of labour, seed and other inputs, Table 1); and the soil nutrient levels. The price of bush bean grains and banana in the market was US\$1/kg and US\$0.15/kg, respectively. Values available in FarmDESIGN and secondary literature were used for obtaining other environmental variables such as deposition and fixation of nitrogen; nitrogen, phosphorus, potassium and dry matter content of the crop residues; and the organic matter decomposition rates. HarvestPlus food composition table for Central and Eastern Uganda (Hotz, et al. 2012; HarvestPlus, 2017) and the USDA food composition table (USDA, 2017) were used to determine the nutritional compositions for the two crop species. Nutrient contents available in literature were used for calliandra and tithonia (Heuzé et al., 
2017). Variable yields have been reported for calliandra (7 to $55 \mathrm{Mg} \mathrm{ha}^{-1}$; Jilna et al., 2018; Wiersum and Rika, 2016; Orwa et al., 2009) and a modest yield estimate of 20 $\mathrm{Mg} \mathrm{ha}^{-1}$ was used for calliandra while a yield of $25 \mathrm{Mg} \mathrm{ha}^{-1}$ was used for tithonia (Nguyen et al., 2010). For the goat manure, nutrient levels $(1.36 \% \mathrm{~N}, 0.06 \% \mathrm{P}$ and $\mathrm{K}$ ) from on farm experiments in Uganda (Songyo et al., 2014) with similar settings to the current study area are used for the model.

Objectives: Four objectives were explored in this study: operating profit maximisation, $\mathrm{N}$ input minimisation, soil organic matter (SOM) balance maximisation, and protein yield maximisation. Operating profit and dietary diversity are important objectives for smallholder farmers in the study region, related to income and food security, with beans integrated within banana to primarily meet their protein needs. Nutritional yield of proteins was determined as the number of adults that can obtain $100 \%$ of their recommended daily reference intake (DRI) per year (DeFries, et al., 2015) from a hectare of land planted with the crop(s) of interest. SOM, N, P and K balances are crucial for supporting the productivity of the system. For example, $\mathrm{K}$ and $\mathrm{N}$ are respectively, required in large quantities by the banana crop and systems (Nyombi et al., 2010; Taulya, 2013).

\section{Model exploration}

In all explorations, the practice of intercropping bush beans with banana plants having four leaves (i.e. treatment T6) served as a starting point. The model was set to generate 1000 alternative solutions over 2000 iterations of optimisation with the evolutionary algorithm. The optimization aimed at searching for improvements relative to the current or original farm configuration (Groot et al., 2012). The model was separately optimized for the scenarios, first for BaU scenario and for the other five scenarios for improving the soil nutrient balances. The model outcomes (solution sets) from the different runs were compared with each other. From the cloud of the FarmDESIGN solution sets, Pareto-frontier configurations that performed better than the original configuration for pairs of objectives (marked " 0 " in Fig. 1 above) were examined and plotted to simplify the output and to make the trade-offs and synergies between the objectives explicit. The model trends were also examined for the allocation of land to the treatments and hedges with respect to the objectives.

\subsection{Results}

\section{Treatment comparisons prior to exploration}

Table 2 shows a comparison of the 7 banana-bush bean treatments for BaU prior to optimization. As expected, the highest $\mathrm{N}$ input was observed in the legume plot due 
to symbiotic $\mathrm{N}$ fixation followed by the intercrops, with $\mathrm{N}$ input in the intercrops increasing with leaf pruning levels. $\mathrm{N}$ balances were higher in the bush beans followed by the bush bean-banana intercrop with four leaves. $\mathrm{N}$ balances generally increased with the leaf pruning levels for both the intercrops and sole banana crop. $\mathrm{N}$ for the sole banana plots was contributed by the residual soil $\mathrm{N}$ and the atmospheric $\mathrm{N}$ input. Lower balances occurred for intercrops in which 7 and all leaves had been retained compared to their corresponding monocrops. Soil $\mathrm{K}$ balances were only positive for the bush bean monocrop (T7). Higher protein yield and SOM balance occur for the intercrops though this declines with subsequent leaf pruning levels. In contrast, the sole banana crops outperform the intercrops in terms of operating profit, suggesting a trade-off with $\mathrm{N}$ input, protein yield and SOM balance.

\section{Banana-bush bean field explorations with different input scenarios}

Model exploration for the scenario business as usual (BaU, without extra inputs) only resulted in configurations that are superior to the original field configuration (legume intercropped with banana having four leaves) for operating profit and $\mathrm{N}$ input (Fig. 3). Lower performances relative to the original field configuration are observed for protein yield and the SOM balance for BaU (Fig. 3b-f). Soil K balance was also negative for the BaU scenario. Thus, improvements in the system for these objectives and $\mathrm{K}$ balance are not feasible and viable through re-arranging the field components alone in the BaU scenario. Compared to T6 the starting point of the exploration, treatments T1-T5 had lower $\mathrm{N}$ input values to be adopted by the model for the BaU scenario. In contrast, T7 was low in productivity (operating profit, protein yield and SOM balance) to be adopted by the model.

Profound improvements in model explorations and overall system performance compared to BaU occurred with most of the input scenarios and objectives (Fig. 3). The scenarios with $\mathrm{BaU}$ and $\mathrm{H}$ generally had small clouds of the solution sets, with the hedges often performing more poorly than BaU for some objectives (Fig. 3, Table 3). 


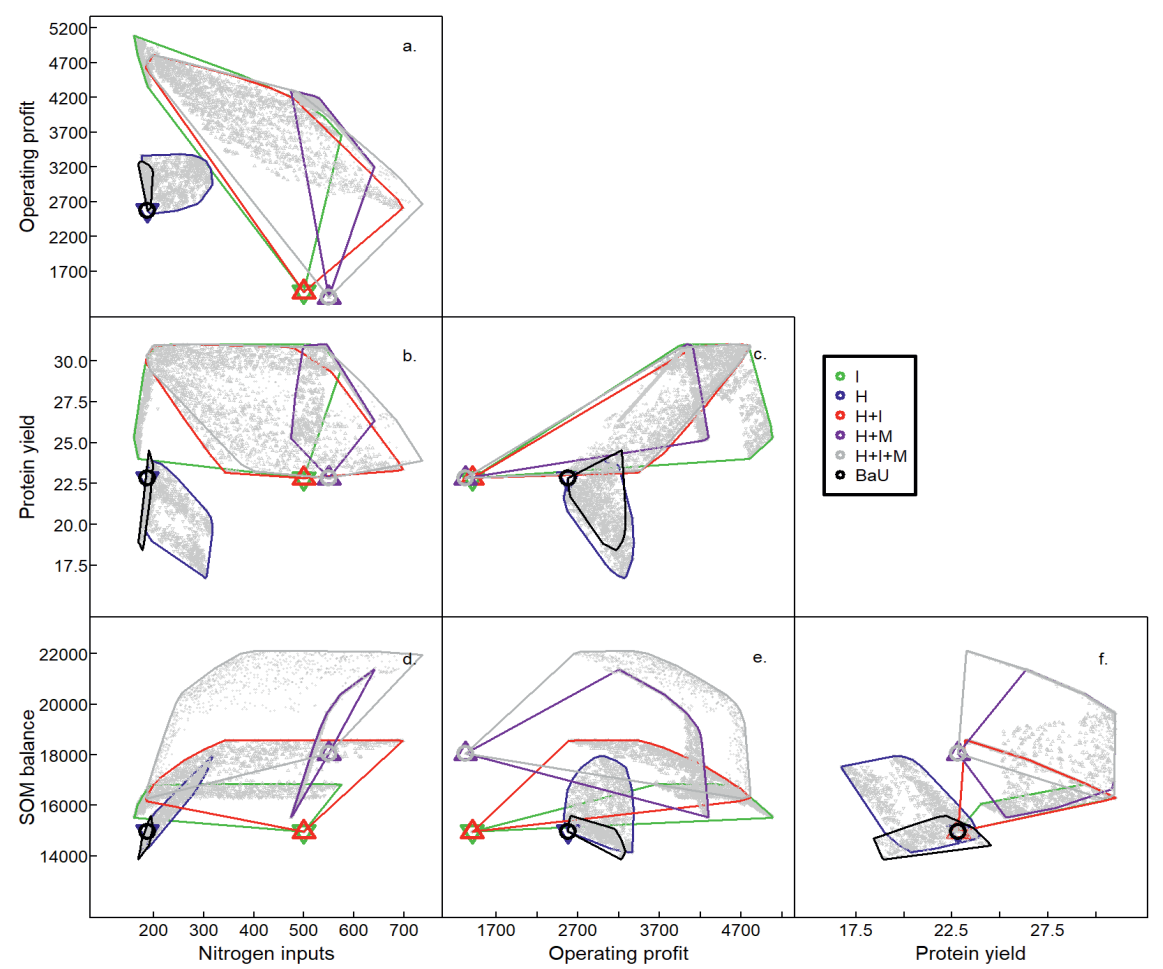

Figure 3. FarmDESIGN modelled alternative banana-bush bean field intensification configurations (represented by dots) for different pairs of objectives: minimising soil nitrogen (N) input; maximising operating profit, protein yield and soil organic matter (SOM) balance for five different nutrient input scenarios. The input scenarios include: i) business as usual i.e. no supplementation (BaU); supplementation with ii) live hedges $(\mathrm{H})$; iii) inorganic $\mathrm{N}, \mathrm{P}$ and $\mathrm{K}$ sources (I); iv) $\mathrm{H}+\mathrm{l}$; v) $\mathrm{H}$ and goat manure $(\mathrm{M})$ and vi) $\mathrm{H}+\mathrm{I}+\mathrm{M}$. The circles (for the $\mathrm{BaU}$ scenario) and triangles represent the original field configuration (i.e. intercrop of bush beans with banana pruned to four leaves).

Overall, scenarios with inorganic input performed better for operating profit, protein yield and $\mathrm{N}$ input while those with manure had the highest improvements for SOM balance. For example, the maximum operating profits varied between 4810 and 5085 US\$ for input scenarios with inorganic fertilizers compared with 3279 US\$ for $\mathrm{BaU}, 3385$ for hedges only and 4298 US\$ for the combination of hedges and manure (Table 3). The minimum $\mathrm{N}$ inputs varied between $162-186 \mathrm{~kg}$ for inorganic inputs compared with 170, 176, and $474 \mathrm{~kg}$ for $\mathrm{BaU}$, hedges and hedges with manure, respectively. The combination of hedges with manure generally had the worst performance for $\mathrm{N}$ input. With exception of $\mathrm{BaU}$ and $\mathrm{H}$ (protein yield between 17 and 25 persons/ha/y), protein yield increased to a maximum of 31 persons/ha/y from 23 persons/ha/y (Figs. 3b, 3c, 3e; Table 3). Zones of trade-offs and synergies 
were visible in the clouds of alternative solutions for the different scenarios. The model also differently allocated land that was a constraint across the input scenarios and objectives. For $\mathrm{BaU}$ and $\mathrm{H}$ were the supply of soil nutrients was low or limiting the model seemed to spread the available land to a large number of treatments, whereas, fewer treatments are allocated for the other input scenarios.

Table 3. The range of the performance scores for different production objectives in a bananabush bean system under different soil nutrient improvement scenarios.

\begin{tabular}{|c|c|c|c|c|c|c|c|c|}
\hline & \multicolumn{2}{|c|}{$\begin{array}{l}N \text { input } \\
(\mathrm{kg} / \mathrm{ha} / \mathrm{y})\end{array}$} & \multicolumn{2}{|c|}{$\begin{array}{l}\text { Operating profit } \\
\text { (US\$/ha/y) }\end{array}$} & \multicolumn{2}{|c|}{$\begin{array}{c}\text { Protein yield } \\
\text { (persons/ha/y) }\end{array}$} & \multicolumn{2}{|c|}{$\begin{array}{c}\text { SOM balance } \\
(\mathrm{kg} / \mathrm{ha} / \mathrm{y})\end{array}$} \\
\hline & Min & Max & Min & Max & Min & Max & Min & Max \\
\hline $\mathrm{BaU}$ & 170 & 199 & 2575 & 3279 & 18 & 25 & 13875 & 15604 \\
\hline $\mathrm{H}$ & 176 & 318 & 2524 & 3385 & 17 & 24 & 14147 & 17957 \\
\hline 1 & 162 & 574 & 1403 & 5085 & 23 & 31 & 14962 & 16851 \\
\hline $\mathrm{H}+\mathrm{I}$ & 185 & 697 & 1403 & 4811 & 23 & 31 & 14962 & 18585 \\
\hline$H+M$ & 474 & 640 & 1321 & 4298 & 23 & 31 & 15534 & 21373 \\
\hline $\mathrm{H}+\mathrm{I}+\mathrm{M}$ & 186 & 735 & 1321 & 4810 & 23 & 31 & 13875 & 22116 \\
\hline
\end{tabular}

$\mathrm{BaU}=$ Business as usual (i.e. no additional external inputs), $\mathrm{H}=$ hedges, $\mathrm{I}=$ inorganic fertilizer and $\mathrm{M}=$ goat manure

Operating profit: For the BaU and hedge scenarios, low operating profit was associated with a higher relative area for bush bean intercrop with banana having four leaves (T6) (Figs. 4a, 4e) while land was predominantly allocated to the intercrop of bush beans with banana having all leaves retained (T4) for the other input scenarios (Figs. 4i, 4m, 4q, 4u). At high operating profit levels, the model allocated land to combinantion of T2 (banana-7 leaves monocrop), bush bean monocrop (T7) and T4 for the BaU (Fig. 4a) whereas to T2, T1 (banana-all leaves monocrop) and T7 for the hedge scenario (Fig. 4e). For the inorganic input (Fig. 4i) and combination of hedge with manure (Fig. $4 q$ ), the model increased land allocation to T1 while for combinations of hedge with inorganic fertilizer (Fig. $4 \mathrm{~m}$ ) and hedge, manure and inorganic fertilizer (Fig. $4 \mathrm{u}$ ), the share for T4 increased with increasing profit. For combinations of hedge with inorganic fertilizer and hedge, manure and inorganic fertilizer, low amounts of the hedges (calliandra (T8) and tithonia (T9)) are observed at lower levels of operating profit.

$\mathbf{N}$ input: A low $\mathbf{N}$ input for BaU was mainly associated with sole banana crops with 7 (T2) or 4 (T4) leaves (Fig. 4b). In contrast, a higher relative land area was allocated to T2, T1 and T7 for hedges (Fig. 4f), T1 and T4 for inorganic fertilizers (Fig. 4j) and combination of hedge with manure (Fig. 4r), T4 for combinations of hedge with 
inorganic fertilizer (Fig. 4n) and hedge with inorganic fertilizer and manure (Fig. 4v). At high $\mathrm{N}$ input, BaU was mainly associated with T7 and T4 compared with T6, T5 (intercrop of bush beans with banana having 7 leaves) and T7 for hedges and T4 for the ther input scenarios.

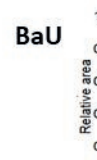

H
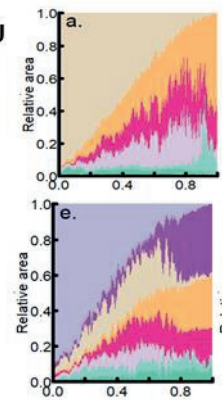

I

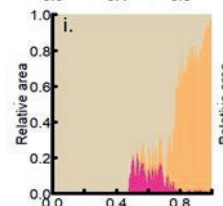

$\mathbf{H + l}$
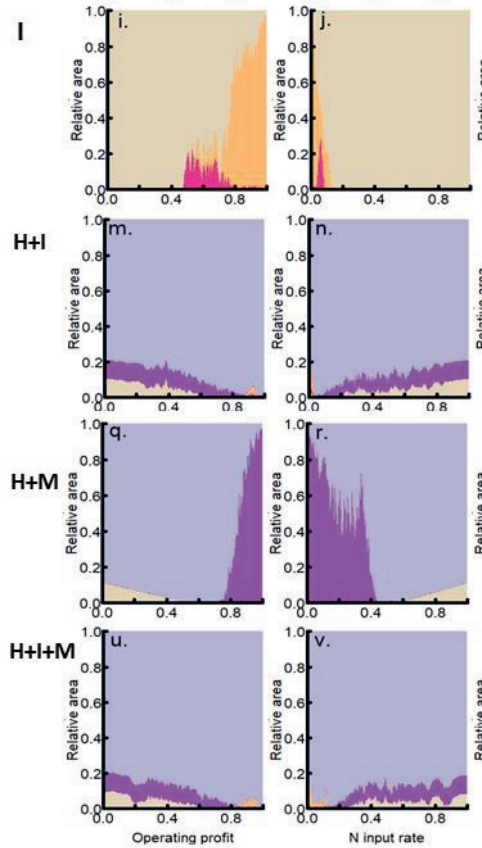
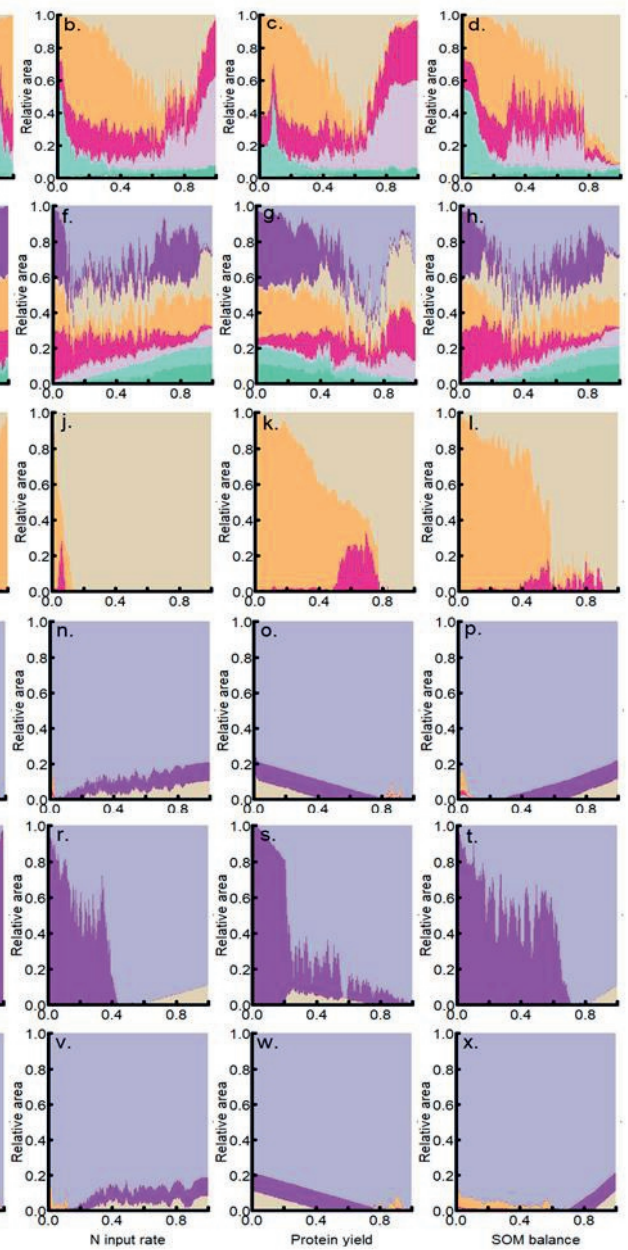
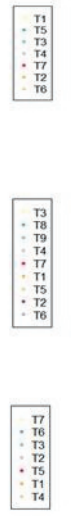

Figure 4. Model allocation of relative land area to different alternative treatments (i.e. banana-bush bean management options) optimized for minimising soil nitrogen $(\mathrm{N})$ input; maximising operating profit, protein yield and soil organic matter (SOM) balance for five different nutrient input scenarios. The input scenarios include: i) business as usual i.e. no supplementation (BaU); supplementation with ii) live hedges $(\mathrm{H})$; iii) inorganic $\mathrm{N}, \mathrm{P}$ and $\mathrm{K}$ sources (I); iv) $\mathrm{H}+\mathrm{l}$; v) $\mathrm{H}$ and goat manure (M) and vi) $\mathrm{H}+\mathrm{I}+\mathrm{M}$. Treatments $\mathrm{T} 1$ to $\mathrm{T} 3$ depict banana monocrops in which all, 7 and four leaves have been respectively, retained, T4 to T6 bush bean intercrops with banana having all, 7 and four leaves, T7 a bush bean monocrop, T8 a calliandra hedge and T9 a tithonia hedge. 
Protein yield: Land allocation with protein yield varied across the input options. A low protein yield was predominantly associated to treatment T2 for BaU (Fig. 4c) and treatments $\mathrm{T} 2$ and $\mathrm{T} 1$ for hedges (Fig. 4g). For the inorganic input and the combination of hedges with manure, a low protein yield was mainly associated to the banana monocrop $\mathrm{T} 1$, while the remaining scenarions were mainly associated with T4. At high protein yield, large allocations to the bush bean monocrop (T7) occurred for BaU and hedges, with T4 for BaU and T6 and T5 for hedges accounting for the other key treatments. In contrast, T4 predmoniates for the other input scenarios at high protein yield.

Soil organic matter (SOM) balance: For the BaU, a low SOM balance was associated to treatments $\mathrm{T} 2, \mathrm{~T} 5$ and $\mathrm{T} 7$ while to treatment $\mathrm{T} 2, \mathrm{~T} 7$ and $\mathrm{T} 1$ for the hedge scenario. For scenarios inorganic fertilizer and hedge-manure combination, more land is allocted to T1 a low SOM balance while to T4 when inorganic fertilizers are combined with hedges or hedges and manure. At high SOM balance, most of the land is allocated to T6 for BaU, combination of T6, T5 and T1 for hedges and to T4 for other input options.

\section{Pareto-frontier trade-offs and synergies between production objectives}

At the rank " 0 " Pareto frontier (c.f. Fig. 2), trade-offs and synergies between the four production objectives explored were explicit. Figure 5 explores the relations between the four production objectives i.e. minimisation of $\mathrm{N}$ input, maximisation of operating profit, protein yield and SOM balance at the rank " 0 " Pareto-optimal frontier of the plots in figure 3.

$\mathbf{N}$ input vs operating profit: Apart from a small section of the scenario combining hedges with inorganic input and manure, synergies were explicit between $\mathrm{N}$ input and operating profit across the input scenarios at the rank " 0 " Pareto-optimal frontier (Fig. 5a). The model predominantly allocated land to un-pruned bananabush bean intercrop (T4, 97-100\%) at the rank " 0 " Pareto-frontier for the scenarios combining hedges with inorganic fertilizer and manure, and hedges with inorganic fertilizer. For the inorganic input only, 99\% of land allocation was allocated to unpruned sole banana crop (T1) at the high operating profit vs low $\mathrm{N}$ input end of the rank "0" Pareto-optimal frontier while 98\% to T4 at low operating profit vs high $\mathrm{N}$ input. BaU and hedges had a small window of exploration, having low score for $\mathrm{N}$ input but performing poorly for operation profit (Fig. 5a). The allocation of land between treatments was also not precise for BaU and hedges at the rank " 0 " Paretooptimal frontiers. The model had the highest allocations of $20 \%, 28 \%, 49 \%$ of the land to T7, T3 and T2, respectively at high operating profit and low N input for BaU, while between 20 and 29\% to T7, T2, T4 and T6 at low operating profit and high $\mathrm{N}$ 
input. For the hedge scenario, the model allocated $26 \%, 28 \%$ and $41 \%$ of the land to T6, T1 and T2 respectively at the rank " 0 " Pareto frontier. Hedge and manure performed sub-optimally for $\mathrm{N}$ input, with high $\mathrm{N}$ input levels above $450 \mathrm{~kg} \mathrm{ha}^{-1}$ year${ }^{1}$ at the rank " 0 " Pareto-optimal frontier (Fig. 3a, 5a). 97\% of land was assigned to T1 at high operating profit vs low $\mathrm{N}$ input while $83 \%$ and $17 \%$ to $\mathrm{T} 4$ and $\mathrm{T} 1$, respectively at lower operating profit and high $\mathrm{N}$ input for hedge and manure scenario.
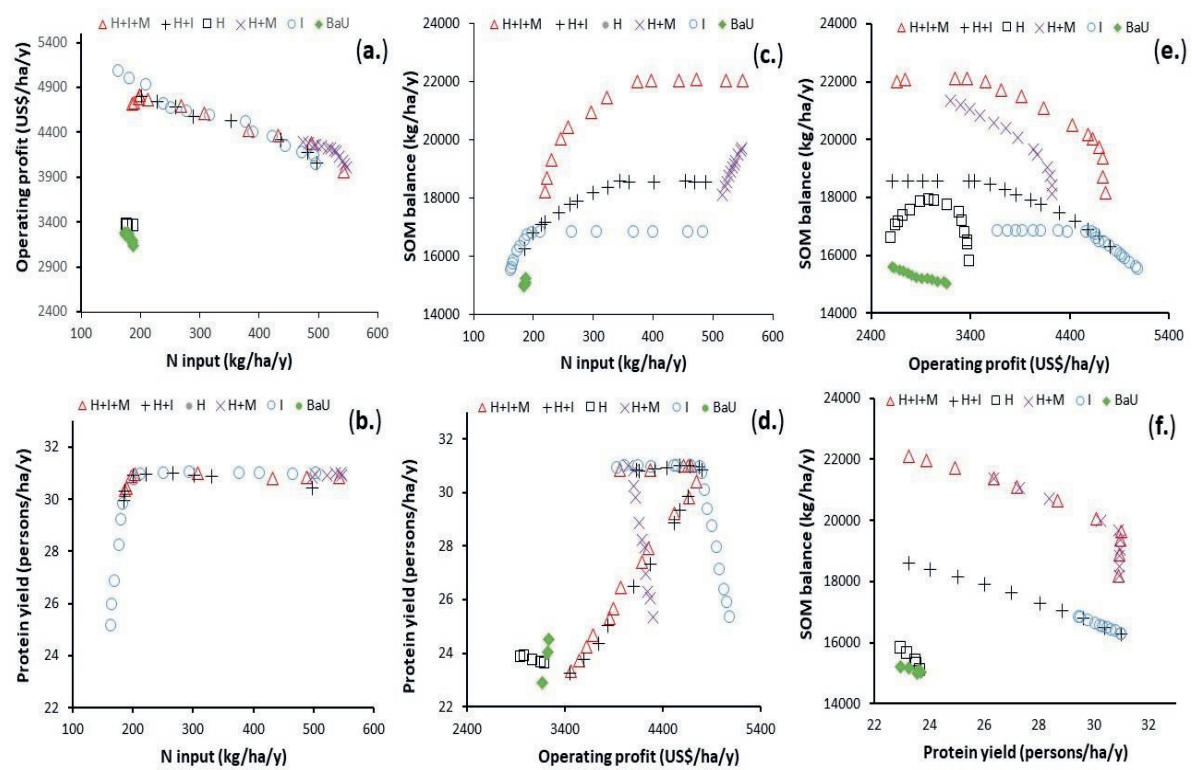

Figure 5. Plot of the Pareto-optimal frontiers of the FarmDESIGN solution spaces - comparing 5 alternatives/ or combinations for improving soil nutrient balance in a banana bush bean system. Input sources included i) inorganic fertilizers (I), ii) calliandra and tithonia hedge (H), iii) a combination of inorganic fertilizer and the hedges $(\mathrm{H}+\mathrm{l})$, iv) a combination of goat manure and the hedges $(\mathrm{H}+\mathrm{M})$ and $\mathrm{v}$ ) a combination of the inorganic fertilizers, hedges and goat manure $(\mathrm{H}+\mathrm{I}+\mathrm{M})$.

$\mathbf{N}$ input vs protein yield: No solution sets for $\mathrm{BaU}$ and hedge scenarios had a rank "0" score at the Pareto-frontier for $\mathrm{N}$ input vs operating profit (Fig. 5b). A trade-off between $\mathrm{N}$ input and protein yield is observed for the remaining input scenarios. For these scenarios, protein yield was observed to be nearly constant between $\mathrm{N}$ input levels of 600 and $200 \mathrm{~kg} / \mathrm{ha} / \mathrm{y}$ and thereafter declined with further decline in $\mathrm{N}$ input. At the extreme ends of the rank " 0 " Pareto-optimal frontier, $83-100 \%$ of the land was allocated to T4 for scenarios combining hedges with inorganic fertilizer and manure, hedges with manure and hedges with inorganic fertilizer. For the inorganic fertilizer only, $98 \%$ of land was assigned to $\mathrm{T} 1$ at low $\mathrm{N}$ input vs high protein yield 
end while $100 \%$ to T4 at high N input vs high protein yield end of the rank "0" Paretooptimal frontier.

N input vs SOM balance: No field configuration had a rank " 0 " Pareto rank for hedges for these two objectives (Fig. 3d, 5c). A trade-off was observed for all the other input scenarios for $\mathrm{N}$ input vs SOM balance. $\mathrm{N}$ input (minimised) increased with increasing SOM balance (maximised) (Fig. 5c). Input scenarios with manure had the highest scores for SOM whereas they performed more poorly for $\mathrm{N}$ input. The inorganic input had the best performance for $\mathrm{N}$ input though with a low SOM balance. For BaU, at high $\mathrm{N}$ and SOM balance end of the rank " 0 " Pareto-optimal frontier, 9\%, 33\% and $50 \%$ of land was allocated to T7, T6 and T2, respectively while $12 \%, 39 \%$ and $43 \%$ to T7, T6 and T2 at low $\mathrm{N}$ input and SOM balance end. For the hedge plus inorganic fertilizer and manure, $75-96 \%$ of the land was assigned to T4. For hedge plus manure, hedge plus inorganic fertilizer and inorganic fertilizer only, about $75-95 \%$ of the land at the rank " 0 " Pareto-optimal frontier was assigned to T4 at high $\mathrm{N}$ input and SOM balance while $90-98 \%$ to $\mathrm{T} 1$ at low $\mathrm{N}$ input and SOM balance.

Operating profit vs protein yield: The input scenarios responded differently for operating profit and protein yield along the rank " 0 " Pareto-frontier (Fig. 5d). Synergies were visible for $\mathrm{BaU}$, the combination of hedges with inorganic fertilizer and manure, and the combination of hedges with inorganic fertilizer. Land allocation at the rank "0" Pareto frontier for BaU varied from 31-37\% for T1 and 43-55\% for T4, area under both treatments increasing with increasing operating profit and protein yield. At low operating profit and protein yield, $11 \%$ of land is also allocated to T2 for $\mathrm{BaU}$. For hedges plus inorganic fertilizer and manure and hedges plus inorganic fertilizer at the rank " 0 " Pareto-optimal frontier, between 75 and $99 \%$ of land is assigned to T4 with the other proportion going to the hedges, the proportion to T4 increasing with operating profit and protein yield. In contrast, trade-offs occurred for hedge, hedge plus manure and inorganic fertilizer scenarios (Fig. 5d). For the hedge scenario, the model apportions land to a large number of treatments, with the highest going to T5 (34\%) and T6 (32\%) at low operating profit vs high protein and to T2 (48\%), T1 (28\%) and T7 (28\%) at high operating profit and low protein yield. Land alloctaion for hedge plus manure and inorganic fertilizer at the rank " 0 " Paretooptimal frontier was similar, with $94-99 \%$ of land assigned to T1 at high operating profity vs low protein yield and $95-100 \%$ to $\mathrm{T} 4$ at lower operating profit and higher proteing yield.

Operating profit vs SOM balance: With the exception of hedges that had both points of synergy and trade-offs, trade-offs occurred for all other input scenarios between operating profit and SOM balance at the rank " 0 " Pareto-frontier (Fig. 5e). For BaU, $86 \%$ of land was assigned to T6 at low operating profit vs high SOM end of the rank 
"0" Pareto-optimal frontier whereas 33\% and 52\% of land were assigned to T7 and T4 at high operating profit vs low SOM balance end of the rank " 0 " Pareto-optimal frontier. For the hedge scenario, no clear pattern occurred for the allocation of land to the treatments at the extreme ends of the rank " 0 " Pareto-optimal frontier, with T6 (28\%) accounting for the highest land portion at low operating profit vs SOM balance and T2 (33\%) and T1 (33\%) at th high operating profit vs low SOM balance end. For the hedge plus inorganic fertilizer and manure, and hedge plus inorganic manure, 75 and $99 \%$ of land assigned to T4 at the low operating profit vs high SOM balance and the high operating profit vs low SOM balance ends of the rank " 0 " Pareto-optimal frontier, respectively. High SOM balance in these scenarios was also associated with a high land allocation to hedges. In the hedge plus manure and the inorganic fertilizer scenarios, a high operating profit vs low SOM balance had $96-99 \%$ of the land allocated to T1 while a low operating profit vs high SOM balance had 86$99 \%$ of land allocated to T4.

Protein yield vs SOM balance: Trade-offs were explicit between protein yield and SOM balance at the rank "0" Pareto-frontier (Fig. 5f). BaU and hedges recorded the least performance for both objectives. For $\mathrm{BaU}, 23,27$ and $34 \%$ of the land was assigned to T6, T7 and T4, respectively at low protein yield and SOM balance while $33 \%$ and $53 \%$ to $\mathrm{T} 7$ and $\mathrm{T} 4$, respectively at high protein vs low SOM balance. For the hedges T5 had the highest land allocation (37 and 42\%) at both ends of the rank " 0 " Pareto-optimal frontier while T7 (18-27\%), T4 (16-18\%) and T6 (16\%) also received significant land allocations. Land allocations at the rank " 0 " Pareto-optimal frontier were similar for the remaining input scenarios. $75-100 \%$ of the land for these input options was allocated to T4, with the share of T4 increasing with increasing protein yield. At high SOM balance, $18-20 \%$ of the land was assigned to the hedges for scenarios with hedges.

\subsection{Discussions}

The FarmDESIGN model has been used to unravel complexities at farm level through determining of trade-offs and synergies between farm objectives and exploring windows of opportunities for improving farm performance. In the current study, the model was applied at field level to address complexities assocaited with the management and the interaction in a banana-bush bean intercrop. Complexities in this system also arise from the difficulties in measuring environment and nutrition related objectives that are often subtle to farmers and directly observable or measurable. The computer based FarmDESIGN model explored the trade-offs and 
synergies, the most economically viable and environmentally sound management alternatives, and scenarios for improving the banana-bush bean system.

Pruning of banana leaves to integrate legumes profoundly reduced the operating profit, and SOM balance of the system, whereas $\mathrm{N}$ input into the system increased with increasing leaf pruning. Reduction in operating profit and SOM balances with increased leaf pruning can be attributed to the reduced photosynthetic capacity that affects overall growth and development and fruit filling. Leaf area of the banana crop has been reported to be positively correlated to bunch weight and overall performance of the crop (Stover and Simmonds, 1987; Mukasa et al., 2005). Ocimati et al. (2019) reported the cutting of leaves to integrate legumes to result in an economically inefficient system despite a higher agronomic efficiency for moderate leaf pruning. Increase in $\mathrm{N}$ input with increasing levels of leaf pruning can be attributed to increased vigour of the bush bean due to higher access to light and higher biological nitrogen fixation. This is supported by the fact that $\mathrm{N}$ balances were lower for intercrops in which seven and all banana leaves had been retained compared with the sole banana crops. Profound reduction in root growth and nodulation with a subsequent depression in biological $\mathrm{N}$ fixation in legume spp. has been reported due to shading (Butler et al., 1959; Bloom et al., 1985; Fujita et al., 1992). Bloom et al. (1985) reported a higher allocation of dry matter to shoots when light is limiting, thus the poor root and nodule development. N, P and $\mathrm{K}$ balances also increased with increasing leaf pruning levels possibly due to the better performance of the legume component as described above and reduced uptake by the banana crop. The reduced uptake by the banana crop can be attributed to a reduced root mass associated with leaf pruning (Blomme et al., 2001).

Model exploration without extra inputs (BaU) i.e. re-arranging the field components alone and addition of hedges only did not result in profoundly superior alternative solutions for most objectives. In contrast, explorations with scenarios that included addition of inorganic fertilizer and goat manure profoundly improved the performance of the system for most objectives explored. This suggests soil nutrients were a major limiting factor for the banana bush-bean system. The dismal performance of the hedge scenario is possibly because hedges mainly helped in nutrient recycling (Fairhurst, 2012). More still, hedges reduced the total area that could be allotted to the banana and the legume crop.

The inorganic N, P, K sources outperformed the other input scenarios for the operating profit (maximised), protein yield (maximised) and $\mathrm{N}$ input (minimised) objectives. This can be attributed to a relatively lower cost of, and the ease to adequately fulfil the multiple nutrient requirements of the system through the inorganic sources. In contrast, the goat manure only scenario had a very high $\mathrm{N}$ input 
and SOM balance. The goat manure had a low $\mathrm{K}$ content (i.e. $0.06 \%$ ). Soil $\mathrm{K}$ is the most limiting nutrient for banana production (Nyombi et al., 2010; Taulya, 2013) and the east African highland bananas are for example, reported to 'worry' more about potassium than other factors (Taulya, 2013). Thus, large amounts of goat manure need to be applied to reach sufficient levels of $\mathrm{K}$ content, leading to above optimal levels of $\mathrm{N}$ input. In contrast the amount of carbon in the goat manure was large. The $\mathrm{N}$ input ranges for all the input scenarios $\left(162-735 \mathrm{~kg} \mathrm{ha}^{-1}\right.$ year $\left.^{-1}\right)$ were higher than the recommended blanket rate (i.e. $100 \mathrm{~kg} / \mathrm{ha}$ ) for east African highland banana systems in Uganda (Ssali et al., 2003) but corresponded to recommendations for high yielding banana plantations (i.e. 300-450 kg N/ha) elsewhere (Lahav and Turner, 1983; Robinson, 1996). More recent studies (e.g. Nyombi et al., 2010; Taulya, 2013) show better response of the east African highland banana to high higher levels of $\mathrm{N}$, $P, K$ (i.e. $150-400 \mathrm{~kg} \mathrm{~N} \mathrm{ha}^{-1}$ year $^{-1}, 50 \mathrm{~kg} \mathrm{P} \mathrm{ha}^{-1}$ year $^{-1}$ and 250-600 kg K ha ${ }^{-1}$ year $^{-1}$ ) and these $\mathrm{N}$ input values are comparable to the outcome from the FarmDESIGN model in this study.

Land allocations to treatments across the input scenarios were influenced strongly by the availability of nutrients. For BaU and hedges that had a smaller window of exploration due to lack of additional inputs, land was predominantly allocated to treatments that had a lower demand for nutrients. These predominantly included the severe case of banana leaf pruning to integrate legumes, legume monocrop and intercrops under moderate leaf pruning. In contrast, for scenarios that included inorganic fertilizer or a mixture of inorganic fertilizers and manures, the models predominantly selected intercrop of bush beans with un-pruned banana and/or a sole un-pruned banana monocrop that demanded more nutrients. The prioritisation of intercrops with severely pruned treatments under low input scenarios suggests that severe leaf pruning on farmers' fields though primarily to improve light interception can lower nutrient uptake enabling the fields to remain productive for longer time periods. Pruning of the banana plants potentially reduces banana root mass and the plants ability to take up nutrients whereas the improved light to the legume results in better biological nitrogen fixation and $\mathrm{N}$ balances. $\mathrm{A}$ sole un-pruned banana as a monocrop or intercrop would result in a higher nutrient uptake, a more rapid soil nutrient depletion and in the long run potentially affecting the productivity and resilience of the systems in absence of external inputs. Ocimati et al. (2019) observed the practice of severe leaf pruning to be agronomically and economically in-efficient and recommend its discouragement. However, such a move will need to be supported with efforts to supplement the soils with external inputs. More still, the ability to grow a sole crop could be limited with declining sizes of the fields. 
Trade-offs and synergies were visible between the objectives at the Paretooptimal frontiers. Synergies occurred between $\mathrm{N}$ input and operating profit, suggesting that both could be improved jointly. Synergies were also observed for operating profit and protein yield when input scenarios contained hedges. The observed synergies could be attributed to the fact that the FarmDESIGN model is static, thus unable to capture yield responses due to improved nutrition. Trade-offs were profoundly visible between the other interactions of the objectives. Strategies to manage these trade-offs will be crucial and may be more dependent on farmers priorities and access to resources. For example, a resource endowed - marketoriented farmer may be willing to invest more in external inputs to increase his profitability with the contrary when a farmer is producing for home consumption.

A strong association was observed between a large land area allocation to hedges (tithonia and calliandra) and a high SOM balance and $\mathrm{N}$ input. This suggests that hedges could potentially help in improving the SOM and $\mathrm{N}$ balances. Planting hedges along boundaries of homesteads and farms primarily to secure and beautify homes, and to demarcate farms is a common practice in the study region and could be exploited. $\mathrm{N}$ fixing and $\mathrm{N}$-rich hedges with high biomass production ability have been reported to potentially improve soil fertility (Fairhurst, 2012; Ocimati et al. 2018). These hedges could as well be a good source of fodder for integrating zerograzed livestock; and improving nutrient recycling. They can also be used as mulch or green manure thus reducing wind and water erosion on these smallholder farms. Hedges are also known to harbour natural enemies of crop pests and increase agrobiodiversity within farms (Groot et al., 2010). Calliandra is reported to be beneficial for rehabilitation of erosion-prone areas and lands exhausted by agriculture, providing shade for partially shade-tolerant trees and crops, fixing $\mathrm{N}$ through its symbiotic Rhizobium bacteria and root fungus, improving soil through its high $\mathrm{N}$ rich leaf biomass yields and well-developed lateral rooting system (Orwa et al., 2009). It is reported to be compatible with crops having both extensive fibrous roots and deep roots, thus suitable for hedgerow boundaries (Orwa et al. 2009). Positive effects of tithonia on subsequent rice and maize crops have also been reported (Devide, 2013; Olabode et al., 2007). Tithonia is omnipresent in the study region, growing wildly, as a hedge or weed on farms. Enlightening farmers on its potential benefits could increase its role in nutrient recycling within this production systems.

The FarmDESIGN model provided an opportunity for an additional, deeper analysis of the empirical experiment and unravelled the relations between production objectives (i.e. operating profit, $\mathrm{N}$ input, protein yield and SOM balances), constraints and decision variables, which would be challenging to explore 
using the empirical experiment only. The model generated numerous rank " 0 " Pareto-optimal alternative farm configurations, giving a large set of alternative choices that farmers can choose from. It also made the synergies and trade-offs between the objectives explicit. Trade-offs and synergies with environmental and nutrition objectives are especially very crucial given they are often ignored or unknown to farmers and difficult to measure. The model could thus facilitate discussions between extension and/or research staff with farming communities to support and improve farm decision making with respect to moderating of the different farm objectives, production constraints and decision variables. However, the high variability within farms across the study area and data demand suggest the need for good data collection and management to support decision making based on this tool. Available literature and databases e.g. on nutrient composition tables (Harvest plus, 2017; USDA, 2017) are useful inputs for the FarmDESIGN model. Important to note is that the FarmDESIGN model is static, as such does not adapt crop yields to management practices like increased fertilizer levels (Groot et al., 2012), but uses production activities that represent discrete steps in fertilizer input and nutrient sufficiency as reflected in nutrient balances. The model was thus not able to reflect a continuous relation to reach potential yield and incomes that could have arisen from the improved soil nutrient balances associated with the input scenarios in this study. Factoring nutrient response curves to capture the effect of fertilizers through linking the model to existing algorithms for nutrient responses could be a pathway to arrive at more robust outcomes.

\subsection{Conclusion}

Severe leaf pruning to integrate legumes resulted in a reduced nutrient demand and better N, P and $\mathrm{K}$ balances. Though primarily aimed at improving light to the legume crop, it could indirectly slow the rate of soil nutrient depletion thus extending the productive life span of the soils. However, it compromised the operating profit, SOC and nutritional yield of the system. The model results suggest that scenarios that did not profoundly improve nutrient availability (i.e. BaU and hedges) stifled model exploration, whereas addition of external inputs profoundly generated several solution sets that improved the overall performance of the banana-bush bean system. FarmDESIGN model was found to be very helpful for exploring trade-offs and synergies between multiple objectives, identifying Pareto-optimal field configurations for the banana-bush bean system. FarmDESIGN model is as such a useful tool and could be widely promoted to support decision making at field level for a more sustainable banana production system. 


\subsection{Acknowledgements}

We are grateful for the financial support from the Belgian Directorate General for Development through the Consortium for Improving Agriculture-based Livelihoods in Central Africa. This research was conducted in the framework of the Roots, Tubers and Banana program of the CGIAR (CRP RTB).

\section{References}

Abele, S., Twine, E., and Legg, C. (2007). Food security in Eastern Africa and the Great Lakes. Crop Crisis Control Project Final Report to USAID. Pp. 110. http://c3project.iita.org/Doc/Final\%20report\%20C3P\%20small.pdf. Accessed on $18^{\text {th }}$ March 2015.

Blomme, G., Ocimati, W., Groot, J.C.J., Ntamwira, J., Bahati, L., Kantungeko, D., ... and Tittonell, P. (2018). Agroecological integration of shade-and drought-tolerant food/feed crops for year-round productivity in banana-based systems under rain-fed conditions in Central Africa. Acta Hort. 1196, 41-54.

Blomme, G., Ocimati, W., Sivirihauma, C., Vutseme, L., Mariamu, B., Kamira, M., ... and Ntamwira, J. (2017). A control package revolving around the removal of single diseased banana stems is effective for the restoration of Xanthomonas wilt infected fields. Eur. J. Plant Pathol. 149(2), 385-400.

Blomme, G., Tenkouano, A., and Swennen, R. (2001). Influence of leaf removal on shoot and root growth in banana (Musa spp.). InfoMusa 10(2), 10-13.

Bloom, A.J., Chapin III, F.S., and Mooney, H.A. (1985). Resource limitation in plants-an economic analogy. Annu. Rev. Ecol. Syst. 16, 363-392.

Butler, G.W., Greenwood, R.M., and Soper, K. (1959). Effects of shading and defoliation on the turnover of root and nodule tissue of plants of Trifolium repens, Trifolium pratense, and Lotus uliginosus. New Zeal. J. Agr. Res. 2(3), 415-426.

DeFries, R., Fanzo, J., Remans, R., Palm, C., Wood, S., and Anderman, T.L. (2015). Global nutrition. Metrics for land-scarce agriculture. Sci. 349, 238-40

Ditzler, L., Komarek, A.M., Chiang, T.W., Alvarez, S., Chatterjee, S.A., Timler, C., ... and Groot, J.C.J. (2019). A model to examine farm household trade-offs and synergies with an application to smallholders in Vietnam. Agr. Syst. 173, 49-63.

Edmeades, S., Smale, M., Kikulwe, E.M., Nkuba, J., and Byabachwezi, M.S.R. (2007). Characteristics of banana-growing households and banana cultivars in Uganda and Tanzania. Pages 49-74 in: An Economic Assessment of Banana Genetic Improvement and Innovation in the Lake Victoria Region of Uganda and Tanzania. M. Smale and W.K. Tushemereirwe, eds. IFPRI Research Report 155. IFPRI, Washington, DC.

Fairhurst, T. (2012). Handbook of integrated soil fertility management. Africa soil health consortium, Nairobi. 
FAO (2015). FAPDA country fact sheet on food and agriculture policy trends - BURUNDI. http://www.fao.org/3/a-i4909e.pdf

FAO (2018). http://faostat3.ao.org/browse/Q/*/E. Accessed on 22 ${ }^{\text {nd }}$ March 2018.

Fujita, K., Ofosu-Budu, K.G. and Ogata, S. (1992). Biological nitrogen fixation in mixed legumecereal cropping systems. Plant and Soil, 141(1-2), pp.155-175.

Goldberg, D.E. (1989). Genetic Algorithms in Search, Optimization, and Machine Learning. Addison Wesley, Reading, Massachusetts, 1989.

Groot, J.C.J., and Rossing, W. (2011). Model-aided learning for adaptive management of natural resources. An evolutionary design perspective. Methods Ecol. Evol. 2, 643-650.

Groot, J.C., Jellema, A., and Rossing, W.A. (2010). Designing a hedgerow network in a multifunctional agricultural landscape: balancing trade-offs among ecological quality, landscape character and implementation costs. Eur. J. Agron. 32(1), 112-119.

Groot, J.C.J. (2018). Farm DESIGN Manual - Version 4.21.0.

Groot, J.C.J., Oomen, G., and Rossing, W.A.H. (2007b). Model-based on farm design of mixed farming systems. 1er Congr. en Co-Innovacion Sist. Sostenibles Sustento Rural. 155-158.

Groot, J.C.J., Oomen, G.J.M., and Rossing, W.A.H. 2012. Multi-objective optimization and design of farming systems. Agr. Syst. 110, 63-77.

Groot, J.C.J., Rossing, W.A., Jellema, A., Stobbelaar, D.J., Renting, H., and Van Ittersum, M.K. (2007a). Exploring multi-scale trade-offs between nature conservation, agricultural profits and landscape quality-a methodology to support discussions on land-use perspectives. Agr. Ecosyst. Environ. 120(1), 58-69.

HarvestPlus (2017). Food composition table Uganda. Kampala.

Heuzé, V., Tran G., Doreau, M., and Lebas, F. (2017). Calliandra (Calliandra calothyrsus). Feedipedia, a programme by INRA, CIRAD, AFZ and FAO. https://www.feedipedia.org/node/586 Last updated on April 7, 2017, 16:02

Heuzé, V., Tran, G., Giger-Reverdin, S. and Lebas, F. (2016). Mexican sunflower (Tithonia diversifolia). Feedipedia, a programme by INRA, CIRAD, AFZ and FAO. https://www.feedipedia.org/node/15645 (Accessed: March, 2018)

Hotz, C., Abdelrahman, L., Sison, C., Moursi, M., and Loechl, C. (2012). A food composition table for Central and Eastern Uganda. Washington DC: HarvestPlus.

IFAD (2018). The Democratic Republic of Congo. https://www.ifad.org/en/web/operations/country/id/dr congo\#anchor-3

Jagwe, J., Ouma, E., van Asten, P., and Abele, S. (2014). Banana marketing in Rwanda, Burundi and South Kivu CIALCA project survey report.

Janssen, S., and van Ittersum, M.K. (2007). Assessing farm innovations and responses to policies: a review of bio-economic farm models. Agr. Syst. (3), 622-636.

Joy, J., Raj, A.K., Kunhamu, T. K., and Jamaludheen, V. (2018). Forage yield and nutritive quality of three-years-old calliandra (Calliandra calothyrsus Meissn.) under different management options in coconut plantations of Kerala, India. Indian J. Agrofor. 20(1), 1115.

Karamura, E.B., Turyagyenda, F.L., Tinzaara, W., Blomme, G., Molina, A., and Markham, R. (2008). Xanthomonas Wilt (Xanthomonas campestris pv. musacearum) of Bananas in 
East and Central Africa. Diagnostic and Management Guide. Fountain Publishers, Kampala, Uganda.

Lahav, E., and Turner, D.W. (1983). Fertilizing for High Yield-Banana. International Potash Institute, Bulletin no. 7, Berne, Switzerland, p. 62.

Mukasa, H.H., Ocan, D., Rubaihayo, P.R., and Blomme, G. (2005). Relationships between bunch weight and plant growth characteristics of Musa spp. assessed at farm level. MusAfrica 16, 2-4.

Nandwa, S.M., and Bekunda, M.A. (1998). Research on nutrient flows in east and Southern Africa: state-of-the-art. Agr. Ecosyst. Environ. 71, 5-18.

Ntamwira, J., Pypers, P., van Asten, P., Vanlauwe, B., Ruhigwa, B., Lepoint, P., ... and Blomme, G. (2014). Effect of banana leaf pruning on banana and legume yield under intercropping in farmers' fields in eastern Democratic Republic of Congo. J. Hortic. For. 6(9), 72-80.

Ntamwira, J., Pypers, P., van Asten, P., Vanlauwe, B., Ruhigwa, B., Lepointe, P., and Blomme, G. (2013). Effect of leaf pruning of banana on legume yield in banana-legume intercropping systems in eastern Democratic Republic of Congo. In: Blomme G, van Austen P and Vanlauwe B (eds) Banana Systems in the Humid Highlands of Sub-Saharan Africa: enhancing resilience and productivity. CABI, Wallingford, Oxfordshire, UK, pp. 158-165.

Nyombi, K. (2014). Fertilizer management of Highland bananas in East Africa. Better Crops, 98, 29-31.

Nyombi, K., Van Asten, P.J., Corbeels, M., Taulya, G., Leffelaar, P.A., and Giller, K.E. (2010). Mineral fertilizer response and nutrient use efficiencies of East African highland banana (Musa spp., AAA-EAHB, cv. Kisansa). Field Crops Res. 117(1), 38-50.

Ocimati, W., Karamura, D., Rutikanga, A., Sivirihauma, C., Ndungo, V., Ntamwira, J., ... and Blomme, G. (2013). Agronomic practices for Musa across different agro-ecological zones in Burundi, Eastern Democratic Republic of Congo and Rwanda. In Banana Systems in the Humid Highlands of Sub-Saharan Africa: Enhancing Resilience and Productivity, G. Blomme, B. Vanlauwe, and P. van Asten, eds. (Wallingford, UK: CAB International), p.175-190.

Ocimati, W., Ntamwira, J., Groot, J.C.J., Taulya, G., Tittonell, P., Dhed'a, B., ... and Blomme, G. (2019). Banana leaf pruning to facilitate annual legume intercropping as an intensification strategy in the East African highlands. Eur. J. Agron. 110, 125923.

Orwa, C., Mutua, A., Kindt, R., Jamnadass, R., and Anthony, S. (2009). Agroforestree Database:a tree reference and selection guide version 4.0 (http://www.worldagroforestry.org/sites/treedbs/treedatabases.asp)

Robinson, J.C. (1996). Bananas and Plantains. CAB International, UK.

Robinson, J.C., Anderson, T., and Eckstein, K. (1992). The influence of functional leaf removal at flower emergence on components of yield and photosynthetic compensation in banana. J. Hortic. Sci. 67(3), 403-410.

Songyo (2014). Towards sustainable banana production in central Uganda: assessing four alternative banana cropping systems. MSc thesis. [Available at: http://edepot.wur.nl/416414] (Accessed: March 2019) 
Ssali, H., McIntyre, B.D., Gold, C.S., Kashaija, I.N., and Kizito, F. (2003). Effects of mulch and mineral fertilizer on crop, weevil and soil quality parameters in highland banana. Nutr. Cycl. Agroecosyst. 65, 141-150.

Stover, R.H., and Simmonds, N.W. (1987). Bananas (3 $\left.{ }^{\text {rd }} \mathrm{Ed}^{\mathrm{n}}\right)$, Tropical Agricultural Series, Longman, Essex, UK, $468 \mathrm{p}$.

Sunday, G., and Ocen, D. (2015). Fertilizer consumption and fertilizer use by crop in Uganda. [Available at: http://www.africafertilizer.org/wp-content/uploads/2017/05/FUBCUganda-final-report-2015.pdf]

Taulya, G. (2013). East African highland bananas (Musa spp. AAA-EA) 'worry' more about potassium deficiency than drought stress. Field Crops Res. 151, 45-55

Tinzaara, W., Stoian, D., Ocimati, W., Kikulwe, E., Otieno, G., and Blomme, G. (2018). Challenges and opportunities for smallholders in banana value chains. In: Achieving sustainable cultivation of banana. Pp. 85-110. Burleigh Dodds Science Publishing.

Uganda Investment Authority (2018). Agriculture. https://www.ugandainvest.go.ug/projects/ USDA (2017). USDA Food Composition Databases. Retrieved December 13, 2017, from https://ndb.nal.usda.gov/ndb/search/list Wall

van Asten, P.J.A., Gold, C.S., Okech, S.H.O., Gaidashova, S.V., Tushemereirwe, W., and De Waele, D. (2004). Soil quality problems in East African banana systems and their relation with other yield loss factors. InfoMusa 13, 20-25.

Van Sao, N., Mui, N.T., and Van Binh, D. (2010). Biomass production of Tithonia diversifolia (Wild Sunflower), soil improvement on sloping land and use as high protein foliage for feeding goats. Livest. Res. Rural Dev. 22(8), 2010.

Wiersum, K.F., and Rika, I.K. (2016). Calliandra calothyrsus (PROSEA). https://uses. plantnetproject.org/en/Calliandra_calothyrsus_(PROSEA) (Accessed: March 2019). 


\section{Chapter 8}

\section{Agroecological integration strategies for optimal exploitation of available land spaces under banana}

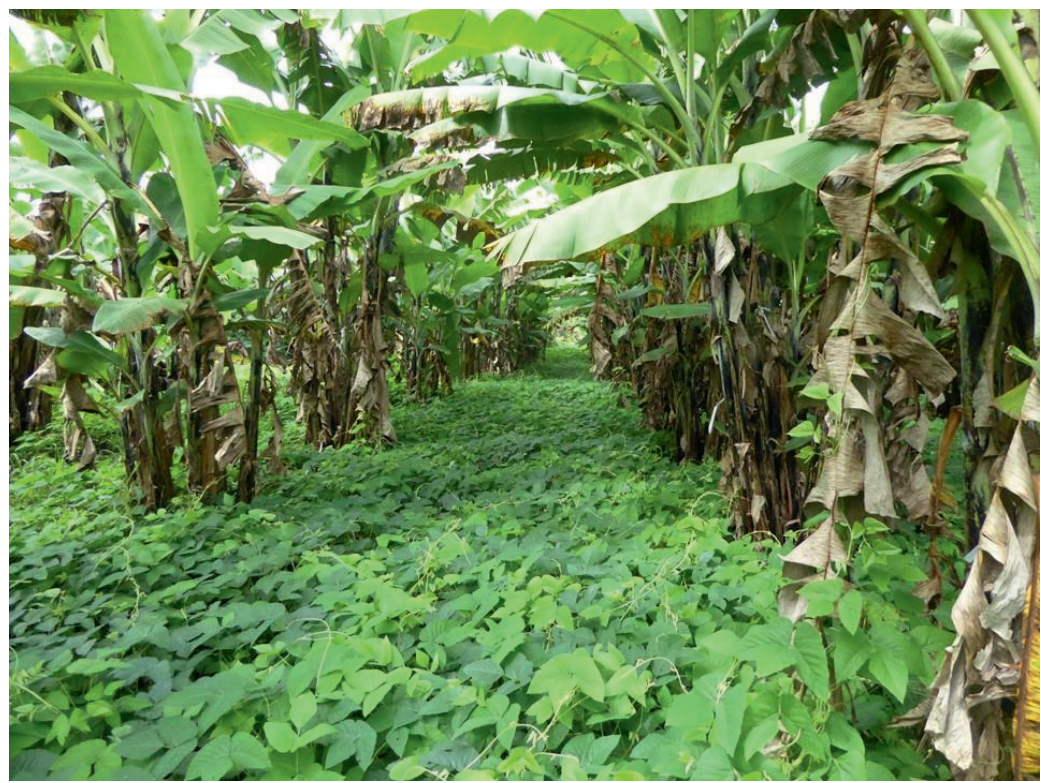

Published as:

Blomme, G., Ocimati, W., Groot, J.C.J., Ntamwira, J., Bahati, L., Kantungeko, D., Remans, R., and Tittonell, P. (2016). Agroecological integration of shade-and drought-tolerant food/feed crops for year-round productivity in banana-based systems under rain-fed conditions in Central Africa. In X International Symposium on Banana: ISHS-ProMusa Symposium on Agroecological Approaches to Promote Innovative Banana 1196 (pp. 41-54). 


\section{Abstract}

Yield gaps in banana-based production systems have increased in the past two decades due to declining soil fertility, drought and biotic stresses. Sustainable, environmentally sound and economically viable strategies for intensification in these systems are urgently needed. Agroecological practices, such as the integration of shade- and drought-tolerant crops, nitrogen-fixing and cover crops could potentially improve soil fertility and moisture retention, reduce the weed burden, narrow yield gaps and increase overall plot/farm productivity in these systems. In Malaysia, leguminous crops like Pueraria phaseoloides, Calopogonium caeruleum and Centrosema pubescens are often cultivated as cover crops (to suppress weeds, and reduce moisture loss and soil erosion) in young rubber and oil palm plantations with low shade levels. Even in mature oil palm plantations with less than $30 \%$ light intensity, various shade-tolerant crops are grown, e.g. elephant foot yam, turmeric and arrow root. In humid tropical Africa, Colocasia (taro) and Xanthosoma (cocoyam) are reported to tolerate shade conditions and hence often planted under perennial banana/plantain plantations. Drought tolerance is a less common feature of most annual crops grown in the humid tropics. A few root and tuber crops (e.g. cassava, taro, yam and sweetpotato) remain in the field during the dry season in Central Africa and are then harvested according to household needs. This paper also reports on crops (Mucuna, lablab and chickpea) with potential for integration into bananabased systems during the dry season, if planted during the last month of the rainy season. These crops are reported to use the residual soil moisture content for continued growth during the dry season months. The paper concludes with detailed descriptions (from a literature review) on drought- and shade-tolerance characteristics of various crops which have long been integrated in Central African banana-based cropping systems, crops with a more recent cultivation history and crops with potential for system integration.

Keywords: intensification, resilience, small-scale farming, year-round productivity, yield gaps. 


\subsection{Introduction}

Banana in the East and Central African region is predominantly grown by smallholder farmers (<2 ha), who realize low yields of 5-30 $\mathrm{Mg} \mathrm{ha}^{-1}$ year ${ }^{-1}$ (Wairegi et al., 2010; Okumu et al., 2011) when compared with $>70 \mathrm{Mg} \mathrm{ha}^{-1}$ year $^{-1}$ at experimental stations (van Asten et al., 2004). The low yields are attributed to the sub-optimal crop management practices and several abiotic and biotic stresses (pests and diseases). Banana weevils (Cosmopolites sordidus), nematodes (Jones, 2000; Tushemereirwe et al., 2004), Xanthomonas wilt of banana and enset (XW, caused by Xanthomonas campestris pv. musacearum), Fusarium wilt (caused by Fusarium oxysporum f. sp. cubense) and banana bunchy top disease (BBTD, caused by the banana bunchy top virus (BBTV), genus Nanavirus (Niyongere et al., 2012; Ocimati et al., 2014; Blomme et al., 2014) are currently the main biotic constraints to banana production. The life span of banana plantations, especially in the low-altitude areas, has as such been drastically reduced to 5-10 years compared to plantation lifespans of 25-50 years during the mid-20th century, due to these constraints (Bekunda, 1999; Gold et al., 1999). The perennial nature of the crop and high population density result in fragmented and small land holdings per household across the region, which means that most farmers cannot afford to grow banana in mono-cropped stands (Ocimati et al., 2013). Farms are as such under continuous production every season or year without permitting the soils to restore their fertility. This is coupled to the fact that nutrients are constantly mined through bunch exports. Soil infertility and drought have actually been reported as main abiotic constraints to banana production in the East and Central African region (Wairegi et al., 2010; van Asten et al., 2011).

Shade cast by the banana leaf canopy is also an important constraint to intensification on smallholder farms as it hinders intercropping with most shorterstature crop species. Banana intercropping with annual crops is widely practiced in the rainy seasons and in widely spaced or young banana fields in East and Central Africa. The most common advantage of intercropping is the production of greater total agricultural yield on a given piece of land by making more efficient use of the available growth resources using a mixture of crops of different rooting ability, canopy structure, height and nutrient requirements based on the complementary utilization of growth resources by the component crops. In addition, intercropping often improves soil fertility through nitrogen fixation through the use of legumes, reduces pest incidence at the plot level, and increases soil conservation through greater ground cover than sole cropping (Ouma, 2009; Lithourgidis et al., 2011; Gebru, 2015).

With an increasing range of biotic and abiotic constraints, sustainable, 
environmentally sound and economically viable strategies/options for intensification in these production systems are urgently needed to bridge yield gaps. The use of agroecological approaches, such as the integration of shade-tolerant crops in mature banana fields and drought-tolerant crops during the dry season months across the whole farm, nitrogen-fixing crops and cover crops to potentially narrow yield gaps in these systems and maintain or increase overall whole plot/farm productivity, are envisaged.

Bommarco et al. (2013) suggested the use of ecological approaches that optimize ecosystem services in low-input farming systems as the best option for enhancing productivity in such settings with wide yield gaps. This manuscript reviews intensification scenarios for obtaining year-round whole-plot/farm productivity and increased resilience of production systems, tailored to small-scale, rain-fed banana farm settings in Central Africa. The manuscript reviews potential crop species that could be integrated spatially and temporally in banana-fields to particularly enhance systems resilience to shade, drought and XW, a biotic constraint.

\subsection{How cultivation constraints (banana shade, drought and Xanthomonas wilt) influence crop intensification}

High shade levels under banana canopies are a major constraint to intensification through intercropping under smallholder banana systems. Field trials carried out in South Kivu province, east Democratic Republic of Congo (DR Congo) showed a 75\% reduction in Photosynthetically Active Radiation during the $3^{\text {rd }}$ annual cropping season under expanding banana leaf canopy, i.e. 13-16 months after establishing banana plants at a spacing of $3 \times 3 \mathrm{~m}$. As a result, grain yields $(\mathrm{kg} / \mathrm{ha})$ of the shadesensitive bush bean 'HM21-7' and climbing bean 'Namulenga' were reduced to zero during this $3^{\text {rd }}$ annual cropping season. To reduce shade levels for annual intercrops, farmers often cut banana leaves at the onset of the rainy season. Modest leaf cutting is most often practiced. However, farmers in e.g. North Kivu province, east DR Congo sometimes cut off all banana leaves in densely grown plots at the onset of the annual cropping season (Fig. 1A), to provide sunlight for the legume intercrop. Field experiments to enhance light penetration through banana leaf cutting (as observed in farmer fields in South Kivu province) have shown an increase in legume yields with a reduction in shade level (Ntamwira et al., 2013a, b; 2014). However, banana leaf cutting affects banana bunch weights, and significant reductions in bunch weight of $1-11 \%$ and $30-40 \%$ have been observed for plants that had respectively 7 and 4 leaves retained during their entire lifespan (Ntamwira et al., unpublished). With increasingly smaller farm sizes, strategies to enable the use of space under banana with minimal 
trade-offs in yield and which could potentially increase overall farm productivity are needed. The integration of shade-tolerant crop species offers a potential alternative for improving the overall productivity of these systems.

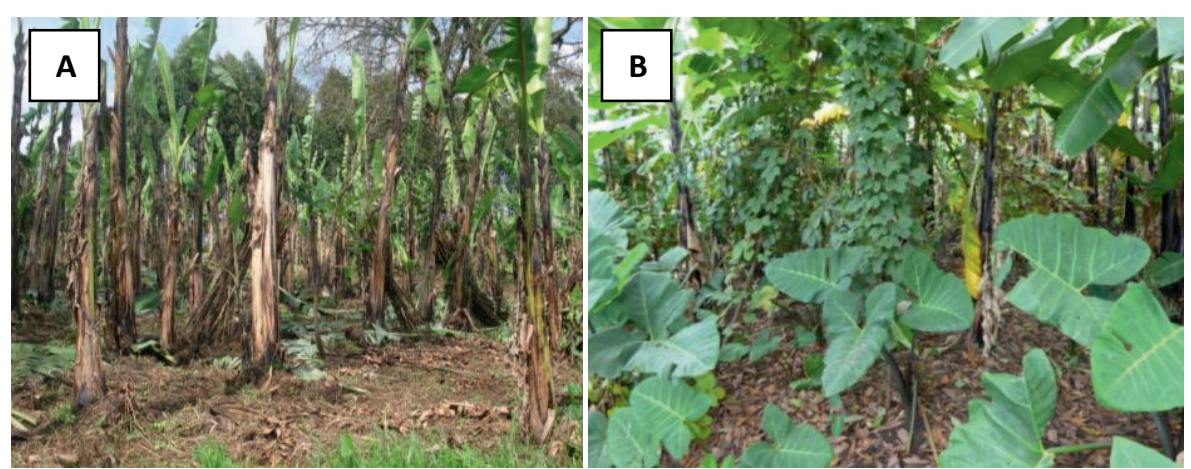

Figure 1. A. Farmers in North Kivu, eastern DR Congo sometimes cut off all banana leaves in densely grown plots at the onset of the annual cropping season to provide sunlight for the legume intercrop. B. Taro/cocoyam and yam intercropped with banana in South Kivu, eastern DR Congo.

Year-round and optimum whole-farm productivity has also been constrained by dry seasons and a lack of irrigation options for most small-scale farmers in Central Africa. Apart from banana and some tree species (i.e. multipurpose trees and coffee), very few annual crops such as sweetpotato, yam, taro and cassava are present in the plots during the dry season. These crops are gradually harvested during the dry season according to household needs. Crop species that can withstand the heat stress and thrive on low soil moisture contents give a window of opportunity for improving biomass production within the banana-based systems. The integration of food or feed crops that can be planted during the latter phase of the rainy season and which can use the residual soil moisture for continued growth and yield in the dry season should be explored.

The presence of XW in Central Africa is a particularly important driver for the development of sustainable banana-based production systems. A package of control options is available, comprising amongst others whole mat uprooting and Single Diseased Stem Removal (Blomme et al., 2014). Through these packages that are currently being disseminated and applied across various Central African countries, mats or plants are removed from the plots, creating open spaces and increased ground level light penetration favourable for annual crop cultivation. Integration of annual crops during the recovery phase of previously heavily diseased banana plots forms part of the system-level intensification efforts. However, banana canopies in 
new or recovering fields eventually close, creating the need for shade-tolerant crop options. Overall efforts hence need to focus on optimum use of space (ground layers) in time (across rainy and dry seasons, and under a growing banana crop) for optimum year-round whole plot/farm productivity, improved soil fertility, reduced erosion, increased moisture retention in the dry season and a reduced weed burden.

\subsection{Currently cultivated shade- and drought-tolerant crops in banana fields in central Africa}

The cultivation of shade-tolerant cover crops has been widely reported. For example, in Malaysia, the leguminous crops Pueraria phaseoloides, Calopogonium caeruleum and Centrosema pubescens are often cultivated as cover crops (to prevent weed growth, moisture loss and soil erosion) in young rubber and oil palm plantations with low shade levels. Even in mature oil palm plantations, where the availability of light is less than $30 \%$, various shade-loving and shade-tolerant crops are grown, e.g. elephant foot yam, turmeric and arrow root (Ramachandrudu et al., 2013).

In Central African banana-based farms, taro is the main and most widely grown crop under banana (Fig. 1B), while yam, cassava and African bird's eye chili pepper are grown to a lesser extent under shade. Taro leaves are harvested yearround and prepared as a vegetable in e.g. eastern DR Congo. Yam is grown in shaded banana fields (Fig. 1B), although yields reported by farmers were sub-optimal (Ntamwira, J., personal communication, 2016). Cassava is often intercropped in sparsely spaced banana plantations for tubers and leaves in eastern DR Congo, while monocropping is preferred in western Burundi as the production objective is tuber yield. Cassava leaves are important as a vegetable in diet and for income; however, its production in highly shaded banana fields has not been explored. Taro, cassava and yam stay in the field during the dry season, and the tubers are then harvested according to household needs. Sweetpotato is another tuber crop that stays in the field during the dry season. This crop is however predominantly grown as a monocrop or in widely spaced banana plots, as it is sensitive to shade. African bird's eye chili pepper is a shade-loving plant observed to grow (mostly as a volunteer crop) in heavily shaded banana fields.

The section below summarizes (from a literature review) drought- and shadetolerance characteristics of various crops which have long been integrated in Central African banana-based cropping systems (taro (Colocasia esculenta), cassava (Manihot esculenta), yam (Dioscorea esculenta), sweetpotato (Ipomoea batatas)and African bird's eye chili (Capsicum frutescens)), crops with a more recent cultivation history (Mucuna (Mucuna spp.) and Lablab (Lablab purpureus) and crops with potential for cropping system integration (elephant foot yam (Amorphophallus paeoniifolius), cocoyam (Xanthosoma spp.) (Aroid), ginger (Curcuma amada), turmeric (Curcuma longa) and chickpea (Cicer arietinum)) (Table 1). 
Table 1. Crop sensitivity or tolerance to shade and water stress (due to drought and dry seasons).

\begin{tabular}{|c|c|c|c|}
\hline $\begin{array}{l}\text { Crop sensitivity } \\
\text { or tolerance }\end{array}$ & Shade & $\begin{array}{l}\text { Water stress (due } \\
\text { to drought and } \\
\text { dry seasons) }\end{array}$ & References \\
\hline $\begin{array}{l}\text { Sensitive (only } \\
\text { coping with low } \\
\text { levels of shade) }\end{array}$ & $\begin{array}{l}\text { Bush bean, } \\
\text { climbing bean and } \\
\text { amaranth }\end{array}$ & $\begin{array}{l}\text { Bush bean, } \\
\text { climbing bean } \\
\text { and amaranth }\end{array}$ & \\
\hline $\begin{array}{l}\text { Semi-tolerant } \\
\text { (coping with } \\
\text { medium levels } \\
\text { of shade) }\end{array}$ & $\begin{array}{l}\text { Cassava (for } \\
\text { leaves), yam, } \\
\text { mango ginger and } \\
\text { turmeric }\end{array}$ & & $\begin{array}{l}\text { Okoli and Wilson (1986); } \\
\text { Johnston and Onwueme } \\
\text { (1998); Jayachandran and } \\
\text { Sreekandan Nair (1998); } \\
\text { Nybe (2007). }\end{array}$ \\
\hline $\begin{array}{l}\text { Tolerant (coping } \\
\text { with high levels } \\
\text { of shade) }\end{array}$ & $\begin{array}{l}\text { Taro, African bird } \\
\text { eye chili, cocoyam } \\
\text { and elephant foot } \\
\text { yam }\end{array}$ & $\begin{array}{l}\text { Cassava, yam, } \\
\text { taro, African bird } \\
\text { eye chili, } \\
\text { cocoyam and } \\
\text { elephant foot } \\
\text { yam }\end{array}$ & $\begin{array}{l}\text { Onwueme and Johnston } \\
\text { (2000); Kaudo (2014); } \\
\text { Johnston and Onwueme } \\
\text { (1998); Ramesh et al. } \\
\text { (2007); Agrifarming (2016) }\end{array}$ \\
\hline $\begin{array}{l}\text { Tolerant (when } \\
\text { planted a month } \\
\text { before the end } \\
\text { of the rainy } \\
\text { season; relay } \\
\text { cropping) }\end{array}$ & & $\begin{array}{l}\text { Mucuna, lablab } \\
\text { and chickpea }\end{array}$ & $\begin{array}{l}\text { Chiu (2004); Maass at al. } \\
\text { (2010); Guretzki and } \\
\text { Papenbrock (2014); Kokila } \\
\text { et al. (2014); Johansen et } \\
\text { al. (1994); Kumar and Abbo } \\
\text { (2001); Berger et al. (2004) }\end{array}$ \\
\hline
\end{tabular}

\subsection{The potential of shade- and drought tolerant root and tuber crops in existing banana systems (with commonly applied on farm banana planting densities): cocoyam, taro and elephant foot yam}

Taro and other aroids such as cocoyam/tannia (Xanthosoma sagittifolium) and elephant foot yam, are well adapted to shade conditions and are hence highly suitable for intercropping (Lebot, 2009; Verheye, 2010). In experiments to determine and compare the relative shade-tolerance and adaptability of taro, cocoyam/tannia, sweetpotato, yam and cassava through examining the effect of shade or full sunlight on leaf chlorophyll and carotenoids, all five species of root crops were observed to adapt to shade (Johnston and Onwueme, 1998). The leaf area and chlorophyll concentration increased, while the chlorophyll a:b ratio, carotenoids per unit chlorophyll, and the weight per unit area of leaf were lower in the shade than in the sun in all the crops. The extent of the changes, however, differed between species, with the aroids (taro and tannia) being more shade-tolerant (less change in chlorophyll a:b ratios) than the other species. This suggests that the light-harvesting systems of aroids may be adapted to shade conditions. Taro and tannia also had a greater proportional increase in leaf size, a smaller reduction in leaf weight per unit 
area and a greater proportional increase in chlorophyll and carotenoids per leaf than the other species (Johnston and Onwueme, 1998). Yam compensated for shade by having a large proportional increase in leaf size and appeared to be moderately tolerant to shade, while sweetpotato and cassava appeared to be the least tolerant to shade among these major tropical root crops (Johnston and Onwueme, 1998).

Taro: Taro (Colocasia esculenta) plants grown at $30 \%$ of full sunlight have increased stomatal and chlorophyll density, probably increasing photosynthetic efficiency at low levels of light (Onwueme and Johnston, 2000). Results of experiments conducted under artificial shade provided by a canopy of $50 \%$ shade cloth gave higher plant height and leaf area under shaded conditions compared to full sunlight. Rogers and losefa (1993) also observed a total increase in taro plant biomass under $50 \%$ shade. The corm yields were not affected by shade while the number and weight of plant suckers increased. Corm percentage dry matter, which reflects quality, was higher under shade. The fact that total plant biomass is increased by shade indicates greater photosynthetic efficiency (Rogers and losefa, 1993). However, a shade/cultivar interaction has been reported, suggesting the need to select cultivars appropriate to the shade levels found in farmers' fields (Rogers and losefa, 1993). Taro has a good level of drought tolerance and is currently even cultivated in Sahelian countries such as Burkina Faso (Lebot, 2009).

Cocoyam/tannia: Cocoyam/ tannia (Xanthosoma sagittifolium) is highly ranked in cultivation and production in tropical regions (Onwueme and Charles, 1994), where it is an important food for some 400 million people (Onokpise et al., 1999). It has overtaken taro as the main edible aroid in many tropical areas (Matthews, 2002). It has the advantage of growing under the full intensity of sunlight and tolerating shade (Onwueme and Charles, 1994; Johnston and Onwueme, 1998). Cocoyam is one of the most shade-tolerant food crops (Johnston and Onwueme, 1998; Ramesh et al., 2007) and is as such often intercropped with perennial food and cash crops such as cocoa, bananas, oil palms, etc., especially at the early stage of these plantations in West Africa (Onyeka, 2014). It is thus a commonly grown crop in the farming systems of the forest and forest/savanna transition zones in most countries in West Africa (Onyeka, 2014). In the humid zones of West Africa, plantains and cocoyam are as such ecologically complementary, with the moisture-loving cocoyams grown as understory plants beneath the canopy layer formed by the plantains (Harlan, 1976). Cocoyam is also considered as drought tolerant and often stays in the field during the dry season (Lebot, 2009).

Elephant foot yam: Elephant foot yam (Amorphophallus paeoniifolius) is a native of tropical Asia. The elephant foot yam is mainly cultivated in India, Sri Lanka, the Philippines and Southeast Asia. The elephant foot yam also belongs to the family 
Araceae. It is one of the most productive and profitable tuber crops cultivated in India. The tubers are consumed as vegetables after thorough cooking, while chips are also made from these starch-rich tubers. Tender stems and yam leaves are also consumed as vegetable. Elephant foot yam can also be intercropped in banana, coffee, areca nut, rubber and coconut plantations due to its shade tolerance (Agrifarming, 2016). The introduction of new crops into the Central African cropping systems would however be challenging due to socio-economic and cultural constraints.

\subsection{The potential of shade-sensitive and drought-tolerant root and tuber crops: yam, cassava, sweet potato}

Yam: Yam (Dioscorea esculenta) is not a shade-loving plant. It has however been reported to be moderately tolerant to shade (Johnston and Onwueme, 1998). Yam plants grown under shade produce larger leaves, but only to yield extremely small tubers (Onwueme and Charles, 1994). Yams grown without stakes have also been observed to yield less than those grown with stakes (Coursey, 1967, 1968; Lyonga et al., 1973) and this has been attributed to the greater amount of mutual leaf-shading that occurs in the unstacked yam plants. More still, the highest yam yields in the West African yam zone have been reported in the northern limits of the forest and in the savanna zones, with less cloud cover compared with the zones deeper in the forest, that have heavier and longer rainfall with frequent cloud cover (Onwueme and Charles, 1994). It therefore seems that yam not only tolerates but requires high intensities of sunlight to be maximally productive. FAO (2010) also reported yam plants to exhibit early shade tolerance during establishment but require full sun for good yields.

The yam plant is however relatively tolerant to dry conditions (Onwueme and Charles, 1994). In many yam-growing districts, planting is done during the dry season. The setts planted in dry soil must remain there for 2-3 months before the rainy season starts. They not only survive this period, but commence sprouting before the rains come (Onwueme, 1976; Onwueme and Charles, 1994). Even after sprouting, the yam seedling can tolerate periods of drought to a greater extent than many other crops, mainly due to moisture stored in the parent sett and vigorous root development so that the young plant is able to exploit whatever little moisture might be present in the sub-soil. However, yam yield will be significantly affected even though yams are able to cope with drought (Onwueme and Charles, 1994).

Sweetpotato: Sweet potato (Ipomoea batatas) grows best in high-rainfall areas of about 1500-2500 mm/year. Higher rainfall may induce excessive vegetative growth at the expense of tuber growth. The crop grows well in a variety of well-drained soil types but does not tolerate shading (FAO, 2010). Sweetpotato shoot morphological 
alterations in response to 55 and $73 \%$ shade included fewer but larger leaves and longer branches (Roberts-Nkrumah et al., 1986a). Tuber fresh weight in four sweetpotato cultivars (A28/7, TIS 2328/6 and C26/7) was not affected in $25 \%$ shade, but values were lower in $55 \%$ shade, and tuber development was almost completely suppressed in $73 \%$ shade for all cultivars (Roberts-Nkrumah et al., 1986b).

Sweetpotato however has a good degree of drought tolerance after establishment. Hence, its yield potential is generally greater than that of popular staple crops, such as maize (Motsa et al., 2015). The sweetpotato genotypes 420014, 440286, 189148.7, 44109, 440287 and 187017.1 for Kiboko and genotypes 421066, 420014, 421006 194573.9, 192033.3 and 189135.9 for Marigat were identified as genotypes with good performance, high drought tolerance, high dry matter and high levels of beta-carotene in Kenya (Agili et al., 2012). Drought tolerance in sweetpotato is attributed to the ability of its adventitious roots arising from the stem cuttings to rapidly penetrate the soil to depths of over 2 meter, enabling the crop to obtain water from deeper soil layers (Onwueme and Charles, 1994). The same authors also reported that sweetpotato can be cultivated in dry years when other cops such as cereals may have failed.

Cassava: Cassava (Manihot esculenta) is grown primarily for its starchy tuberous roots, which are an important staple for more than 800 million people, mostly in subSaharan Africa, but also in other parts of Africa, Asia, the Pacific, South America and the Caribbean. Cassava is important for both small-scale farmers and larger-scale plantations due to its low requirement for nutrients, ability to tolerate dry conditions and easy, low-cost propagation. It is sometimes referred to as the "drought, war and famine crop of the developing world", and reliance upon this crop is expected to increase in the coming years as the global climate changes (Burns et al., 2010). Onwueme and Charles (1994) reported cassava plants to be relatively droughttolerant except during the first few weeks after planting. Okogbenin et al. (2013) also reported that cassava can be produced adequately in dry conditions making it the ideal food security crop in marginal environments. Despite cassava's tolerance to drought, $500 \mathrm{~mm}$ of rain and a period of six months of rainfall per year is needed, with optimum rainfall being between $1000 \mathrm{~mm}$ and $1500 \mathrm{~mm}$ per year (Raemaekers, 2001; FAO, 2010). Higher rainfall levels can reduce tuber growth.

Cassava however, requires high solar radiation for efficient photosynthesis, and therefore shade has a considerable effect on cassava growth and production. Under shading, the root bulking process starts later and the number of roots per pant is reduced. All levels of shade delay root bulking, and at 20, 40, 50, 60 and 70\% shade, cassava yield reductions of $43,56,59,69$ and $80 \%$, respectively, have been reported (Okoli and Wilson, 1986). Shading also increases plant height (Okoli and Wilson, 1986). Shade induced elongated stems and thinner leaves, which resulted in reduced tuber yield. 


\subsection{Other shade-tolerant root and tuber crops with potential for integration/expansion into banana-based systems:}

Mango-ginger (Curcuma amada): Field trials on the performance of mango-ginger conducted in Kerala, India for two seasons under varying levels of shade revealed that rhizome yield under open and $25 \%$ shade were on par indicating that the crop is shade-tolerant and suitable for intercropping situations (Jayachandran and Sreekandan Nair, 1998). A possible drawback in intercropping banana with ginger is the fact that both crops are highly susceptible to the burrowing nematode (Radopholus similis) (Thorne 1961; Orton Williams and Siddiqi 1973; Sipes et al. 2001), especially when grown at elevations below 1400 meter.

Tumeric (Curcuma longa): Response of turmeric to different levels of shade (0, 25, 50 and $75 \%$ ) was studied by Nybe (2007). The highest turmeric yield was recorded at $50 \%$ shade. The crop is classified as shade loving and it can be successfully intercropped with perennial crops such as coconut and poplar trees (Nybe, 2007; Kaur et al., 2014). Kaur et al. (2014) also reported cultivar effects on shade tolerance. Better finger size and yield were recorded in ginger and turmeric from intercropped plots than sole crops (Vanlalhluna et al., 2014).

\subsection{A shade-tolerant spice with potential for integration in banana- based systems}

African bird's eye chili pepper: African bird's eye chili pepper (Capsicum frutescens) also sometimes known as Piri or Pili, is a small chili pepper, with red to purple berries that typically grow erect and are ellipsoid-conical to lanceoloid shaped. The African bird's eye chili is one of the most pungent chili types in the world. The plant is a small bush that can grow to a height of about $1.5 \mathrm{~m}$ with a productive life of 2-3 years. It requires minimal inputs/investments and its hardiness makes it very suitable for production by small-scale farmers in marginal areas (Kaudo, 2014). Historically found in the African wild, it has recently been grown commercially in some parts of Africa. The crop can provide an additional income source for small-scale farmers. The interest in African bird's eye chilies is growing rapidly in e.g. Kenya as farmers realize that there is a ready market, both locally and international, for the crop. For example, Mace Foods, a processing firm based in the town of Eldoret in the Rift Valley, Kenya, has marketing contracts with farmers. African bird's eye chilies are used as food ingredient (e.g. in soups, stews, hot sauces and chicken dishes), pharmaceuticals, organic pest control spray and in making tear gas/pepper spray (Kaudo, 2014). Currently, farmers in eastern DR Congo do not see great value of producing the crop in large quantities other than using it for spicing their food, making sausages, and as a drug for chicken (Bahati L., personal communication, 2016). However, given the 
crops' market potential, it could be used to increase the efficiency of using banana fields. Wide adoption of the cultivation of this crop would however need to be backed by rigorous value-chain and market studies. Important to note is the fact that pepper is a host for various strains of viruses, such as tobacco mosaic virus and cucumber mosaic virus (Kenyon et al., 2014). Integrated and pragmatic virus control measures will thus have to be sought e.g. combination of cultural practices that reduce sources of virus inoculum and decrease the rate of spread of viruliferous vectors into the pepper crop and other host crops (Kenyon et al., 2014).

\subsection{Crops that could be integrated into banana-based systems during the dry season, if planted during the last month of the rainy season}

Mucuna spp.: Mucuna spp. is an annual legume and is grown for its good quality forage, seeds, its binding capacity of atmospheric nitrogen in the soil (about $100 \mathrm{~kg}$ of nitrogen fixed per hectare of crop) and soil protection by its cover (Raemaekers, 2001). Mucuna has two main species: M. pruriens and M. bracteata. Most Mucuna spp. exhibit reasonable tolerance to several abiotic stresses, including drought, low soil fertility and high soil acidity, although they are sensitive to frost and grow poorly in cold, wet soils (Duke, 1981). Mucuna bracteata is drought tolerant because its roots can grow 2-3 meters deep (Chiu, 2004). In recent exploratory studies carried out in South Kivu province by the current authors, mono-cropped $M$. pruriens sowed late in the rainy season (i.e. 3 weeks to onset of the dry season) and before harvest of annual crops was observed to grow vigorously during the dry season months and cover the ground surface, suppressing weeds and offering a good green manure or mulch for the next crop. Intercropped Mucuna grown during the same period had a reduced biomass production, indicating significant shade effects.

Chiu and Bisad (2006) reported that dry matter production of $M$. bracteata under shade ( 60 to $70 \%$ ) to be about $40 \%$ less than in the open, despite the shaded plot being 2 years older. These findings concur with Mathews (1998) who reported $M$. bracteata to grow under shade but at a comparatively slow rate. Despite its shade-tolerant characteristics, Goh (2007) and Surani et al. (2010) found it difficult to cultivate $M$. bracteata under mature palms where their canopies had already overlapped. Similar observations have been reported by Mathews (1998), Chiu et al. (2001) and Ciza (2013). In Burundi, M. pruriens is commonly grown and is used as animal feed (cows, goats) during the dry season. Despite its slow growth and lower biomass production under shade, it could be grown in less dense mono-cropped banana plots to reduce water runoff, fix nitrogen, suppress weeds (also reducing labour expenses) and to provide fodder for livestock.

The integration of Mucuna in plots with low/declining soil fertility in Kenya was observed to improve the production and quality of feed resources, cereal crop yields and livestock production on low external input smallholder farms (Nyambati, 
2002), offering an alternative to commercial N sources. Relay-cropped Mucuna survived the dry season producing a total biomass yield of $4 \mathrm{t}$ ha-1 on the research station and 2.3 tha-1 on farmers' fields. Inclusion of the green manures in the maizebean intercrop increased subsequent bean and maize yields (by $21 \%$ ) compared with the natural fallow control (Nyambati, 2002).

Lablab: Lablab (Lablab purpureus) (for food and forage) is better adapted to drought than common beans (Phaseolus vulgaris) or cowpea (Vigna unguiculata), both of which have been preferred to lablab in African agricultural production systems (Maass et al., 2010). Lablab's popularity has mainly spread throughout much of South and Southeast Asia. The legume has however received less attention in Africa because its use is eclipsed by its popular cousin, the soybean. In the face of climate change and drought, however, this resilient and delicious plant is likely to make a comeback (Stone et al., 2011). Once established, lablab is highly drought resistant, often staying green during the dry season (Schaaffhausen, 1963b). Lablab is drought tolerant (Guretzki and Papenbrock, 2014; Kokila et al., 2014), producing reliably under a wide range of conditions, out-yielding conventional crops such as velvet bean (Stizolobium deeringianum) and cowpea, particularly when grown under conditions of drought (Murtagh and Dougherty 1968; Wilson and Murtagh 1962). For example, it has been grown in arid, semi-arid and humid regions with rainfall levels between 200 and $2500 \mathrm{~mm}$ (Hendricksen and Minson, 1985; Cameron, 1988). Staying green during the dry season, it has been known to provide up to $6 \mathrm{t}^{\mathrm{tha}} \mathrm{h}^{-1}$ of dry matter (Murphy and Colucci, 1999). With its deep tap root, lablab is not only drought resistant, but is able to bring minerals, otherwise not available for annual crops, from the depths to the top soil (Schaaffhausen, 1963a). This deep root also serves to stabilize the landscape as soil erosion and runoff are reduced by leguminous covers. Just like for Mucuna, relay cropped/the off-season integration of lablab in plots with declining or poor soil fertility in Kenya was observed to improve the subsequent production and quality of feed resources, cereal crop yields and livestock/dairy production in smallholder farms under low external input regimes (Nyambati, 2002).

Chickpea (Cicer arietinum): About 90\% of this crop is grown in eastern Africa and the Indian subcontinent by resource-poor farmers under rain-fed conditions as a postrainy season crop. The crop is most often planted during the latter phase of the rainy season and grows under receding soil-moisture conditions during the dry season months (Johansen et al., 1994; Kumar and Abbo, 2001; Berger et al., 2004).

\subsection{Conclusions}

There is an urgent need to identify windows of opportunity to sustainably intensify small-scale banana production systems in East and Central Africa. Integration, 
introduction or expansion of shade- and drought-tolerant crops offer good opportunities for optimum and a more sustainable use of the increasingly shrinking banana farms in the humid tropical regions in Africa. Aroid crops (e.g. taro, elephant foot yam and cocoyam) could be integrated in more mature banana plots with medium to high shade levels, while the cultivation of African bird's eye chili could be expanded if additional research on value chains and markets indicates export potential. Although promising, the cultivation of cassava (predominantly for leaves) and yam (for tubers) under various levels of shade needs more field assessment. Similarly, relay planting of Mucuna, lablab and chickpea at 1 month before the end of the rainy season, and with subsequent growth during the dry season months using residual soil moisture needs further field assessments. Mucuna and lablab integration could potentially improve the soil fertility conditions, suppress weeds (reducing labour needs) and open doors for livestock integration. Model-based support can be used to further analyse the banana farms/systems to identify opportunities for re-configuration of farms for multiple objectives. Pareto-based multi-objective optimization models are suitable for exploring trade-offs and synergies in these systems (Groot et al., 2007). Bioversity International and the Farming Systems Ecology department of Wageningen University Research (WUR) envisage using the FarmDESIGN model, a mechanistic multi-objective model (Groot et al., 2007; 2012) to optimize banana-based farming systems. This model will take biophysical (e.g., drought, shade and plant disease effects), economic and environmental production objectives into account, while determining the best-fit land use and agroecological intensification prototypes.

\subsection{Acknowledgements}

We would like to thank the Directorate General for Development, Belgium for funding scientist time to carry out this review in the framework of the Consortium for Improving Agriculture-based Livelihoods in Central Africa (CIALCA) project. This review was conducted under the framework of the Roots, Tubers and Banana programme of the CGIAR (CRP RTB)

\section{References}

Agili, S., Nyende, B., Ngamau, K., and Masinde, P. (2012). Selection, Yield Evaluation, Drought Tolerance Indices of Orange-Flesh Sweet potato (Ipomoea batatas Lam) Hybrid Clone. J. Nutr. Food Sci. 2,138. doi:10.4172/2155-9600.1000138.

Agrifarming (2016). http://www.agrifarming.in/elephant-foot-yam-cultivation.

Bekunda, M. (1999). Farmers' responses to soil fertility decline in banana-based cropping systems of Uganda. Managing Africa's Soils No. 4. [Available at: http://pubs.iied.org/pdfs/7397IIED.pdf] (Accessed on 24th Nov. 2016).

Berger, J.D., Turner, N.C., Siddique, K.H.M., Knights, E.J., Brinsmead, R.B., Mock, I., ... and Khan, T.N. (2004). Genotype by environment studies across Australia reveal the importance of 
phenology for chickpea (Cicer arietinum L.) improvement. Aust. J. Agr. Res. 55, 10711084.

Blomme, G., Jacobsen, K., Ocimati, W., Beed, F., Ntamwira, J., Sivirihauma, C., ... and Karamura, E. (2014). Fine-tuning banana Xanthomonas wilt control options over the past decade in East and Central Africa. Euro. J. Plant Pathol. 139, 265-281.

Bommarco, R, Kleijn, D., and Potts, S.G. (2013). "Ecological Intensification: Harnessing Ecosystem Services for Food Security." Trends Ecol. Evol. 28(4), 230-38.

Burns, A., Gleadow, R., Cliff, J., Zacarias, A., and Cavagnaro, T. (2010). Cassava: the drought, war and famine crop in a changing world. Sust. 2, 3572-3607.

Cameron, D.G. (1988). Tropical and subtropical pasture legumes. Queensland Agri. J. pp 110113.

Chiu, S.B. (2004). Mucuna bracteata dry matter conversion and decay rate of litter. The Planter, 80, 461-464.

Chiu, S.B., Aloysius, S. and Emilia, F. (2001). Mucuna bracteata - Supper legume cover crop revisited. The Planter, 77, 575-583.

Chiu, S.B., and Bisad, M. (2006). Mucuna bracteata-Biomass, Litter and Nutrient Production. The Planter, 82, 247-254.

Ciza, J. (2013). Contribution à l'étude de la diversité agrostologique du Burundi cas de la Commune Matana. Mémoire de fin d'étude universitaire, Université du Burundi, FACAGRO.

Coursey, D.G. (1967). Yams. An account of the Nature, Origins, Cultivation and Utilisation of the Useful Members of the Dioscoreaceae. Tropical Agricultural Series. Longmans, Green and Co. Ltd. Londres, UK. 230 p.

Coursey, D.G. (1968). Edible ariods. / Worldcrops 20: 25/30. Wilson 1984.

Duke, J.A. (1981). New York, NY, USA: Plenum press; Handbook of legumes of world economic importance.

FAO, (2010). MODULE4, PACIFIC ROOT CROPS, PACIFIC FOOD SECURITY TOOLKIT Building resilience to climate change - root crop and fishery production, http://www.fao.org/docrep/013/am014e/am014e04.pdf, pp. 79.

Gebru, H. (2015). A review on the comparative advantage of intercropping systems. J. Biol. Agr. Healthcare, 5(7), 28-38.

Goh, K.J. (2007). Mucuna bracteata: A Cover Crop and Living Green Manure. Cover crops. pp.183.

Gold, C.S., Karamura, E.B., Kiggundu, A., Bagamba, F., and Abera, A.M.K. (1999). Geographic shifts in highland cooking banana (Musa spp., group AAA-EA) production in Uganda. Int. J. Sustain. Dev. World Ecol. 6, 45-59.

Groot, J.C.J., Oomen, G.J.M., and Rossing, W.A.H. (2012). Multi-objective optimization and design of farming systems. Agric Sys. 110, 63-77.

Groot, J.C.J., Rossing, W.A.H., Jellema, A., Stobbelaar, D.J., Renting, H., and Van Ittersum, M.K. (2007). Exploring multi-scale trade-offs between nature conservation, agricultural profits and landscape quality -a methodology to support discussions on land-use perspectives. Agric Ecosyst Environ. 120, 58-69.

Guretzki, S., and Papenbrock, J. (2014). Characterization of Lablab purpureus Regarding Drought Tolerance, Trypsin Inhibitor Activity and Cyanogenic Potential for Selection in Breeding Programmes. 200(1), 24-35. DOI: 10.1111/jac.12043.

Harlan, J.R. (1976). Origins of African Plant Domestication. J.R. Harlan, J.M.J. De Wet, A.B.L Stemler (Eds.), DE GRUYTER MOUTON publishers. World Anthropology. pp. 493. DOI (Book):10.1515/9783110806373 
Hendricksen, R.E., and Minson, D.J. (1985). Lablab purpureus - A Review. Herbage Abstracts. 55, 215-227.

Jayachandran, B.K., and Sreekandan Nair, G. (1998). Performance of mango-ginger (Curcuma amada Roxb.) under different levels of shade. J. Spices Aromat. Crops 7(2), 145-146.

Johansen, C., Krishnamurthy, L., Saxena, N.P., and Sethi, S.C. (1994). Genotypic variation in moisture response of chickpea grown under line-source sprinklers in a semi-arid tropical environment. Field Crop Res. 37, 103-112.

Johnston, M., and Onwueme, I.C. (1998). Effect of shade on photosynthetic pigments in the tropical root crops: Yam, taro, tannia, cassava and sweet potato. Exp. Agr. 34(03), 301312. DOI: $10.1017 /$ S0014479798343033

Jones D.R. (ed) (2000). Diseases of Banana, Abaca and Enset. CABI Publishing. Wallingford Oxon, UK, 544pp

Kaudo, O.H. (2014). African Bird's Eye Production. Modern Crop Production. Using Modern technologies to get profit from farming. Target High yields based on the best management practices. http://hellenomondikaudo.blogspot.com/2014/11/africanbirds-eye-production.html (accessed on 20 November, 2016).

Kaur, N., Gill, R.I.S., and Singh, B. (2014). Productivity and financial viability of potential agroforestry systems in North-Western India. Book of Abstracts, 3rd World Congress on Agroforestry, Trees for life - Accelerating the impact of agroforestry. Nairobi: World Agroforestry Centre.

Kenyon, L., Kumar, S., Tsai, W.S., and Hughes, J.d'A. (2014). Virus diseases of peppers (Capsicum spp.) and their control. Adv. Virus Res. 90, 297-354.

Kokila, S., Myrene, R.D., and Varadahalli R.D. (2014). Response of Lablab purpureus (Hyacinth bean) cultivars to drought stress. Asian J. Plant Sci. Res. 4(5), 48-55.

Kumar, J., and Abbo, S. (2001). Genetics of flowering time in chickpea and its bearing on productivity in semiarid environments. In: D.L. Spaks (Ed.), Adv. Agron. vol. 2, Academic press, New York (2001), p. 22.

Lebot, V. (2009). Tropical Root and Tuber Crops: Cassava, Sweet Potato, Yams and Aroids. CABI, Technology and Engineering. pp. 433.

Lithourgidis, A.S., Dordas, C.A., Damalas, C.A., and Vlachostergios, D.N. (2011). Annual intercrops: an alternative pathway for sustainable agriculture. Aust. J. Crop Sci. 5(4), 396410.

Lyonga, S.N., Fayemi, A.A., and Agboola A.A. (1973). Agronomic studies on edible yam in grassland plateau region of the United Republic of Cameroon. Proc 3rd Int. Sympo. Trop. Root Crops, pp 340-346.

Maass, B.L., Knox, M.R., Venkatesha, S.C., Angessa, T.T., Ramme, S., and Pengelly, B.C. (2010). Lablab purpureus - a crop lost for Africa? Trop. Plant Biol. 3(3), 123-135.

Mathews, C. (1998). Introduction and establishment of a new leguminous cover plant, Mucuna bracteata under oil palm in Malaysia. The Planter, 74, 359-368.

Matthews, P.J. (2002). An introduction to the history of taro as a food. In: Potential of root crops for food and industrial resources. Twelfth Symposium of the International Society for Tropical Root Crops (ISTRC). (Eds. M. Nakatami \& K. Komaki). Tsukuba, Japan, pp. 484497.

Motsa, N.M., Modi, A.T., and Mabhaudhi, T. (2015). Sweet potato (Ipomoea batatas L.) as a drought tolerant and food security crop. S. Afr. J. Sci. 111(11-12), 1-8.

Murphy, A.M., and Colucci, P.E. (1999). A tropical forage solution to poor quality ruminant diets: A review of Lablab purpureus. Livest Res. Rural Dev. (11)2. 
Murtagh, G.J., and Dougherty, A.B. (1968). Relative yields of lablab and velvet bean. Trop. Grasslands, 2, 57-63.

Niyongere, C., Losenge, T., Ateke, E.M., Nkezabahizi, D., Blomme, G., and Lepoint, P. (2012). Occurrence and distribution of banana bunchy top disease in the Great Lakes Region of Africa. Tree and For. Sci. Biotechnol. 6, 102-107.

Ntamwira, J., Pypers, P., van Asten, P., Vanlauwe, B., Ndungo, V., Badesire, A., and Blomme, G. (2013a). Effect of banana leaf pruning on banana and bean yield in an intercropping system in eastern Democratic Republic of Congo. Afr. J. Plant Sci. Biotechnol. 7(1), 4.

Ntamwira, J., Pypers, P., van Asten, P., Vanlauwe, B., Ruhigwa, B., Lepoint, P., and Blomme, G. (2013b). Effect of leaf pruning of banana on legume yield in banana-legume intercropping systems in eastern Democratic Republic of Congo. In: Blomme G, van Austen P and Vanlauwe B (eds) Banana Systems in the Humid Highlands of Sub-Saharan Africa: enhancing resilience and productivity. $C A B$ International pp. 158-165.

Ntamwira, J., Pypers, P., van Asten, P., Vanlauwe, B., Ruhigwa, B., Lepoint, P., ... and Blomme, G. (2014). Effect of banana leaf pruning on banana and legume yield under intercropping in farmers' fields in eastern Democratic Republic of Congo. J. Hort. For. 6(9), 72-80.

Nyambati, E.M. (2002). Management and Nutritive Evaluation of Mucuna Pruriens and Lablab Purpureus-Maize Intercrops in The Sub-Humid Highlands of North-western Kenya. Phd Thesis, University of Florida, pp. 219.

Nybe, E.V. (2007). Spices. New India Publishing. pp. 330.

Ocimati, W., Karamura, D., Rutikanga, A., Sivirihauma, C., Ndungo, V., Ntamwira, J., ... and Blomme, G. (2013). Agronomic practices for Musa across different agro-ecological zones in Burundi, Eastern Democratic Republic of Congo and Rwanda. In: Blomme G, Vanlauwe $B$, van Asten $P$, eds. Banana Systems in the Humid Highlands of Sub-Saharan Africa: Enhancing Resilience and Productivity. Wallingford, UK: CAB International, 175-190 ISBN:9781780642314.

Ocimati, W., Nakato, G. V., Fiaboe, K.M., Beed, F., and Blomme, G. (2015). Incomplete systemic movement of Xanthomonas campestris pv. musacearum and the occurrence of latent infections in Xanthomonas wilt-infected banana mats. Plant Pathol. 64(1), 81-90.

Okogbenin, E., Setter, T.L., Ferguson, M., Mutegi, R., Ceballos, H., Olasanmi, B., and Fregene, M. (2013). Phenotypic approaches to drought in cassava: review. Front. Physiol. 4, 93.

Okoli, P.S.O., and Wilson, G.F. (1986). Response of cassava (Manihot esculenta Crantz) to shade under field conditions. Field Crops Res. 14(4), 349-359.

Okumu, M.O., van Asten, P.J.A., Kahangi, E., Okech, S.H.J., Jefwa, J., and Vanlauwe, B. (2011). Production gradients in smallholder banana (cv. Giant Cavendish) farms in central Kenya. Sci. Hort. 127, 475-481.

Onokpise, O.U., Wutoh, J.G., Ndzana, X., Tambong, J.T., Mekoba, M.M., Sama, A.E., ... and Burns, M. (1999). Evaluation of macabo cocoyam germplasm in Cameroon. In: J. Janick (Ed.), Perspectives on New Crops and New Uses, pp. 339-396. ASHS Press, Alexandria, VA.

Onwueme, I.C. (1976). Performance of yam (Dioscorea spp.) planted without water. J. Agric. Sci. Cambridge 87, 413-415.

Onwueme, I.C., and Charles, W.B. (1994). Tropical root and tuber crops. FAO, Rome. pp. 228.

Onwueme, I.C., and Johnston, M. (2000). Influence of shade on stomatal density, leaf size and other characteristics in the major tropical root crops, tannia, sweet potato, yam, cassava and taro. Exp. Agr. 36, 509-516.

Onyeka, J. (2014). Status of Cocoyam (Colocasia esculenta and Xanthosoma spp.) in West and Central Africa: Production, Household Importance and the Threat from Leaf Blight. Lima 
(Peru). CGIAR Research Program on Roots, Tubers and Bananas (RTB). [Available at: www.rtb.cgiar.org]

Orton Williams, K.J., and Siddiqi, M.R. (1973). Radopholus similis C.I.H. Description of PlantParasitic Nematodes. Set 2, No. 27, pp. 4. Commonwealth Institute of Helminthology, St. Albans, Herts, UK.

Ouma, G. (2009). Intercropping and its application to banana production in East Africa: A review. J. Plant Breed. Crop Sci. 1(2), 13-15.

Raemaekers, R.H. (2001). Crop Production in Tropical Africa. DGIC, Brussels, Belgium. p. 1540.

Ramachandrudu, K., Arulraj, S., and Rao, B.N. (2013). Scope for inter cropping in grown up oil palm gardens. http://www.krishisewa.com/articles/production-technology/309-intercropping-oil-palm-gardens.html (Accessed: October 2016).

Ramesh, V., John, K.S., Ravindran, C.S., and Edison, S. (2007). Agrotechniques and plant nutrition of tannia (Xanthosoma sp.): an overview. Root Crops 33(1), 1-11.

Roberts-Nkrumah, L.B., Wilson, L.A., and Ferguson, T.U. (1986a). Responses of four sweet potato cultivars to levels of shade. 1. Dry matter production, shoot morphology and leaf anatomy. Trop. Agri. 63, 8-64.

Roberts-Nkrumah, L.B., Wilson, L.A., and Ferguson, T.U. (1986b). Responses of four sweet potato cultivars to levels of shade. 2. Tuberization. Trop. Agric. 63, 265-270.

Rogers, S., and losefa, T. (1993). Potentials for shade management in agroforestry systems for taro cropping. In: Ferentinos L, editor. Proceedings of the Sustainable Taro Culture for the Pacific Conference. Sustainable Taro Culture for the Pacific Conference; 1992 Sept 24-25; Honolulu, Hawaii. Honolulu (HI): University of Hawaii. p. 62-65.

Schaaffhausen, R.V. (1963a). Dolichos lablab or Hyacinth Bean; Its uses for feed, food and soil improvement. Econ. Bot. 17, 146-153.

Schaaffhausen, R.V. (1963b). Economical methods for using the legume Dolichos lablab for soil improvement, food and feed. Turrialba. 13, 172-178.

Sipes, B.S., Schmitt, D.P., and Nelson, S.C. (2001). Burrowing Nematode, a Major Pest in the Tropics Cooperative Extension Service. Plant Dis. PD-21, pp. 3.

Stone, A., Massey, A., Theobald, M., Styslinger, M., Kane, D., Kandy, D., ... and Davert, E. (2011). Africa's Indigenous Crops. State Of The World 2011. Lisa Mastny (ed.). Innovations that Nourish the Planet. WorldWatch Institute. http://www.worldwatch.org/system/files/NtP-Africa's-Indigenous-Crops.pdf (Accessed: October 2016).

Surani, C., Lalani, S., and Ranjith, B.M. (2010). Litter accumulation from Mucuna bracteata cover crop and its effects on some soil chemical properties in rubber plantations. J. Rubber Res. Inst. Sri Lanka, 90, 49-57.

Thorne, G. (1961). Principles of Nematology. McGraw-Hill Book Company, Inc. New York, NY.

Tushemereirwe, W.K., Kangire, A., Kubiriba, J., Nakyanzi, M. and Gold, C.S. (2004). Diseases threatening banana biodiversity in Uganda. Afr. Crop Sci. J. 12, 19-26.

van Asten, P.J.A., Gold, C.S., Okech, S.H.O., Gaidashova, S.V., Tushemereirwe, W., and De Waele, D. (2004). Soil quality problems in East African banana systems and their relation with other yield loss factors. InfoMusa 13, 20-25.

van Asten, P.J.A., Wairegi, L.W.I., Mukasa, D., and Uringi, N.O. (2011). Agronomic and economic benefits of coffee-banana intercropping in Uganda's smallholder farming systems. Agric. Syst. 104, 326-334.

Vanlalhluna, P.C., Sahoo, UK., and Singh, S.L. (2014). Growth and yield of agricultural crops intercropped under three multipurpose trees (MPTs) in Mizoram, northeast India. Book 
of Abstracts, 3rd World Congress on Agroforestry, Trees for life - Accelerating the impact of agroforestry. Nairobi: World Agroforestry Centre.

Verheye, W.H. (2010). Soils, Plant Growth and Crop Production - Volume II. EOLSS Publications, pp. 454.

Wairegi, W.I.L., van Asten, J.A.P., Tenywa, M.M., and Bekunda, A.M. (2010). Abiotic constraints override biotic constraints in East African highland banana systems. Field Crops Res. 117, 146-153.

Wilson, G.P. and Murtagh, G.J. (1962). Lablab - New forage crop for the north coast. New South Wales Agricultural Gazette 73, 460-462. 


\section{Chapter 9}

General discussion

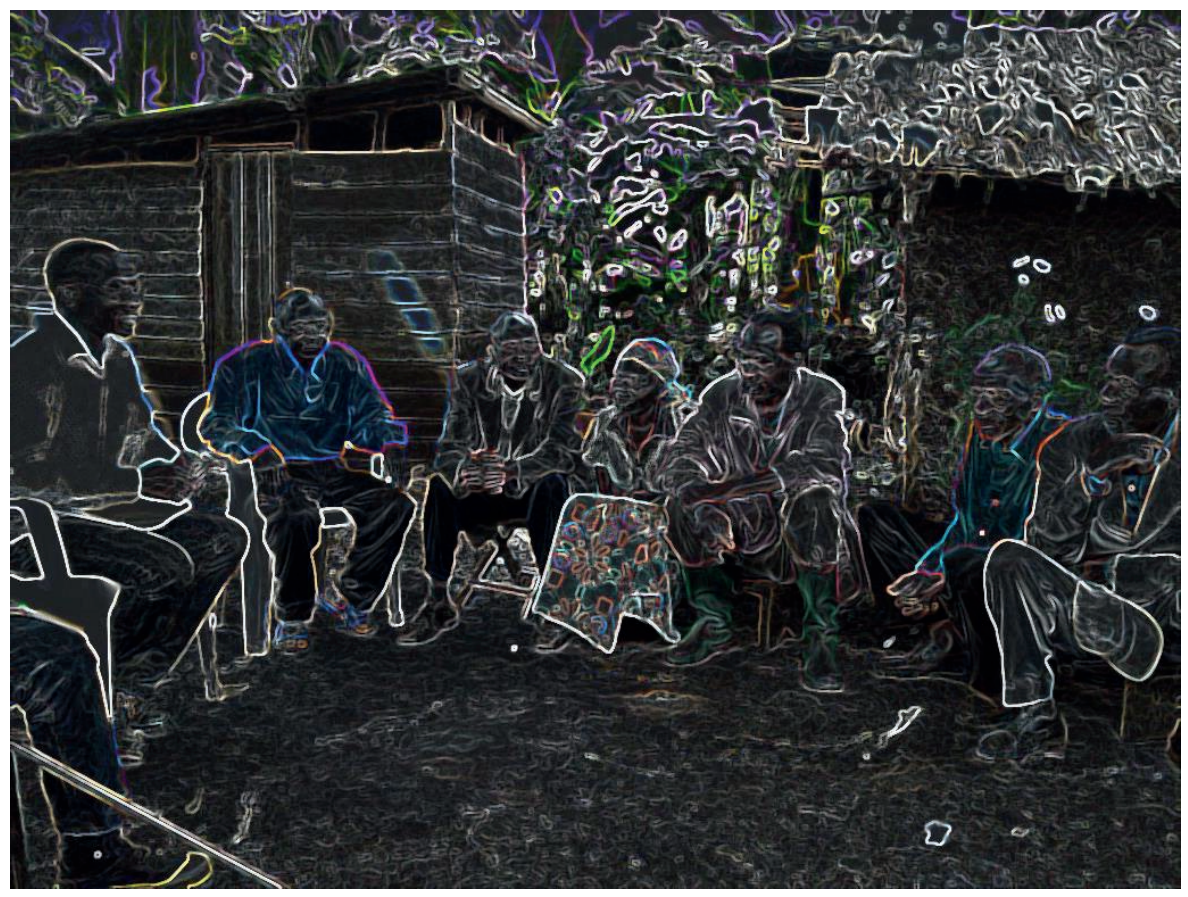




\subsection{Introduction}

The banana crop serves multiple functions in the banana-based landscapes across the African Great Lakes region (AGLR), supporting the resilience of the smallholder households and farms. The recent outbreak of XW disease has put the banana-based agroecosystems under intense pressure, compromising livelihoods of the households, communities and the resilience of the entire production system. This study suggests a broader approach for improving the buffering and adaptive capacity of the bananabased agroecosystems towards XW and other diseases. This chapter briefly determines if the evidence generated through the different chapters answer the study hypotheses (section 9.2) presented in Chapter 1 and discusses the key lessons from the thesis (9.39.7). Section 9.8 of this chapter discusses the use of computer-based simulation models for improving the performance of banana-based agroecosystems while 9.9 focuses on the applicability of the approaches and findings of the study to the other banana diseases and agroecosystems. Section 9.10 draws brief conclusions and suggestions for further studying.

\subsection{Answers to the research hypothesis}

The findings of the different chapters of this thesis support the hypotheses advanced for objectives 1-3 and 5 whereas a mixed picture is obtained for objective 4 . The respective hypotheses for the objectives are as below:

i. XW is driving changes in land-use within farms and landscapes and these changes are not only independent of the time of exposure to the shock but also negatively impact on the supply of supporting and regulatory ecosystem services within the landscape.

ii. The spatial risk of XW is influenced by its characteristic biotic and abiotic covariates such as banana cultivar composition, vegetation, rainfall, temperature, crop and disease management practices.

iii. Though Xanthomonas campestris pv. musacearum $(x \mathrm{~cm})$ can affect or survive on other crops and weeds in the banana-based agroecosystems, this association poses no risk to banana or these other crops.

iv. In addition to spreading $X W$ disease, the current practice of banana leaf pruning to intercrop legumes results in a sub-optimal performance for a broad range of production objectives and this could form a good basis for discouraging the practice.

$v$. Best-fit agroecological intensification strategies are needed to mitigate XW effects on the supply of key ecosystem services within fields, farms and landscapes.

In accordance with hypotheses $1, \mathrm{XW}$ outbreaks reduced the dominance of banana across farms and landscapes, whereas crop species richness increased at farm level (Chapter 2). In addition, field measurements (Chapter 2) and review of literature 
(Chapter 3), showed that death of banana plants and the current land-use changes and trajectories due to XW had a negative effect on the supply of some supporting and regulatory ecosystem services. At landscape level, through regression indicator kriging of survey data to environmental and expert generated covariates, in agreement with hypothesis 2 , the risk of XW was found to be strongly influenced by precipitation and XW management (Chapter 4). At field level, in agreement with hypothesis 3, though Canna spp. was ranked to offer a moderate-high risk as an alternative host to $\mathrm{Xcm}$ the pathogen causing XW, it did not influence XW incidence and prevalence on farms. Instead, XW incidence and prevalence was reduced by banana cultivar mixtures and when farmers have access to information on XW epidemiology and management while it was increased by presence of susceptible ABB Musa types on farm. In Chapter 6, in agreement with the hypothesis 4 , severe banana leaf pruning to integrate legumes was found to be inefficient agronomically and economically. Mild pruning was agronomically more efficient (Chapter 6) while the un-pruned banana was economically more efficient (Chapter 6 and 7). Severe leaf pruning was however observed to be the best option for a production system that lacked external inputs (Chapter 7). Evidence generated through review of literature (Chapters 3 and 8 ) and model explorations (Chapter 7) are in support of hypothesis 5, that the performance of the banana agroecosystems can be improved through integration of some agroecological practices.

\subsection{Broad insights from the thesis}

The information generated through the different chapters of this study build on to each other and create a strong framework for a comprehensive XW management strategy. Chapters 2 and 3 show that XW is driving changes in land-use across the banana-based agroecosystem with profound negative environmental effects. Chapter 5 reveals field level risk factors that can reduce or hasten XW spread and perpetuation while Chapters 6 and 7 generate evidence in support or against banana intercrop management practices as a basis for dissuading farmers or improving system performance. Findings in Chapters 5-7 are usual for reducing XW effects observed in Chapters 2-3. Chapter 8 explores agroecological strategies for improving the resilience of the banana production systems. Through mapping and identification of the key covariates responsible for XW spread at landscape level, disease hot spots, fronts and vulnerable landscapes (Chapter 4), pro-active measures integrating findings in Chapters 5-8 can be developed to prevent spread and mitigate disease effects observed in Chapters 23. The disease map generated in Chapter 4 can help to pin-point regional and national priority zones for implementation of the disease management and control strategies. 


\subsection{Disease effects on land-use, food systems and ecosystems services}

In Chapter 2 of this thesis, the dominance of banana (i.e. area under banana) across farms and landscapes had declined while crop species richness at farm level had increased due to XW outbreaks. XW effects on crop diversity were not influenced by the exposure time, possibly due to its rapid and multiple modes of spread (e.g. insect vectors, contaminated farm tools, infected planting materials, birds, bats and browsing animals), variable incubation periods ( 2 weeks to 2 years) and high levels of latent infections (Ocimati et al., 2013a; 2014; Blomme et al., 2014). For example, a single farm operation with a contaminated farm tool, can potentially infect an entire plantation while long incubation periods and high latent infections slow field recovery thus discouraging farmers. The impact of XW unlike most diseases of banana that gradually build up with gradual increase in yield losses, is also rapid and extreme (Tinzaara et al., 2013). However, improving access to information on disease epidemiology and control could translate into better disease management and reduce farmers' frustration. In eastern DR Congo, that had a low access to information, several farmers believed XW to be a curse from God while others believed it was soil borne and were thus resigned to it. The importance of information on disease epidemiology and control are also highlighted by the findings in Chapters 4 and 5 .

Overall, the ranking of banana in importance had dropped across XW affected landscapes and communities. Absence of mitigation measures against XW across banana-based agroecosystems will keep farmers discouraged and result in a continuous decline in the area under banana and its importance in these food systems. This could in the short term increase the vulnerability of smallholder households, communities and other actors along the value chain of the crop. For example, unlike the other food crops that are seasonal, banana provides a year-round supply bunches and is thus important for the stability of food and income security. Socially, the loss of the local beer banana has led to influx of more potent alcoholic beverages that have reduced the lifespan and productivity of youth and men. Smallholder households are also not able to meet urgent expenses given the crop is an important source of collateral. For example, farmers could easily borrow money using standing plants as collateral to meet urgent expenses e.g. school fees and health expenses.

The loss of banana also negatively impacts on key ecosystem services other than provisioning services (Chapters 2-3). For example, higher erosion levels ( $\mathrm{Mg}$ ha $^{-1}$ year- ${ }^{1}$ ) were observed under cassava (1.7-148.9), a major crop substituting banana compared with 0.3-10.7 for banana and 0.3-5.9 for tree crops. The effects of diseases on supply of ecosystem services other than 
provisioning services from agroecosystems has received little attention (Cheatham et al., 2009). This could be due to the more recent interest in the role of ecosystem services in a wide range of sectors (MEA (Millennium Ecosystem Assessment), 2005). Agroecosystems have also been narrowly defined as ecosystems managed with the aim of producing, distributing, and consuming food, fuel, and fibre (Cabell and Oelofse, 2012). Consistent with the above definition, most of the studies on XW and other diseases have focused on provisioning services. Literature on disease effects on regulatory, provisioning and cultural services from agroecosystems was lacking. These services were also not clear to the farmers involved in the study. It is critical to improve the understanding and experiences of farmers and other actors in the agroecosystem on the value of the different ecosystem services, if their benefits are to be effectively realised. Disease management strategies also need to target mitigation of the negative effects of diseases on the broad range of ecosystem services attainable from agroecosystems. In Chapter 3, an Ecosystem Services-broad framework drawing all key actors, especially the farmers, extension and research bodies and policy makers is proposed and described as a means of attaining this. This will need to be supported with rapid and easy to use assessment methods and tools.

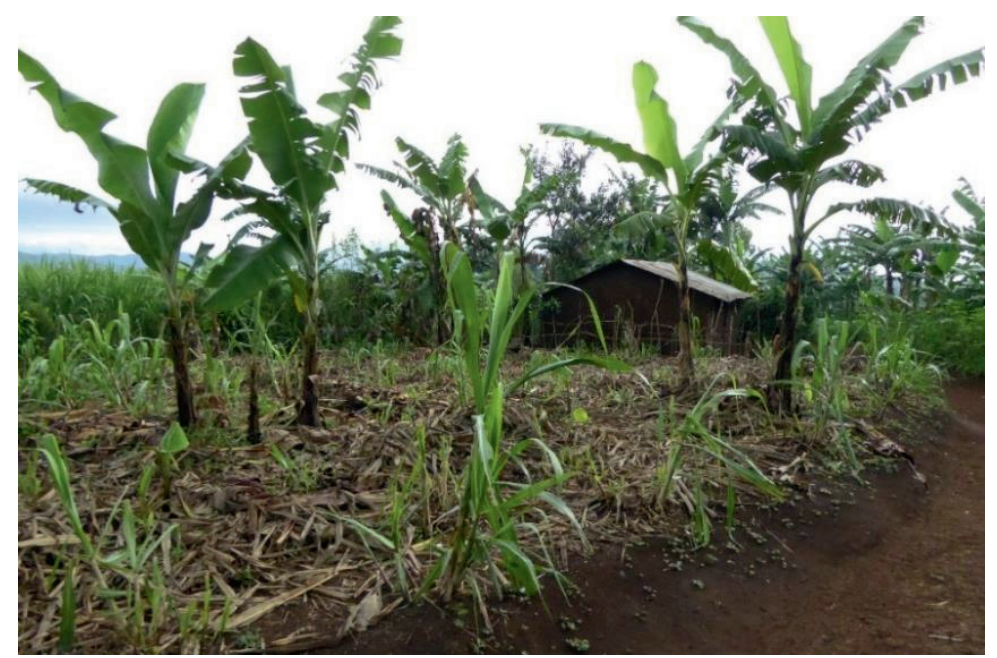

Fig. 9.1. A field previously under banana now planted with sugarcane.

Though not investigated in this study, banana agroecosystems can be described to be vulnerable. This vulnerability arises from the fact that the smallholder banana fields are perennial and often interconnected resulting in a large monoculture. This leads to a rapid build-up and spread of pests and diseases, making the crop and system vulnerable. The banana crop is also a heavy feeder, drawing large amount of nutrients, 
especially potassium, nitrogen and phosphorus (Okumu et al., 2011; Nyombi et al., 2010). Given that nutrient exports through harvested bunches are large and smallholders in the AGLR hardly apply external inputs, soils under banana systems, especially fields away from the homesteads can get rapidly depleted and rendered un-productive. Fields close to homesteads receive more nutrient inputs through addition of household/ kitchen wastes and manure from livestock that are often tethered close to homesteads at night (Bekunda and Woomer, 1996). Okumu et al. (2011) reported bunch yields and soil and plant tissue nutrient levels to decline with distance from the homesteads. Similar nutrient gradients have been reported for maize systems in Kenya (Vanlauwe et al., 2006).

On the positive end, the reduction in the dominance of the banana crop and subsequent increase in crop diversity in these agroecosystems could in the long run strengthen the resilience of households and the production systems. There is increasing evidence that diverse cropping systems such as intercropping, agroforestry and cover cropping increase functional biodiversity resulting in more stable and resource conservation (Altieri, 1995, 1999; Vandermeer, 1995). For example, intercropping and cover cropping with crops that have dissimilar rooting patterns allows for exploration of a greater soil volume than monocrops, resulting in better utilization of growth resources and nutrient recycling (Gliessman, 1985; Altieri, 1999; Gebru, 2015). Different crop canopy heights, leaf orientations in mixed cropping results in a better soil cover, reduce weed growth, and a more efficient use of solar radiation (Gliessman, 1985; Altieri, 1995). High crop diversity is also associated with suppression of undesirable organisms (Altieri, 1999; Vidal et al., 2017; Li et al., 2018). It also reduces the risk of crop failures e.g. due to drought stress and pest and disease attacks (Altieri, 1995; Jassogne et al., 2013). High biodiversity also helps in the detoxication of chemicals and regulation of microclimate and local hydrological processes (Altieri, 1999). Exploring opportunities for increasing the diversity of the banana agroecosystems therefore offers a good opportunity for improving its resilience.

At landscape level crop species richness did not however change. I attribute this to farmers' reliance on the available species diversity within their landscapes for adapting to the disease. The effect of the disease is drastic and does not give farmers the opportunity to experiment with alien crop species. This is supported by the fact that fast maturing crops, especially cassava, beans, sweet potato, taro and maize dominated the crops that replaced the banana. More still, experimenting on new crop species is often a time consuming, costly and risky (Le Gal et al., 2011). Supporting farmers under such stresses with rapid decision-making tools such as computer-based 
models would rapidly help to identify viable alternative land-use options and potentially minimise the impact of these stresses.

\subsection{Farm and field level $\mathrm{XW}$ risk factors}

At farm/field level XW risk factors related to farm characteristics and management were studied. Canna spp. a common weed posed a high risk to the banana crop, though no association [in farmer's fields] occurred between presence of Canna spp. and XW. The risk from intercrops varied from zero to moderate. These findings suggest the that despite the benefits of biodiversity (emphasized above), the interaction of plant pest and pathogens with different crop/ plant species in a system need to be understood to avoid negative and exploit the positive interactions. XW incidence in farmer's fields reduced with increasing access to training and the number of banana cultivars in field. These emphasize the importance of cultivar mixtures with varying disease resistance/tolerance levels on suppression of diseases. This study also stresses the importance of equipping farmers with knowledge on the epidemiology and management of disease.

Some banana intercrop management especially use of tools remove excess suckers, cutting fresh leaves to reduce banana canopy cover contribute to XW spread, increasing the XW problem. Chapters 6-7 explore the trade-offs associated with banana leaf pruning to integrate legumes as a basis for dissuading farmers from it or fine tuning for better performance. Severe leaf pruning to integrate legumes was suboptimal for all production objectives, though selected by the model as the best option for resource poor farmers that were not able to add in external inputs. This can be attributed to; i) the fact that pruning reduces banana root mass and ultimately nutrient uptake and ii) the high vigour of the legume component thus increasing $N$ input with the system. Soil nitrogen, phosphorus and potassium are reported to be the main limiting factor to the banana production systems in the region (Nyombi et al., 2010; Taulya, 2013). Though not the intended purpose, this practice slows nutrient mining and degradation of banana fields, thus potentially enabling farmers to use their fields productively for a much longer time. Moderate leaf pruning resulted in higher land use efficiency and moderate economic efficiency. The un-pruned banana grown as a sole crop or intercrop with legumes was efficient for operating profit, SOM and protein yield, but not for $\mathrm{N}$ input and was predominantly selected in explorations with external input addition(s). The poor performance of the severely pruned treatments could be a good basis for dissuading farmers from the practice, given it role in the spread of XW. However, such efforts could be hampered by access and knowledge on external inputs. These studies (Chapters 6-7) show the importance of recognizing and understanding 
farmers indigenous practices as a basis introducing innovations. These model outcomes will be useful in discussions with farmers towards improving systems performance.

\subsection{Landscape and field level risk of XW}

At landscape level, XW was mainly influenced by precipitation and the level of disease management. High moisture offers conducive conditions for pathogen survival whereas poor access to information results in a poor disease management. The spatial spread map of XW highlighted XW hotspots, front lines and the vulnerable landscapes with low (e.g. the northern region of Tanzania) and no XW (e.g. northern Mozambique) in the AGLR and tropical banana growing regions of Africa. The maps show that the eastern DR Congo, a zone where the plantains (Musa $A A B$ ) and the East African highland bananas (Musa AAA) meet is a major hotspot, thus a potential gateway of infections to the plantain belt of Central and West Africa. With the complexity of XW spread and management in mind, these maps form a good basis/guide for more proactive approaches rather than the current reactive or mitigative approaches for XW management, targeting mainly the frontline zones and vulnerable landscapes. Being proactive is crucial because disease eradication is complicated once XW is established due to the diverse modes of spreading, long incubation periods coupled with a high rate of latent infections (Ocimati et al., 2013; 2014). Proactive measures could include routine XW surveillance in the highlighted vulnerable sites, community sensitisation and quarantines. Such measures will in the first place prevent the disease from being introduced, and in case of entry result in timely control efforts thus increasing chances for disease eradication or at least minimise losses.

\subsection{Agroecological intensification for enhancing agroecosystem resilience}

Agroecology is the application of ecological concepts and principles to the design and manage sustainable agroecosystems (Gliessman, 2000). Agroecological intensification has been defined as a way of improving the performance of agriculture while minimising environmental impacts and reducing dependency on external inputs through integration of ecological principles into farm and system management (Milder et al., 2012; Tscharntke et al., 2012; Vanlauwe et al., 2013; CCRP, 2013; Wezel et al., 2015). Some of the common agroecological practices mentioned by different authors include: intercropping, cover cropping, crop rotation, soil and water conservation, integrated soil and nutrient management, judicious use of pesticides and inorganic inputs, mulching and use of organic inputs (Altieri, 1999; 
Gliesseman, 2000; Côte et al., 2010; Milder et al., 2012; Ochola et al., 2013; Karamura et al., 2013; Vanlauwe et al., 2013; Wezel et al., 2015; Teixeira et al., 2018).

Altieri (1999; Wezel et al., 2015) reports agroecological practices such as intercropping, agroforestry, cover cropping, shifting cultivation and other traditional farming methods to mimic natural ecological processes. Teixeria et al. (2018) also reported agroecological farms to have a great potential to provide a wide range of ecosystem services. Making such practices an integral part of managing our agroecosystems would thus boast their adaptive and/or buffering capacity. In the case of the XW affected banana-based agroecosystem, the buffering and adaptive capacity of un-affected and diseased fields and landscapes and new land-uses can be boasted through integration of leguminous cover crops, shade and drought tolerant crops, hedges and agroforestry species in the production systems (c.f. Chapters 2, 3, 8). For example, the high erosion levels under cassava, a common crop replacing banana could be reduced by integration of leguminous cover crops and hedge crops. Intercropping, a key agroecological practice however, must be deployed with caution as some intercrops and/ or their management practices can perpetuate some pests and diseases. For the banana crop, to avoid management practices such as pruning to increase light to the shorter intercrops that enhance $X W$, the agroecological option of integrating shade-tolerant crop species is recommended (Chapter 8). Such species however need to compliment the banana crop to minimise both above and below ground competition. Zero tillage under banana is also recommended to minimise XW spread through damage to root and corms. Though not explored in this study, different banana spacings could also be explored to minimise leaf pruning and de-suckering. Highlighting the potential of different agroecosystems to supply a broad range of ecosystem services and the potential effects of diseases on these services and systems at local, regional and national levels is also important for influencing policy decisions and ensuring that resource investments match with the disease problem.

\subsection{Role of model simulations in fostering sustainable banana systems}

The FarmDESIGN model has been shown to support with great success farm level explorations in several studies (Ditzler et al., 2019; Groot et al., 2007; 2012). However, there are no studies focused on field level explorations. The potential of this model to explore trade-offs and synergies, and to guide decision making at field level was demonstrated using data from empirical experiments simulating farmers' bananabush bean intensification practices in eastern DR Congo (Chapter 7). The model revealed that banana leaf pruning lowered nutrient requirements of the system whereas increasing $\mathrm{N}$ input thus matching the available soil nutrients to the nutrient 
requirements of the mixtures, though possibly not consciously done. The legume component increased $\mathrm{N}$ input in the severely pruned banana crops under low input scenarios. Optimal performance of the system for operating profit, SOM balance and protein yields and $\mathrm{N}$ input was only attained when external inputs were added, and land allocated to a sole banana or intercrop of banana in which all leaves had been retained. Beyond the often easy to determine objective of incomes and productivity, the model was able to explore objectives such as nutritional yield and soil nutrient levels that are often difficult to assess or intangible to smallholder farmers. The model also made explicit the trade-offs and synergies, between selected economic, environmental and nutritional objectives for different input scenarios for the bananabush bean system (Chapter 7). The FarmDESIGN model is thus useful in supporting field level explorations and decision making. Such models potentially cut down the time, complications, costs and risk in identification of promising technologies and overall decision making on farm that would arise from trial and error experiments by farmers (Le Gal et al., 2011). Despite the usefulness of this model, it is static in terms of inter annual dynamics, and expected yield responses due to improved supply of soil nutrients are not simulated. Linking such data through other dynamic models to this model could be helpful in improving model performance and needs to be explored. Using the current model outcomes to engage with farmers, e.g. using focus group discussions is recommended as a next step for improving the banana-legume intercropping practice in the region. As a follow up, farm level explorations with the FarmDESIGN model of the banana system focusing on proposed agroecological intensification practices for improving the banana systems in the study region are recommended.

\subsection{Innovativeness and transferability of the approaches and findings}

To understand land-use changes and trajectories, a combination of focus group discussions and the four-cell analysis (Chapter 2) were used. The four-cell analysis enabled the communities to rapidly rank the changes in land-use along two axes, i.e. change in land area and the number of people growing the crop as a result of the disease. The use of the four-cell analysis to assess the effect of a disease on land-use is particularly novel and relevant for rapid assessment of the impact of similar and other production constraints on land-use diversification and biodiversity.

Past studies on XW management focused mainly on the banana as a sole commodity and its roles as a food and income source. I argue that this limited the focus and investment in XW management/ control and has greatly contributed to its continued spread and persistence. Banana is grown in association with other crop 
species that can influence the disease through interactions with its pathogens or their management. Through a combination of laboratory, screenhouse and field studies crops (Chapter 5), Canna spp. was observed to succumb to XW, and its risk ranked as moderate to high. No association was however observed between Canna spp. prevalence and XW incidence. Xcm was also recovered from other crop species and a moderate risk assigned to sugarcane which is perennial. Other studies have reported some crop and weed species to act as alternative hosts to pathogens of other crops (Ramappa et al., 1998; Grünwald and Flier, 2005, Coutinho et al., 2015; Ocimati et al. 2017). The importance of the knowledge of the interactions between crop pathogens with other plants in a system is thus relevant for all crop species. The combination of methods in this study can also be used for understanding the relationship between crop pathogens and other species for other agroecosystems.

Directly and indirectly, XW also negatively affected the supply of other ecosystem services that are crucial for the sustainability of the production systems (Chapter 2 and 3). I argue that similar effects will arise from other diseases and crops if disease containment is not timely, especially for crops with similar characteristics (e.g. perennial tree crops) to banana. The suggested ecosystem services-broad framework (c.f. Chapter 3 ) in this thesis is transferable and should be adopted for the management of similar constraints of banana (e.g. banana bunchy top disease, Fusarium wilt) as well as for crop species. For example, apart from supplying food and income, tree crops supply other services such as sequestration of carbon (a public good), nutrient recycling and soil erosion control. Thus, the role of these crops in the supply of ecosystem services other than the provisioning services needs to be acknowledged and their potentials for different services mapped. Quantification and knowledge of the potential losses across all services due to a constraint will help inform decision making at the different levels, including policies on investments to management the diseases.

The regression indicator kriging method used for mapping XW risk for the AGLR (Chapter 4) has been widely used in other studies (e.g. Goovaerts, 1997; Hosmer and Lemeshow, 2000; Bouwmeester et al., 2014, 2016). However, in addition to the environmental covariates, through review of available literature and expert knowledge, an additional covariate "management" was added to capture the level community access to information. For the Africa wide mapping, most of the environmental covariates were out or range, as such expert generated covariates were developed and used. These two aspects are novel and could be adopted for other studies especially where disease spread mechanisms are complex as is for XW disease. The mapping reveals disease hotspots, fronts and vulnerable landscapes. Successful management of diseases with complex spread mechanisms 
such as XW will require such knowledge for pro-active control strategies. Such strategies could include, routine surveillance at disease fronts, building capacities of actors at disease fronts and in vulnerable landscapes on disease diagnosis, epidemiology and eradication and institution of active quarantine measures.

FarmDESIGN model has to date been applied at farm level and this study shows that it can effectively be used to explore trade-offs at field level for crop intercrops and rotations. More still, combining such models with empirical experiments is helpful for more robust outcomes.

Chapters 2, 7 and 8 of this study suggest agroecological intensification options for improving the adaptive and buffering capacity of the banana agroecosystems. These practices are also transferable to other crops/ agroecosystems.

\subsection{Conclusions and recommendations}

Finally, I highlight the following key messages and future perspectives that have emerged from this thesis.

\section{Key messages}

- $\mathrm{XW}$ is still a major constraint to banana production across landscapes in the AGLR and a key threat to other production zones in Africa, especially west of the AGLR.

- Xanthomonas wilt of banana is driving changes in land-use with a higher trajectory towards short maturing crops with potentially negative effects on the supply of ecosystem services, households and communities in the affected agroecosystems. Potential positive effects due to increased crop diversity and more evenness are anticipated in the long run.

- Effective management of XW should consider a broad framework addressing all the ecosystem services and involving all the stakeholders. Such measures should be proactive instead of the current responsive or mitigative approach.

- At field level, XW disease is exacerbated by the presence of ABB Musa types whereas its incidence is reduced by growing banana in mixtures of cultivars and increasing access to information on disease epidemiology and management.

- Knowledge of the interaction of plant pests and pathogens with other plant species in a system is crucial for avoiding or minimising any potentially negative interactions. With respect to banana, Canna spp. has the potential to harbour and spread $\mathrm{Xcm}$ the XW causing pathogen and thus needs close monitoring. 
- Farmers indigenous intensification practices e.g. the management of banana in the banana-bush intercropping practice, are complex and advice to farmers will require an in-depth understanding of the trade-offs between the production objectives.

- The management of XW should consider redesign of the production systems to improve their adaptive and/ or buffer capacity. Agroecological practices such as cover cropping, hedges, water retention ditches, agroforestry could improve capacity of new land use options in the supply of key ecosystem services lost through loss of the banana crop.

- The ability of banana to provide multiple services gives it an edge over other crops in the landscape. As part of the management, efforts are needed to restore farmers' confidence and production in the affected landscapes through improving access to information on disease epidemiology and management and quality seed.

- The FarmDESIGN model is helpful tools for improving the performance of smallholder farming systems.

\section{Future perspectives}

- Explore through models and field studies the usefulness of a range of agroecological practices in fostering the resilience of banana-based agroecosystems.

- Explore best strategies for packaging and communicating the trade-offs, synergies associated with banana intercrop management practice and other findings of the study to the farming communities and other key actors in the study region.

- Using models such as FarmDESIGN, jointly with key actor's co-design banana-based agroecosystems to foster system resilience at household, field/ farm and landscape level.

- Mapping of species and their characteristics that minimise trade-offs when intercropped with banana.

- Explore linkages between the FarmDESIGN model with dynamic fertilizer response models for more robust outcomes.

- Engage with actors including farmers and policy makers to popularize study findings. Potential strategies could include meeting, policy briefs and other information, communication tools.

\section{References}

Altieri, M.A. (1995). Agroecology - The science of sustainable agriculture. Westview Press, Colorado, USA.

Altieri, M.A. (1999). "The Ecological Role of Biodiversity in Agroecosystems." Agr. Ecosys. Environ. 74(1-3), 19-31. 
Bekunda, M.A., and Woomer, P.L. (1996). Organic resource management in banana-based cropping systems of the Lake Victoria Basin, Uganda. Agr. Ecosyst. Environ. 59, 171-180.

Cabell, J.F., and Oelofse, M. (2012). An indicator framework for assessing agroecosystem resilience. Ecol. Soc. 17(1), 18. http://dx.doi.org/10.5751/ES-04666-170118

Cheatham, M.R., Rouse, M.N., Esker, P.D., Ignacio, S., Pradel, W., Raymundo, R., ... and Garrett, K.A. (2009). Beyond yield: Plant disease in the context of ecosystem services. Phytopathol. 99, 1228-1236.

Côte, F., Tomekpe, K., Staver, C., Depigny, S., Lescot, T., and Markham, R. (2010). Agroecological intensification in banana and plantain (Musa spp.): an approach to develop more sustainable cropping systems for both smallholder farmers and large-scale commercial producers. Acta Hort. 879, 457-464.

Ditzler, L., Komarek, A.M., Chiang, T.W., Alvarez, S., Chatterjee, S. A., Timler, C., ... and Groot, J.C. (2019). A model to examine farm household trade-offs and synergies with an application to smallholders in Vietnam. Agr. Syst. 173, 49-63.

Gebru, H. (2015). A review on the comparative advantage of intercropping systems. J. Biol. Agric. Health. 5, 28-38.

Gliessman, S.R. (1985). Multiple cropping systems: A basis for developing an alternative agriculture, in: US Congress Off Ice of Technology Assessment. Innovative Biological Technologies for Lesser Developed Countries: Workshop Proceedings. University of California, Washington, D.C., USA, pp. 69-83.

Gliessman, S.R. (2000). Agroecology: Ecological processes in sustainable agriculture. Lewis Publishers, Boca Raton, Florida, USA.

Groot, J.C.J., Oomen, G.J.M., and Rossing, W.A.H. (2012). Multi-objective optimization and design of farming systems. Agr. Sys. 110, 63-77.

Groot, J.C.J., Rossing, W.A.H., Jellema, A., Stobbelaar, D.J., Renting, H., and Van Ittersum, M.K. (2007). Exploring multi-scale trade-offs between nature conservation, agricultural profits and landscape quality -a methodology to support discussions on land-use perspectives. Agr. Ecosyst. Environ. 120, 58-69.

Jassogne, L., van Asten, P.J.A., Wanyama, I., and Baret, P.V., (2013). Perceptions and outlook on intercropping coffee with banana as an opportunity for smallholder coffee farmers in Uganda. Int. J. Agr. Sustain. 11, 144-158.

Kamusingize, D., Majaliwa, J.M., Komutunga, E., Tumwebaze, S., Nowakunda, K., Namanya, P., and Kubiriba, J. (2017). Carbon sequestration potential of East African Highland Banana cultivars (Musa spp. AAA-EAHB) cv. Kibuzi, Nakitembe, Enyeru and Nakinyika in Uganda. J. Soil Sci. Environ. Manag. 8 (3), 44-51.

Karamura, E.B., Jogo, W., Rietveld, A., Ochola, D., Staver, C., and Tinzaara, W. (2013). Effectiveness of agroecological intensification practices in managing pests in smallholder banana systems in East and Central Africa. Acta Hort. 986, 119-126.

Le Gal, P., Dugué, P., Faure, G., and Novak, S. (2011). How does research address the design of innovative agricultural production systems at the farm level? A review. Agric. Syst. 104, 714-728. 
Lufafa, A., Tenywa, M.M., Isabirye, M., Majaliwa, M.J.G., and Woomer, P.L. (2003). Prediction of soil erosion in a Lake Victoria basin catchment using a GIS-based Universal Soil Loss Model. Agr. Syst. 76, 883-894.

MEA (Millennium Ecosystem Assessment) (2005). Ecosystems and Human Well-being: Synthesis. Island Press, Washington, DC.

Ochola, D, Jogo, W., Ocimati, W., Rietveld, A., Tinzaara, W., Karamura, D.A., and Karamura, E.B. (2013) Farmers' awareness and perceived benefits of agro-ecological intensification practices in banana systems in Uganda. Afr. J. Biotechnol. 12(29), 4603-4613

Ocimati, W., Nakato, G.V., Fiaboe, K. M., Beed, F., and Blomme, G. (2015). Incomplete systemic movement of Xanthomonas campestris pv. musacearum and the occurrence of latent infections in Xanthomonas wilt-infected banana mats. Plant Pathol. 64(1), 81-90.

Ocimati, W., Ssekiwoko, F., Karamura, E., Tinzaara, W., Eden-Green, S., and Blomme, G. (2013). Systemicity of Xanthomonas campestris pv. musacearum and time to disease expression after inflorescence infection in East African highland and Pisang Awak bananas in Uganda. Plant Pathol. 62, 777-785.

Okumu, M.O., van Asten, P.J.A., Kahangi, E., Okech, S.H.J., Jefwa, J., and Vanlauwe, B. (2011). Production gradients in smallholder banana (cv. Giant Cavendish) farms in central Kenya. Sci. Hort. 127, 475-481.

Teixeira, H., van den Berg, L., Cardoso, I., Vermue, A., Bianchi, F., Peña-Claros, M., and Tittonell, P. (2018). Understanding farm diversity to promote agroecological transitions. Sustain. 10(12), 4337.

Vandermeer, J. (1995). The ecological basis of alternative agriculture. Annu. Rev. Ecol. Syst. 26, 201-224.

Vanlauwe, B., Tittonell, P., and Mukalama, J. (2006). Within farm soil fertility gradients affect response of maize to fertilizer application in western Kenya. Nutr. Cycl. Agroecosyst. 76, 171-183.

Vanlauwe, B., van Asten, P., and Blomme, G. (2013). Agro-ecological intensification of agricultural systems in the African Highlands. Routledge, New York, USA.

Wezel, A., Soboksa, G., McClelland, S., Delespesse, F., and Boissau, A. (2015). The blurred boundaries of ecological, sustainable, and agroecological intensification: a review. Agron. Sustain. Dev. 35, 1283-1295. 


\section{Summary}

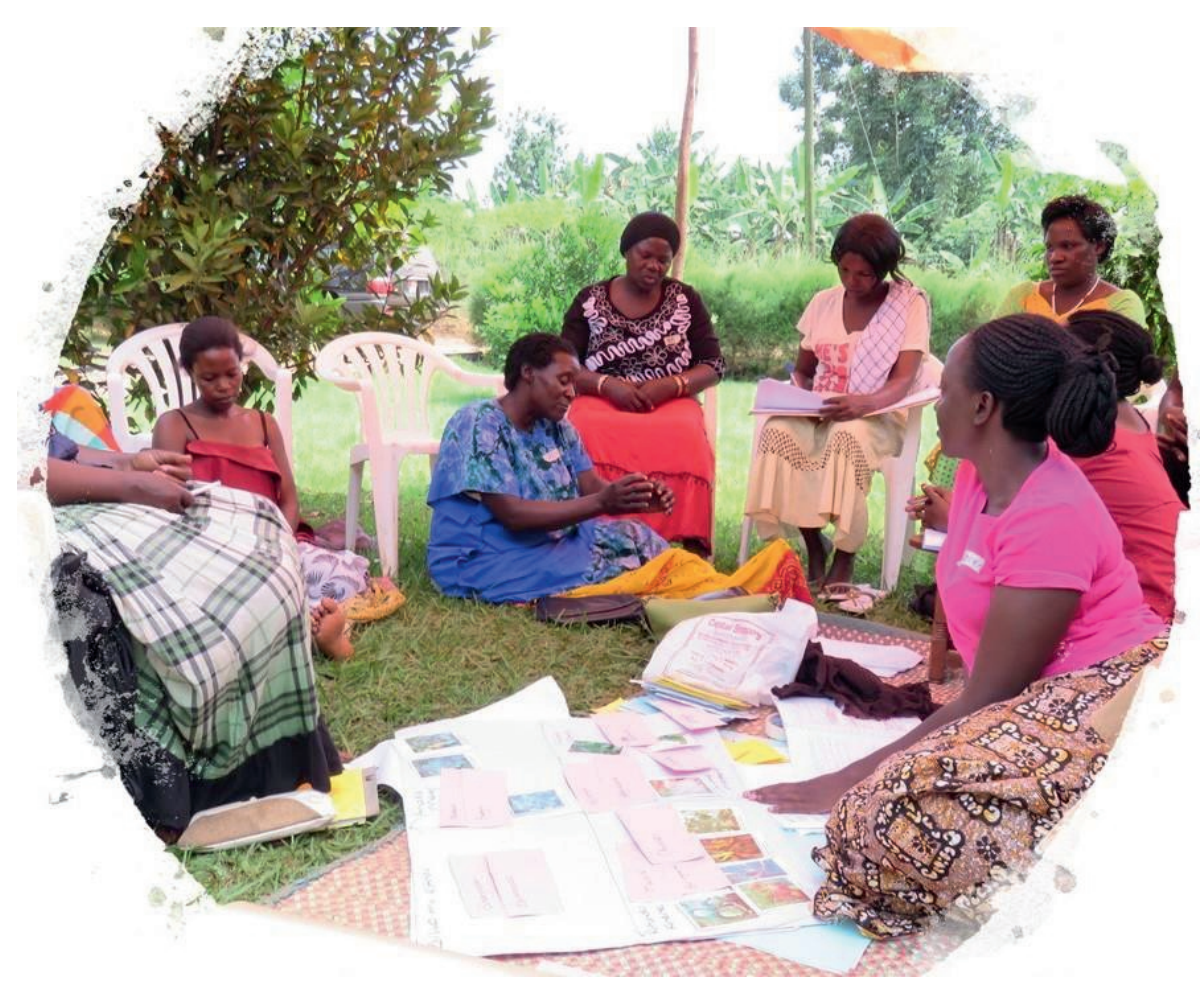




\section{English Summary}

Banana (plantains inclusive) provide multiple functions in the banana-based landscapes across the African Great Lakes region (AGLR). The crop produces bunches all year round, thus a backbone of food and income security for over 70 million people. In addition, to these provisioning services, banana plantations are a good source of regulatory and supporting services that to date have received little attention within agroecosystems. The recent outbreak of Xanthomonas wilt disease (XW) of banana (first reported in 2001) has put banana-based agroecosystems under intense pressure, compromising food and income security of the households and communities. Disease effects on land-use and the other ecosystem services other than the provisioning services are not well known and could profoundly reduce the resilience and performance of the agroecosystems. Management of the disease has mainly been reactive and mitigative, as such the disease has persisted and continues to spread into new farms and landscapes. In-depth understanding of the risk factors at landscape and field/ farm level are thus crucial.

This thesis explored strategies for preventing and minimising shocks caused by XW disease outbreaks and improving the adaptive and/or buffering capacity of banana-based agroecosystems. Chapter 1 of this thesis describes the research context, the problem statements, the research objectives and guiding hypotheses. We next characterised retrospectively the XW-driven land-use changes and trajectories across landscapes in eastern DR Congo (Chapter 2) and potential effects of the disease and the changes in land-use on the supply of key ecosystem services in the banana-based agroecosystems (Chapters 2-3). In Chapter 4, with XW incidence as a dependant variable and environmental and/ or expert developed covariates as independent variables, we developed XW risk maps for the AGLR and banana producing zones across Africa. At field/ farm level, we first determined the field level risk factors including the role of intercrops and weeds in harbouring and perpetuating the disease (Chapter 5). Secondly, we determined the effect of banana leaf pruning to integrate legumes on agronomic and economic efficiency (Chapter 6); and trade-offs and synergies between production and environmental objectives (Chapter 7), as a basis for discouraging leaf pruning or improving the intercrop management (Chapters 6-7). In addition, we explored agroecological options for improving the adaptive and buffering capacity of the banana-based agroecosystems (Chapters 3, 7-8). Finally, Chapter 9 provides a synthesis of the whole thesis.

The retrospective characterisation of XW affected landscapes through focus group discussions and the four-cell analysis showed that XW was driving changes within banana-based agroecosystems (Chapter 2). The dominance of the banana 
crop declined across all the landscapes whereas, the area allocated to other crops (especially cassava and other annuals) and the number of people growing the crops had increased. Crop diversity increased at household level but not at field level, suggesting that farmers relied on crops within the landscapes for adapting to the shock. XW effects are not only drastic/fast and experimentation with new crop species is a time consuming, costly and risky process. Through laboratory analysis of soil nutrient contents of the key land-use trajectories, field measurement of soil erosion levels using the Universal Soil Loss Equation for key land-use trajectories (Chapter 2) and review of literature (Chapter 3), XW was observed to reduce the supply of key ecosystem services other than the provisioning services. This necessitates an ecosystem services broad framework for addressing XW and other diseases of banana and other crops with similar characteristics (Chapter 2 and 3 ).

At landscape level, $\mathrm{XW}$ increased with increasing precipitation and declining investment in disease and crop management (Chapter 4). The spatial XW spread map highlights XW hotspots and front lines (e.g. eastern DR Congo) and the vulnerable landscapes with low (e.g. north-western Tanzania) or no XW (northern Mozambique). The eastern DR Congo, a zone where the plantains (Musa AAB) and the East African highland bananas (Musa AAA) meet was a major hotspot and is thus a potential gateway for XW to spread into the plantain belt of Central and West Africa. These maps are a good starting point for guiding proactive strategies for XW prevention, eradication and control.

In Chapter 5, through screenhouse and laboratory experiments Xanthomonas campestris pv. musacearum the causal organism of XW was observed to survive within some banana intercrops (e.g. maize, millet, sorghum, sugarcane) and weeds (Canna spp. and wild sorghum). XW characteristic symptoms only occurred on millet, sorghum and Canna spp. while death only occurred in Canna spp. The risk from the annual crops was rated as zero to low because they are wind pollinated and a short cycle, while the risk from sugarcane was rated as low-moderate due to its perennial nature and propagation through the rhizome. Insect mediated spread in the process of collecting nectar, sap and pollen, and spread from one plant to another connected through the rhizome play important roles in XW perpetuation while the pathogen does not survive for long in absence of a living host. Canna spp. propagates through the rhizome and the disease was in some instances observed to cause death in new suckers whereas some suckers emerged without symptoms even after death of the parent plants. Given the susceptibility, mode of propagation and high prevalence of Canna spp. on farms, it was deemed to offer a moderate to high risk to the banana crop. Through survey of farms and multivariate analysis (Chapter 5), Canna spp. however did not influence XW risk at farm level. Risk on farm was instead lowered by growing banana in mixture of 
cultivars and increasing access to information on disease epidemiology and access; and increased by the presence of $A B B$ banana types that are susceptible to insect mediated $X W$ spread. The role of farmers knowledge and $A B B$ banana types is well known whereas the impact of mixtures on $X W$ is novel and needs to be integrated into the current XW management packages. Though Canna spp. has no association with the observed XW risk on farm it warrants close monitoring.

Through a field experiment (Chapter 6 ), farmers practice of severe banana leaf pruning to increase light intercepted by the shorter crops that currently enhances XW spread found to in efficient both agronomically and economically. Mild pruning however improved the agronomic efficiency whereas unpruned banana whether as intercrop or sole crop was more efficient economically. Moderate leaf pruning to integrate legumes and not pruning at all could thus be considered as a trade-off between agronomic and economic efficiency for the banana-legume intercrop system.

In Chapter 7, additional, deeper analysis of the empirical experiment is conducted using the FarmDESIGN optimisation model to unravel the relations between production (maximising income and protein yield) and environmental (minimising $\mathrm{N}$ input and maximising SOM balance) objectives that are often not easy to observe or determine. The FarmDESIGN model was also used to explore scenarios of incorporating different external inputs for improving the banana-legume intercrop. Trade-offs were observed e.g. between $\mathrm{N}$ input and the other production objectives. No profound improvements in the system were feasible without addition of external inputs. Addition of external inputs, especially inorganic fertilizers and manure greatly improved the banana-legume system for all the objectives. The model predominantly allocated land to severely pruned banana-legume intercrop and bush bean monocrop for scenarios with no or low (planting hedges) external inputs. In contrast, when nutrients increased through addition of external inputs, the model allocated land to unpruned banana either as a sole crop or intercrop with legumes. In absence of external inputs, the farmers current practice of severe leaf pruning is thus more feasible. Discouraging severe leaf pruning and improving the performance of the system for all objectives will necessitate investments in external inputs. These findings are a good basis for discussion to initiate co-innovations for improving the system with farmers. FarmDESIGN model is thus useful for supporting field level explorations and decision making and overall, co-designing of the banana agroecosystems.

Through literature review (Chapters 3 and 8 ) and model explorations (Chapter 7), we propose some agroecological practices for improving the buffering and adaptive capacity of the banana-based agroecosystems. Chapter 3 suggests agroecological practices such as cover cropping, integration of nitrogen fixing hedges for boasting and minimising the loss of supporting and regulatory ecosystems services affected by XW 
disease. In Chapter 7 through scenario explorations with the FarmDESIGN model, the study shows the importance of adding external inputs such as artificial fertilizers, manure and hedges for improving the performance of the banana intercrop system. In Chapter 8, we review literature on potential shade and drought tolerant crops for integration within the banana plantations. These practices will increase overall biomass yield while at the same time minimising XW spread through leaf pruning.

Finally, Chapter 9 discusses the salient issues arising from this thesis. It is important to note that effective management of XW disease and other similar diseases needs to look beyond disease effects on the supply of provisioning services to include other affected ecosystem services that play an important role in the sustainability of the agroecosystems. Effective management of diseases also requires a thorough understanding of the role of other crops species in a system and the effect of farmers practices on farm. This thesis also shows that integration of agroecological practices such as cover crops, hedges, crop cultivar mixtures within disease control packages have the potential of enhancing the resilience of landscapes to diseases. Moreover, existing farm optimisation models will be useful for understanding current production systems, management practices and redesigning more agroecological resilient agroecosystems. Finally, strategies for controlling complex diseases such as XW (with multiple modes of spread, fast spread rates, long incubation and high latency rates) will require more proactive measures instead of purely reactive- or mitigationbased approaches. Such measures will in the first place prevent the disease from being introduced and, in case of entry, offer a good buffering capacity and trigger timely control measures to reduce and minimize losses. 
About the author 


\section{About the author}

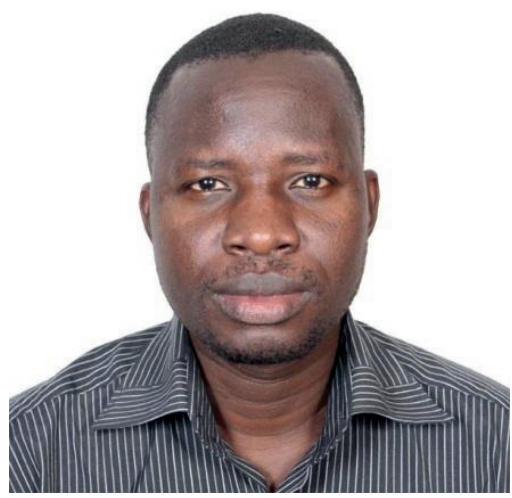

Walter Ocimati was born on the $03^{\text {rd }}$ September 1979 in Uganda. He attended Oninia Primary School, Ombatini Senior Secondary School for his ordinary level education and Mvara Senior Secondary school for his advanced level secondary education. He graduated from Makerere University in Uganda with a BSc. Agriculture in 2003 and a MSc. Crop Sciences 2013. For his MSc study, he conducted his research on the management of bean root rots in Southwestern Uganda under a scholarship offered by the Center for International Tropical Agriculture (CIAT). In the period between 2003 and 2019, with different non-governmental organizations he provided agricultural extension services to vulnerable households that included resource poor smallholder farmers, former combatants and orphaned and vulnerable children in the West Nile region, northern Uganda. From November 2009 to date he has been working for Bioversity International in Uganda as a Research fellow on the epidemiology and management of Xanthomonas wilt disease of banana in the East and Central African region. He has also been involved in studies on Musa spp. agronomy, diversity and conservation. In 2015, he started his PhD programme at Wageningen University \& Research in collaboration with Bioversity International. 


\section{List of Publications}

\section{Peer reviewed journal publications}

Ocimati, W., Bouwmeester, H., Groot, J.C.J., Tittonell, P., Brown, D., and Blomme, G. (2019). The risk posed by Xanthomonas wilt disease of banana: Mapping of disease hotspots, fronts and vulnerable landscapes. PloS one, 14(4), e0213691.

Ocimati, W., Ntamwira, J., Groot, J.C.J., Taulya, G., Tittonell, P., Dhed'a, B., ... and Blomme, G. (2019). Banana leaf pruning to facilitate annual legume intercropping as an intensification strategy in the East African highlands. Eur. J. Agron. 110, 125923.

Blomme, G., Ocimati, W., Sivirihauma, C., Lusenge, V., Bumba, M., and Ntamwira, J. (2019). Controlling Xanthomonas wilt of banana: Influence of collective application, frequency of application, and social factors on the effectiveness of the Single Diseased Stem Removal technique in eastern Democratic Republic of Congo. Crop Prot. 118, 79-88.

Ntamwira, J., Blomme, G., Bahati, L., and Ocimati, W. (2019). Effect of timing of diseased plant cutting, altitude and banana cultivar on efficacy of singly removing Xanthomonas wilt infected banana plants. Eur. J. Plant Pathol. 1-13.

Selvaraj, M.G., Vergara, A., Ruiz, H., Safari, N., Elayabalan, S., Ocimati, W., and Blomme, G. (2019). Al-powered banana diseases and pest detection. Plant Methods, 15(1), 92.

Okonya, J.S., Ocimati, W., Nduwayezu, A., Kantungeko, D., Niko, N., Blomme, G., ... and Kroschel, J. (2019). Farmer Reported Pest and Disease Impacts on Root, Tuber, and Banana Crops and Livelihoods in Rwanda and Burundi. Sust. 11(6), 1592.

Jacobsen, K., Omondi, B.A., Almekinders, C., Alvarez, E., Blomme, G., Dita, M., ... and Staver, C. (2019). Seed degeneration of banana planting materials: strategies for improved farmer access to healthy seed. Plant Pathol. 68(2), 207-228.

Kikulwe, E.M., Kyanjo, J.L., Kato, E., Ssali, R.T., Erima, R., Mpiira, S., ... and Stoian, D. (2019). Management of Banana Xanthomonas Wilt: Evidence from Impact of Adoption of Cultural Control Practices in Uganda. Sust. 11(9), 2610.

Ocimati, W., Were, E., Groot, J.C., Tittonell, P., Nakato, G.V., and Blomme, G. (2018). Risks posed by intercrops and weeds as alternative hosts to Xanthomonas campestris pv. musacearum in banana fields. Frontiers in plant science, 9, 1471.

Ocimati, W., Tusiime, G., Opio, F., Ugen, M.A., \& Buruchara, R. (2017). Sorghum (Sorghum bicolor) as a bean intercrop or rotation crop contributes to the survival of bean root rot pathogens and perpetuation of bean root rots. Plant pathol. 66(9), 1480-1486.

Blomme, G., Dita, M., Jacobsen, K.S., Pérez Vicente, L., Molina, A., Ocimati, W., ... and Prior, P. (2017). Bacterial diseases of bananas and enset: current state of knowledge and integrated approaches toward sustainable management. Front. Plant Sci., 8, 1290.

Blomme, G., Ocimati, W., Sivirihauma, C., Vutseme, L., Mariamu, B., Kamira, M., ... and Ntamwira, J. (2017). A control package revolving around the removal of single diseased banana stems is effective for the restoration of Xanthomonas wilt infected fields. Eur. J. Plant Pathol. 149(2), 385-400. 
Rutikanga, A., Sivirihauma, C., Ocimati, W., Night, G., Murekezi, C., Ndungo, V., ... and Blomme, G. (2016). Breaking the Cycle of Xanthomonas campestris pv. musacearum in Infected Fields through the Cultivation of Annual Crops and Disease Control in Adjacent Fields. J. Phytopathol. 164(9), 659-670.

Ocimati, W., Nakato, G. V., Fiaboe, K. M., Beed, F., and Blomme, G. (2015). Incomplete systemic movement of Xanthomonas campestris pv. musacearum and the occurrence of latent infections in Xanthomonas wilt-infected banana mats. Plant Pathol. 64(1), 81-90.

Ochola, D., Ocimati, W., Tinzaara, W., Blomme, G., and Karamura, E. B. (2015). Effects of water stress on the development of banana Xanthomonas wilt disease. Plant Pathol. 64(3), 552558.

Were, E., Nakato, G. V., Ocimati, W., Ramathani, I., Olal, S., and Beed, F. (2015). The banana weevil, Cosmopolites sordidus (Germar), is a potential vector of Xanthomonas campestris pv. musacearum in bananas. Can. J. Plant Pathol. 37(4), 427-434.

Nakato, G.V., Ocimati, W., Blomme, G., Fiaboe, K.K.M., and Beed, F. (2014). Comparative importance of infection routes for banana Xanthomonas wilt and implications on disease epidemiology and management. Can. J. Plant Pathol. 36(4), 418-427.

Blomme, G., Jacobsen, K., Ocimati, W., Beed, F., Ntamwira, J., Sivirihauma, C., and Karamura, E. (2014). Fine-tuning banana Xanthomonas wilt control options over the past decade in East and Central Africa. Eur. J. Plant Pathol. 139, 265-281

Ocimati, W., Ssekiwoko, F., Karamura, E., Tinzaara, W., Eden-Green, S., and Blomme, G. (2013). Systemicity of Xanthomonas campestris pv. musacearum and time to disease expression after inflorescence infection in East African highland and Pisang Awak bananas in Uganda. Plant Pathol., 62(4), 777-785.

\section{Conference proceedings}

Ocimati, W., Groot, J.C.J., Tittonell, P.A., and Blomme, G. (2016). Effects of banana Xanthomonas wilt and other banana diseases on ecosystem services in banana based agroecosystems. In International Symposium on Banana/ISHS-ProMusa symposium: Agroecological approaches to promote innovative banana production systems.

Blomme, G., Ocimati, W., Groot, J.C.J., Ntmwira, J., Bahati, L., Remans, R., and Tittonell, P. A. (2016). Agroecological integration of shade tolerant and drought tolerant food/feed crops for year round productivity in banana based systems under rain-fed conditions. In International Symposium on Banana/ISHS-ProMusa symposium: Agroecological approaches to promote innovative banana production systems.

Ocimati, W., Groot, J.C.J., Ntmwira, J., Bahati, L., Tittonell, P.A., Taulya, G., ... and Blomme, G. (2016). Land use/cropping pattern changes in retrospect across Xanthomonas wiltinfected landscapes. In International Symposium on Banana/ISHS-ProMusa symposium: Agroecological approaches to promote innovative banana production systems. 


\section{Book chapters}

Blomme, G., and Ocimati, W. (2018) Xanthomonas bacterial wilt. In: Chapter 5: Diseases caused by bacteria and phytoplasmas. Handbook of diseases of banana, abacá and enset. (Jones, D.R. (ed.)). Wallingford (UK) CAB International. pp. 296-313. ISBN: 9781780647197

Tinzaara, W., Stoian, D., Ocimati, W., Kikulwe, E., Otieno, G., and Blomme, G. (2018). Challenges and opportunities for smallholders in banana value chains. In Achieving sustainable cultivation of bananas (pp. 85-110). Burleigh Dodds Science Publishing.

Dawson, I.K., Attwood, S.J., Park, S.E., Jamnadass, R., Powell, W., Sunderland, T., ... and Staver, C. (2019). 'Contributions of biodiversity to the sustainable intensification of food production. Thematic study for The State of the World's Biodiversity for Food and Agriculture', Rome: Food and Agriculture Organization of the United Nations. 
Training and education 


\section{PE\&RC Training and Education Statement}

With the training and education activities listed below the $\mathrm{PhD}$ candidate has complied with the requirements set by the C.T. de Wit Graduate School for Production Ecology and Resource Conservation (PE\&RC) which comprises of a minimum total of 32 ECTS (= 22 weeks of activities)

\section{Review of literature (6 ECTS)}

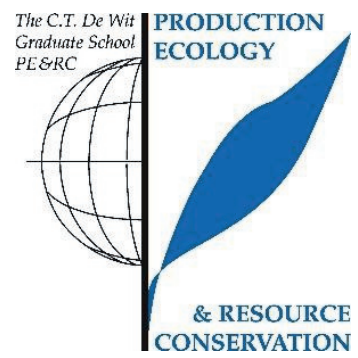

- Effects of Xanthomonas wilt and other banana diseases on ecosystem services in banana-based agroecosystems

- Agroecological integration of shade- and drought-tolerant food/feed crops for yearround productivity in banana-based systems under rain-fed conditions in Central Africa

\section{Writing of project proposal (4.5 ECTS)}

- Agro-ecological intensification options to enhance or recover land productivity and ecosystem service delivery in banana-based agroecosystems affected by banana Xanthomonas wilt disease

\section{Post-graduate courses (9.9 ECTS)}

- Multivariate analysis; PE\&RC (2017)

- Bayesian statistics; PE\&RC (2017)

- Geostatistics course; PE\&RC (2018)

- Quantum Geographical Information System (QGIS) course; GIM GIS Training Centre, Leuven (2018)

- Open Data kit (ODK) course; CIALCA RTB - CGIAR (2018)

- Farming systems and rural livelihoods; PE\&RC (2018)

- Integrating gender and nutrition in agricultural research for development; CIALCA RTB CGIAR (2019)

\section{Laboratory training and working visits (4.5 ECTS)}

- Potential role of banana intercrops and weeds as alternate hosts to Xanthomonas campestris pv. musacearum in banana fields; National Agricultural Research Laboratories, NARO, Uganda (2016-2017)

\section{Invited review of (unpublished) journal manuscript (2 ECTS)}

- Frontiers in Plant Science: application of genetic engineering for control of bacterial wilt disease of enset, Ethiopia's sustainability crop (2019)

- Agricultural Systems: perspectives on science of scaling (2019)

\section{Deficiency, refresh, brush-up courses (3 ECTS)}

- Systems analysis, simulation and systems management; WUR (2015)

- Quantitative Analysis of Land Use Systems (QUALUS); WUR (2016) 
Competence strengthening / skills courses (3 ECTS)

- Reviewing of scientific paper; WUR (2017)

- Project proposal writing; MZN international (2018)

- Scientific integrity; WAIS (2019)

- Ethics for social sciences; PE\&RC (2019)

PE\&RC Annual meetings, seminars and the PE\&RC weekend (1.2 ECTS)

- PE\&RC First years weekend (2015)

- PE\&RC Day (2017)

Discussion groups / local seminars / other scientific meetings (4.7 ECTS)

- Graduate seminars; FSE, PPS (2016-2019)

- Biodiversity international, CGIAR RTB and CIALCA (2016-2019)

- PhD discussions group; Sustainable Intensification of Agricultural Systems (SIAS) (20152019)

International symposia, workshops and conferences (4 ECTS)

- ISHS-ProMusa Symposium, agroecological approaches to promote innovative banana production systems; Montpellie, France (2016)

- Poster presentation to Bioversity International and CIAT board of directors and staff; Rome, Italy (2019)

- Farming Systems Design conference; Montevideo, Uruguay (2019)

\section{Supervision of MSc students (3 ECTS)}

- Diverging perspectives on diversification: a multi objective Pareto-based optimisation for smallholder farmers under Banana Xanthomonas Wilt (BXW) pressure in Uganda

- Exploration of agroecological intensification strategies for optimal farm performance: integration of hedges, agroforestry species, and shade- and drought-tolerant crops in banana-based systems in Uganda 
Acknowledgements 


\section{Acknowledgements}

Time really flies! I can hardly believe that it is already a little over four years from the time I started my PhD studies. This is evidence of how engaging this PhD has been. As I reflect more on this PhD journey, I am reminded of all the hands and voices that supported me through all the way in this journey. Though words may not be adequate, I will make all efforts to acknowledge all who have supported me along this walk.

I am grateful to Bioversity International (BI) my employer for the past 9 years for funding and allowing me to do this study within the framework of my work. I acknowledge the CIALCA project and the CGIAR program of Roots Tubers and Banana (RTB) who through their funds to $\mathrm{BI}$ made this study feasible.

I am greatly indebted to $\mathrm{Dr}$ G. Blomme of BI for the great confidence and trust in my abilities to execute this study and to positively contribute to the body of knowledge and livelihoods of smallholder farmers in the African Great Lakes region. He perfectly complemented my co-promoter Dr J.C.J. Groot and my promoter Prof. Dr P. Tittonell. I also thank Dr R. Remans (BI) for her guidance through the study and together with $\mathrm{Dr}$ G. Blomme ensuring finances didn't hinder my PhD study.

I am also indebted to my promoters Dr J.C.J. Groot and Prof. Dr P. Tittonell for accepting to supervise and support this study. You have been so supportive throughout this journey, calming my 'nerves' at several critical moments to ensure I didn't stumble. Your technical guidance has been invaluable and will always be cherished. I also benefited from the guidance and inspiration through my interactions with Dr G. Taulya (International Institute of Tropical Agriculture (IITA)) and Dr K. Giller (Plant Production Systems) and Dr M. Schut (IITA).

Through the journey, there have been friends who have stood with me very closely. In a special way, I thank $\mathrm{Dr}$ B. Yada for sticking to me more closely than a brother would do. You encouraged me at critical moments, first when my MSc study hit a rock you kept encouraging me not to give up until I got the break through. In the same spirit you have invaluably motivated me through this study. I also thank my friend and $\mathrm{PhD}$ colleague Dr R.B. Onzima. You, like a responsible elder brother who clears all dew along a path to ensure the younger one does not get wet, made my walk through Wageningen more comfortable. I also thank you for the invaluable advise. My gratitude also goes to Dr A. Yayi, P. Acema, D. Asizua, Dr F. Onyilo, Dr V. Nakato and J. Kimunye who have been an inspiration along the journey.

My field, screenhouse and laboratory work would have been a nightmare if not for the support and interactions with farmers, colleagues and friends. I thank all the farmers who allowed me to use their farms for this study. I thank J. Ntamwira, L. Bahati (RIP), M. Kamira and D. Amina for supporting my field data collection in the D.R. Congo. 
My gratitude also goes to E. Were, A. Tazuba, F. Nakamanya, and D. Nassazi who not only supported my laboratory work in Uganda but more often checked on and comforted my family. Your time, thoughts and support will always be cherished. I also extend my appreciation to the MSc students Clara and Tamar who contributed to my study through their MSc research.

I am also reminded of the opportunity I have had to work in very supportive environments. I extend my appreciation to all my Farming Systems Ecology (FSE) colleagues (Carl, Stephanie, Daniel, Mirja, Tibebu, Lenora, Ann, Uma, Roos, Pablo, George, Felix) for supporting me in various ways and making FSE homely. You in different ways were an inspiration to me and I will greatly cherish all those moments. Thank you Carl for supporting me with the Farm Design model. My sincere appreciations to Wampie and Gemma for all the administrative support. Gratitude also goes to all my BI colleagues who in different ways have made my journey much easier. I appreciate your thoughts, criticisms and encouragements.

I am also grateful to my immediate family that had to endure moments without me during the course of this PhD study. Your unceasing prayers and encouragement is invaluable. I thank my dear wife Hellen who on top of her role had to assume my roles to ensure our family remained sound and healthy. I thank my daughters Faith, Mercy, and Everlyn for being positive and supportive through my studies. My gratitude to dad, Richard (RIP) and mum, Edinance for the prayers, words of wisdom and encouragement. Though you (dad) did not leave to see this to fruition, your words to me have been a strong motivation. I am especially reminded at all times of your prayer for all my projects to come to completion. My gratitude to my siblings (Rhone, Godfrey, Jimmy, Jennifer, Sunday) for being supportive and always keeping a keen eye on my family in my absence. Finally thanks to uncle Sam, for your encouragement, support and being an advocate for education.

Finally I bless my Lord Jesus Christ the rewarder of those that diligently seek Him for His faithfulness throughout my study. He took care of my family and brought to my support different people in the course of this study. May He richly reward you all. 
Funding 


\section{Funding}

The research described in this thesis was financially supported by:

- Consortium for Improving Agriculture-based Livelihoods in Central Africa (CIALCA) supported by the Belgian Directorate General for Development Cooperation and Humanitarian Aid (DGD)

- $\quad$ CGIAR Fund Donors through the RTB programme of the CGIAR

Thesis cover design by Fred Byekwaso, Signmarshals Ltd, JP Plaza, Kampala, Uganda Thesis printed by Digiforce | Proefschriftmaken.nl, De Limiet 26, 4131 NR, Netherlands 
